\title{
A FRAMEWORK FOR DEVELOPING AND INTEGRATING EFFECTIVE ROUTING STRATEGIES WITHIN THE EMERGENCY DECISION SUPPORT SYSTEM
}

\author{
A Thesis \\ presented to \\ the Faculty of California Polytechnic State University, \\ San Luis Obispo \\ In Partial Fulfillment \\ of the Requirements for the Degree \\ Master of Science in Civil and Environmental Engineering \\ by \\ Joseph W. Yu \\ December 2011
}


(C) 2011

Joseph W. Yu

ALL RIGHTS RESERVED

ii 


\section{COMMITTEE MEMBERSHIP}

TITLE: A FRAMEWORK FOR DEVELOPING AND INTEGRATING EFFECTIVE ROUTING STRATEGIES WITHIN THE EMERGENCY DECISION SUPPORT SYSTEM

AUTHOR: Joseph W. Yu

DATE SUBMITTED:December 2011

COMMITTEE CHAIR: $\quad$ Anurag Pande, Ph.D

COMMITTEE MEMBER: Cornelius Nuworsoo, Ph.D

COMMITTEE MEMBER: Ashraf Rahim, Ph.D

COMMITTEE MEMBER: Vinayak Dixit, Ph.D

COMMITTEE MEMBER: Nezamuddin, Ph.D 


\begin{abstract}
A FRAMEWORK FOR DEVELOPING AND INTEGRATING EFFECTIVE ROUTING STRATEGIES WITHIN THE EMERGENCY DECISION SUPPORT SYSTEM

Joseph W. Yu

In recent years transportation professionals have shown increasing interest in evacuation planning. With the advances in computing technologies it is possible to simulate urban transportation networks with great detail. These details from the traffic simulation model can be used for devising strategies for evacuation and emergency response in case of a disaster.
\end{abstract}

This thesis describes the modeling, calibration, and validation of the VISSIM traffic simulation model coded for downtown San Jose. The network is then used to test various evacuation scenarios to assess evacuation strategies that would be effective in case of a human-caused disaster.

The network modeled in the simulation software VISSIM required a large amount of data regarding network geometry, signal timings, signal coordination schemes, and turning movement volumes. Turning movement counts at intersections were used to validate the network with an empirical formula to assess the differences between observed and simulated counts. For freeways the simulation model was validated using the actual travel time information. Once the base network was validated, various scenarios were tested to estimate evacuation and emergency response vehicle arrival times. 
It was found that in the event of coordinated terrorist attacks (specified in the disaster scenario) simultaneously occurring at four locations in the downtown San Jose area, severe bottlenecks would result due to evacuee traffic. To alleviate the congestion, contraflow lanes should be used on Montgomery Street (which becomes Bird Avenue) to help reduce congestion. While contraflow lanes helped the situation, traffic incidents potentially resulting from all the chaos could complicate evacuations.

The investigators found that reducing the number of vehicles on the road through public transit ridership would be the optimal approach, while leaving area roads uncongested for the emergency response personnel. In the scenario where $30 \%$ of the evacuees used transit at Diridon Transit Center, the travel times for the remaining evacuees, as well as the first responders, were minimized. None the less, the other scenarios were also critical to this study, since they provided a response strategy in case the transit station is affected by the attacks.

Keywords: Disasters and emergency operations, Safety and security, Medical services, Accidents 


\section{ACKNOWLEDGMENTS}

First, I would like to thank God for guiding me through my college years and also with the thesis research and paper. Even in dark, uncertain times when I felt like giving up and stopping my thesis research, the promises and encouragement in His Word supported me through the difficult times.

Also, many thanks to Dr. Anurag Pande who served as my committee chair and provided advice, direction, and practical knowledge towards shaping this thesis. In addition, he spent many hours reviewing and revising the thesis for which I also am very grateful. Thanks also to two Cal Poly Professors who served as my committee members Dr. Cornelius Nuworsoo and Dr. Ashraf Rahim who reviewed the thesis material. In addition, two thesis committee members, Dr. Nezmuddin and Dr. Vinayak Dixit, from University of Texas - Austin and Louisiana State University, respectively, both shared their experience with the traffic modeling software and aided in the research approach. Thanks also to Dr. Frances Edwards also provided details for developing and implementing the disaster scenarios. Many thanks also to two fellow Cal Poly graduates, Mr. Steven Kilbert and Mr. Reuben Juster who provided VISSIM software experience and help with literature review and data gathering, respectively.

Thanks also to Paul Ma and Casey Hirasaki from the City of San Jose who provided the initial CUBE model of the San Jose and also worked to develop an origin-destination matrix for the research's purpose. 
Lastly, but certainly not least, I would like to thank my parents for their spiritual and financial support as well as their timely advice and constructive criticism. Their continuous love and support in raising me and helping me through the first 25 years of my life are something that will be extremely difficult to repay. 


\section{TABLE OF CONTENTS}

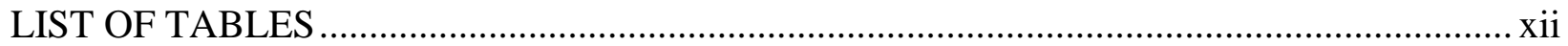

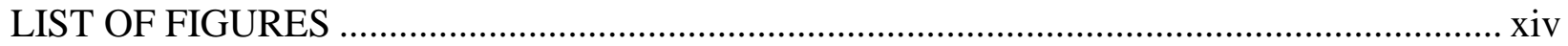

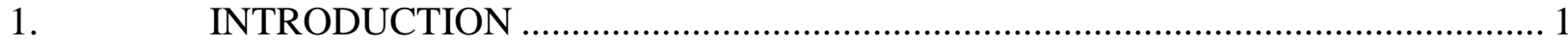

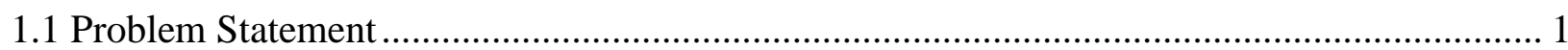

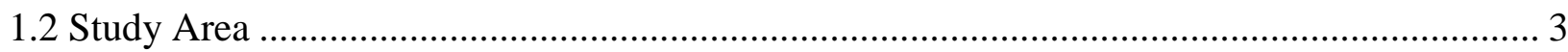

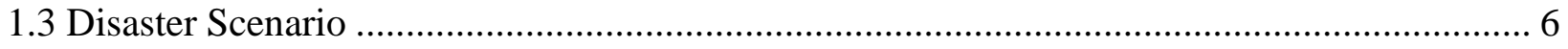

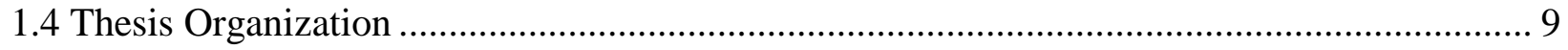

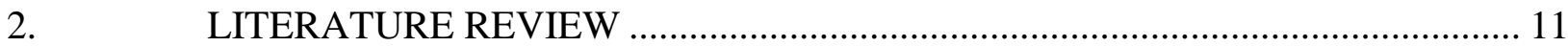

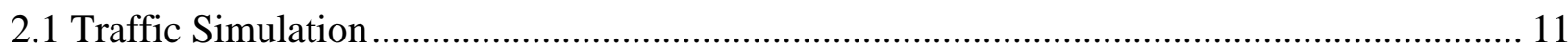

2.2 Simulation Model Choices.......................................................................................... 12

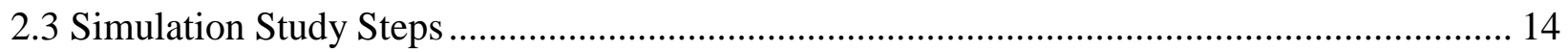

2.4 Advantages and Disadvantages of Traffic Simulation................................................. 17

2.2 Emergency Preparedness Through Traffic Simulation.................................................. 19

2.2.1 Evacuation Modeling: Natural Disasters ............................................................. 19

2.2.2 Evacuation Modeling: Man-made Disasters .......................................................... 21

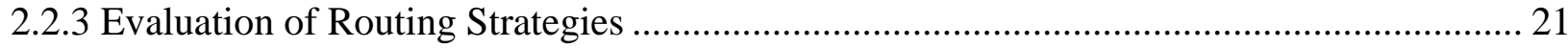

2.3 Conclusions from Literature Review .......................................................................... 23

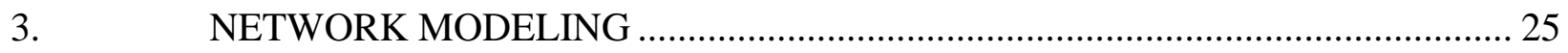

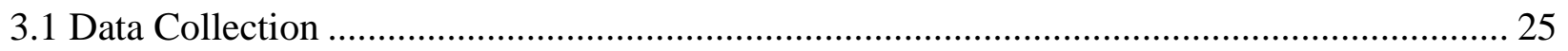

viii 


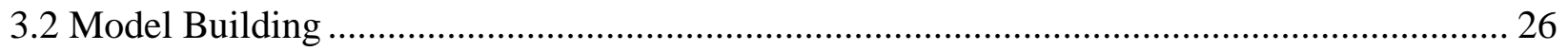

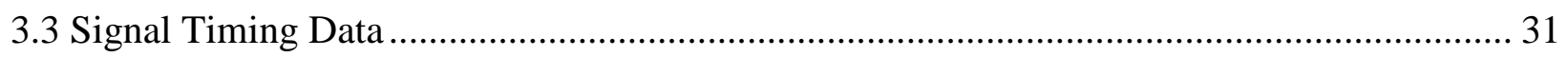

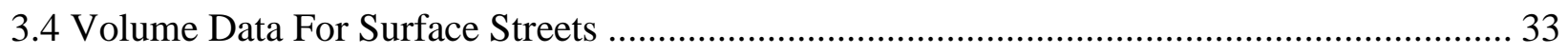

3.5 Volume Data for Freeway and Highway Segments............................................................... 38

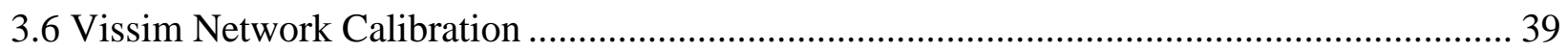

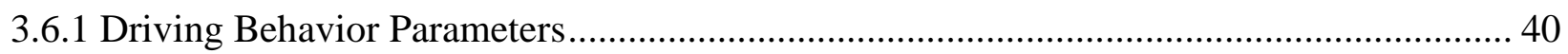

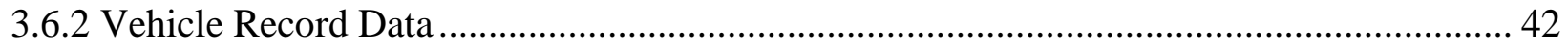

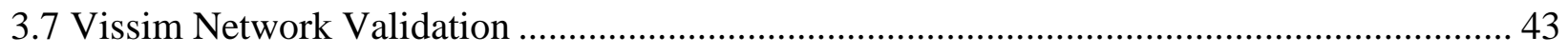

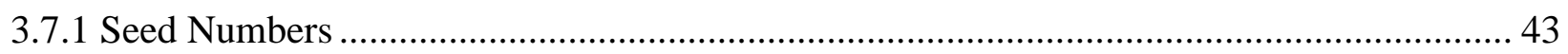

3.7.2 GEH Statistics Validation for Turning Movement Counts................................................... 43

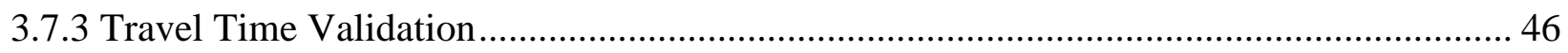

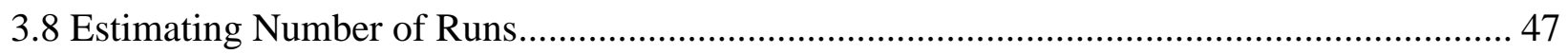

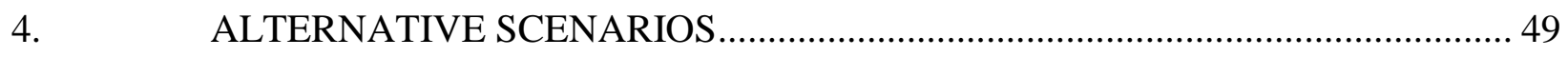

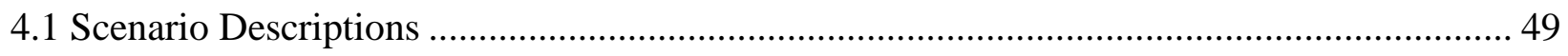

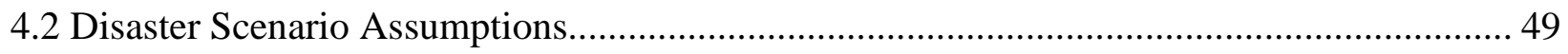

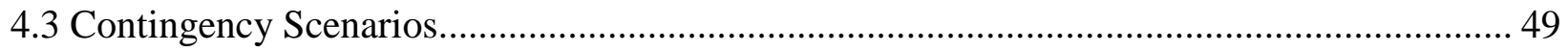

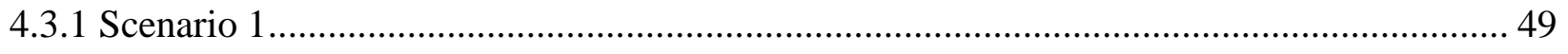

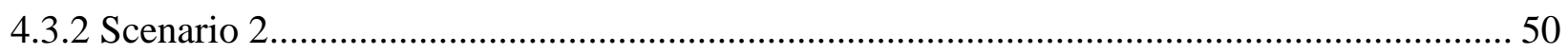

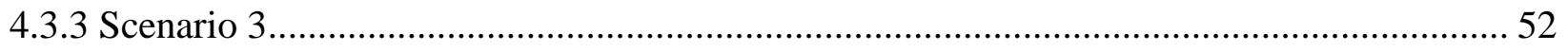




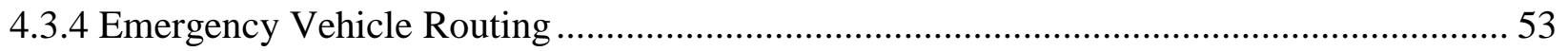

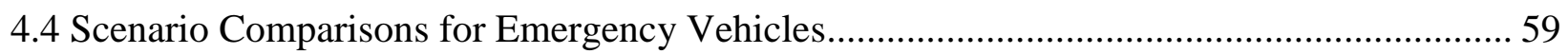

4.4.1 O' Connor Hospital Travel Time Comparison ................................................................ 59

4.4.2 Santa Clara Valley Medical Center Travel Time Comparison ..................................................... 60

4.4.3 Regional Medical Center Travel Time Comparison ........................................................... 62

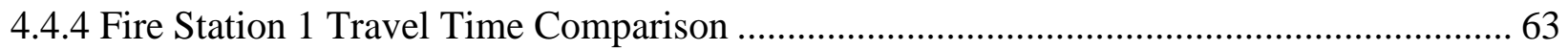

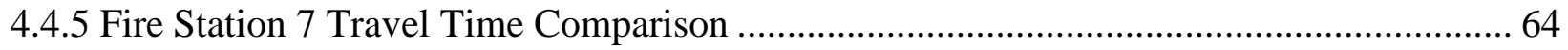

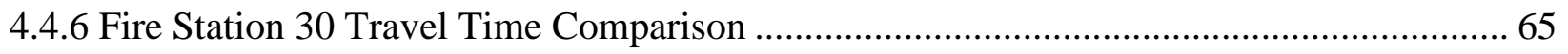

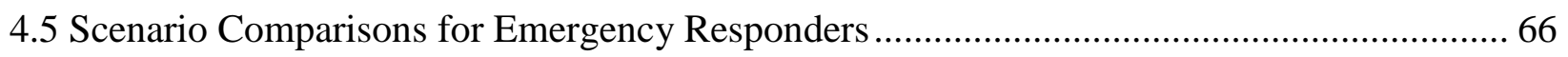

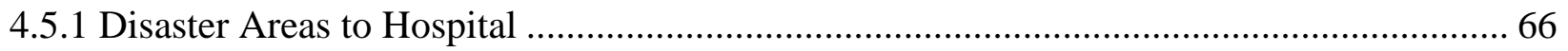

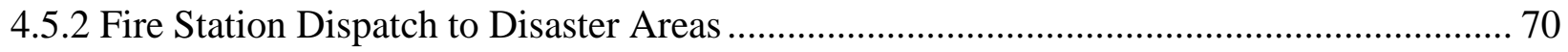

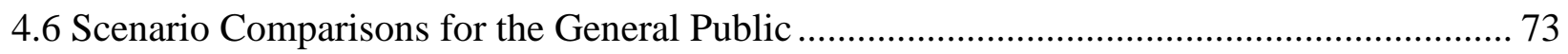

4.7 Difference Among the Mean Travel times (Statistical Analysis) .......................................... 75

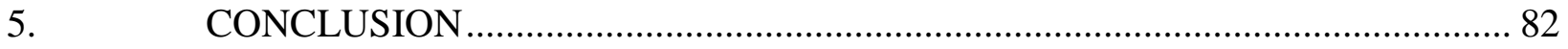

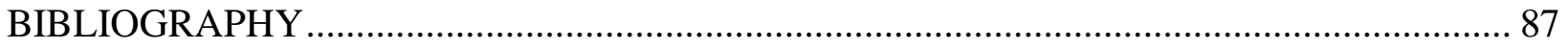

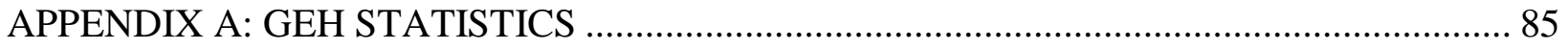

APPENDIX B: TRAVEL TIME SUMMARY FOR CALIBRATION AND VALIDATION .... 91

APPENDIX C: PEAK HOUR TRAFFIC COUNTS IN DOWNTOWN SAN JOSE .................... 92

APPENDIX D: TURNING MOVEMENTS FOR THE BASE CASE SCENARIO ….............. 102 


\section{LIST OF TABLES}

Table 2.1 HCM Analysis of Simulation Modeling .............................................................. 19

Table 3.1 Final Network Summary ................................................................................. 26

Table 3.2 Network Modification Procedure ....................................................................... 30

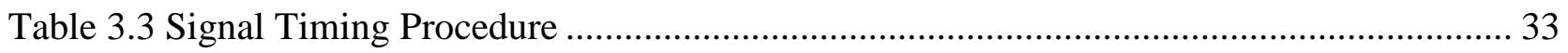

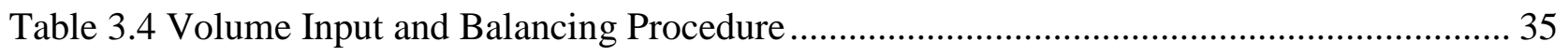

Table 3.5 Mid Block Driveway Coding Procedure ................................................................. 35

Table 3.6 Calibration of Freeway Car-following Model Parameters ....................................... 41

Table 3.7 Initial Run Travel Time Validation and Summary ................................................. 47

Table 3.8 Summary of Number of Simulation Runs Required............................................... 48

Table 4.1 Most Efficient Hospital Routes and Fastest Times to Disaster Areas (O’ Connor Hospital and Santa Clara Valley Medical Center) ........................................................................... 55

Table 4.2Most Efficient Hospital Routes and Fastest Times to Disaster Areas (Regional Medical

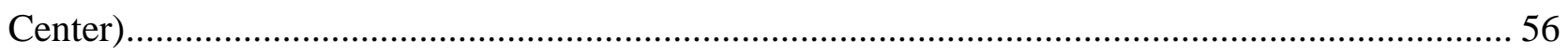

Table 4.3Most Efficient Fire Station Routes and Fastest Times to Disaster Areas (Fire Station 1

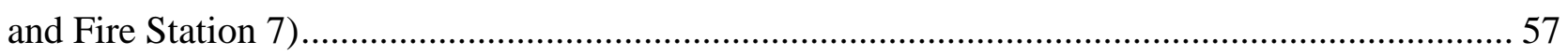

Table 4.4 Most Efficient Fire Station Routes and Fastest Times to Disaster Areas (Fire Station 30) 58

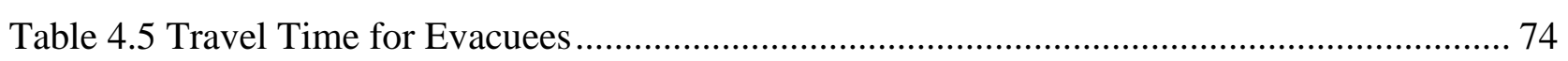

Table 4.6 Significant Mean Difference of Base Case and Scenario 1 ...................................... 77

Table 4.7 Significant Mean Difference of Base Case and Scenario 2 ..................................... 77

Table 4.8 Significant Mean Difference of Base Case and Scenario 3 ....................................... 78 
Table 4.9 Significant Mean Difference of Scenario 1 and Scenario 2 ...................................... 79

Table 4.10 Significant Mean Difference of Scenario 1 and Scenario 3 ...................................... 80

Table 4.11 Significant Mean Difference of Scenario 2 and Scenario 3................................... 80 


\section{LIST OF FIGURES}

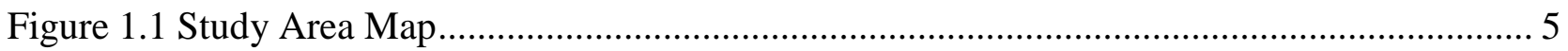

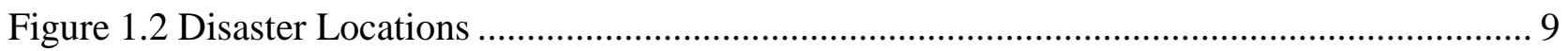

Figure 2.1 Schematic of Contraflow Transition for Interstate 40 in North Carolina..................... 21

Figure 2.2Response Time Before and After Optimization ................................................. 22

Figure 2.3 Simulation Model Output Summary for Mobile County ........................................ 23

Figure 3.1 Evacuation Study Boundary (Google Earth and Google Maps) ............................... 27

Figure 3.2 VISSIM Evacuation Study Area .................................................................. 29

Figure 3.3 Final Evacuation Study Boundary (Google Maps) .............................................. 30

Figure 3.4 Ring Barrier Controller Timing Template....................................................... 32

Figure 3.5 Traffic Volume Excel Spreadsheet.................................................................... 34

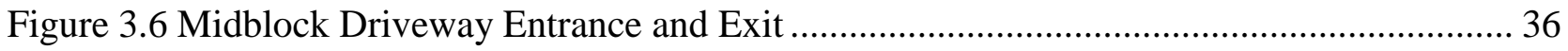

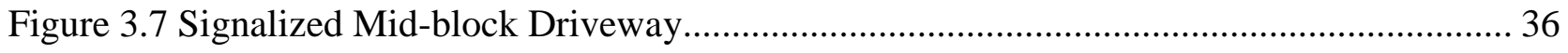

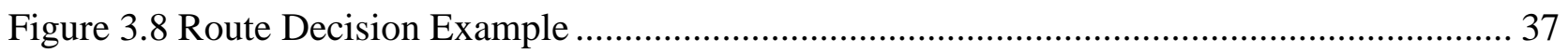

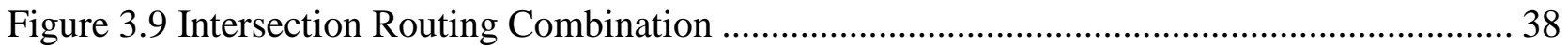

Figure 3.10 Onramp/ Offramp Volumes on a Google Maps Image ......................................... 39

Figure 3.11 Driving Behavior Parameter for Local Roads ................................................ 40

Figure 4.1Scenario 1 - Right Lane Closure On Bird Ave. ................................................... 50

Figure 4.2 Scenario 2 ContraFlow Lanes .................................................................. 51

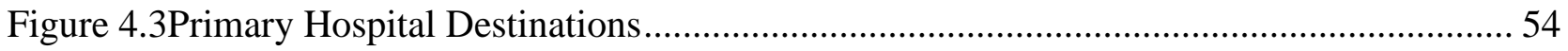

Figure 4.4Primary Fire Station Responders ................................................................. 55

Figure 4.5 Travel Times from O’ Connor Hospital from Disaster Sites ................................... 59 
Figure 4.6 Travel Times from Santa Clara Valley Medical Center from Disaster Sites 60

Figure 4.7 Travel Times from Regional Medical Center of San Jose from Disaster Sites 62

Figure 4.8Travel Time from Fire Station 1 to Disaster Areas .............................................. 63

Figure 4.9 Travel Time from Fire Station 7 to Disaster Areas ............................................ 64

Figure 4.10 Travel Time from Fire Station 30 to Disaster Areas ............................................ 65

Figure 4.11 Travel Time from HP Pavilion to Primary Hospitals .......................................... 66

Figure 4.12 Travel Time from San Jose Convention Center to Primary Hospitals ...................... 67

Figure 4.13 Travel Time from IRS Building to Primary Hospitals ......................................... 68

Figure 4.14 Travel Time from State of California Building to Primary Hospitals ....................... 69

Figure 4.15 Travel Time to HP Pavilion from Fire Stations............................................... 70

Figure 4.16 Travel Time to San Jose Convention Center from Fire Stations............................... 71

Figure 4.17Travel Time to IRS Building from Fire Stations ............................................... 72

Figure 4.18 Travel Time to State of California Building from Fire Stations ............................ 73 


\section{INTRODUCTION}

\subsection{Problem Statement}

In times of crisis, the failure to provide an effective emergency response system can result in a second catastrophe. Ten hurricanes that struck the United States between 1900 and 1992 caused an estimated damage of 15 to 97 million dollars in damage to the United States (Burton and Hicks 2005). With better evacuation plans, however, some of the tragedies that occurred could have been avoided with better evacuation plans. There are important lessons for other communities to learn from in both the hurricane disasters of 2005. Hurricane Rita's evacuation plan failed because of excessive reliance on automobiles, resulting in traffic congestion and fuel shortages (Litman 2006). Also, during Hurricane Katrina, many Amtrak trains left New Orleans empty before the storm because evacuation plans did not incorporate mass transit or heavy rail. Some hurricane victims took shelter at the Ernest N. Morial Convention Center while others chose the Superdome. Those without the resources to leave the area and also sheltered inside the superdome faced miserable circumstances as a loss of air conditioning, a leaking roof, and little food and water compounded problems for those involved (Cooper and Block, 2006). The aftermath of these two devastating hurricanes highlights the need for emergency response planning efforts that integrate relevant planning agencies and use available resources more efficiently.

Nowadays, emergency response agencies in most of the US cities rely on emergency response plans or computerized models to deal with the occurrence of major disasters 
(Chiu and Zheng 2007). An efficient emergency response decisions support system is necessary to save lives as well as coordinate with multiple, independent agencies. Development of a streamlined, coordinated decision process that utilizes real network routing information has the potential to greatly improve disaster management and to minimize fatalities in times of crisis.

Effective integration of the routing strategies with a community's existing emergency response resources requires coordination between traffic operations and disaster management plans. While the local mass transit operator is often listed as a resource within the Logistics Section of the Emergency Operations Plan, it is seldom part of the planning effort. This research would bring together the crucial emergency planning entities, emergency services, transportation and transit - to develop key data for use in the model, resulting in a more practical, realistic and effective plan.

Today, modeling and simulation of traffic flow serve as one of the most promising strategies to generate traffic information. The efficiency of microscopic simulation models is high enough to allow for reproducing the flow of whole networks in multiple real time (Shreckenberg, Neubert, and Wahle 2001). Transportation engineers can utilize traffic simulation to optimize a proposed system and run feasibility tests to determine the system's practicality (Mollaghasemi and Abdel-Aty, 2003). Simulation models can also answer "what-if" questions to aid system designers in assessing the impact of various alternatives on existing systems which cannot be field tested. In addition, interactions of various traffic sectors can be studied from a security-oriented point of view without the risks, costs, and complexity of multiple evacuation drills. 
In light of the disasters that have occurred, a timely and effective response could save a significant number of lives and requires coordination with multiple first responders such as hospitals, fire, and law enforcement.

The objectives of this study were the following:

1. Determine efficient routing strategy given existing transportation network surrounding transit center for dispatching emergency response vehicles

2. Develop a microscopic simulation model to evaluate the pre and post-disaster performance of the downtown street network.

3. Find traffic bottlenecks impeding evacuating traffic and emergency vehicle entry

4. Develop re-routing strategy for vehicles due to network link closures

These objectives are achieved in the context of the downtown San Jose area. In the city of San Jose Diridon transit center is located very close to the HP Pavilion which is home to major events. With this location as the focal point of our studies, disaster scenarios were created in response to what could potentially be a source of routing information in the event of a disaster. Based on the information garnered from the microscopic traffic simulation, an integration of routing strategies within the existing, emergency response framework was developed.

\subsection{Study Area}

The study area (see Figure 1.1) consists of approximately three square miles concentrated around the downtown core of San Jose. The disaster scenario includes the HP Pavilion and Diridon transit center. Within the study area freeways Interstate 280 (I-280) serves as 
an important thoroughfare in our network and during the PM peak hour provides transportation to over 15,000 vehicles. In addition, Highway 87 serves as another important route of entry into the downtown core area, providing access to HP Pavilion, Diridon Station, and surrounding areas within a three mile radius. The highway itself carries over 6,000 vehicles during the PM peak hour.

Diridon Station is a particularly crucial site due to its importance as a central transit hub and passenger rail depot linking the Silicon Valley to the rest of California. In addition, the station is expected to become a future stop on the BART extension to Silicon Valley in 2018 and California High Speed Rail. The station is also adjacent to HP Pavilion where numerous public events are held and the arena itself is home to the San Jose Sharks hockey team. The study area is depicted in Figure 1.1 below. 


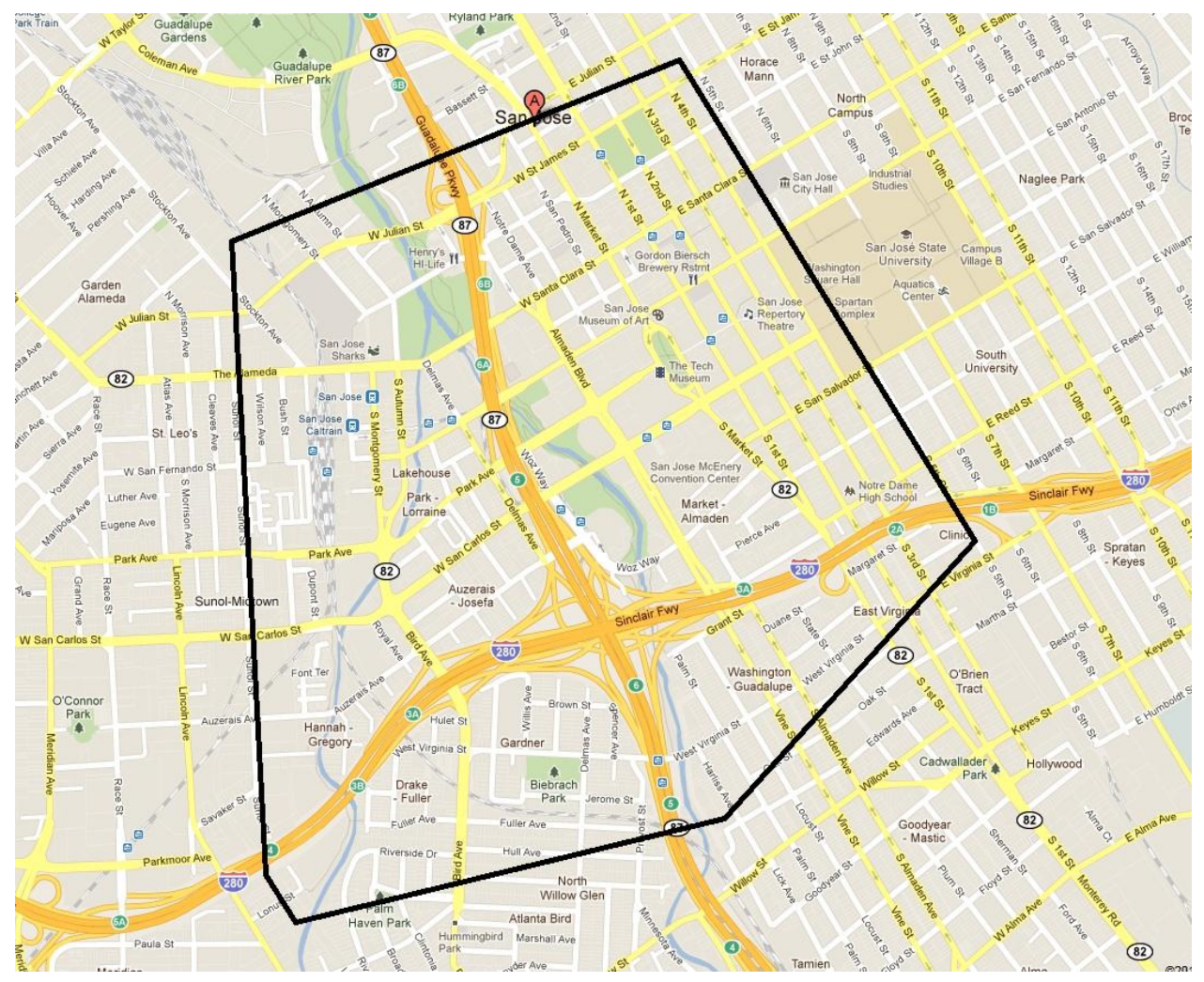

Figure 1.1 Study Area Map

This report describes the use of traffic simulation for evacuation of a downtown region and emergency vehicle routing in case of a disaster. The report also describes a variety of decisions needed to be made in this effort including choice of simulation package, modeling procedure etc. Also, a discussion on advantages and disadvantages of traffic simulation is also provided.

It was ultimately found through the simulation study and analysis that in the event of a man-made disaster occurring throughout the downtown area, Santa Clara Street and Montgomery Street would face severe bottlenecks. To alleviate the congestion, contraflow lanes should be used on Montgomery Street which becomes Bird Ave to help reduce the bottleneck and congestion. In addition to this solution, reducing the number 
vehicles on the road through public transit ridership would also be extremely beneficial to alleviate congestion.

\subsection{Disaster Scenario}

All the disaster scenarios revolved around a series of bombings that occurred around downtown San Jose on a Friday afternoon. To further exacerbate matters, the coordinated bombings all occur in high profile areas such as HP Pavilion and San Jose Convention Center, among other locations around downtown San Jose, during the afternoon peak hour at 4:00 pm. In addition, HP Pavilion was hosting a business seminar, "How to Make \$10K a Month From Home.” This was a sold out event with 19,100 attendees on site. All 1,800 on-site parking slots had been sold as part of "VIP" tickets, and adjacent city and privately-owned parking lots were full. Adjacent lots were located on Santa Clara Street at Delmas, Santa Clara Street at Cahill, and Autumn Street north of Julian. The Santa Clara at Delmas lot has exit potential onto Santa Clara both east and west bound, while the Santa Clara Street at Cahill exits onto Autumn and then Santa Clara in either direction, or Montgomery southbound, with the first cross street being Park Avenue.

At 4:00 pm the bombings began first with a truck bomb in the HP Pavilion parking lot adjacent to the loading dock on Montgomery Street, while a smaller device detonated on the floor of the arena in the middle of the seating area. Secondly, at the State of California building at 100 Paseo de San Antonio, another truck bomb detonated while it was parked on the Third Street side of the building in a no parking zone along the west side of the street. Next, at the IRS building located on S. Market St., a truck laden with explosives, parked on the west side of Market St. in a loading zone, detonated. The last 
bombing occurred at the Convention Center on Almaden Boulevard, where another truck bomb exploded while it was parked on the exhibit area loading ramp adjacent to the exhibit hall door.

Given the above disaster scenario, various response strategies were tested in the simulation model to observe which yielded the most efficient way to evacuate and have the emergency response reach the hospitals from the disaster areas. The different disaster scenarios all share a majority of network features in common, such as signal timing and traffic volumes. All disaster scenarios, as well as the base scenarios in VISSIM, included a 5 minute simulation warm-up period, followed by a 60 minute simulation time, and a 5 minute "clearing period" for the remaining cars to reach their destinations. In addition, only emergency vehicles (such as ambulances and fire vehicles) traveling on I-280 NB or SB could enter or exit into the downtown area. These vehicles were defined as a separate vehicle class in VISSIM. For I-280 NB, the closed off-ramps were from $4^{\text {th }}$ St. to Bird Avenue while on I-280 SB, the exits closed range from Bird Avenue to E. Virginia St. In addition, Highway 87 NB and SB were completely closed to all vehicular traffic except for emergency vehicles. The purpose behind this action was to prevent further gridlock on city streets, as well as potentially providing emergency vehicles a quicker, more efficient route to access the bombing locations. In addition, due to the large number of vehicles expected to exit out of the parking lot across from the San Jose Convention Center, a new intersection was added at Woz Way and Almaden Boulevard Also, another intersection was coded into the network at San Pedro and Santa Clara Streets for the expected mass exodus of cars exiting locations around the bombed out IRS building. 
While there would be many vehicles exiting the bombing locations, emergency vehicles from the three fire stations needed the fastest, most direct route into the disaster areas while ambulances would need the fastest routes to the hospitals from the bombing locations. For this particular study, three hospital locations and three fire station locations were identified as responders within the critical first hour. While no hospitals are located within the simulated area, the routing solution was to use Google Maps to map the travel time to the point where the path to the hospital began in the coded network. The Google Maps travel time was then added to the simulation time to produce an estimate of the total travel time from the hospital to the disaster area.

Also, throughout the report, when Base Case is mentioned prior to Section 4, it refers to the oriringla San Jose traffic network before accounting for the disaster area parking lot traffic. After Section 4, the term Base Case refers to the "Do Nothing" scenario where the disaster area parking lots are releasing their vehicles but there are no special incidents or contraflow lanes used on the network. In Figure 1.2, the locations of the bombing locations are depicted. 


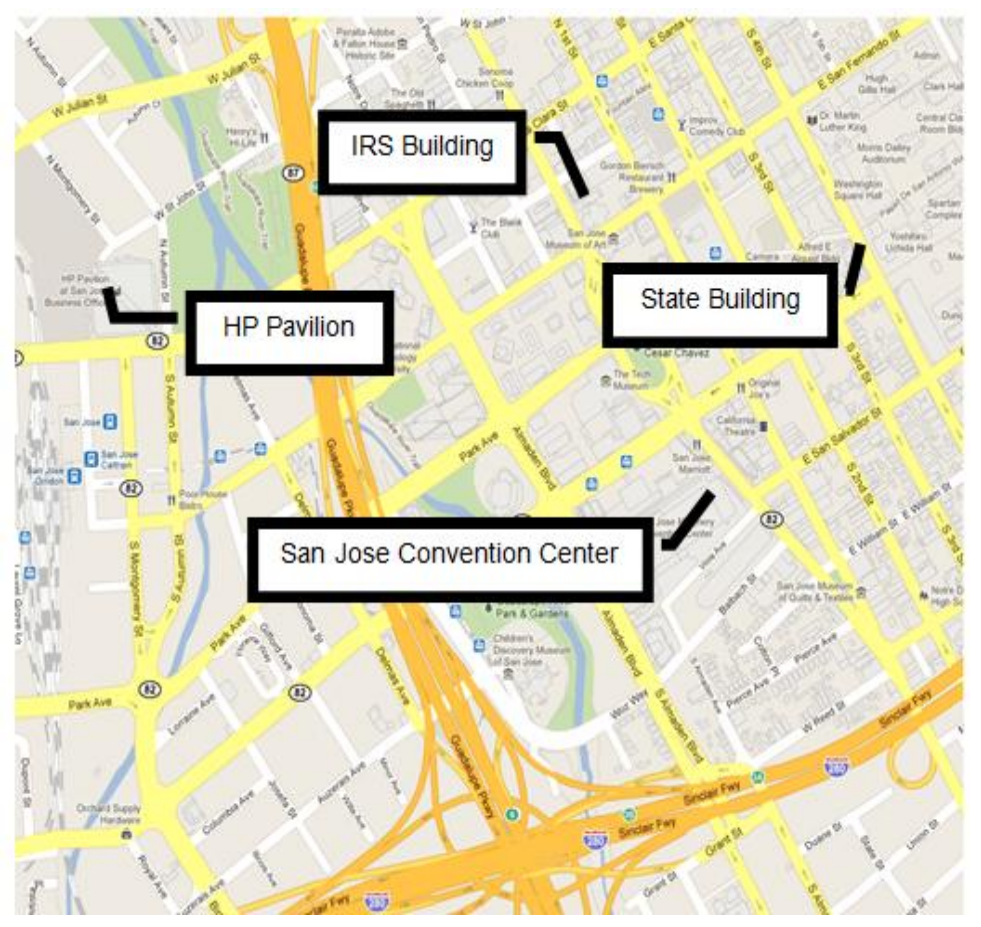

Figure 1.2 Disaster Locations

\subsection{Thesis Organization}

The following chapters present a literature review of related past works, a detailed description of the network's modeling procedure, an analysis of various disaster scenarios, and a conclusion as well as a future scope section.

The literature review provides information into various state-of-the-art traffic simulations that have been conducted for various purposes including emergency evacuation and routing strategy evaluation. Also, the basis for ultimately choosing VISSIM as the microsimulation model is also presented.

Following the literature review, a detailed discussion of the model development and coding is presented. Data collection and network coding in preparation for calibration and 
validation are shown and the process of calibration and validation are also explained as well.

Next, a discussion each of the four disaster scenarios are expanded upon and summaries of simulation results from those disaster scenarios are presented and analyzed. 


\section{LITERATURE REVIEW}

This chapter provides details of simulation applications and potential advantages and disadvantages that microsimulation offers. Also, reviews of prior studies related to simulation model application for emergency response scenarios are presented and analyzed.

\subsection{Traffic Simulation}

Traffic simulation can be defined as a "numeric technique for conducting experiments on a digital computer, which may include stochastic characteristics, be microscopic or macroscopic in nature, and involve mathematical models that describe the behavior of the transportation system over extended periods of real time (Molaghasemi and Abdel-Aty 2003)." Technological advances in personal computing have made traffic simulation models a more feasible option to address traffic management problems. Traffic simulation packages that are currently available offer a wide range of practical traffic analysis tools ranging from evaluation of alternative roadway treatments, evacuation studies, and safety analyses through the creation of artificial traffic accidents. In addition, modern simulation models are based on random vehicular movements, which make them suitable for modeling human driving behavior and also offer opportunities to view animated vehicles on a two or three dimensional graphic representation of the network.

Traffic simulation can be used to treat algorithms used in mathematical and logical modeling that are infeasible or are more complicated to represent a system in sufficient detail. Also congestion effects on roadways can be monitored through the vehicle animation, which gives the system characteristics in minute detail. 


\subsection{Simulation Model Choices}

Traffic simulation models can be broadly classified as microscopic (high fidelity), mesoscopic (mixed fidelity), and macroscopic (low fidelity).

Numerous microscopic traffic simulation models have been developed and are currently being used to study transportation network operations. These models typically offer the greatest flexibility and result in more accurate estimations of measures of performance compared to other model classes. The real world is represented more practically in these models because it can simulate vehicle to vehicle interaction and also give continuous profiles of vehicle locations and speed (Molaghasemi and Abdel-Aty 2003). Given parameters such as travel demand, they can evaluate the dynamic evolution of congested traffic and performance measures of alternative traffic management strategies in response to the traffic congestion. However, network size must be kept at a reasonable level compared with the larger macroscopic planning models due to the comparatively high number of required inputs, calibration and validation efforts, and computing power for modeling and analysis (Rousseau et al. 2007.).

Macroscopic models are more appropriate for regional or large scale studies. They are typically used by transportation planners or demand modelers. Planners take a systematic process to translate land use, household, and employment characteristics, and transportation supply into predictions of current and future travel patterns and demand, through mathematical formulation and simplification. Instead of modeling individual vehicles, cars are aggregated and measurements of flow, density, and average speed are then measured. These models are less accurate than their microscopic simulation 
counterparts but are faster and require fewer variables for network coding. Networks that are developed in this way also provide a static view of the transportation system appropriate for long term planning (Molaghasemi and Abdel-Aty 2003), (Rousseau et al. 2007).

Mesoscopic models have microscopic and macroscopic characteristics. Groups of vehicles or platoons are simulated and microscopic model results are aggregated for use in these models.

Models can also be classified as either stochastic or deterministic. Stochastic models include probability distributions which offer the option to model uncertainty or randomness. On the other hand, deterministic models perform the same way for a given set of initial conditions, in short, meaning that it does not include any randomness.

Depending on the scope of investigation, different levels of detail are necessary in modeling infrastructure and vehicles. The model that is ultimately chosen for a particular project should provide the appropriate functionality, i.e., arterial, freeway, or integrated (Rousseau et al. 2007). For simulations of large road networks the family of macroscopic flow models is the common choice, while microscopic models are more often used for studying the traffic flow in smaller areas, but in greater detail (Fellendorf and Vortisch 2001). In addition to the level of detail offered by each simulation package, other dimensions that require consideration include model flexibility, ease of data collection and coding, cost, training requirements, user friendliness, estimation accuracy, compatibility with other software, and expandability. The model choice is essential to the success of the experiment and this choice is usually a tradeoff between the accuracy and 
the precision of the model and the development costs, data needs, and the time required to execute the simulation (Rousseau et al. 2007).

\subsection{Simulation Study Steps}

Operating a simulation model necessitates experience and awareness of how the model operates to get the best results. The technique suggested by "Monograph on Traffic Flow Theory" is shown below (Lieberman and Rathi 1999):

1. Recognize and establish the scope of the problem

2. Describe the goal of the study

3. Find alternative methods to resolve the problem

4. Explore the available simulation models

5. Fine-tune the model

6. Execute model

7. Check the integrity of model

8. Analyze the model output

Before starting any study, one must first recognize a problem and establish the scope of the problem. Specifically in a transportation study, the scope of the problem includes clarifying the traffic environment (which include factors such as LOS, highway geometrics, and the peak hour factor), boundary of the study (which consists of the specific infrastructure being studied like the city streets, state highways, and interstates), and control environment. 
The second step is describing the goal of the study, (predicting travel demand, picking the least intrusive alignment for a new highway, etc), picking the variables that measure effectiveness (travel time, travel volume, etc.), choosing how specific the study needs to be, the time line, the budget, and the predicted precisions and constancy of the study.

After the goals of the study are established, the next step is to find the way of obtaining the sought after results. A comprehensive literature review needs to be executed to compare how similar studies were conducted, what problems were encountered and the methods used to overcome those problems. All sorts of mathematical and simulation modeling methods are surveyed and their advantages and disadvantages are compared according to the fundamental theories, simplicity, price, computing specifications, assistance available, quality of animation of the software, transparency of the documentation associated with the model. After comparing different types of simulation, the necessity of performing a simulation needs to be checked because in some cases when a mathematical model can solve the problem, a time intensive simulation does not need to be completed. When simulation modeling is chosen over mathematical models, the most desirable model that meets the needs of the problem is picked.

Once there is a specific simulation in mind, the next action is to collect the data that is required for completing the simulation model (details including signal timing plan, overhead photographs, vehicle composition, roadway schematics, and various traffic data like the AADT). Once all the information is obtained, a small section of the study area is tested to calibrate the model. Calibrating a model entails tuning the factors of the simulations (such as perception time, headway allocations, and traffic control devices 
location) with various scenarios. The simulation model is evaluated against the real data and possibly with the widely accepted Highway Capacity Manual.

The usage of simulation models can be thought of performing an extensive statistical experiment. Initially the model needs to be implemented to start up its database. That is required to make the data correctly characterize the starting state of the traffic setting. Analyzing the results is the most crucial and serious step. With the complexity of all the progression occurring in the real-world traffic setting, the researcher needs to be attentive for the following items:

- Make certain that all parts of the model proficiently represent the vital processes

- Confirm the input data that was required for the calibration is free from any typos or other errors

- Verify if the output developed from the simulation trials are up to par

- Ensure that the statistical analysis lacks any flaws from its solution

- Scan for any "bugs" in the model and the demeanor of the algorithms utilized

The detailed inspection of animation is vital because it shows the data and observations from the body of the traffic setting. Animation is the dominant tool for interpreting the simulation output. It gives an outlook on the source and consequence relationship and checks for unusual results. 


\subsection{Advantages and Disadvantages of Traffic Simulation}

The continued increase in computer processing power and improvements in graphical user interface (GUI) have led traffic engineers and planners to turn to traffic simulation techniques. These numerous simulation tools have become very practical traffic analysis tools in providing the benefit of artificially analyzing alternative roadway treatments, testing of new roadway designs, safety analysis through incident recreation, and dynamic emergency evacuation procedures.

The continued increase in computer processing power and improvements in graphical user interface (GUI) have led traffic engineers and planners to turn to traffic simulation techniques. These numerous simulation tools have become very practical traffic analysis tools in providing the benefit of artificially analyzing alternative roadway treatments, testing of new roadway designs, safety analysis through incident recreation, and dynamic emergency evacuation procedures.

Sisiopiku et al. (2004) provided a brief summary of many of the different types of traffic simulation models that are being successfully used to evaluate both microscopic and macroscopic network operations. CORSIM is a microscopic simulation model developed for the Federal Highway Administration (FHWA) and is used mainly in modeling urban traffic conditions. VISSIM is a microscopic simulation model created by PTV Vision that offers the benefit of modeling complex dynamic systems such as the interaction among pedestrian, public transit, and vehicles as well. Integrated Traffic Simulator (INTRAS) is a microscopic simulation model that has been used for incident analysis studies and has also been used to simulate traffic on freeways, ramps, and adjoining streets. 
Our study ultimately decided to use VISSIM due to its strengths as a stochastic microscopic, time step, and behavior based simulation software packaged developed to model urban traffic and transit operations. The program can analyze traffic as well as transit operations under constraints such as lane configuration, traffic composition, traffic signals, and other similar criteria, thus making it a useful tool for the evaluation of various alternatives.

While simulation models are continually improving with better features that can easily incorporate relevant data, there are still many variables that simulation cannot model. Algers et al. (1996) details these variables in his thesis. Some of these limitations include the ability of models to mimic congestion. The majority of simulation model utilize simplistic car following and lane shifting algorithms to decide vehicle motion. Thus, vehicular movement may not realistically replicate driver behavior. Also, with an increasingly greater attention on climate change, there has been an emphasis on including emission generation in simulation models. However, automobile emissions are realistically difficult to model and obtaining current emissions data to validate findings from the simulation may be difficult to obtain.

Both benefits and shortcomings are best summarized in a table shown below found in Chapter 31 of the Highway Capacity Manual (National Research Council 2000) 


\section{Table 2.1 HCM Analysis of Simulation Modeling}

\begin{tabular}{|c|c|}
\hline Simulation Modeling Benefits & Simulation Modeling Shortcomings \\
\hline $\begin{array}{l}\text { - Can move un-served queued traffic from one time to } \\
\text { another } \\
\text { - Can exam with untested scenarios that do not } \\
\text { presently occur in real life } \\
\text { - Can exam the system in condensed, stretched, or } \\
\text { actual time } \\
\text { - Can perform possibly dangerous experiments without } \\
\text { the danger to the researchers } \\
\text { - "Distributions can experiment off-line without using } \\
\text { on-line trial-and-error approach } \\
\text { - Can be the last resort method of analysis } \\
\text { - Can deal with interrelated queuing processes } \\
\text { - Can give time and space sequence with the statistical } \\
\text { information including means and variances } \\
\text { of a system } \\
\text { improvement alternatives }\end{array}$ & $\begin{array}{l}\text { - Output may not be able to be duplicated for each } \\
\text { model trial } \\
\text { - There is a possibility for a less demanding method of } \\
\text { solving the problem such as a mathematical model } \\
\text { - Simulation models necessitate extensive input } \\
\text { parameters and data, which are challenging or } \\
\text { unattainable to find } \\
\text { - Many steps need to be completed to check the } \\
\text { credibility of the simulation model. If those steps are } \\
\text { ignored, the model might not be accurate } \\
\text { - Users of the simulation model may not understand the } \\
\text { model's assumptions or limitations } \\
\text { - Creating a simulation model necessitates the } \\
\text { understanding of statistics, traffic flow theory, and } \\
\text { computer programming } \\
\text { - Researchers using the model may not know what the } \\
\text { model embodies } \\
\text { often lack guides and need special computers }\end{array}$ \\
\hline
\end{tabular}

\subsection{Emergency Preparedness Through Traffic Simulation}

\subsubsection{Evacuation Modeling: Natural Disasters}

In the past, traffic simulation had been used to analyze emergency evacuation conditions for vulnerable coastal areas in the southeastern United States. When Hurricane Floyd struck in 1999, evacuations of North and South Carolina resulted in highly congested 
arterial highways, and as a result, several states created Lane Reversal Plans for interstates and/or divided highways along evacuation routes. To test the plans' effectiveness a major research study was funded by the North Carolina Department of Transportation (NCDOT) to use simulation modeling to determine performance measures. It was ultimately determined that the lane reversals provided considerable capacity increases to traffic attempting to exit the disaster area via Interstate 40 in North Carolina (Tagliaferri 2005).Figure 2.1 below displays one of the evacuation plans for the area.

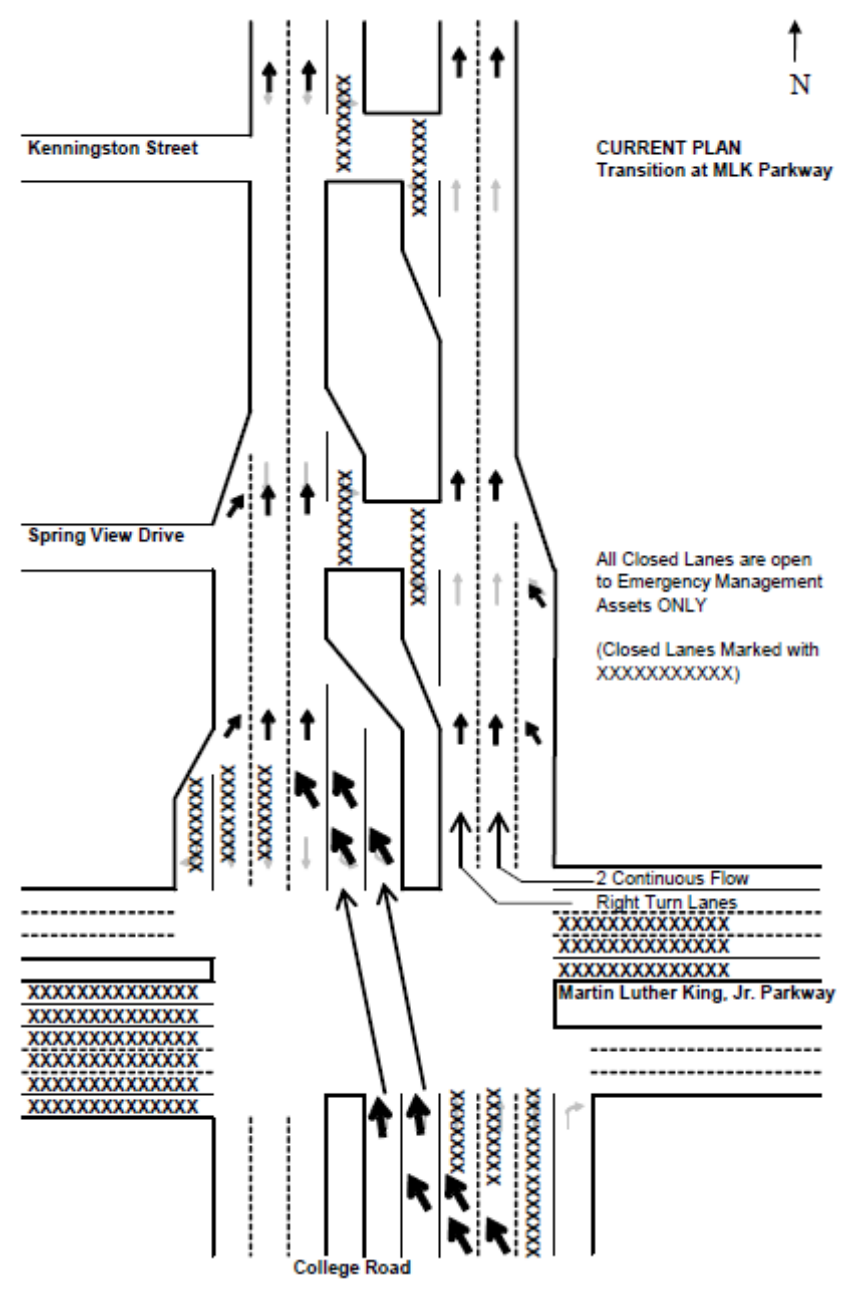




\section{Figure 2.1 Schematic of Contraflow Transition for Interstate 40 in North Carolina}

Source: (Tagliaferri 2005)

In another research study by Theodoulou (2003), CORSIM 5.0 simulation model results were used to evaluate the effectiveness of a contraflow segment on westbound I-10 out of New Orleans. Results showed that the use of contraflow lanes could increase the traffic flow significantly and alternative plans that were developed also were able to display effective roadway usage.

\subsubsection{Evacuation Modeling: Man-made Disasters}

More relevant to this research is the evacuation preparedness that includes urban areas affected by man-made disaster. Two such studies have been conducted in applying microscopic traffic simulation for assessing effective, post-disaster routing of emergency vehicles specifically for man-made disasters. Elmitiny, Ramasamy and Radwan (2007) simulated different strategies to evacuate a transit station to help LYNX bus service in the Orlando Metropolitan region evaluate its evacuation plans. Also, Mollaghasemi and Abdel-Aty (2003) analyzed the highway network around Orlando International Airport to identify the most effective routing strategies for emergency vehicles.

\subsubsection{Evaluation of Routing Strategies}

Other studies conducted by Haghani, Hu, and Tian (2003) provide an integer programming model to conduct a simulation experiment in routing Emergency Medical Service using a dynamic shortest path algorithm. Through a series of mathematical tests to verify the model's validity and sensitivity to changes in various parameters, it was ultimately determined that the new model developed in this study provided advantages in 
real-time emergency vehicle dispatching. Through a dynamic network, individual nodes were treated as moving vehicles which provided a comprehensive, twofold tool. First of all, the emergency response capability for ambulances were improved and secondly dynamic travel time helped to provide an optimal emergency response time to severe incidents. Figure 2.2 below depicts the improved response time after optimization.

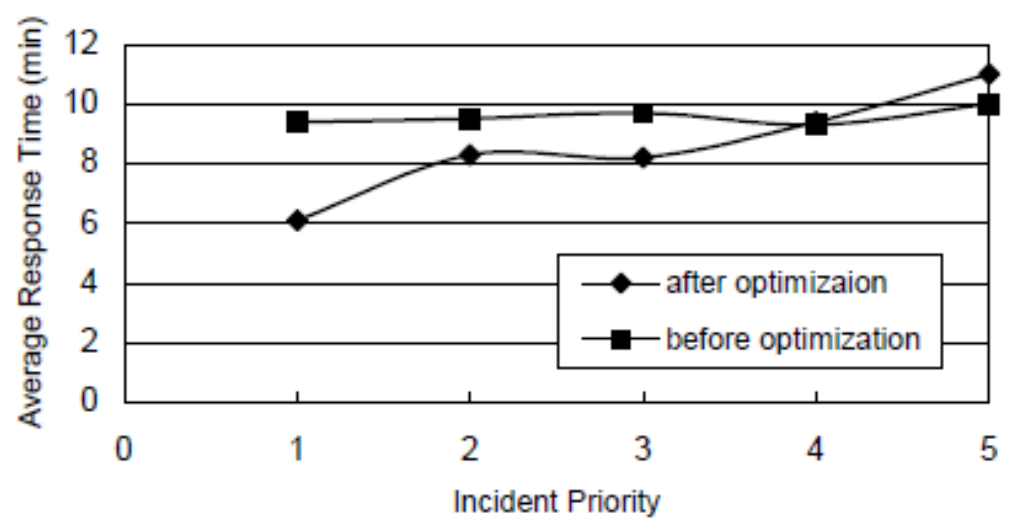

Figure 2.2Response Time Before and After Optimization

Source: Haghani, Hu, and Tian (2003)

Pal, Graettinger, and Triche (2002) used ArcView Geographic Information Systems (GIS) and traffic simulation software Oak Ridge Evacuation Model System (OREMS) 2.5 to development evacuation models for two counties along the Alabama Gulf Coast. This southeastern coast of the United States is particularly well known for its vulnerabilities to hurricanes. Arcview GIS was used to organize various input data from roadway links to population data in preparation for entry into OREMS. Using a system of nodes and links, the resulting simulation showed a complete evacuation of Baldwin and Mobile Counties would take approximately 21 hours and 8 hours, respectively. This 
information along with a progressive evaluation of the percentage of the population evacuated is graphically displayed in Figure 2.3below.

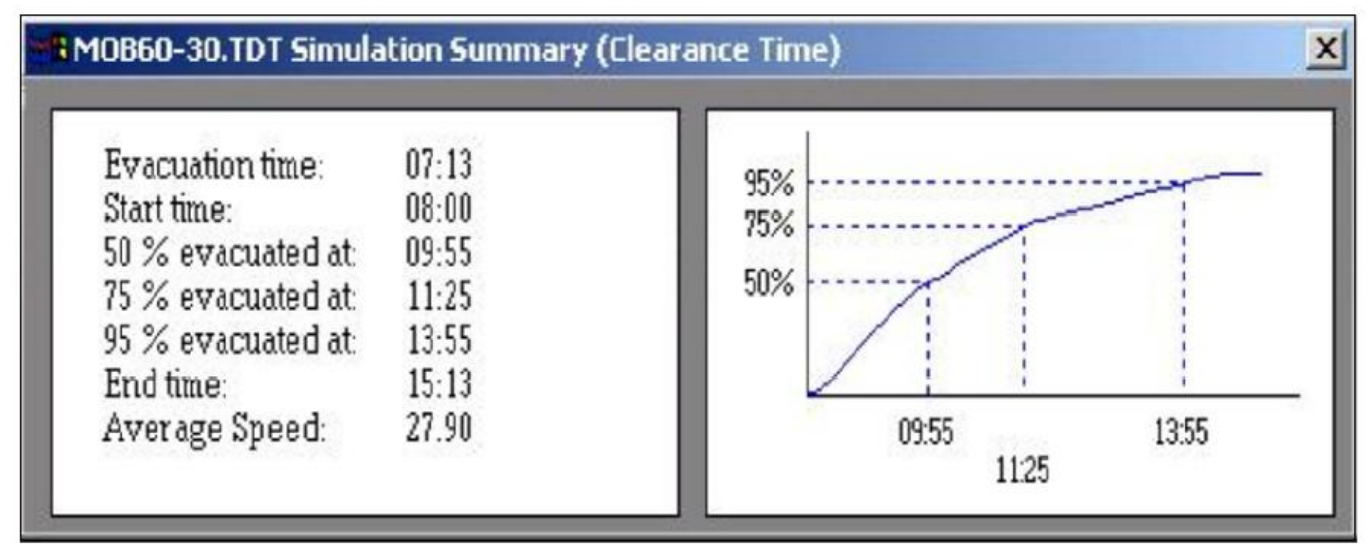

\section{Figure 2.3 Simulation Model Output Summary for Mobile County}

Source: Pal, Graettinger, and Triche (2002)

A general, mathematical evacuation model using linear-programming by Chiu and Zheng (2006) was developed that provided a comprehensive treatment on the simultaneous, multi-dimensional decisions related to multi-priority group mobilization during emergency evacuation. The proposed network transformation from a node to node basis would be changed into a cell transmission technique that permitted complex multidimensional mobilization to be determined in the most efficient way. This paper also acknowledged its limitations as needing future research in improving its model capability.

\subsection{Conclusions from Literature Review}

The aforementioned studies, while thorough and helpful in their own way lack the effective integration of the routing strategies (for emergency vehicles and/or for the evacuees) within the overall emergency response framework for the community. In 
addition, the regional traffic model developed by Sisiopiku et al. is limited in its ability to simulate real-time emergencies and does not model vehicular behavior at the microscopic level. Our research is an attempt to enhance the knowledge in this area with an effective integration strategy. We would provide a clear framework for integrating the routing strategies within the overall response plan for a community.

Based on the detailed review of the literature it was decided that VISSIM microscopic modeling tool will be used in this research. VISSIM was chosen due to its strengths as a stochastic microscopic, time step, and behavior based simulation software developed to model urban traffic and transit operations. The program can analyze traffic as well as transit operations under constraints such as lane configuration, traffic composition, traffic signals, and other similar criteria, thus making it a useful tool for the evaluation of various alternatives.

The study we provide also captures the real dynamics of emergency routing decisions that could be easily extended to other locations around the state. While precise routing strategies may not be directly transferrable to other transit centers, other agencies in the state of California such as Amtrak can first identify the optimal routing strategies for emergency situations. 


\section{NETWORK MODELING}

As mentioned in the disaster scenario the network that needed to be modeled here was the afternoon peak hour on a weekday. The reason is that this research addresses the worstcase scenario involving multiple terrorist bombings throughout the downtown area that would induce a wide scale panic and add to the already congested freeway and highway networks. This chapter describes the network modeling procedure, including the details of data collection, network modeling and validation.

\subsection{Data Collection}

In order to provide a basis for calibration during the base-case PM peak scenario intersection turning movement data for downtown surface streets had to be obtained from the City of San Jose. In addition, freeway counter data for I-280 and counts for Highway 87 were obtained from the Caltrans Performance Measurement System (PeMS). Lastly, a regional Cube Voyager model from the City of San Jose provided another means of obtaining approximate, directional traffic volumes throughout the entire network. After the traffic data was obtained and a calibration base established, the next step included the virtual construction of a traffic model that would accurately simulate driving conditions encountered during the base case. The network creation not only included the links or roads necessary to travel upon, but also included traffic signals, stop signs, yield control, reduced speed areas, and desired speed decisions.

Once these steps were fulfilled, the different driving behavior parameters that VISSIM offers could be implemented to calibrate the simulation to match reality as closely as possible. A summary of the final network is shown in Table 3.1 below. 
Table 3.1 Final Network Summary

\begin{tabular}{|c|c|}
\hline Number of links & 974 \\
\hline Signalized Intersections & 45 \\
\hline Vehicle Inputs & 70 \\
\hline Stop Controlled Intersections & 1 \\
\hline
\end{tabular}

\subsection{Model Building}

The first attempt to recreate the network's geometry involved importing network coded by the City of San Jose using the program Cube Voyager. Cube Voyager is used to model a wide variety of planning policies and improvements at the urban, regional, and longdistance level. Although Cube Voyager is a macroscopic model that is mostly appropriate in forecasting personal travel, it was initially thought to be a viable option. PTV Vision not only offers a microscopic simulation model VISSIM, but also offers a macroscopic planning model called VISUM. Therefore, the Cube Voyager model was imported into VISUM to be lightly edited and then exported into VISSIM.

However, this process proved to be fruitless due to the nature of the Cube Voyager model. For example, the Cube model included an extra HOV lane that was separate from the rest of the freeway lanes and could only connect at certain points. The most critical problem was the program to program data transfer. Attempts to change the network geometry in VISSIM such as lane additions or link movement produced node errors and created an irreparable network. Many other problems encountered in assembling the VISSIM network with this approach are too numerous to detail in this thesis. In other 
words, the macro level model that was attempted to import into VISSIM just lacked appropriate level of details to be applied for this research.

The approach adopted then was to code the network geometry from scratch through multiple aerial images. The network creation began by first capturing an image of the proposed network area from Google Maps. The network was then properly scaled and links (roads) were added to create the vehicle thoroughfares. Initially, it had been decided to model $20 \mathrm{mi}^{2}$ surrounding the downtown area including all the freeways and arterials in the network. The initial evacuation study boundary is depicted in Figure 3.1 below. The left image is from Google Maps and the right image is from Google Earth.

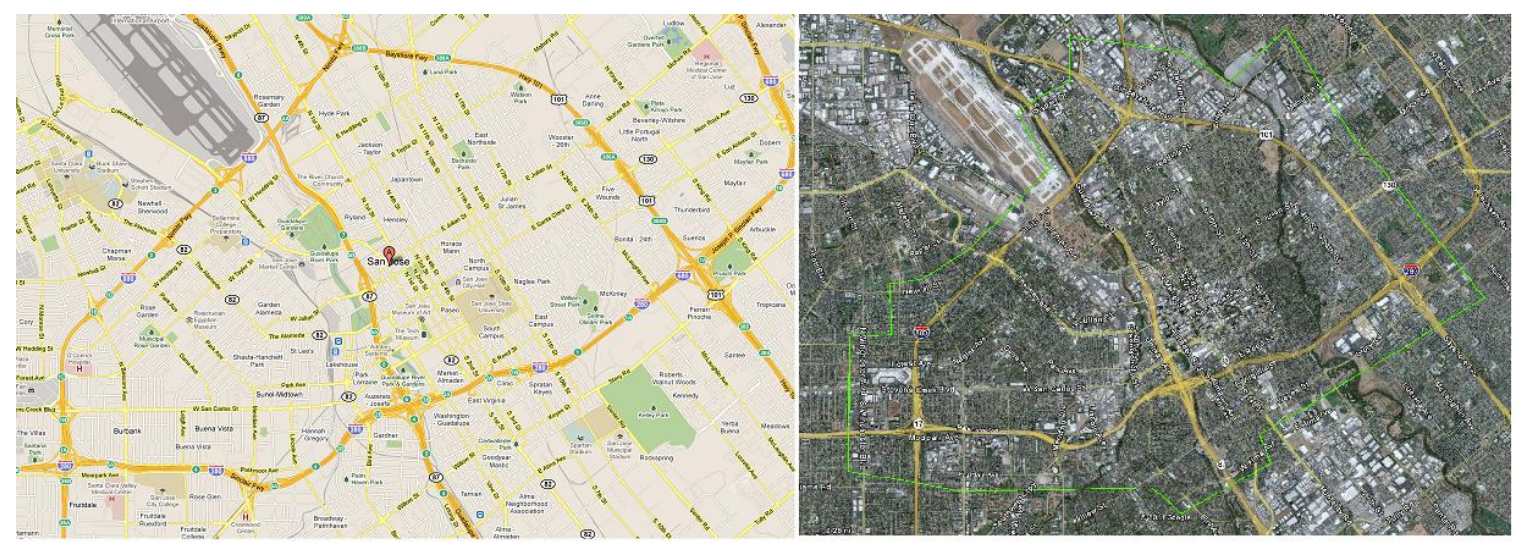

Figure 3.1 Evacuation Study Boundary (Google Earth and Google Maps)

The entire network within the study area displayed above had been coded in VISSIM with the help of multiple images. The network coded in VISSIM is shown in Figure 3.2. However, while calibrating that large a network it appeared that due to a large number of intersections and streets the traffic assignment algorithm was not able to converge. There were multiple attempts to overcome this on the existing network through relaxing constraints on convergence, increasing lengths of some of the links to provide enough 
pockets for queued vehicles to get stored. In addition, a dynamic traffic assignment feature known as "route guidance" which assumes that some cars have GPS systems and will continually gather data on the fastest routes available was used. Also, in attempting to get the dynamic assignment to converge, merging needed to be made smoother such as eliminating locations where two connectors came from a multiple-lane link to a link that had fewer lanes than the previous link. Due to this problem, cars were making unnecessary lane changes due to the fact that there were two possible routes.

However, the enlarged network was never precise enough to provide the modeling detail necessary for the present application. Therefore the network was reduced in scope to be able to precisely model the details of traffic movement. The network ultimately used to evaluate the proposed disaster scenario is shown in Figure 3.3 below. This network captures all the major exit and entry points into downtown and still can be precisely modeled with all the requisite details in a microsimulation environment. 


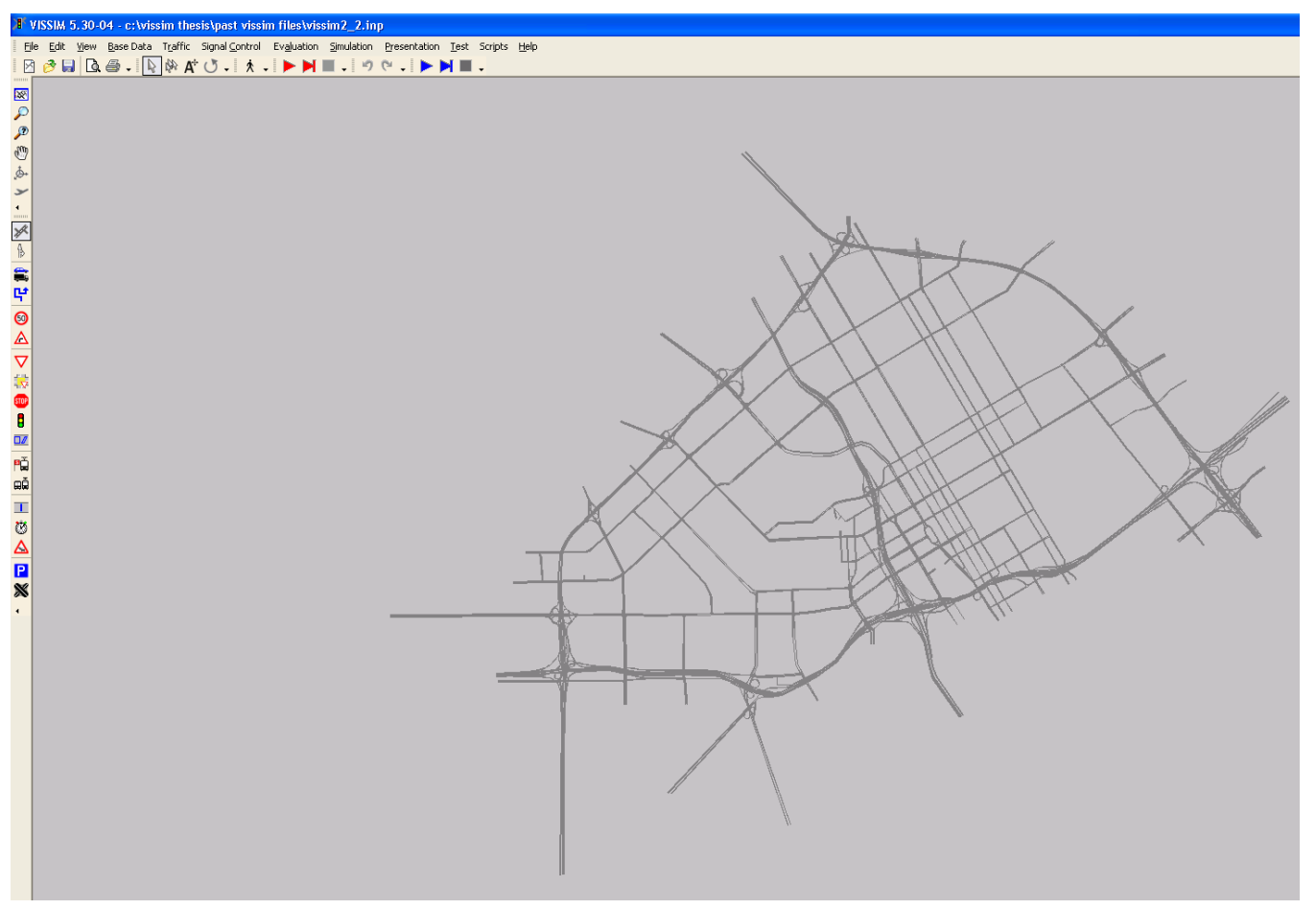

\section{Figure 3.2 VISSIM Evacuation Study Area}

This region was also based on proximity and relevance to the actual terrorist bombings that would occur (according to the disaster scenario described in Section 3) throughout the downtown area. Since the larger network of San Jose had previously been created with traffic signals and desired speed decisions to regulate the roadway velocities the remaining work included simply removing the extraneous freeways and surface streets. The final study area is shown in the image below. 


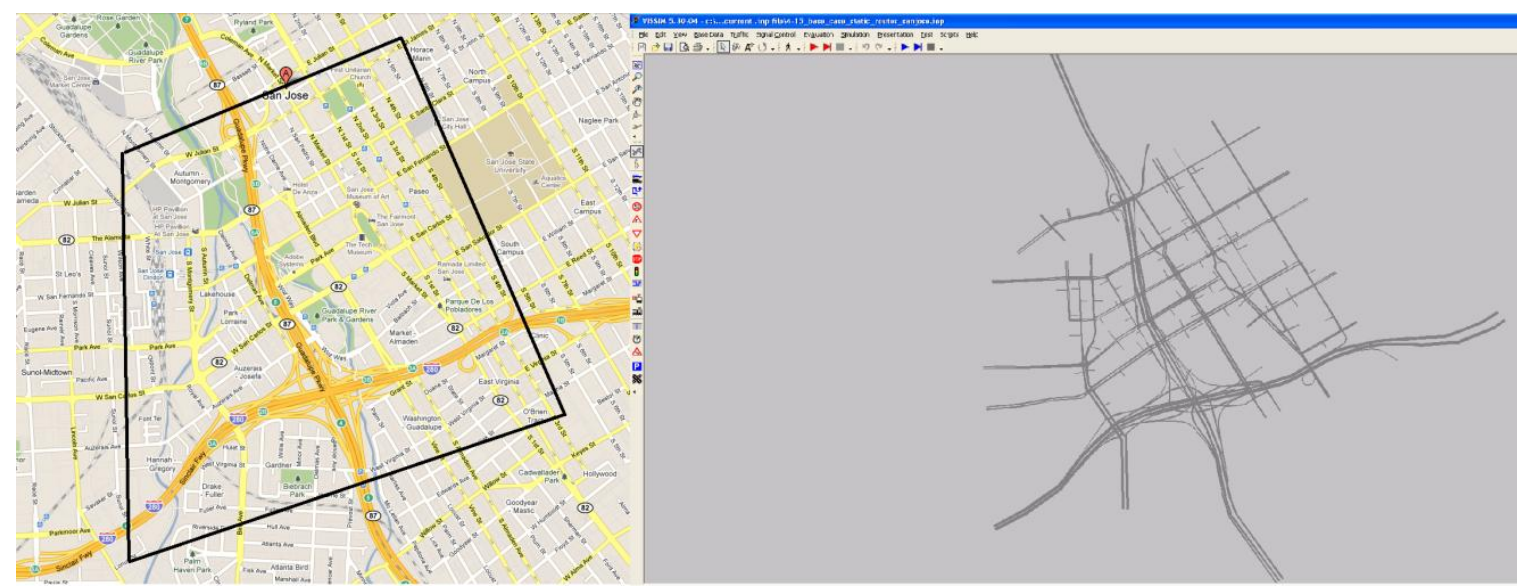

Figure 3.3 Final Evacuation Study Boundary (Google Maps)

In addition to changes such as deletion of irrelevant network elements, there were also functional changes that initially produced unrealistic driver behavior and traffic congestion during test runs. A number of elements had to be carefully changed in order to ensure the simulation replicated reality to the best of program's abilities. Table 3.2 summarizes the detailed, thorough process involved in modifying the network.

\section{Table 3.2 Network Modification Procedure}

1. Insertion of vehicle inputs

2. Routing decision creation from each vehicle input to respective destinations

3. Checked speeds throughout network on desired speed decisions

4. Input stop signs for stop controlled intersections for modeling of right turn on red on signalized intersections

5. Checked conflict areas to ensure proper yield rules at conflict points (such as permitted left turns)

6. Checked proper positioning of signal heads (an improper location in VISSIM may lead to vehicles not stopping at red signals)

7. Input vehicle detectors at intersections working in correspondence with signal heads 


\subsection{Signal Timing Data}

After the network changes were completed and various simulation elements previously described were input throughout the network, the next step involved setting up the signal timing and volumes to match the base case PM peak scenario. During the peak hour the signals were modeled as Ring Barrier Controller in VISSIM since it captures the general signal timing pattern created for the intersections throughout the network.

In order for the network to recognize the signal head, each signal head was assigned a signal controller number. Every time a new signal was input into the network, a new signal file (.rbc for Ring Barrier Controller) was created through the "edit controllers" option. The Ring Barrier Controller software is one of the actuated signal timing options included within VISSIM. The controller dialog consisted of the standard options to create a customized signal timing plan including minimum green time, and yellow and red timings as well. In addition, the Ring Barrier Controller offered the option that sufficiently fulfilled our needs to mostly signalize intersections with four approaches, the occasional protected left turn, vehicle extensions, and vehicle detection. Figure 3.3 below shows the standard signal timing that accommodated the eight movements (four through and four protected left turns) at the intersection. 


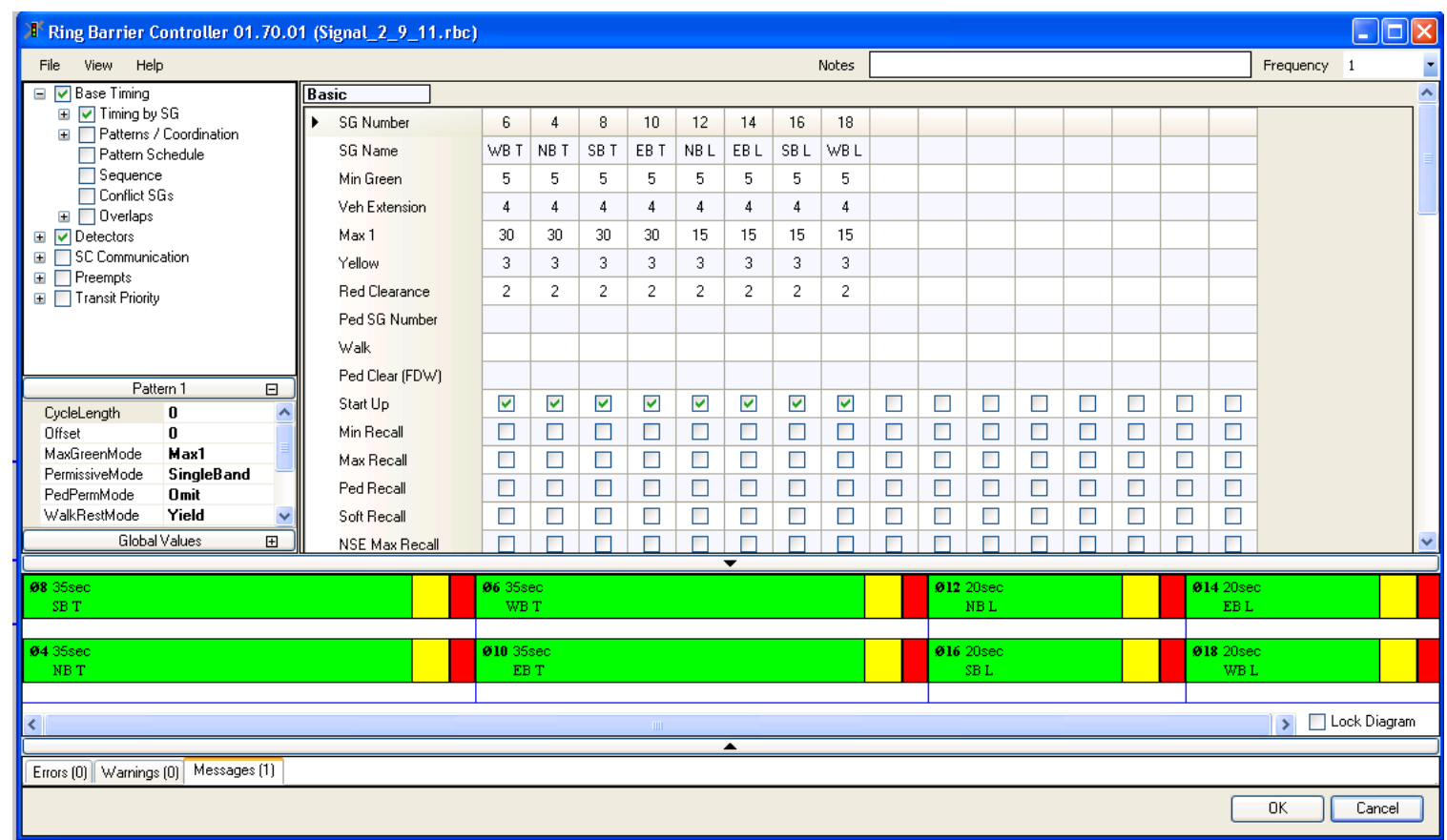

Figure 3.4 Ring Barrier Controller Timing Template

In the event that an intersection only allowed permitted left turns, the left turn only phases of $12,14,16$, and 18 were not inputted, and vehicles were instructed to yield to oncoming traffic in the opposing direction through conflict areas. Another unique feature of Ring Barrier Controllers is the ability to sync vehicle detectors with the signal controllers. This allowed a much more efficient flow of traffic that enabled a phase to be skipped, if necessary, to call on a signal controller that had cars waiting at the intersection.

Just as the network modification procedures followed standard steps, the signal timing was input and tested in simulation to ensure the network traffic ran properly. The steps taken are displayed in Table 3.3 below. 


\section{Table 3.3 Signal Timing Procedure}

1. Input the signal group number, name, minimum green, maximum green, yellow, red, and vehicle extension timings.

2. Check the existing network geometry in Google Streetview to determine whether protected left phases are necessary.

3. Set the phasing order and ensure vehicle detectors are selected according to the signal group numbers

4. Install actual signal heads and detectors within the network

5. Install stop signs on right turning connectors to allow right turn on red

6. Complete simulation test run to ensure proper phasing and vehicle detection

After signal head creation and signal timings have been completed for the PM peak base case scenario, the remaining step is to input and balance the vehicle volumes.

\subsection{Volume Data For Surface Streets}

The final step to creating a fully functional network in VISSIM involved compiling available surface street volume data into one spreadsheet. The best available data was from the City of San Jose which sent over a Microsoft Excel file that included intersection counts throughout downtown San Jose from 2006-2009. However, this information itself was insufficient in determining all the volumes at every intersection. The next, most favorable option was to refer to the Cube Voyager data, also given by the City of San Jose, which included directional traffic volumes throughout the network. Prior to coding the counts in VISSIM, all traffic count data from the City of San Jose's Microsoft Excel file were entered into one single spreadsheet. An intersection was shown as four different approaches as shown in the figure below. 


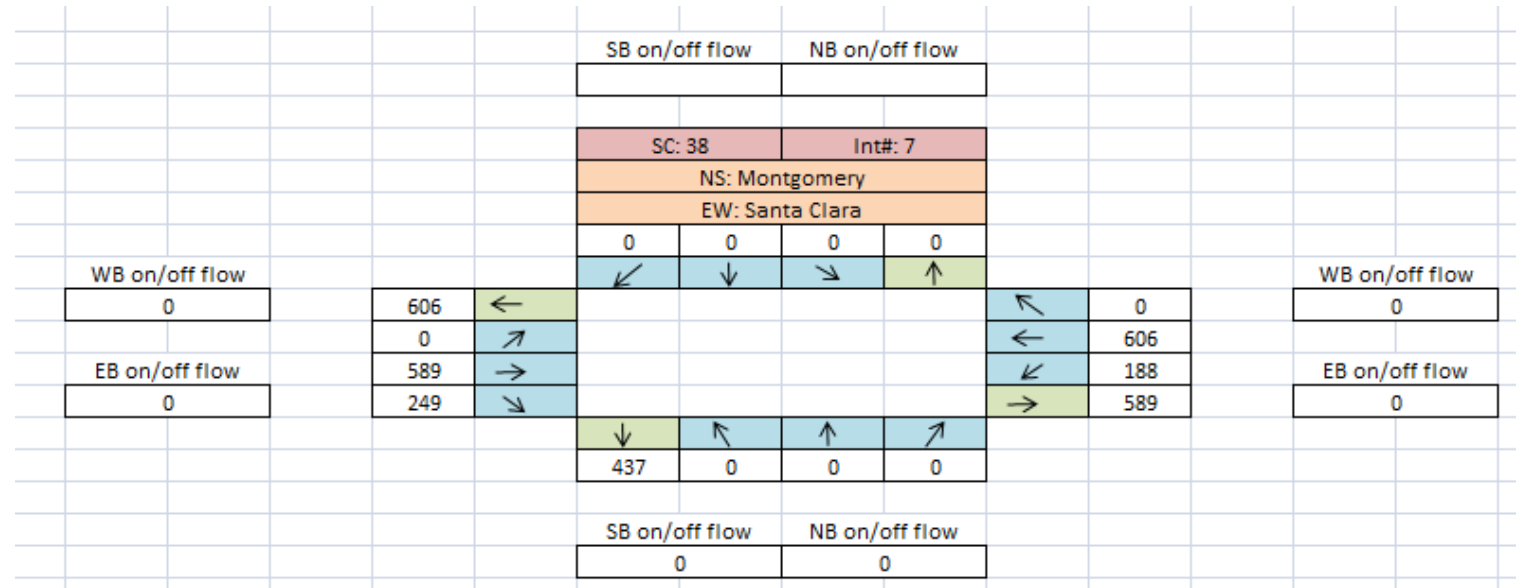

Figure 3.5 Traffic Volume Excel Spreadsheet

The purpose of the directional "On/off flow" cells shown above were to calculate the volume difference between the upstream intersection departure and downstream intersection approach. While the above spreadsheet shows a completely balanced intersection, prior to the volume balancing, if the "On/off flow" cells presented a negative integer, a volume had to exit the road before the next intersection. However, if the cell value was positive, that signified the number of vehicles indicated in the cell should enter the road prior to the adjacent intersection.

The procedure to utilize the best available volumes in the Excel file first followed by Cube Voyager data to fill in the missing intersections is summarized in Table 3.4 below. 


\section{Table 3.4 Volume Input and Balancing Procedure}

1. Volumes from the 2006-2009 Excel files were entered into the turning movement cells at each intersection

2. Working away from the known intersections, the Cube Voyager data was integrated into adjacent intersections. To get the volumes to match, mid-block driveways were used either as feeders or exits from the network.

3. Using an iterative (west to east, north to south approach), the network was balanced so that the "On/off flow" cells were as close to zero as possible.

4. Many iterations were required because volume balances would be upset if any approach fed into the balanced segment from an adjacent intersection.

Prior to entering routing decisions throughout the network, the next step was to create the mid-block driveways in the network using the procedure shown in Table 3.5 below.

\section{Table 3.5 Mid Block Driveway Coding Procedure}

1. A roadway was selected in VISSIM and a single link was placed at each location depending on whether the link served as a feeder into the network or exit from the network. If the spreadsheet showed a volume departing from the road, an exit was created where as if vehicles had to enter the road from, an entrance was coded.

2. Driveway locations included links, connectors, and conflict areas to resolve right of way issues.

3. Mid-block exits were coded as far upstream as possible to discourage unrealistic weaving and to allow adequate lane change distance for vehicles. Mid block entrances were created as far upstream as possible to again allow ample lane change distance.

4. Once the driveways were placed on their respective roads, the traffic volume compilation was referred to and the corresponding volumes were placed into the network.

Figure 3.6 below shows the layout of a typical entrance and exit. For most driveways, if traffic flowed in, there were no vehicles departing from the driveway and vice versa. Occasionally, the placement of a mid block driveway was not realistic (i.e. Bird St. interchange and Julian St. interchange) and were not coded with driveways. 


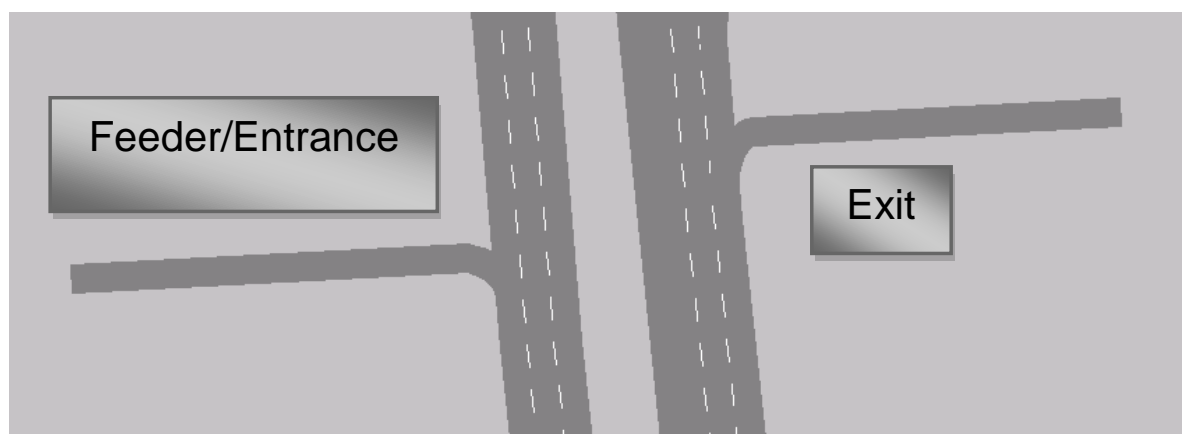

Figure 3.6 Midblock Driveway Entrance and Exit

Certain mid-block feeders and exits even warranted signals due to the large entering/exiting volumes and their placement in reality. Figure 3.7 shown below depicts the placement of one such mid-block feeder with signals. This was one example where both an entrance and exit were warranted due to the large number of vehicles entering and exiting. Also, a signal exists in reality at that location.

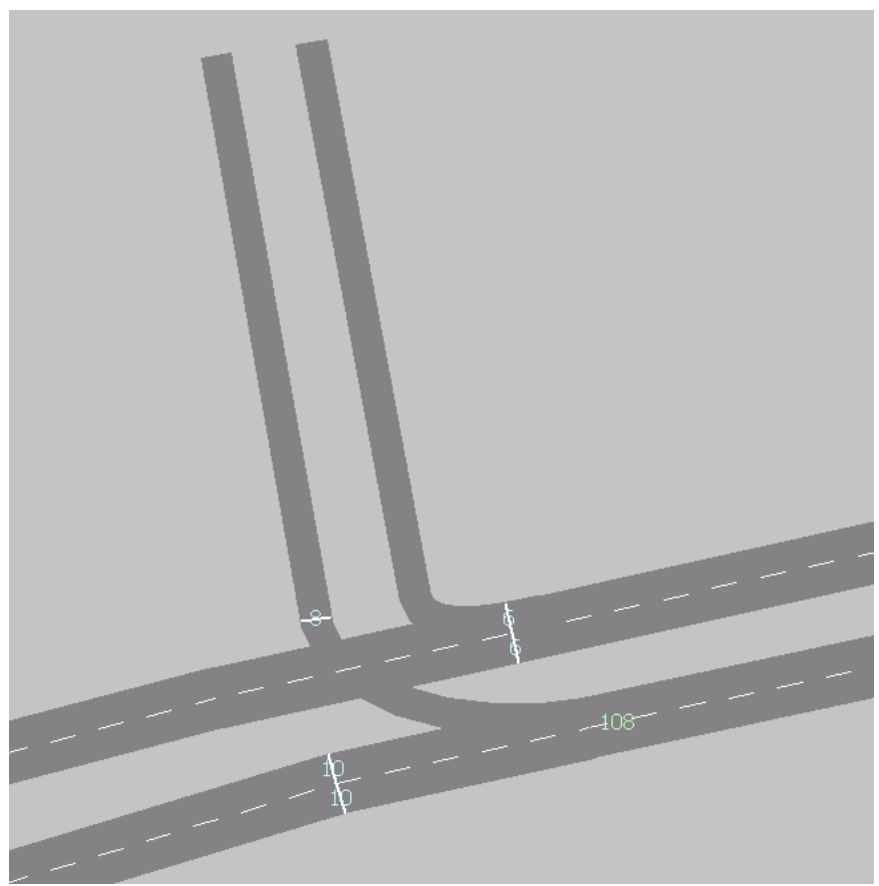

Figure 3.7 Signalized Mid-block Driveway 


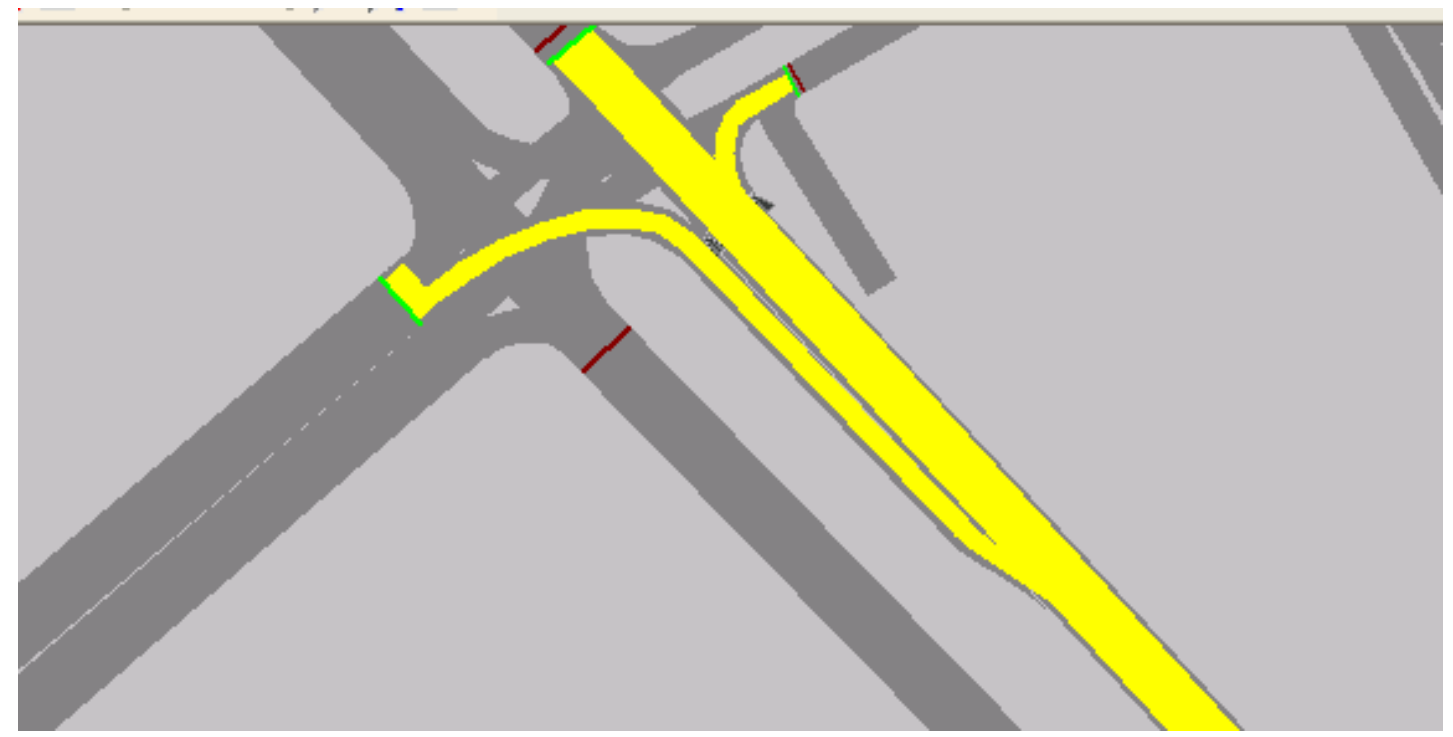

Figure 3.8 Route Decision Example

Following the driveway coding, the traffic volumes and turning movements from the compiled spreadsheet were entered into the vehicle routing decisions. Figure 3.8 above shows a route decision that branches through several intersections after a routing combination. There were also locations throughout the network where closely placed intersections exhibited large through and turning volumes. As a result, some cars could not change lanes fast enough to access the connector it should have traveled on. The solution to this was to create one routing decision that would span over several intersections to allow vehicles ample time to make necessary lane changes. Figure 3.9 below depicts the intersection routing combinations necessary to allow for vehicles to probably access their destinations. 


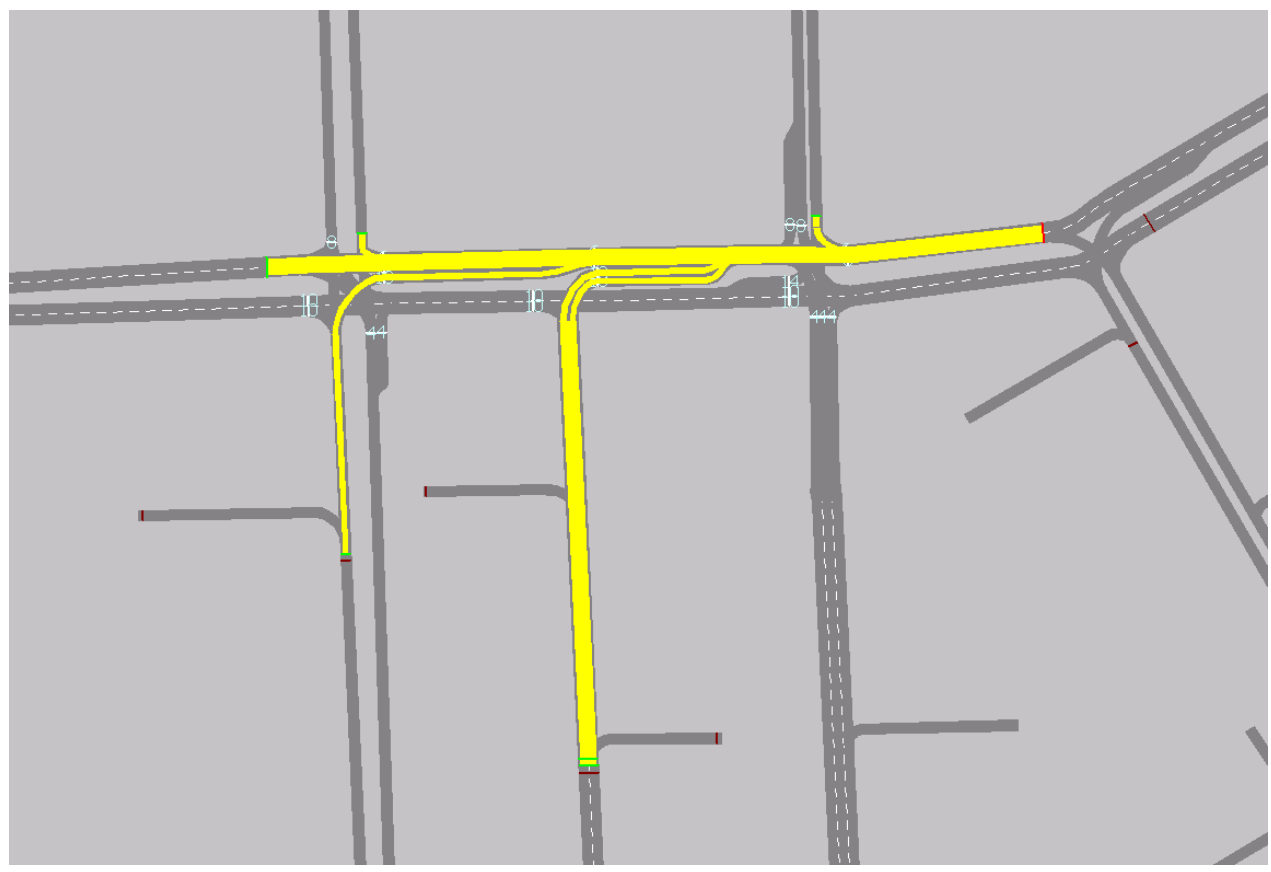

Figure 3.9 Intersection Routing Combination

\subsection{Volume Data for Freeway and Highway Segments}

Caltrans has placed data counters on both I-280 and Highway 87 as well. Through Caltrans' PeMS system data for those respective locations, volumes for both locations were obtained. However, data for the freeway/highway segments only included one set of counters each on I-280 southbound (SB) and eastbound (NB) at I- 280 and Highway 87 interchange. In addition, there was only one counter along Highway 87 northbound (NB) and none on the southbound (SB) direction. The data for Highway 87 NB, which was last collected in 2006, displayed approximately 9,000 less vehicles than a more current (2009 Annual Average Daily Traffic "Peak Hour”) set of data.

Therefore, the most current data available was used for all freeway and highway segments. As for the onramps and offramps, the turning movement spreadsheet occasionally contained volumes coming onto the surface streets from an offramp or 
vehicles departing onto the freeway/highway. This data was used first and Cube Voyager data was utilized to fill in the locations where no traffic count data was present.

An AutoCAD file shown below in Figure 3.10 depicting the highways and freeways were created along with the respective onramp and offramp volumes for visualization purposes.

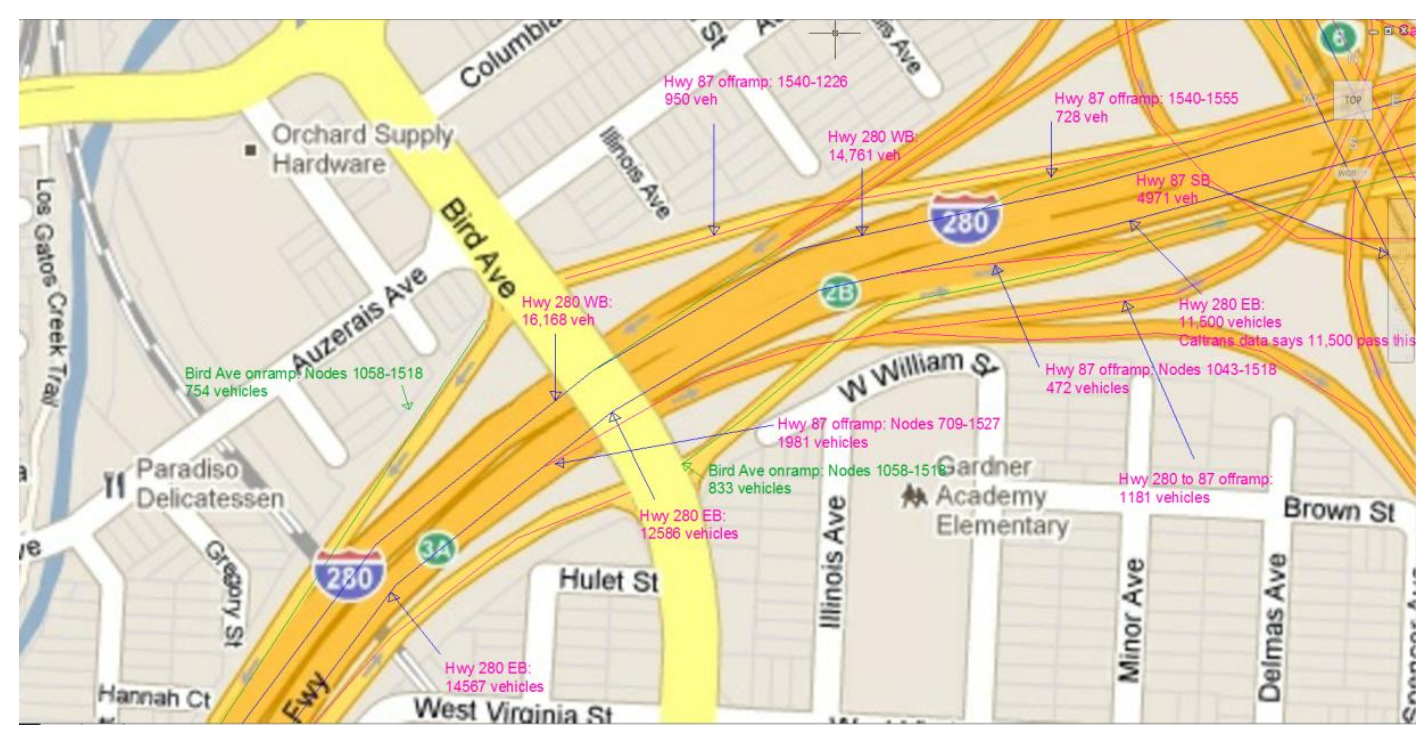

Figure 3.10 Onramp/ Offramp Volumes on a Google Maps Image

\subsection{Vissim Network Calibration}

After entering routing decisions, the last two steps before scenario creation and comparison are calibration and validation. Calibration in the completed VISSIM network for the base case PM peak scenario involved refining and adjusting the network to simulate realistic driving conditions. Calibrating a microscopic simulation model can include adjusting components such as turning movement volumes, car-following model parameters, and traffic speeds. A well calibrated model is essential for our studied system because of its impact on predicting future vehicle behavior and modeling alternate 
disaster scenarios. The plan was to compare the model's volumes to those of the City of San Jose or Caltrans' data. If the data did not resemble that of the models', various behavior parameters in VISSIM were modified in the completed VISSIM network and the entire process would be repeated. The following sections describe the calibration process in additional detail.

\subsubsection{Driving Behavior Parameters}

The final network consisted of both freeway and local streets that involved different car following model parameters and driving behavior. Surface streets that used the "Urban (motorized)" driving behavior were not altered. A screenshot of the default values used in the simulation is displayed in Figure 3.11 below.

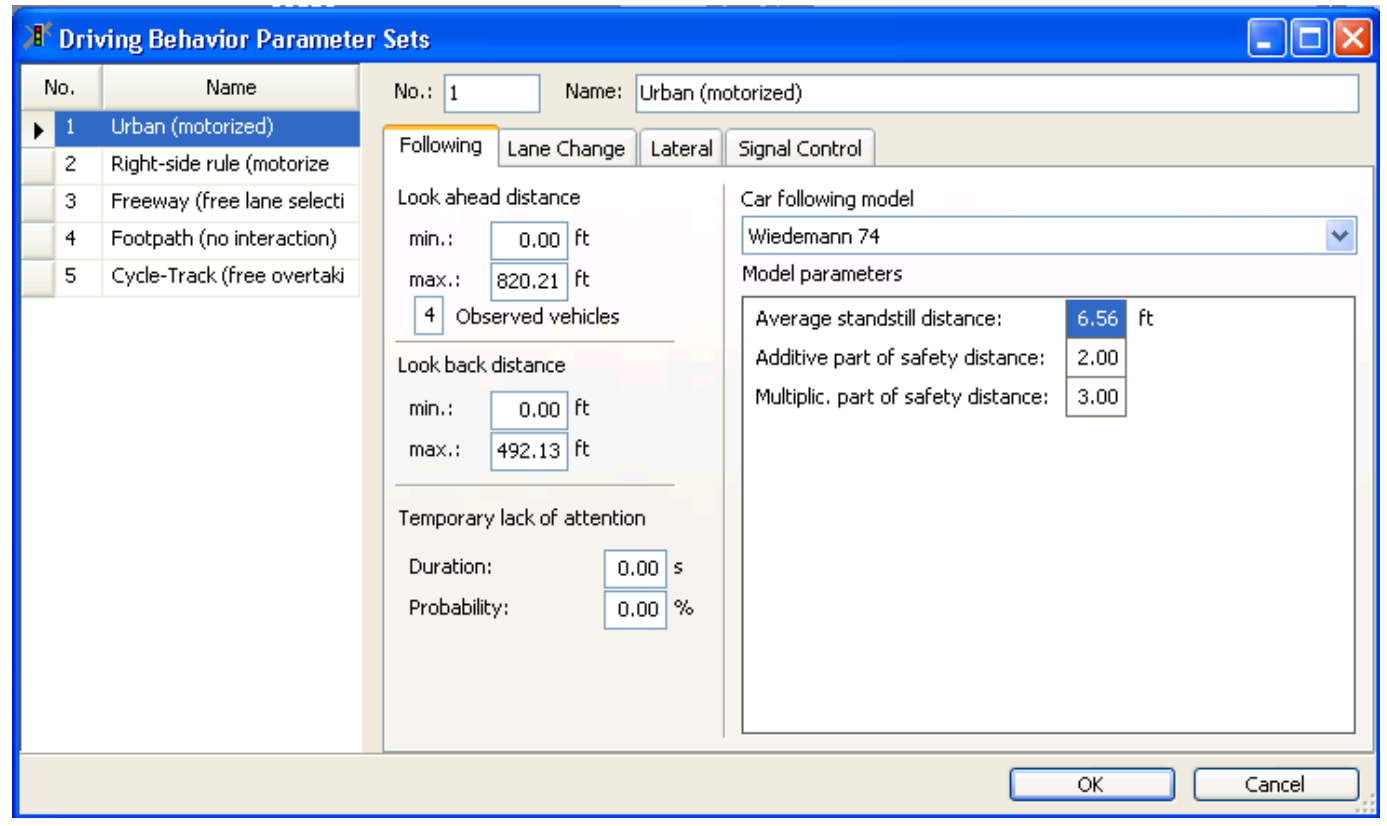

Figure 3.11 Driving Behavior Parameter for Local Roads

However, for freeway driving behavior, several of the car following parameters were altered. The purpose of the alterations were an attempt to adjust the network behavior to 
resemble reality. During the simulation process, unrealistic congestion built up at the onramps and offramps of the freeways and highways, namely I-280 NB and SB as well as Highway $87 \mathrm{NB}$ and SB. The congestion was created by many free flowing vehicles traveling on the right most lanes which prevented other vehicles on an adjacent onramp enter into the freeway. Also, free flowing vehicles that were in an exit only lane on the freeway would change lanes too late and would also create congestion. The method to correct the congestion was under the "Lateral" tab for Freeway (free lane selection). The desired position at free flow on the freeways had previously been set to the middle of the lane, but this was changed to the left lanes on the freeway instead. Afterwards, vehicles no longer queued at the onramps nor offramps.

In addition, Table 3.6 below displays the default values, a short description of the parameter, as well as the value that was used if the parameter was altered.

Table 3.6 Calibration of Freeway Car-following Model Parameters

\begin{tabular}{|c|c|c|c|}
\hline Parameters & Parameter description & Default value & Parameter values \\
\hline $\mathrm{CC} 0$ & -(Standstill distance) or distance between stopped cars & 4.92 & $1.51 \mathrm{ft}$ \\
\hline $\mathrm{CC} 1$ & $\begin{array}{l}\text {-(Headway time) or time driver wants to maintain } \\
\text { while following another car } \\
\text { Example: The higher the value the more cautious the } \\
\text { driver. }\end{array}$ & 0.90 & $1.00 \mathrm{~s}$ \\
\hline $\mathrm{CC} 2$ & $\begin{array}{l}\text {-(Following variation) or max distance a driver can go } \\
\text { beyond safety distance before moving closer to front } \\
\text { car. Example: The higher the value, the more } \\
\text { aggressive the driver. }\end{array}$ & 13.12 & $13.12 \mathrm{ft}$ \\
\hline $\mathrm{CC} 3$ & $\begin{array}{l}\text {-(Threshold for entering "Following") defines when a } \\
\text { driver needs to accelerate before reaching safety } \\
\text { distance }\end{array}$ & -8.00 & -8.00 \\
\hline $\mathrm{CC} 4$ and $\mathrm{CC} 5$ & $\begin{array}{l}\text {-("Following" thresholds) control speed differences } \\
\text { during "Following" state. } \\
\text {-CC4 is used for negative and CC5 for positive speed } \\
\text { differences. } \\
\text { Example: Smaller values result in a more sensitive } \\
\text { reaction of drivers to accelerations or decelerations of } \\
\text { the preceding car, i.e., the vehicles are more tightly }\end{array}$ & $(-0.35,0.35)$ & $(-0.35,0.35)$ \\
\hline
\end{tabular}




\begin{tabular}{|c|c|c|c|}
\hline & coupled. & & \\
\hline CC6 & $\begin{array}{l}\text {-(Speed dependency of oscillation) describes effect of } \\
\text { distance on speed oscillation in the following process } \\
\text { - If parameter is zero, the speed oscillation will be } \\
\text { independent of distance to preceding car. } \\
\text { Example: Larger values cause greater speed oscillation } \\
\text { with increasing distance. }\end{array}$ & 11.44 & 11.44 \\
\hline CC7 & $\begin{array}{l}\text {-(Oscillation acceleration) defines acceleration during } \\
\text { oscillation process. }\end{array}$ & $0.82 \mathrm{ft} / \mathrm{s}^{2}$ & $0.82 \mathrm{ft} / \mathrm{s}^{2}$ \\
\hline $\mathrm{CC} 8$ & $\begin{array}{l}\text {-(Standstill acceleration) defines desired acceleration } \\
\text { from standstill situation. }\end{array}$ & $11.48 \mathrm{ft} / \mathrm{s}^{2}$ & $11.48 \mathrm{ft} / \mathrm{s}^{2}$ \\
\hline CC9 & $\begin{array}{l}\text {-(Acceleration at } 50 \mathrm{mph}) \text { defines desired acceleration } \\
\text { at } 50 \mathrm{mph} \text {. }\end{array}$ & $4.92 \mathrm{ft} / \mathrm{s}^{2}$ & $4.92 \mathrm{ft} / \mathrm{s}^{2}$ \\
\hline
\end{tabular}

\subsubsection{Vehicle Record Data}

Once behavior parameters were altered to represent reality to a satisfactory performance within the simulation, data had to be collected in order to advance to the final step of base network validation. While there are a number of different ways to collect data in VISSIM, the method used in our network was to place data counters that collected the number of vehicles passing a particular intersection point. In addition, travel time counters were placed for the entire length of the freeway and highway segments on the network. The two data collection methods were believed to be the best suited to measure the network's similarity to data collected on individual vehicles throughout San Jose. The number of vehicles passing through an intersection was tallied every time it passed a data counter, and at the end of the simulation period of 4500 seconds, the data was written to a file. For the time travel counters, data was collected every 1500 seconds and the average was taken. 


\subsection{Vissim Network Validation}

Although the calibration process facilitated the creation of a VISSIM simulation that was visually similar to reality, the network was tested to see how it would respond to changes in the seed numbers. This process is important because if successful, it would result in the validation of the network and justify the network's usage in different disaster scenarios and also be able to realistically compare their performance.

\subsubsection{Seed Numbers}

The network's performance was tested with 10 different seed numbers on the same network. When a random seed is chosen for a microscopic simulation, a random number generator assigns values for certain parameters based off stochastic (probabilistic) distributions built into VISSIM. The random number generator produces different numbers for parameters such as lane changing, driver behavior, route choice, and car following. From running the simulation many times with the same seed number, it was observed that the same exact results were produced both for travel time as well as the number of vehicles. When seed numbers were altered, the simulation output displayed differing values based on different numbers assigned to driving behavior parameters.

\subsubsection{GEH Statistics Validation for Turning Movement Counts}

After each simulation run based on one of the random seeds, turning movements at the three intersection locations were collected for analysis. The intersections were Santa Clara St. \& Market St, Park Avenue \& Almaden Boulevard, and San Carlos and Almaden Boulevard. In order to define a baseline accuracy to test the simulation's validity, 
Geoffrey E. Havers (GEH) statistics were used to compare field counts by the City of San Jose to the simulation turning volumes.

GEH statistics are commonly used in transportation analysis and simulation to compare two sets of traffic volumes. The empirical formula is similar to that of a Chi-squared test shown below in the following equation:

$G E H=\sqrt{\frac{2(M-C)^{2}}{M+C}}$

Where $\mathrm{M}=$ Traffic count from the simulation model

$\mathrm{C}=$ traffic count volume observed in the real world

While the GEH statistic is not considered a true statistical test it has been notably useful in comparing traffic volumes. Because the formula does not follow a linear pattern due to the potentially large variations in traffic volumes, it avoids common pitfalls witnessed in using simple percentage comparisons (Kilbert 2010)

The simulation of downtown San Jose was assumed to be reasonably accurate when GEH statistics for all 36 turning movements were less than five. The averaged statistics for the initial run that are shown below in the table are an average of the 10 different seed number runs. None of the recorded volumes displayed a GEH statistics of over five which validated the surface streets. Table 3.7 displays the average vehicle counts for 10 simulation runs using different seed numbers and also includes the GEH Statistic. The tables for the complete statistics detailing each simulation run and random seed are included in the appendix. 
Table 3.7GEH Statistics Summary of the Initial Run for City of San Jose Model

\begin{tabular}{|c|c|c|c|c|}
\hline Roadway/Intersection & Movement Direction & Simulation $^{\mathrm{a}}$ & Actual $^{\mathrm{a}}$ & GEH statistic \\
\hline \multirow{12}{*}{ Almaden \& San Carlos } & $\mathrm{NbR}$ & 132 & 158 & 2.17 \\
\hline & $\mathrm{NbT}$ & 285 & 348 & 3.56 \\
\hline & $\mathrm{NbL}$ & 69 & 88 & 2.10 \\
\hline & EbR & 217 & 209 & 0.54 \\
\hline & $\mathrm{EbT}$ & 826 & 759 & 2.37 \\
\hline & $\mathrm{EbL}$ & 198 & 184 & 1.01 \\
\hline & $\mathrm{SbR}$ & 103 & 100 & 0.29 \\
\hline & $\mathrm{SbT}$ & 1009 & 1017 & 0.25 \\
\hline & $\mathrm{SbL}$ & 113 & 104 & 0.89 \\
\hline & $\mathrm{WbL}$ & 120 & 106 & 1.33 \\
\hline & $\mathrm{WbT}$ & 588 & 514 & 3.16 \\
\hline & $\mathrm{WbR}$ & 94 & 83 & 1.22 \\
\hline \multirow{12}{*}{ Almaden \& Park } & $\mathrm{NbR}$ & 34 & 36 & 0.37 \\
\hline & $\mathrm{NbT}$ & 223 & 237 & 0.93 \\
\hline & $\mathrm{NbL}$ & 35 & 37 & 0.36 \\
\hline & $\mathrm{EbR}$ & 116 & 117 & 0.13 \\
\hline & $\mathrm{EbT}$ & 83 & 86 & 0.37 \\
\hline & $\mathrm{EbL}$ & 97 & 105 & 0.79 \\
\hline & $\mathrm{SbR}$ & 87 & 86 & 0.10 \\
\hline & $\mathrm{SbT}$ & 955 & 965 & 0.33 \\
\hline & $\mathrm{SbL}$ & 43 & 48 & 0.70 \\
\hline & $\mathrm{WbL}$ & 178 & 163 & 1.17 \\
\hline & WbT & 112 & 104 & 0.79 \\
\hline & WbR & 68 & 60 & 0.98 \\
\hline \multirow{12}{*}{ Market and Santa Clara } & $\mathrm{NbR}$ & 47 & 41 & 0.93 \\
\hline & $\mathrm{NbT}$ & 276 & 231 & 2.85 \\
\hline & $\mathrm{NbL}$ & 79 & 69 & 1.14 \\
\hline & $\mathrm{EbR}$ & 119 & 114 & 0.49 \\
\hline & EbT & 613 & 581 & 1.29 \\
\hline & $\mathrm{EbL}$ & 92 & 87 & 0.51 \\
\hline & $\mathrm{SbR}$ & 125 & 80 & 4.48 \\
\hline & $\mathrm{SbT}$ & 886 & 760 & 4.40 \\
\hline & $\mathrm{SbL}$ & 79 & 118 & 3.93 \\
\hline & $\mathrm{WbL}$ & 107 & 90 & 1.68 \\
\hline & $\mathrm{WbT}$ & 448 & 395 & 2.56 \\
\hline & $\mathrm{WbR}$ & 91 & 80 & 1.20 \\
\hline \multicolumn{5}{|r|}{ rough the data } \\
\hline
\end{tabular}




\subsubsection{Travel Time Validation}

The reason that GEH statistics were not fully adequate for the entire network was due to the capacity limitations in VISSIM. In VISSIM and in any microsimulation program the vehicles' entry point via vehicle inputs or nodes, respectively, cannot exceed the capacity of the road. Based on the Highway Capacity Manual (HCM), for a single freeway lane with a 65 mile per hour (mph) speed limit, the assumed capacity of the freeway is 2,250 vehicles per hour per lane. Therefore, since the entry point for vehicles on I-280 NB and SB are both 5 lanes, the capacity theoretically should be 11,250 vehicles per hour.

To find the vehicle input volumes for the freeway and highway segments, Caltrans data was used. However, VISSIM was unable to output the required traffic volumes for the allotted 3900 seconds that vehicles were allowed to enter the network. For example, on I$280 \mathrm{NB}$, the expected vehicle input volume was 8,233 vehicles but after many simulations the generated volume could only reach 6,937 vehicles. For I-280 SB, the expected vehicle input volume was 6,207 vehicles but the vehicle input could only generate 4,207 vehicles over 3900 seconds.

To validate the network, another method other than GEH statistics would be needed. Ultimately, travel times were recorded separately for each highway and freeway segment in question by driving the highways for the same distance as was coded into the network. The actual travel times were compared to the simulation times. The freeways in the network that required the driving times were I-280 NB and SB while the highways were Highway 87 NB and SB. 
According to calibration targets developed by Wisconsin Department of Transportation (DOT) for their Milwaukee freeway system model, for model travel times to be accepted, they must be within $15 \%$ of the observed travel times for more than $85 \%$ of the cases. The average statistics for the initial run are shown below in Table 3.8. None of the recorded volumes displayed a percentage error of over $15 \%$. The tables for the complete statistics detailing each simulation run and random seed are included in the appendix.

Table 3.8 Initial Run Travel Time Validation and Summary

\begin{tabular}{|c|c|c|c|}
\hline Roadway & Actual Travel Time & Percent Error & Simulation Average Travel Time (min) \\
\hline I-280 NB & 3.43 & $-3.3 \%$ & 3.3 \\
\hline I-280 SB & 4.15 & $-3.2 \%$ & 4.0 \\
\hline Hwy 87 NB & 3.15 & $-2.5 \%$ & 3.1 \\
\hline Hwy 87 SB & 3.15 & $7.1 \%$ & 3.4 \\
\hline
\end{tabular}

\subsection{Estimating Number of Runs}

To determine the appropriate number of runs for the disaster scenarios, ten simulation runs using the random seeds displayed in the table above were utilized to determine an appropriate confidence level for each performance metric using the following equation:

$$
n_{r} \geq \frac{s^{2} z^{2} \alpha / 2}{\varepsilon^{2}}
$$

where $s^{2}=$ performance metric variance based on 10 trial runs

$z_{\alpha / 2}^{2}=$ threshold value for a $100(1-\alpha)$ percent confidence interval

$n_{r}=$ required number of times to run the simulation

$\varepsilon=$ maximum error of the estimate 
To determine the number of simulation runs required, travel times were chosen as a convenient performance measure. For the chosen performance metric, a 95\% confidence level $(\alpha=.05)$ was chosen which corresponds to a $z$-value of 1.96 . The maximum error of the estimate $(\varepsilon)$ was assumed to be $5 \%$ of the mean for each performance metric. The number of runs required from each calculation was rounded up to the nearest whole number. The minimum number of runs specified from each performance metric on each roadway were $3,1,1$, and 1 as shown in the Table 3.9 below.

Table 3.9 Summary of Number of Simulation Runs Required

\begin{tabular}{|c|c|c|c|c|}
\hline Roadway & I-280 NB & I-280 SB & Hwy 87 NB & Hwy 87 SB \\
\hline Average (min) & 3.3 & 4.0 & 3.1 & 3.4 \\
\hline Standard Deviation (s) & 0.1 & 0.1 & 0.1 & 0.0 \\
\hline Variance (s^2) & 0.0 & 0.0 & 0.0 & 0.0 \\
\hline$Z_{\alpha / 2}$ for 95\% confidence level & 1.96 & 1.96 & 1.96 & 1.96 \\
\hline$z^{2}{ }_{\alpha / 2}$ for 95\% confidence level & 3.84 & 3.84 & 3.84 & 3.84 \\
\hline$\varepsilon$ & 0.2 & 0.2 & 0.2 & 0.2 \\
\hline Number of Runs Required (n) & 3 & 1 & 1 & 1 \\
\hline
\end{tabular}

Although all of the values displayed the necessary runs as less than five, the number of simulations run for the disaster scenarios was indeed 10. It can be concluded from the table above that 10 simulation runs should be more than sufficient to establish a travel time estimate for the disaster scenarios with a $95 \%$ level of confidence and only a 5\% maximum allowable error. 


\section{ALTERNATIVE SCENARIOS}

\subsection{Scenario Descriptions}

After ensuring that the base case disaster scenario had been properly calibrated and validated, the base case network is acceptable to use for estimating network performance and related variations due to the mass exodus of vehicles from the downtown area.

\subsection{Disaster Scenario Assumptions}

One important assumption that was common to all disaster scenarios was that all the parking lots are filled to capacity due to the special events being organized. In addition, some other assumptions common to all the scenarios include HP Pavilion traffic leaving from the directly adjacent parking lot would divide evenly $(1 / 4$ of 1,460$)$ meaning 365 vehicles each were inputted onto Julian St., Cahill, Alamden, N. Autumn to all leave at approximately the same time. Also, for the San Jose Convention Center parking lot across from the convention center $3 / 4$ of the capacity would exit onto Almaden Blvd. from Woz Way. The other $1 / 4$ of vehicle traffic would exit onto Woz Way towards the Highway 87 NB offramp. The base case disaster scenario is compared with the three different scenarios, which might affect the evacuation of downtown area. In each of the three cases the different travel times are compared to this base case disaster scenario.

\subsection{Contingency Scenarios}

\subsubsection{Scenario 1}

The first contingency scenario was created to test the effect of an incident such as an accident or redevelopment resulting in road closure due to possible construction work. At 
the peak hour during the disaster scenario, one lane on Bird Ave was closed as cars were trying to leave HP Pavilion and the other disaster areas. The closure was positioned southbound along Bird Avenue between San Carlos St. and the I-280 NB onramp. Figure 4.1 depicts the location of Scenario 1.

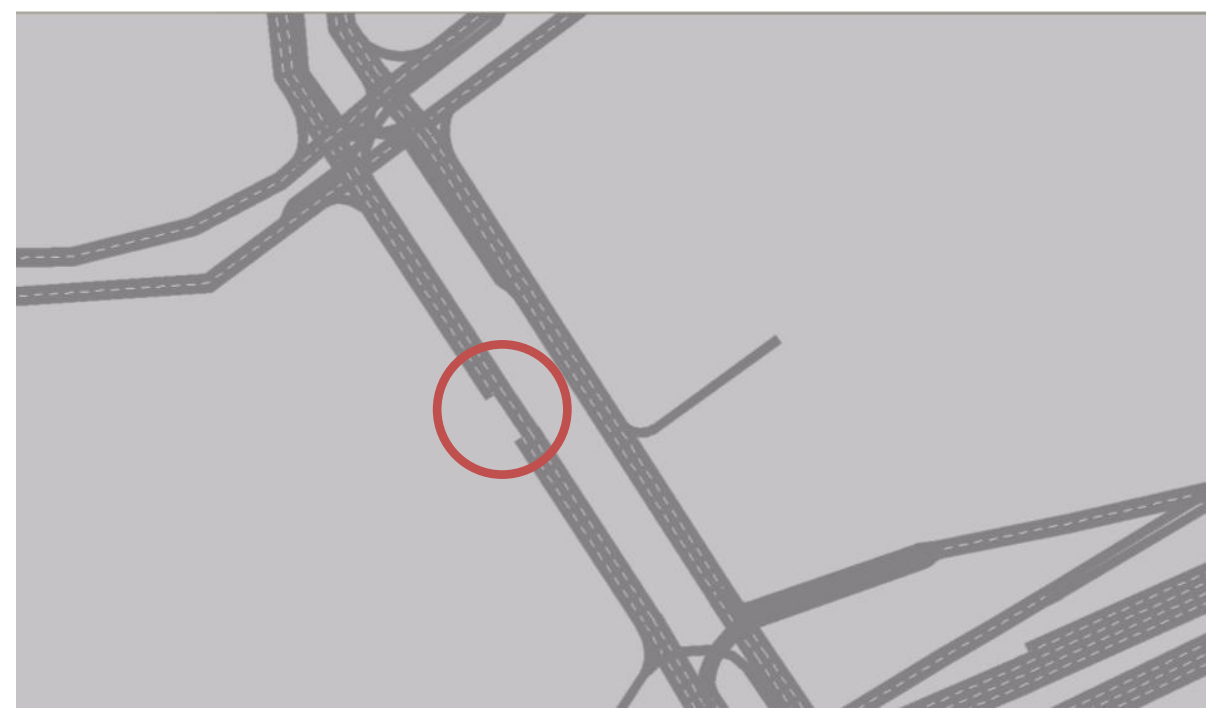

Figure 4.1Scenario 1 - Right Lane Closure On Bird Ave.

\subsubsection{Scenario 2}

The second scenario was to test the effects, if any, of contraflow lanes (having traffic lanes normally used for eastbound and westbound traffic used for traffic in the same direction for evacuation), exiting towards the freeway on S. Montgomery Street, beginning at the Montgomery and Park intersection, and heading southbound towards I280 and past the on- and off-ramps. With all the traffic expected to depart from HP Pavilion towards the freeway, the contra flow lanes were an attempt to provide another path to exit the area. The lane configurations from Montgomery Street to Bird Ave are shown in the Figure 4.2 below. 


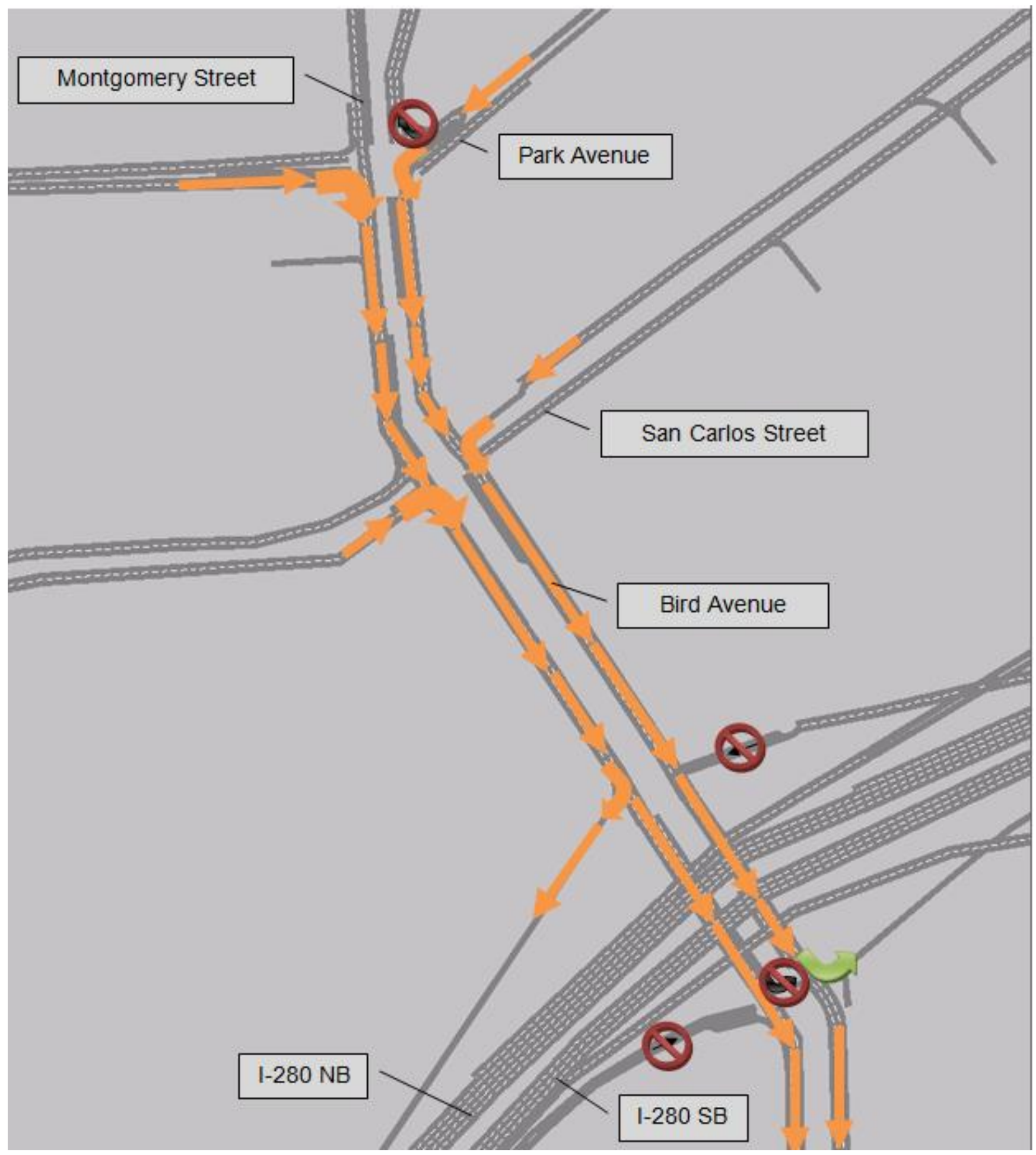

Figure 4.2 Scenario 2 ContraFlow Lanes

This was the most complex scenario to model because it involved traffic rerouting on at least four different streets and one freeway onramp. The expected congestion on 
Montgomery Street / Bird Avenue could potentially be alleviated by creating a path for left turning vehicles from both San Carlos and Park Avenue to quickly exit towards I280. Also, for vehicles heading east on both Park Avenue and San Carlos Street, right turning vehicles have two right turn lanes onto Montgomery Street / Bird Avenue. In addition, left turn and through movements from this intersection approach are prohibited.

Vehicles traveling west on San Carlos and Park Avenue will have one left turn lane each when turning onto Montgomery Street / Bird Avenue. Through movements are prohibited, but from Park Avenue only emergency vehicles are allowed to make a right turn going northbound towards HP Pavilion. From San Carlos Street, right turn movements are entirely prohibited for everyone including emergency vehicles because there is no emergency vehicle only lane.

Also, the Bird Avenue exits for both I-280 NB and SB are open to emergency assets only. In addition, for vehicles wanting access to the I-280 SB onramp to Bird Avenue, vehicles must be on the contraflow lanes, not the original lanes on Bird Avenue because there will be no left turns from the original Bird Avenue lanes onto the I-280 SB ramp. The green arrow in the figure above indicates the permitted left turn movement from the contraflow lanes onto the freeway.

\subsubsection{Scenario 3}

The last scenario involved an assumption that if more people were to ride public transit from the Diridon Station to exit the disaster area, there could possibly be less congestion and a faster exit time from the disaster area for everyone. To implement this scenario, volume from the exiting parking lots of the disaster areas were reduced by $30 \%$ from 
their original volume. There were a total of 24 "parking lots" whose volumes were reduced as a result of the evacuees using the transit from the Diridon station. This scenario was created to demonstrate how effective public transit can be in a downtown area for contingency planning. It is worth mentioning that in VISSIM, any vehicle generating point within the simulation is called a "parking lot."

\subsubsection{Emergency Vehicle Routing}

VISSIM, the traffic simulation model used in this project was applied to aid in determining the optimal routing strategy for dispatching a fleet of emergency response vehicles from fire stations while hospitals would see incoming patients from the various disaster areas. Based on the results from the simulation model for the traffic network in downtown San Jose the optimal routes for the three hospitals and three fire stations near the disaster areas were determined. The primary hospitals which would receive patients requiring medical attention were (1) O’ Connor Hospital, (2) Valley Medical Center, and (3) Regional Hospital (HCA) which are displayed in Figure 4.3below. 


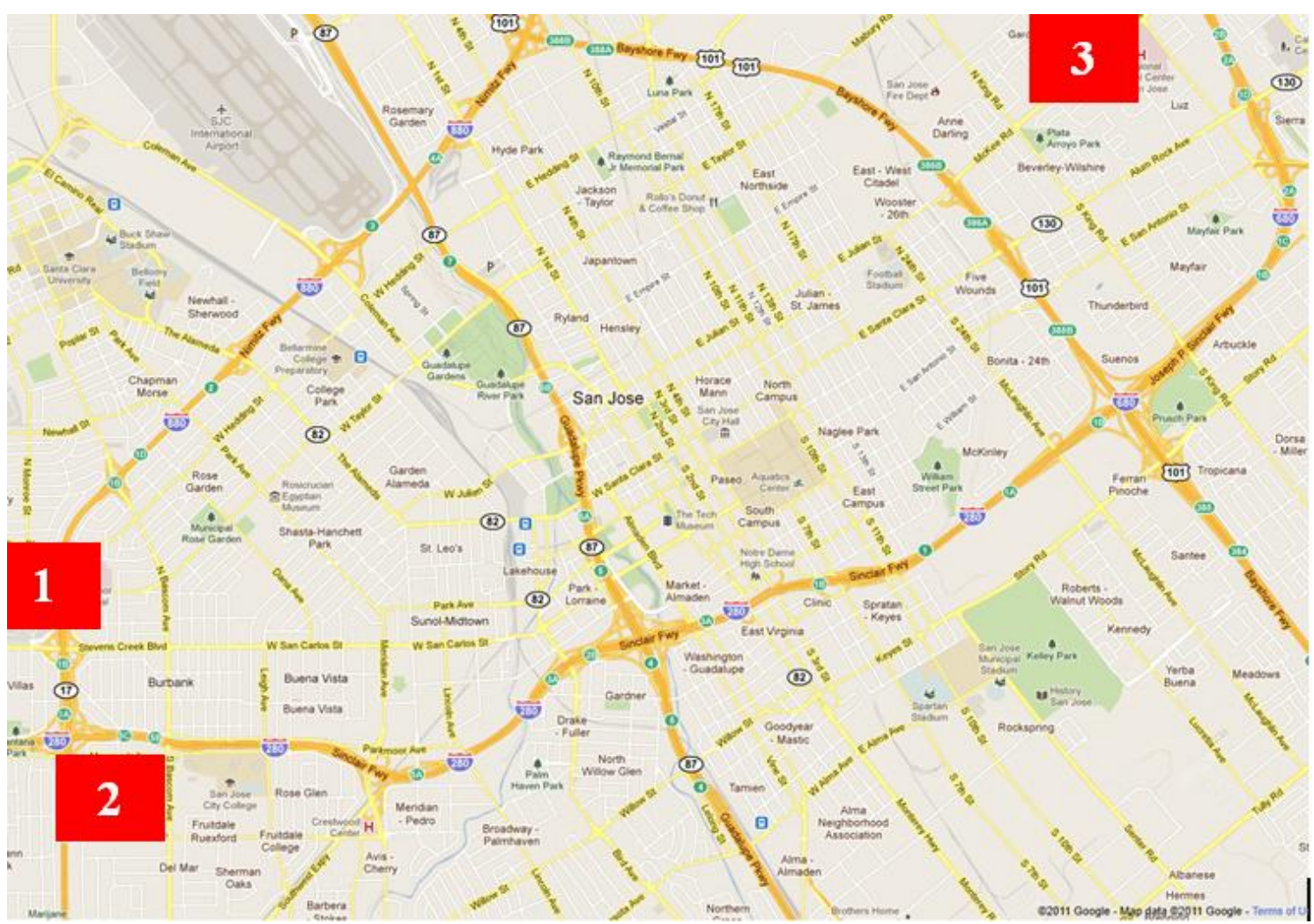

Figure 4.3Primary Hospital Destinations

The three fire stations that would certainly respond in a disaster scenario are all located in San Jose and are Fire Stations 1, 7, and 30. The locations of the three fire stations are depicted in Figure 4.4below. 


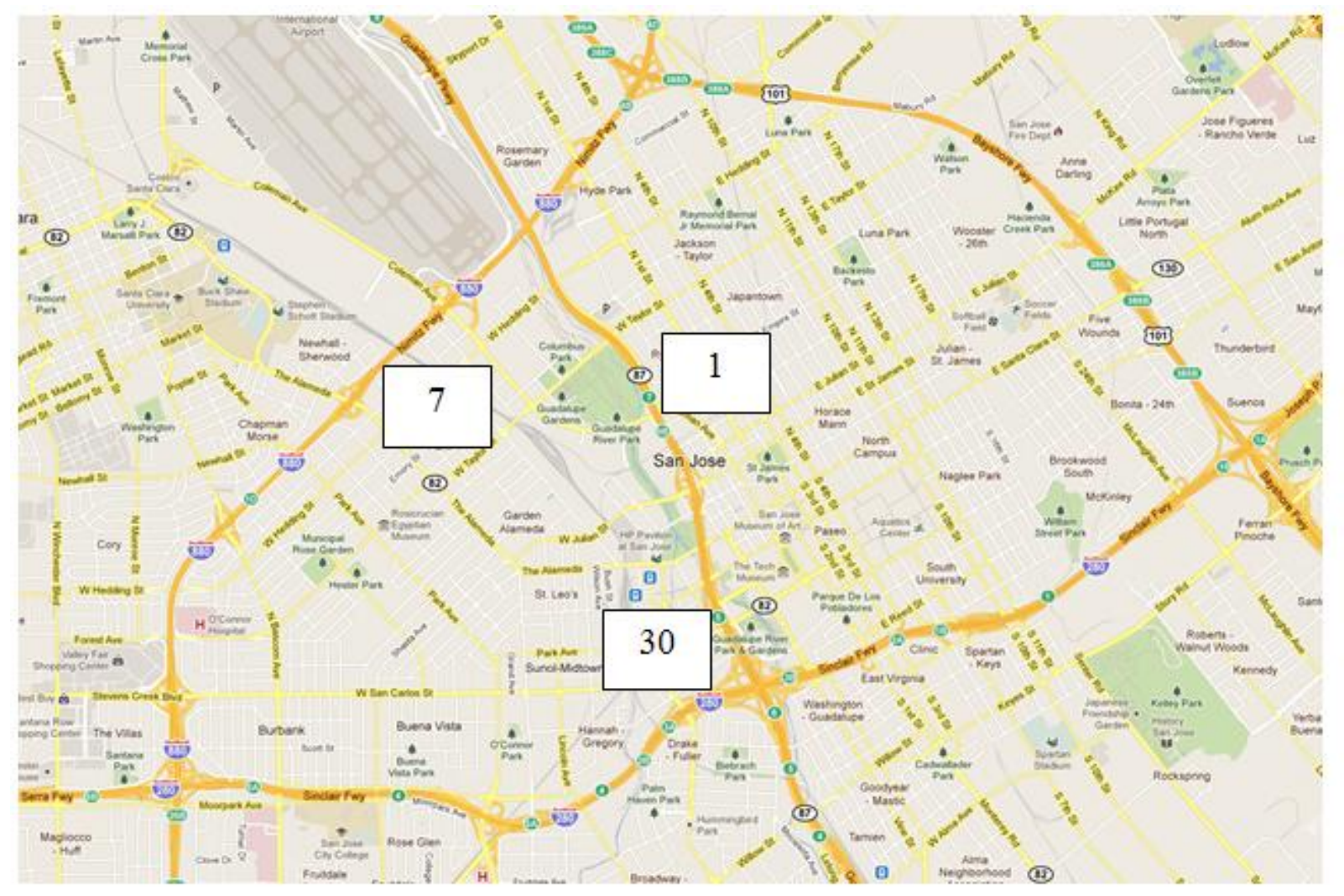

Figure 4.4Primary Fire Station Responders

For each scenario, including the base case, the fastest route was determined with the traffic simulation, along with Google Maps travel times. For example, from HP Pavilion to $\mathrm{O}^{\prime}$ Connor Hospital during the base case scenario, the fastest total time from beginning to end traveled via Montgomery, R onto Julian -> R onto Hwy 87 SB onramp -> R onto I- 280 NB -> R onto I- 880 NB -> Exit R onto Stevens Creek Blvd. -> L onto Bellerose -> L onto Forest. Since O' Connor Hospital was outside the simulated network a Google Maps time was substituted for the time until a coded network road began in the simulation. Therefore, while the total travel time was 11.3 minutes, 5 minutes was the Google Maps travel time, and 6.3 minutes was the simulation time. 
However, for the fire stations, two out of the three fire stations were contained within the network, and the travel times from the fire stations to each of the disaster areas were recorded. To record the travel time for the emergency vehicles, two new vehicle compositions were created. For network locations where emergency vehicles and other vehicles could emerge together, a vehicle composition called Car + Emergency was created that would generate $3 \%$ of the total flow as emergency vehicles. In situations where only fire station vehicles would emerge, a separate vehicle composition called Fire stations was created, and consisted of Heavy Gross Vehicles (HGV) which would represent the fire trucks and engines. In addition, new routing decisions for the vehicles had to be created and directed to the disaster sites, as well. For every scenario tested, the averaged fastest travel times, as well as the most efficient routes for both hospitals and fire stations, are listed separately in Tables 4.1 to 4.4 below. 
Table 4.1 Most Efficient Hospital Routes and Fastest Times from Disaster Areas (O' Connor Hospital and Santa Clara Valley Medical Center)

\begin{tabular}{|c|c|c|c|c|c|c|}
\hline Hospital & Origin & Base Case Routes & Total Time Base Case $^{\mathrm{a}}$ & ${\text { Total Time Scenario } 1^{\mathrm{a}}}$ & ${\text { Total Time Scenario } 2^{\mathrm{a}}}$ & Total Time Scenario $3^{\mathrm{a}}$ \\
\hline \multirow{5}{*}{ O' Connor Hospital } & HP Pavilion & $\begin{array}{l}\text { From Montgomery, R onto Julian }>\text { R onto Hwy } 87 \text { SB onramp }>R \\
\text { onto I- } 280 \mathrm{NB} \rightarrow>\mathrm{R} \text { onto I- } 880 \mathrm{NB} \rightarrow>\text { Exit R onto Stevens Creek Blvd. } \\
>>\text { L onto Bellerose }>>\text { L onto Forest }\end{array}$ & 11.3 & 11.8 & 11.7 & 11.5 \\
\hline & \multirow{2}{*}{ San Jose Convention Center } & $\begin{array}{l}\text { From Almaden exit from San Jose Convention Center }->\text { L onto } \\
\text { Almaden } \rightarrow \text { R onto I-280 NB onramp -> Exit R onto I--880 NB onramp at } \\
\text { interchange }>\text { Exit } R \text { onto Steven's Creek Blvd }>>\text { L onto Bellerose }>\text { R } \\
\text { onto Forest Ave. }\end{array}$ & 8.1 & 8 & 8 & 7.9 \\
\hline & & $\begin{array}{l}\text { From Market St. exit from San Jose Convention Center }>\text { R onto Market } \\
->R \text { - }>\text { on W Reed }>\text { Straight onto I-280 NB onramp }>>\text { Exit R onto I- } \\
880 \text { NB onramp at interchange }>\text { Exit R onto Steven's Creek Blvd }>\text { L } \\
\text { onto Bellerose }>>\text { R onto Forest Ave. }\end{array}$ & 8.3 & 8.9 & 8.8 & 8.8 \\
\hline & IRS building & 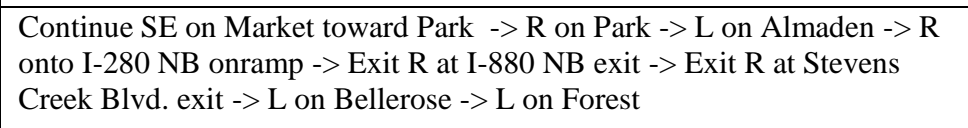 & 13.1 & 18.9 & 12.6 & 12.6 \\
\hline & 100 Paseo de San Antonio & $\begin{array}{l}\text { From 3rd continue towards San Fernando }>\text { R on San Fernando }>\text { R on } \\
\text { 4th }->\text { Continue onto 4th St. onramp for I-280 NB } \rightarrow \text { Exit right at the I- } \\
880 \text { NB interchange }>\text { Exit right onto Stevens Creek }>\text { L onto Bellerose } \\
->\text { L onto Forest }\end{array}$ & 10.9 & 11 & 10.8 & 10.9 \\
\hline \multirow{5}{*}{ Santa Clara Valley Medical Center } & HP Pavilion & $\begin{array}{l}\text { Continue on Montgomery toward Julian }>>\text { R on Julian }->\text { R onto Hwy } 87 \\
\text { SB } \rightarrow \text { R onto I-280 NB }>>\text { Exit R at Parkmoor }>\text { L L onto Bascom }>\text { R } \\
\text { onto Renova }\end{array}$ & 11.3 & 11.8 & 11.7 & 11.5 \\
\hline & \multirow{2}{*}{ San Jose Convention Center } & $\begin{array}{l}\text { From Market exit from San Jose Convention Center }>>->R \text { onto Market } \\
->R \text { on } W \text { Reed } \rightarrow>\text { Straight onto I-280 NB onramp }>>\text { Exit } R \text { at Parkmoor } \\
\rightarrow>\text { onto Bascom }>\text { R onto Renova }\end{array}$ & 8.1 & 8 & 8 & 7.9 \\
\hline & & $\begin{array}{l}\text { From Almaden exit from San Jose Convention Center }>\text { L onto } \\
\text { Almaden }>\mathrm{R} \text { onto I-280 NB onramp -> Exit R at Parkmoor }>\text { L L onto } \\
\text { Bascom }>\text { R onto Renova }\end{array}$ & 8.9 & 8.9 & 8.8 & 8.8 \\
\hline & IRS building & $\begin{array}{l}\text { 1. Continue SE on Market toward Park }>\mathrm{R} \text { on Park }->\mathrm{L} \text { on Almaden }-> \\
R \text { onto I-280 NB onramp }>>\text { Exit } R \text { at Parkmoor }>>\text { at Bascom }>\mathrm{R} \text { on } \\
\text { Renova }\end{array}$ & 12.1 & 17.9 & 11.5 & 11.6 \\
\hline & 100 Paseo de San Antonio & $\begin{array}{l}\text { 1. Continue on 3rd towards San Fernando }>\text { R onto San Fernando }>\text { R on } \\
\text { 4th } \rightarrow \text { R onto I-280 NB 4th St. onramp }>\text { Exit R at Parkmoor }>\text { L o on } \\
\text { Bascom }>\text { R on Renova }\end{array}$ & 9.9 & 10 & 9.8 & 9.9 \\
\hline \multicolumn{7}{|l|}{ Notes: } \\
\hline a. Travel times are in minutes. & & & & & & \\
\hline
\end{tabular}


Table 4.2Most Efficient Hospital Routes and Fastest Times from Disaster Areas (Regional Medical Center)

\begin{tabular}{|c|c|c|c|c|c|c|}
\hline Hospital & Origin & Base Case Routes & $\underline{\text { Total Time Base Case }}^{\mathrm{a}}$ & ${\underline{\text { Total Time Scenario } 1^{\mathrm{a}}}}$ & $\underline{\text { Total Time Scenario } 2^{\mathrm{a}}}$ & $\underline{\text { Total Time Scenario }^{3}}$ \\
\hline \multirow{5}{*}{ Regional Medical Center of San Jose } & HP Pavilion & 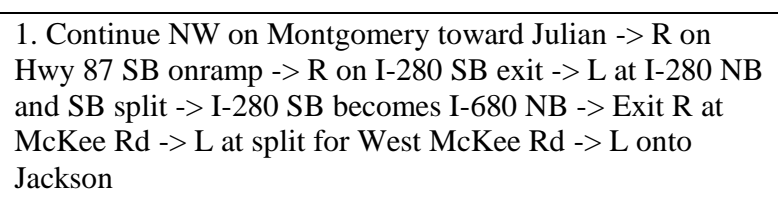 & 14.3 & 14.5 & 14.5 & 13.3 \\
\hline & \multirow{2}{*}{ San Jose Convention Center } & $\begin{array}{l}\text { 1. From Market St. exit }->\mathrm{R} \text { onto Market }>>\text { R onto I-280 } \\
\text { SB onramp -> I-280 SB becomes I- } 680 \mathrm{NB} \rightarrow>\text { Exit McKee } \\
\text { Rd }>>\text { L onto Jackson }\end{array}$ & 13.5 & 13.1 & 11.7 & 10.9 \\
\hline & & 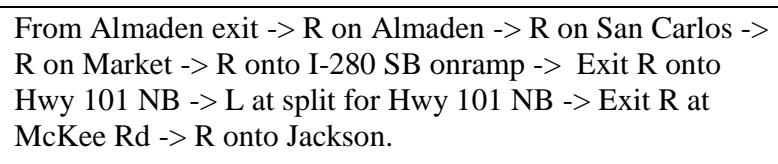 & 10.1 & 10.1 & 10 & 9.9 \\
\hline & IRS building & $\begin{array}{l}\text { 1. Continue SE on Market towards I-280 -> R onto I-280 } \\
\text { SB ramp - Continue onto I-680 N -> Exit R at McKee Rd - } \\
>\text { - L at split for McKee Rd W }>\text { - L onto Jackson }\end{array}$ & 15.2 & 14.9 & 13.6 & 13.4 \\
\hline & 100 Paseo de San Antonio & 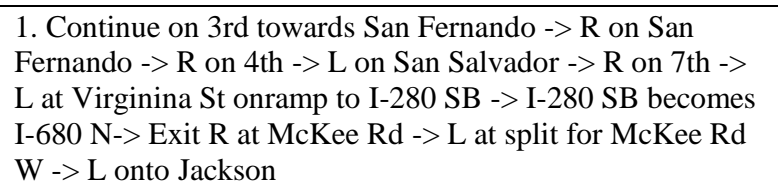 & 15.3 & 15.3 & 15.4 & 15.3 \\
\hline \multicolumn{7}{|l|}{ Notes: } \\
\hline
\end{tabular}


Table 4.3Most Efficient Fire Station Routes and Fastest Times to Disaster Areas (Fire Station 1 and Fire Station 7)

\begin{tabular}{|c|c|c|c|c|c|c|c|c|c|}
\hline Fire Station & Destination & $\underline{\text { Base Case Routes }}$ & Total Time Base Case (min) & Scenario 1 Routes & Total Time Scenario 1 (min) & Scenario 2 Routes & Total Time Scenario 2 (min) & Scenario 3 Routes & Total Time Scenario 3 (min) \\
\hline \multirow{4}{*}{ 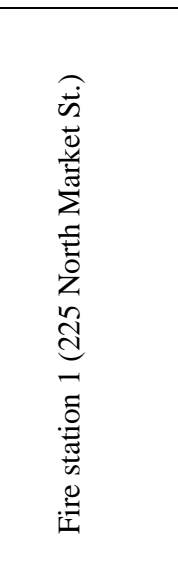 } & HP Pavilion & $\begin{array}{l}\text { Beginning from Julian } \\
\text { L onto Almaden }\end{array}$ & 9.7 & $\begin{array}{l}\text { Beginning from Julian L } \\
\text { onto Almaden }\end{array}$ & 9.6 & $\begin{array}{l}\text { Beginning from } \\
\text { Julian L onto } \\
\text { Almaden }\end{array}$ & 9.7 & $\begin{array}{l}\text { Beginning from Julian } \\
\text { L onto Almaden }\end{array}$ & 9.5 \\
\hline & San Jose Convention Center & $\begin{array}{l}\text { Down Market St -> R } \\
\text { onto Santa Clara -> L } \\
\text { onto San Carlos St. }\end{array}$ & 8.2 & $\begin{array}{l}\text { Down Market St }->\mathrm{R} \\
\text { onto Santa Clara -> L } \\
\text { onto San Carlos St. }\end{array}$ & 8.5 & $\begin{array}{l}\text { Down Market St }->\mathrm{R} \\
\text { onto Santa Clara -> L } \\
\text { onto San Carlos St. }\end{array}$ & 7.6 & $\begin{array}{l}\text { Down Market St }->\mathrm{R} \\
\text { onto Santa Clara -> L } \\
\text { onto San Carlos St. }\end{array}$ & 8.2 \\
\hline & IRS building & $\begin{array}{l}\text { Beginning on Market } \\
\text { St. head south }\end{array}$ & 3.4 & $\begin{array}{l}\text { Beginning on Market St. } \\
\text { head south }\end{array}$ & 3.9 & $\begin{array}{l}\text { Beginning on Market } \\
\text { St. head south }\end{array}$ & 3.6 & $\begin{array}{l}\text { Beginning on Market } \\
\text { St. head south }\end{array}$ & 3.5 \\
\hline & 100 Paseo de San Antonio & $\begin{array}{l}\text { Beginning on Market } \\
\text { St. head south }>\text { L } \\
\text { onto San Carlos -> } \\
\text { L onto 3rd }\end{array}$ & 2.5 & $\begin{array}{l}\text { Beginning on Market St. } \\
\text { head south } \rightarrow \text { L onto San } \\
\text { Carlos } \rightarrow \quad \text { L onto 3rd }\end{array}$ & 2.5 & $\begin{array}{l}\text { Beginning on Market } \\
\text { St. head south }>\text { L } \\
\text { onto San Carlos }>\text { L } \\
\text { onto 3rd }\end{array}$ & 2.3 & $\begin{array}{l}\text { Beginning on Market } \\
\text { St. head south }>\text { L } \\
\text { onto San Carlos -> } \\
\text { L onto 3rd }\end{array}$ & 2.3 \\
\hline \multirow{4}{*}{ 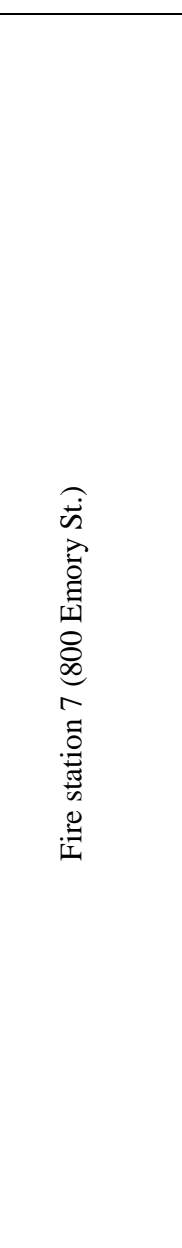 } & HP Pavilion & $\begin{array}{l}\text { From Emory St. }>\text { R } \\
\text { on Laurel }->\text { L on } \\
\text { Taylor } \rightarrow \text { R on } \\
\text { Stockton }>\text { L onto } \\
\text { Julian }>\text { R on } \\
\text { Mongomery }\end{array}$ & 3.5 & $\begin{array}{l}\text { From Emory St. }>\text { R on } \\
\text { Laurel }->\text { L on Taylor }-> \\
\text { R on Stockton }->\text { L onto } \\
\text { Julian }>\text { R on } \\
\text { Mongomery -> }\end{array}$ & 3.5 & $\begin{array}{l}\text { From Emory St. -> R } \\
\text { on Laurel -> L on } \\
\text { Taylor } \rightarrow \text { R on } \\
\text { Stockton }->\text { L onto } \\
\text { Julian }>\text { R on } \\
\text { Mongomery -> }\end{array}$ & 3.5 & $\begin{array}{l}\text { From Emory St. -> R } \\
\text { onto Laurel -> L onto } \\
\text { W. Taylor St. .> } \\
\text { Merge onto Hwy } 87 \\
\text { SB -> Exit Julian St -> } \\
\text { Right onto } \\
\text { Montgomery }\end{array}$ & 3.5 \\
\hline & San Jose Convention Center & $\begin{array}{l}\text { From Emory St. -> R } \\
\text { onto Laurel -> L onto } \\
\text { W. Taylor St. -> Merge } \\
\text { onto Hwy 87 SB -> } \\
\text { Exit Park Ave. - - L } \\
\text { onto San Carlos }\end{array}$ & 6.3 & $\begin{array}{l}\text { From Emory St. }>\text { R onto } \\
\text { Laurel }->\text { L onto W. } \\
\text { Taylor St. }>\text { Merge onto } \\
\text { Hwy S7 SB } \rightarrow>\text { Exit Park } \\
\text { Ave. -> L onto San Carlos }\end{array}$ & 7.8 & $\begin{array}{l}\text { From Emory St. -> R } \\
\text { onto Laurel -> L onto } \\
\text { W. Taylor St. -> } \\
\text { Merge onto Hwy } 87 \\
\text { SB }>>\text { Exit Park Ave. } \\
\text { > L onto San Carlos }\end{array}$ & 7.2 & $\begin{array}{l}\text { From Emory St. -> R } \\
\text { onto Laurel -> L onto } \\
\text { W. Taylor St. -> } \\
\text { Merge onto Hwy } 87 \\
\text { SB - E Exit Park Ave. - } \\
\text { > L onto San Carlos }\end{array}$ & 7.4 \\
\hline & IRS building & $\begin{array}{l}\text { From Emory St. -> R } \\
\text { onto Laurel -> L onto } \\
\text { W. Taylor St. ->R onto } \\
\text { Coleman -> Colemana } \\
\text { becomes Market }\end{array}$ & 8 & $\begin{array}{l}\text { From Emory St. } \rightarrow \text { R onto } \\
\text { Laurel }->\text { L onto W. } \\
\text { Taylor St. }>\text { R onto } \\
\text { Coleman }>\text { Coleman } \\
\text { becomes Market }\end{array}$ & 8.4 & $\begin{array}{l}\text { From Emory St. >> R } \\
\text { onto Laurel }->\text { L onto } \\
\text { W. Taylor St. ->R } \\
\text { onto Coleman -> } \\
\text { Coleman becomes } \\
\text { Market }\end{array}$ & 8.3 & $\begin{array}{l}\text { 1. From Emory St. -> } \\
\text { R onto Laurel }->\text { L } \\
\text { onto W. Taylor St. ->R } \\
\text { onto Coleman -> } \\
\text { Coleman becomes } \\
\text { Market }\end{array}$ & 8.4 \\
\hline & 100 Paseo de San Antonio & $\begin{array}{l}\text { From Emory St. -> R } \\
\text { onto Laurel -> Lonto } \\
\text { W. Taylor St. - >R onto } \\
\text { Coleman -> Coleman } \\
\text { becomes Market } \rightarrow>\text { L } \\
\text { onto San Carlos -> } \\
\text { L onto 3rd }\end{array}$ & 9 & $\begin{array}{l}\text { From Emory St. -> R } \\
\text { onto Laurel -> L onto W. } \\
\text { Taylor St- }>\text { R onto 4th -> } \\
\text { R onto San Carlos -> } \\
\text { Right on 3rd }\end{array}$ & 10.3 & $\begin{array}{l}\text { From Emory St. -> R } \\
\text { onto Laurel -> L onto } \\
\text { W. Taylor St-> R } \\
\text { onto 4th -> R onto } \\
\text { San Carlos -> Right } \\
\text { on 3rd }\end{array}$ & 10.2 & $\begin{array}{l}\text { From Emory St. -> R } \\
\text { onto Laurel -> Lonto } \\
\text { W. Taylor St. - >R onto } \\
\text { Coleman -> Coleman } \\
\text { becomes Market } \rightarrow>\text { L } \\
\text { onto San Carlos -> } \\
\text { L onto 3rd }\end{array}$ & 10.3 \\
\hline
\end{tabular}


Table 4.4 Most Efficient Fire Station Routes and Fastest Times to Disaster Areas (Fire Station 30)

\begin{tabular}{|c|c|c|c|c|c|c|c|c|c|}
\hline Fire Station & Destination & Base Case Routes & Total Time Base Case (min) & Scenario 1 Routes & Total Time Scenario 1 (min) & Scenario 2 Routes & Total Time Scenario 2 (min) & Scenario 3 Routes & Total Time Scenario 3 (min) \\
\hline \multirow{4}{*}{ 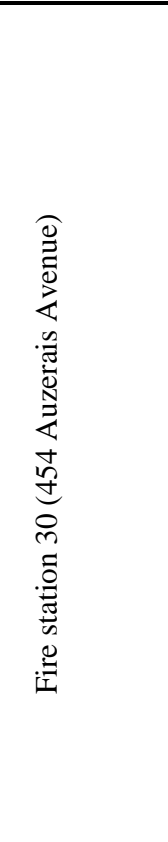 } & HP Pavilion & $\begin{array}{l}\text { 2. L on San Carlos - } \\
>\text { R on Montgomery } \\
\text { > L on St. John }\end{array}$ & 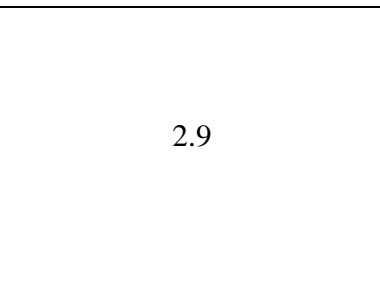 & $\begin{array}{l}\text { 1. R on Montgomery } \\
\text { (from Auzerais) -> L } \\
\text { on St. John }\end{array}$ & 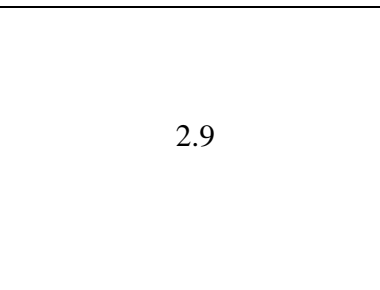 & $\begin{array}{l}\text { L on San Carlos -> R on } \\
\text { Montgomery -> L on } \\
\text { St. John }\end{array}$ & 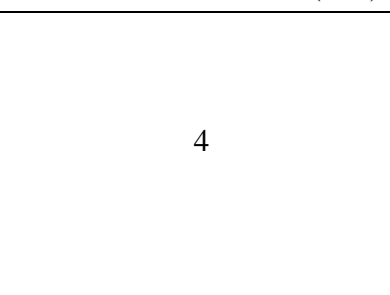 & $\begin{array}{l}\text { L on San Carlos - } \\
>\mathrm{R} \text { on } \\
\text { Montgomery -> L } \\
\text { on St. John }\end{array}$ & 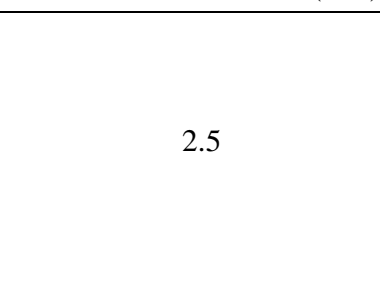 \\
\hline & San Jose Convention Center & $\begin{array}{l}\text { R on Gilford }>\mathrm{R} \\
\text { on San Carlos }\end{array}$ & 1.9 & $\begin{array}{l}\text { R on Gilford }->\text { R on } \\
\text { San Carlos }\end{array}$ & 1.8 & $\begin{array}{l}\mathrm{R} \text { on Gilford }>\mathrm{R} \text { on } \\
\text { San Carlos }\end{array}$ & 1.2 & $\begin{array}{l}\text { R on Gilford }>\text { R } \\
\text { on San Carlos }\end{array}$ & 1.4 \\
\hline & IRS building & $\begin{array}{c}\text { R on Gilford }>\text { R } \\
\text { on San Carlos }->\text { L } \\
\text { on Almaden }>\text { R on } \\
\text { Santa Clara -> L on } \\
\text { Market }\end{array}$ & 7.1 & $\begin{array}{c}\text { R on Gilford }->\text { R on } \\
\text { San Carlos }>\text { L on } \\
\text { Almaden -> R on } \\
\text { Santa Clara }>\text { L on } \\
\text { Market }\end{array}$ & 6.1 & $\begin{array}{c}\text { R on Gilford }>\text { R on } \\
\text { San Carlos }->\text { on on } \\
\text { Almaden }>\text { R on Santa } \\
\text { Clara }>\text { L on Market }\end{array}$ & 5.6 & $\begin{array}{c}\text { R on Gilford }>\text { R } \\
\text { on San Carlos }>\text { L } \\
\text { on Almaden -> R } \\
\text { on Santa Clara - } \\
\text { L on Market }\end{array}$ & 3 \\
\hline & 100 Paseo de San Antonio & $\begin{array}{c}\text { R on Gilford -> R } \\
\text { on San Carlos -> L } \\
\text { on 3rd St. }\end{array}$ & 7 & $\begin{array}{l}\mathrm{R} \text { on Gilford }>\mathrm{R} \text { on } \\
\text { San Carlos }>\mathrm{L} \text { on 3rd } \\
\text { St. }\end{array}$ & 2.9 & $\begin{array}{c}\text { R on Gilford }>>\text { R on } \\
\text { San Carlos }>\text { L on 3rd } \\
\text { St. }\end{array}$ & 2.3 & $\begin{array}{c}\mathrm{R} \text { on Gilford }>\mathrm{R} \\
\text { on San Carlos -> L } \\
\text { on 3rd St. }\end{array}$ & 2 \\
\hline
\end{tabular}




\subsection{Scenario Comparisons for Emergency Vehicles}

\subsubsection{O’ Connor Hospital Travel Time Comparison}

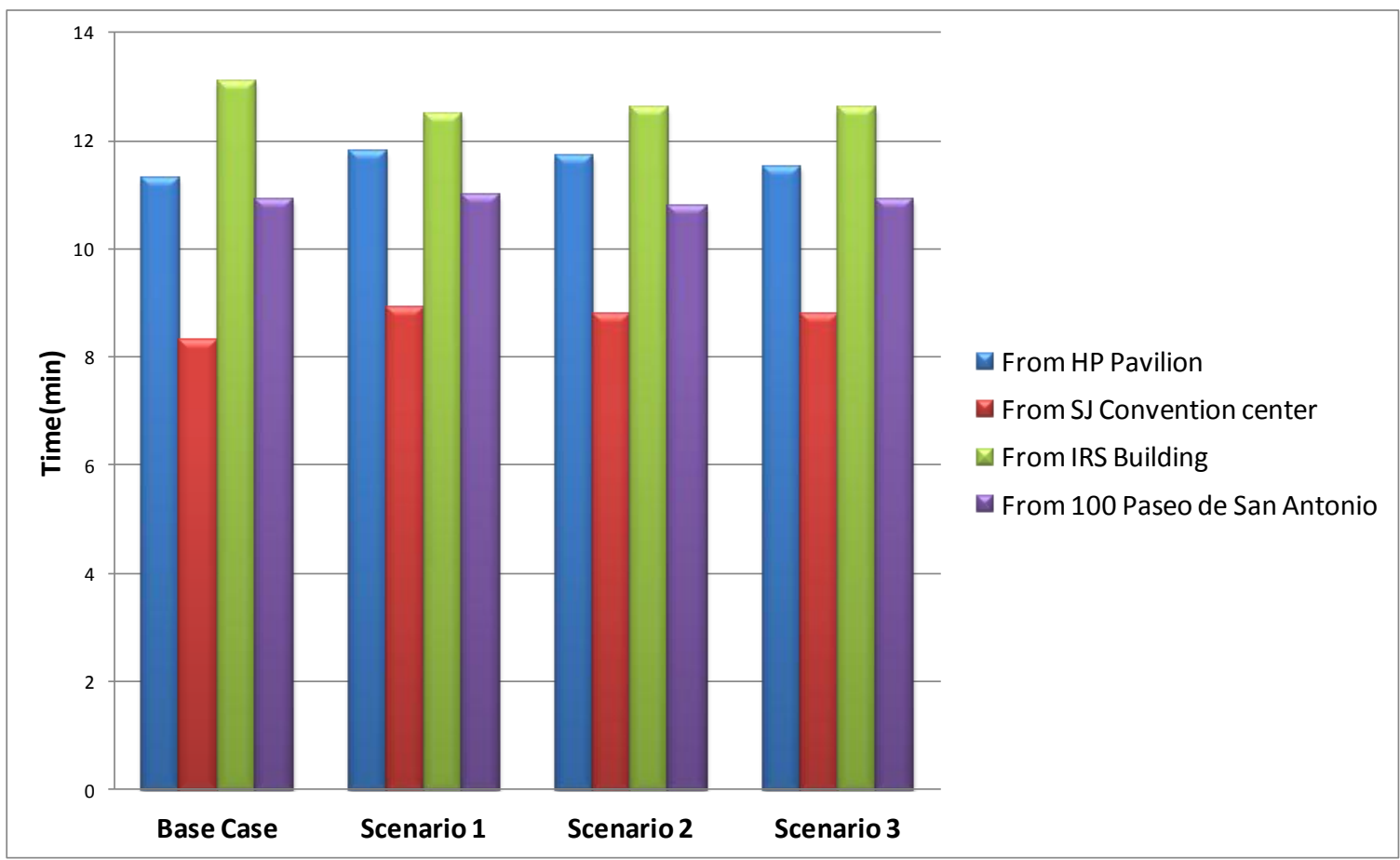

Figure 4.5 Travel Times to O' Connor Hospital from Disaster Sites

From Figure 4.5, it can be concluded that travel time for ambulances from the disaster sites to O' Connor Hospital were relatively consistent for all four scenarios. For example, an ambulance traveling from HP Pavilion to O' Connor Hospital would encounter an identical travel time whether it be Scenarios 1 to 3, including the base case scenario. Likewise, if ambulances were going from the San Jose Convention Center, the times would be relatively consistent and at a maximum only differing by half a minute, or 30 seconds of travel time. One of the reasons for the consistent travel times is that ambulances going to O' Connor Hospital were each traveling on the most optimized routes, which happen to be the same routes for each scenario. 


\subsubsection{Santa Clara Valley Medical Center Travel Time Comparison}

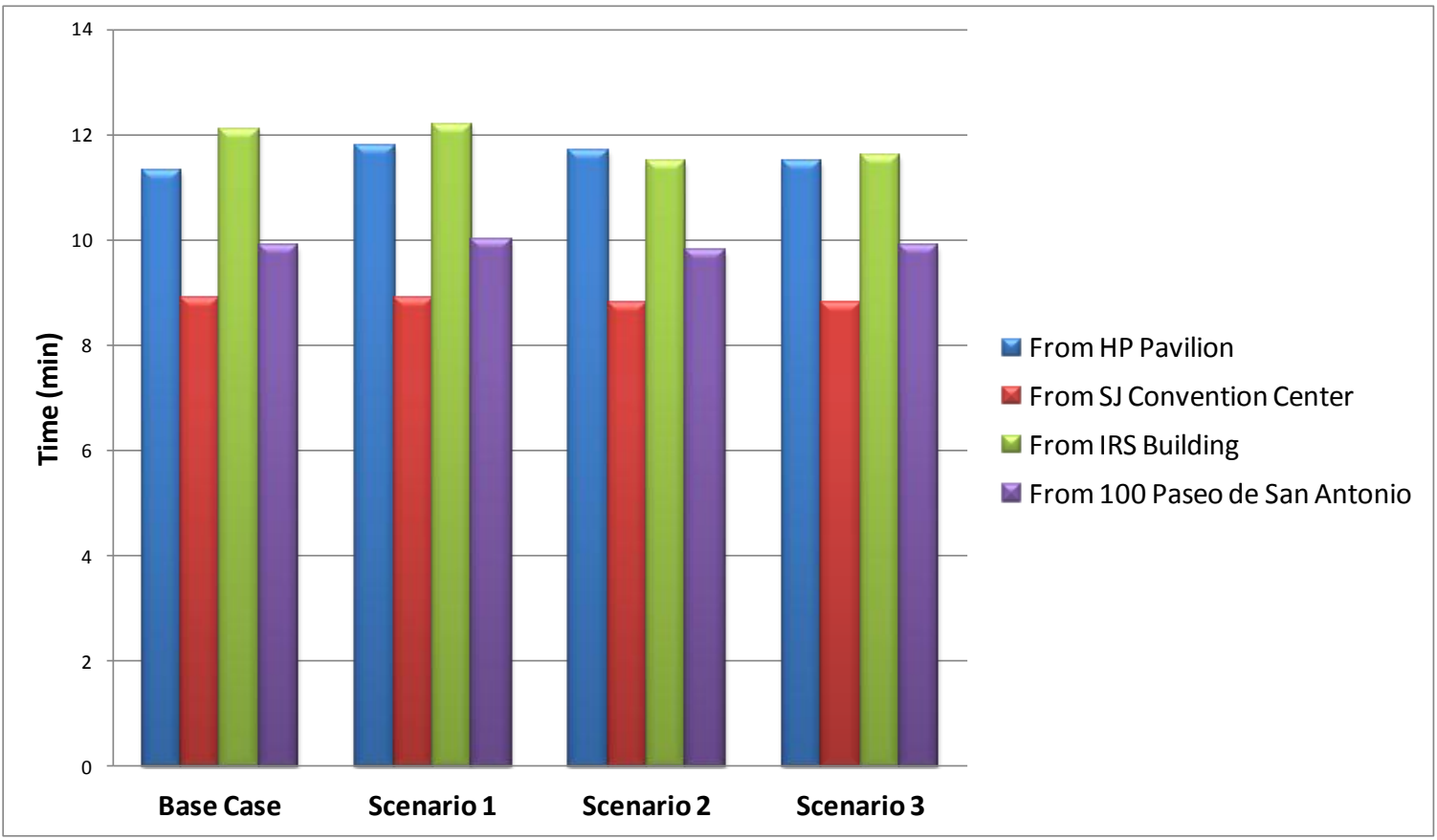

Figure 4.6 Travel Times from Santa Clara Valley Medical Center to Disaster Sites

For ambulances dispatched to Santa Clara Valley Medical Center from HP Pavilion, the results were very similar in their consistency to that of O' Connor Hospital, except for the differing travel times. Overall, the emergency vehicle travel times from San Jose Convention Center displayed in Figure 4.6 accounted for the least amount of total time traveled. It can be concluded here that for trips to Santa Clara Valley Medical Center, the travel time is mostly unaffected by the existing traffic, as well as additional congestion created by the mass exodus of vehicles from the disaster area parking lots. The reason for this is that most of the ambulance route from San Jose Convention Center is on Interstate $280 \mathrm{NB}$, which would encounter less of an impact compared to local and collector roads near the disaster area. 
For ambulances from the HP Pavilion, none of the scenarios showed significant differences in travel time. This is due in large part to ambulances having sole access to Highway 87. It suggests that authorities may be able to get help to the HP Pavilion victims quite easily under the given circumstances. Without any congestion, the ambulances were able to quickly gain access to the necessary route from HP Pavilion compared to other route options, which traveled less distance, but would have to travel on local roads.

Traveling from the IRS building would be the most time consuming route for the Base case, Scenario 1, and Scenario 2. The results are an indication of the congestion severity encountered along Santa Clara Street that was seen during the simulation runs. For the Base Case, Scenario 1, and Scenario 2, the simulation showed that vehicles would travel quickly along Highway 87, but would encounter severe congestion approaching via the Santa Clara Street off-ramp. Other route options explored consumed even more time than the ultimate, fastest route according to the simulation. For ambulances traveling from 100 Paseo de San Antonio, there were no significant differences in travel time. 


\subsubsection{Regional Medical Center Travel Time Comparison}

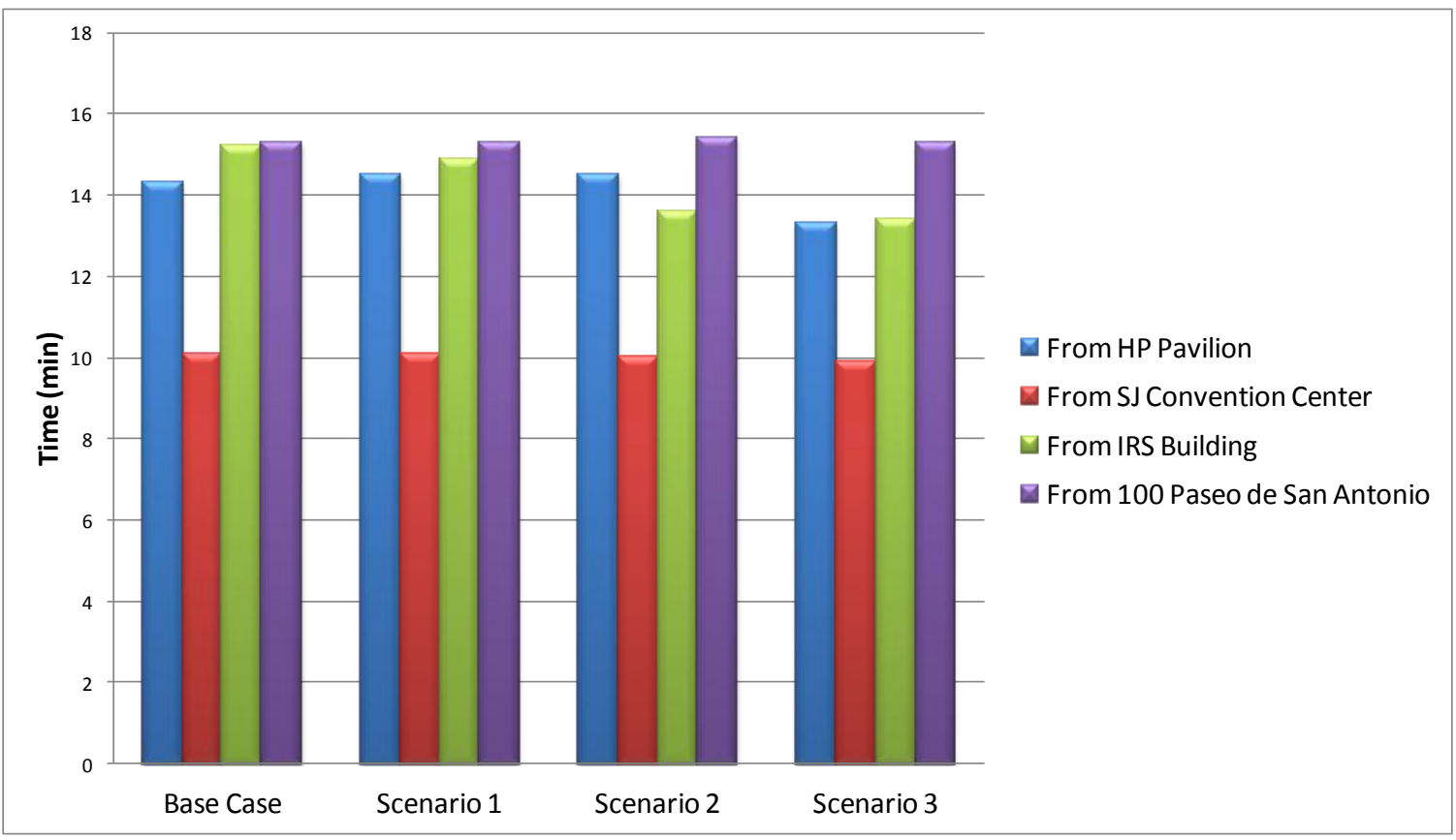

Figure 4.7 Travel Times from Regional Medical Center of San Jose to Disaster Sites

The results of the Regional Medical Center travel time comparison displayed in Figure 4.7 shows a very consistent travel time for ambulances going from HP Pavilion. This can be attributed again to emergency vehicles having exclusive access to Highway 87, thereby avoiding any congestion from the local roads. For ambulances traveling from San Jose Convention Center, there was the same consistency in travel times compared to ambulances traveling from HP Pavilion. Ambulance access from the State Building would take the longest amount of time for any of the scenarios due to the congestion on $4^{\text {th }}$ Street attempting to access I-280 NB. For ambulances heading from the State of California building at 100 Paseo de San Antonio, the travel times were relatively consistent. 


\subsubsection{Fire Station 1 Travel Time Comparison}

This section examines the travel time so that the best dispatch location for each affected area in this study could be identified.

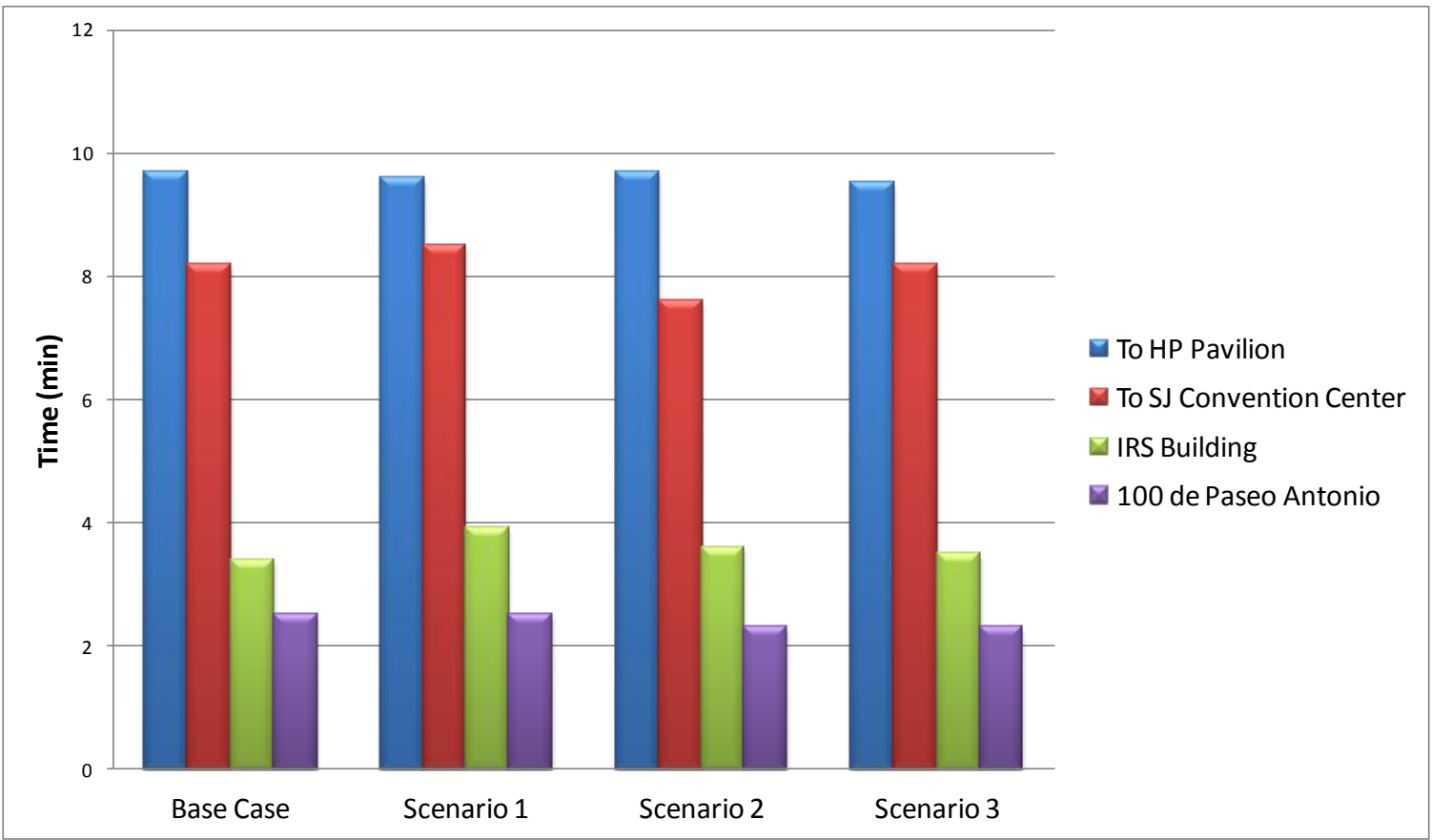

Figure 4.8Travel Time from Fire Station 1 to Disaster Areas

According to Figure 4.8, the longest travel time for each scenario was the emergency vehicles' trip from Fire Station 1 to HP Pavilion. Although emergency vehicles from this location only have to travel 0.7 miles to arrive at their destination, the long travel time is indicative of the congestion on Julian Street as a result of the vehicles exiting the parking lots in addition to the regular traffic flow. For emergency vehicles going to the San Jose Convention Center, the travel times were pretty consistent at approximately 8 minutes. Also, travel times to the IRS building, which was straight down the street, did not encounter any congestion. Based on this analysis it is clear that Fire Station 1 should be used to dispatch the vehicles to the IRS building as well as the State Building. 


\subsubsection{Fire Station 7 Travel Time Comparison}

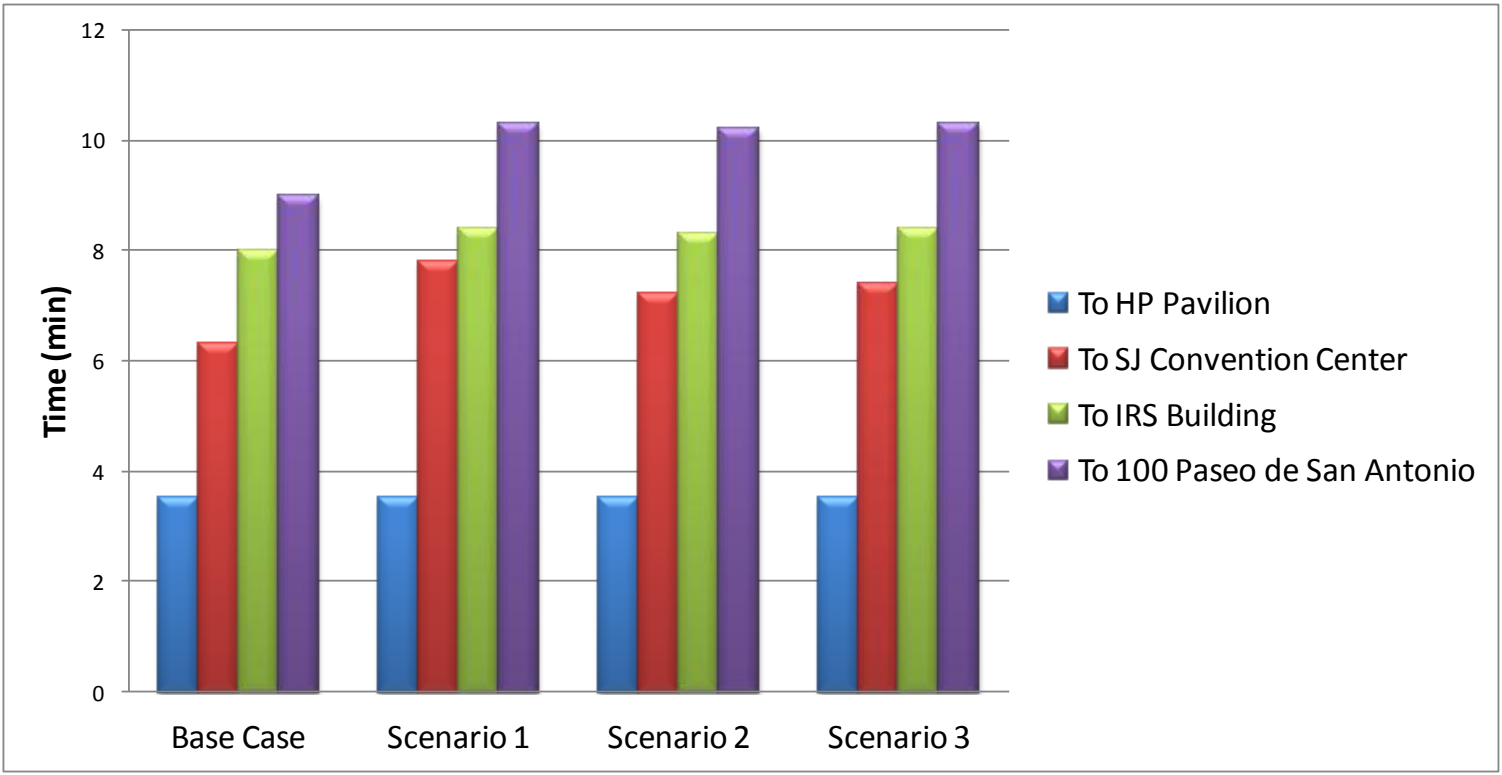

Figure 4.9 Travel Time from Fire Station 7 to Disaster Areas

From the results in Figure 4.9 above, there was very little significant difference when comparing travel times from Fire Station 7 to their respective destinations. For example, for emergency vehicles traveling from Fire Station 7 to HP Pavilion, the travel time was identical across all four scenarios, and this was the case for most of the destinations, 


\subsubsection{Fire Station 30 Travel Time Comparison}

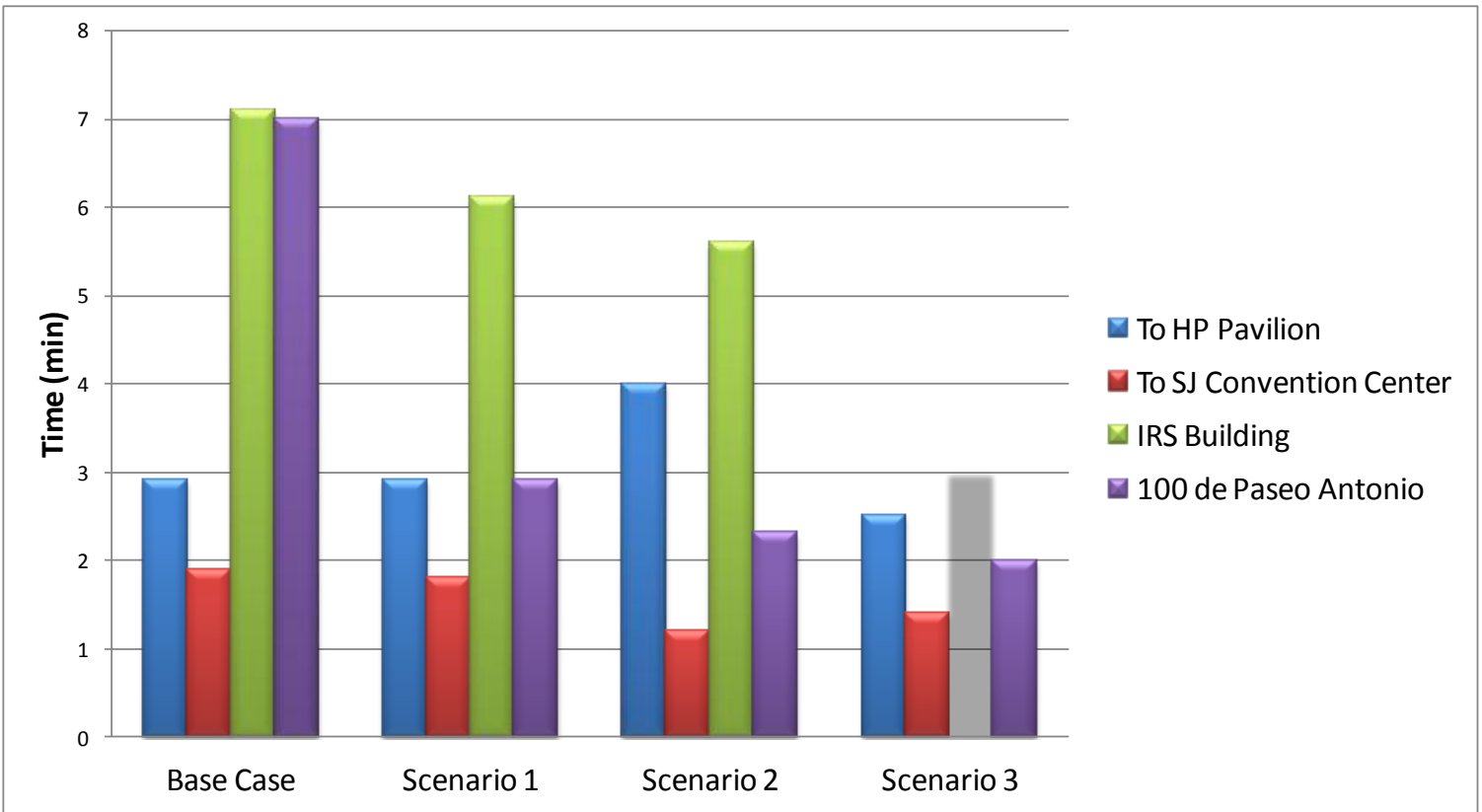

\section{Figure 4.10 Travel Time from Fire Station 30 to Disaster Areas}

According to Figure 4.10, emergency vehicles from Fire Station 30 traveling to HP Pavilion would encounter very similar travel times of around 3 minutes except for Scenario 2. The simulation travel time was actually half the predicted Google Maps travel time of five minutes. However, with Scenario 2 and the contraflow lanes providing traffic routing away from HP Pavilion, the lanes seemed to have an adverse effect on the emergency vehicle travel time. Also, for emergency vehicles traveling to the San Jose Convention Center, the travel times were around one to two minutes. The emergency vehicle trips to the IRS building most clearly highlighted the effects of the vehicle reduction in Scenario 3. Whereas the three preceding scenarios exhibit longer travel times of over 5 minutes, the scenario 3 travel times were around 1.5 to three minutes. 


\subsection{Scenario Comparisons for Emergency Responders}

\subsubsection{Disaster Areas to Hospital}

Next, for a particular disaster area, the hospital to which patients could most quickly arrive at was analyzed. For example, the figure below displays the travel times from HP Pavilion to different hospitals under the disaster scenarios.

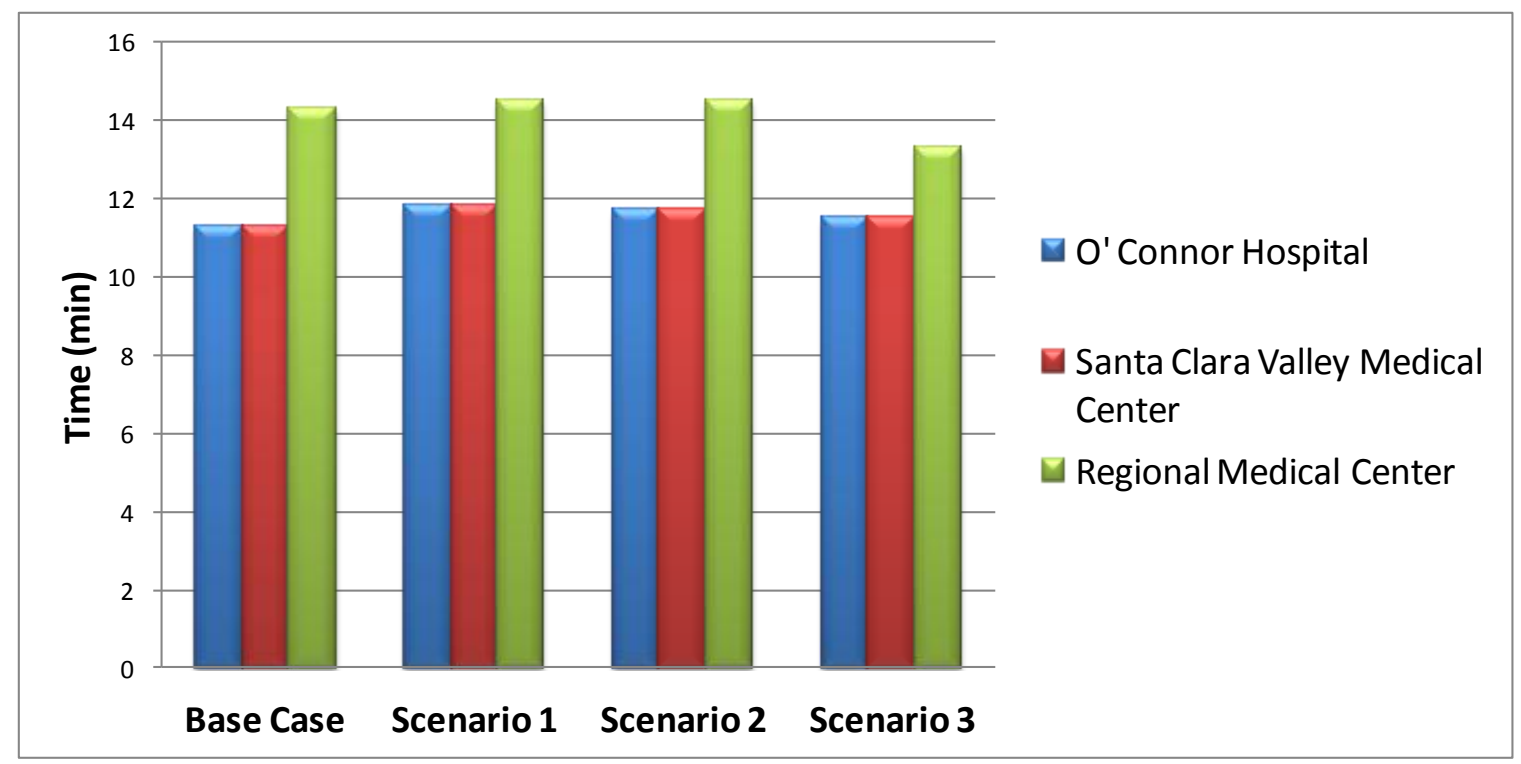

Figure 4.11 Travel Time from HP Pavilion to Primary Hospitals

From Figure 4.11, it's clear that either O' Connor Hospital or Santa Clara Valley Medical Center could be the hospitals to which ambulances could take patients affected by the disaster. The travel times from HP Pavilion were all very close to 11 minutes proving also that the ambulance routes were relatively unaffected by the scenario changes. 


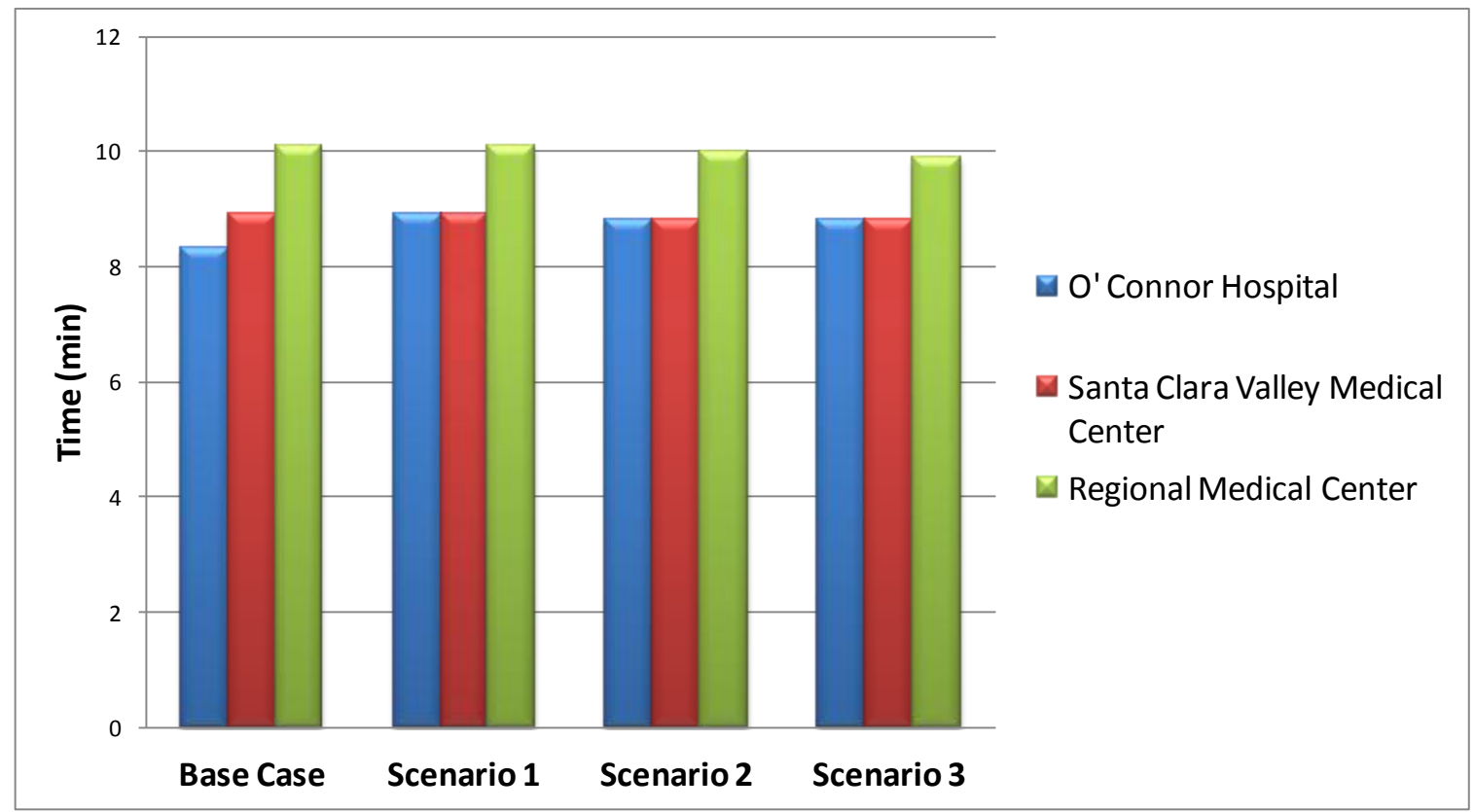

Figure 4.12 Travel Time from San Jose Convention Center to Primary Hospitals

From Figure 4.12, patients from the San Jose Convention Center should be dispatched to either O’ Connor Hospital or Santa Clara Valley Medical Center for Scenarios 1, 2, and 3 because all three aforementioned scenarios had the faster travel time compared to Regional Medical Center. For the Base Case Scenario, however, O' Connor Hospital would be the ideal hospital as it is faster than the next closest hospital, Santa Clara Valley Medical Center, by 1 minute. 


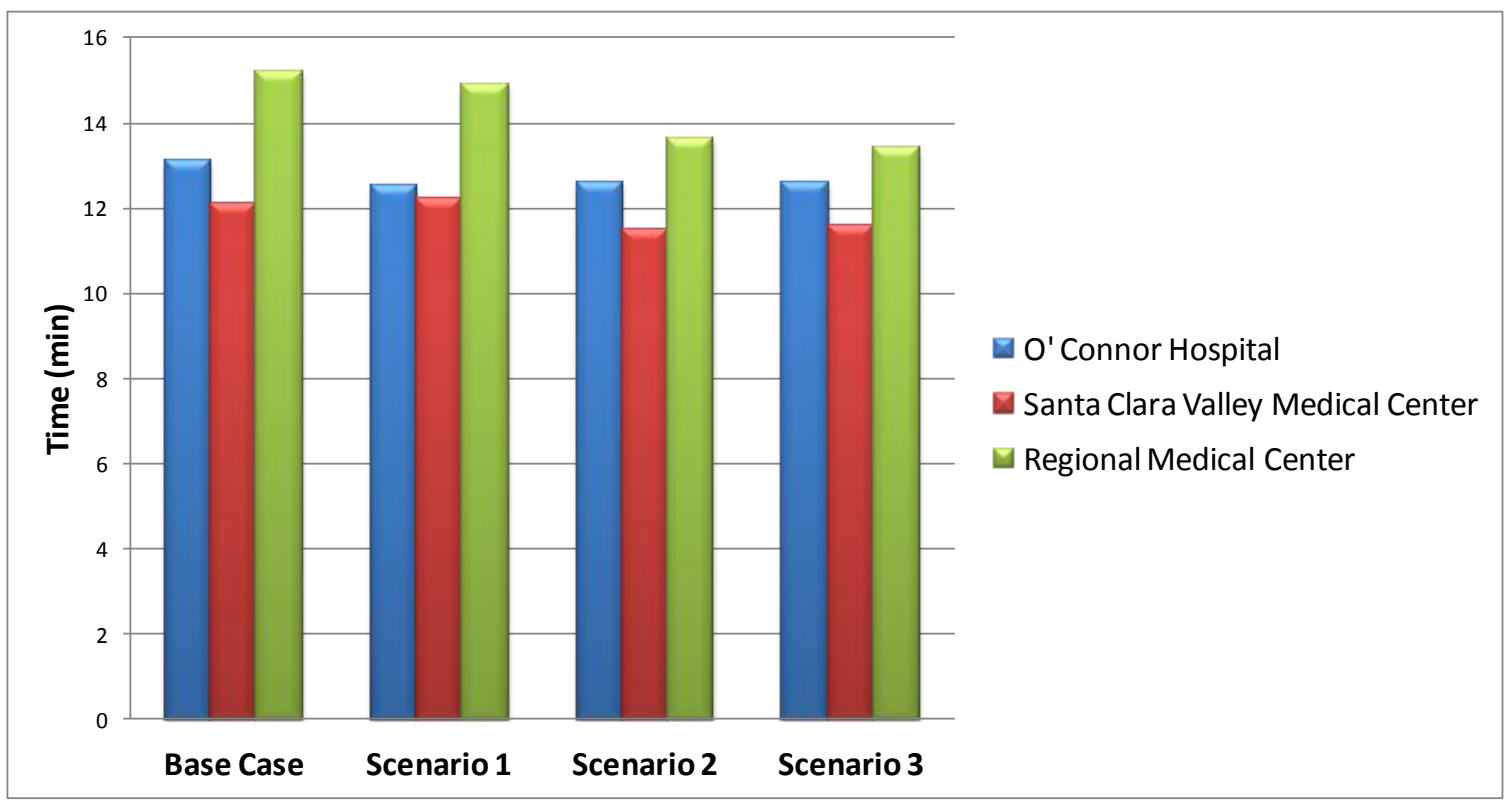

Figure 4.13 Travel Time from IRS Building to Primary Hospitals

From Figure 4.13, ambulances traveling from the IRS building at 55 South Market should be dispatched to Santa Clara Valley Medical Center the Base Case, Scenario 2, and Scenario 3, patients should be dispatched to Santa Clara Valley Medical Center. O' Connor Hospital would be the next best option as the travel time differences from $\mathrm{O}^{\text {' }}$ Connor Hospital to Santa Clara Valley Medical Center range about a minute or less. 


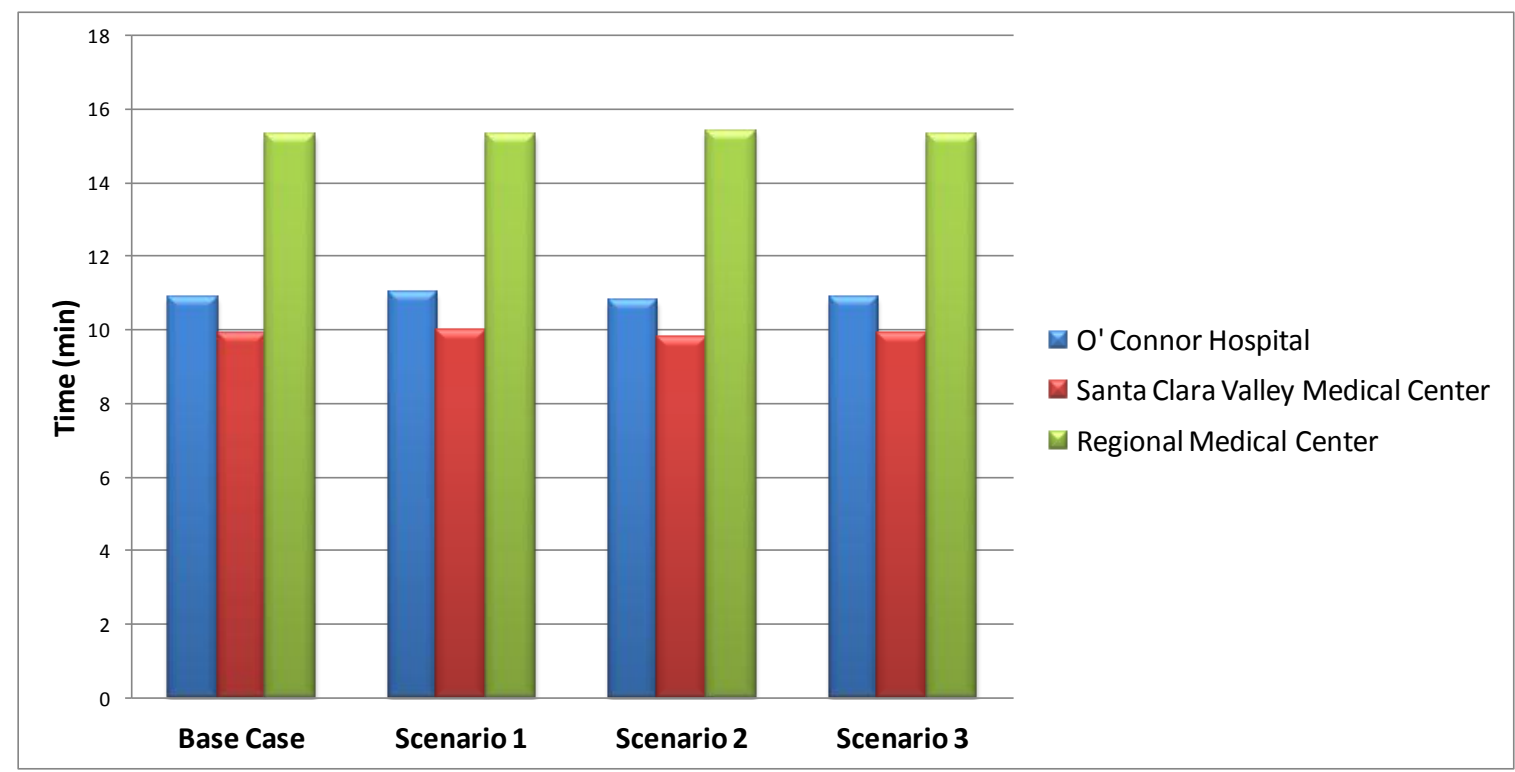

Figure 4.14 Travel Time from State of California Building to Primary Hospitals

For the State of California Building, the hospital that consistently received ambulances the fastest was Santa Clara Valley Medical Center for all of the scenarios. Figure 4.14 above also displays that the time discrepancy from O' Connor Hospital was approximately one minute or less. Therefore, O' Connor Hospital would be the second most viable option for patients dispatched from the State of California Building. 


\subsubsection{Fire Station Dispatch to Disaster Areas}

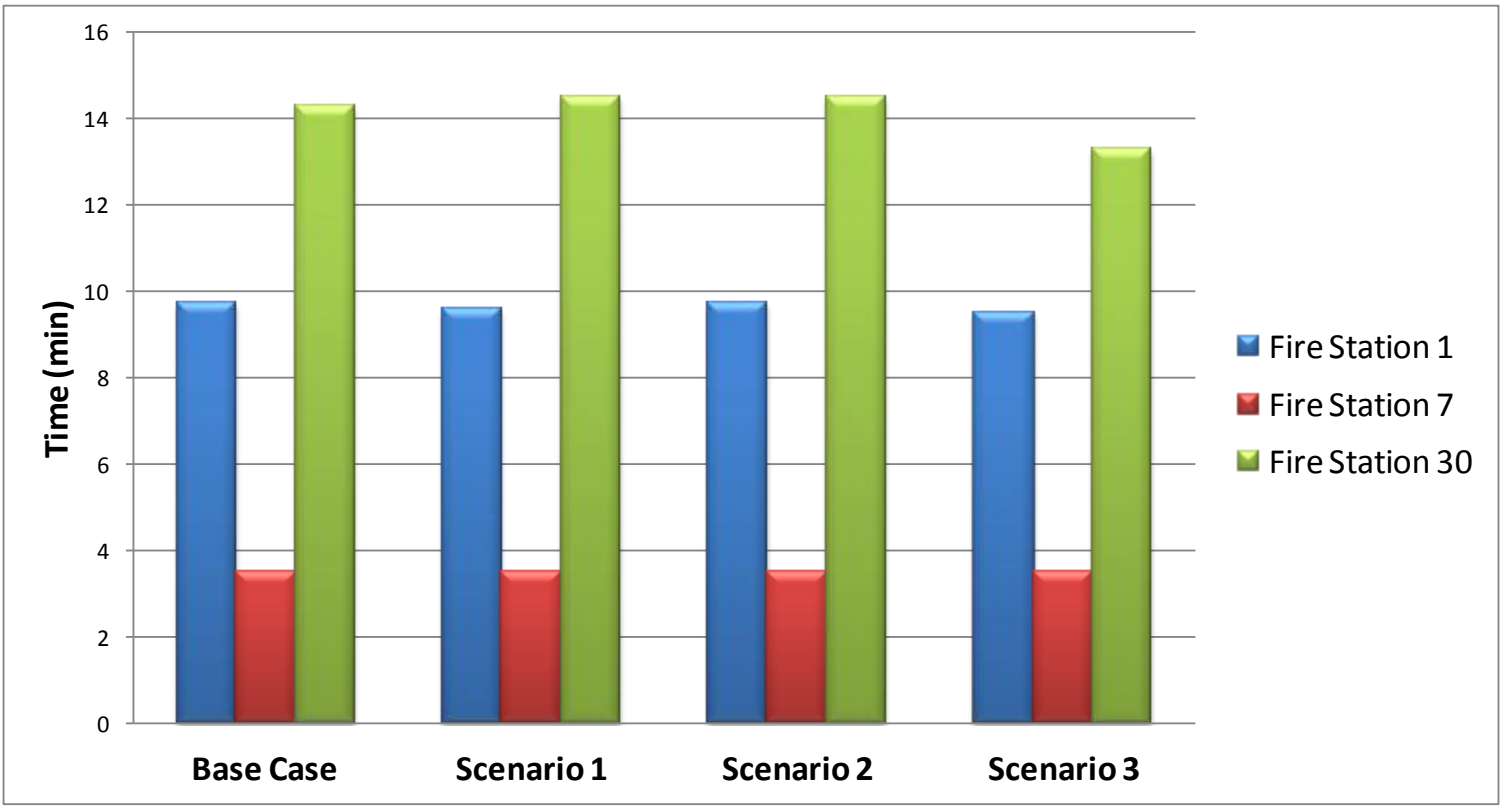

Figure 4.15 Travel Time to HP Pavilion from Fire Stations

From Figure 4.15 above, Fire Station 7 should be the primary responder in all of the simulated scenarios, and in all four of the scenarios its response time was consistently faster than the next closest fire station, which was Fire Station 30, by approximately 7 minutes for each scenario. 


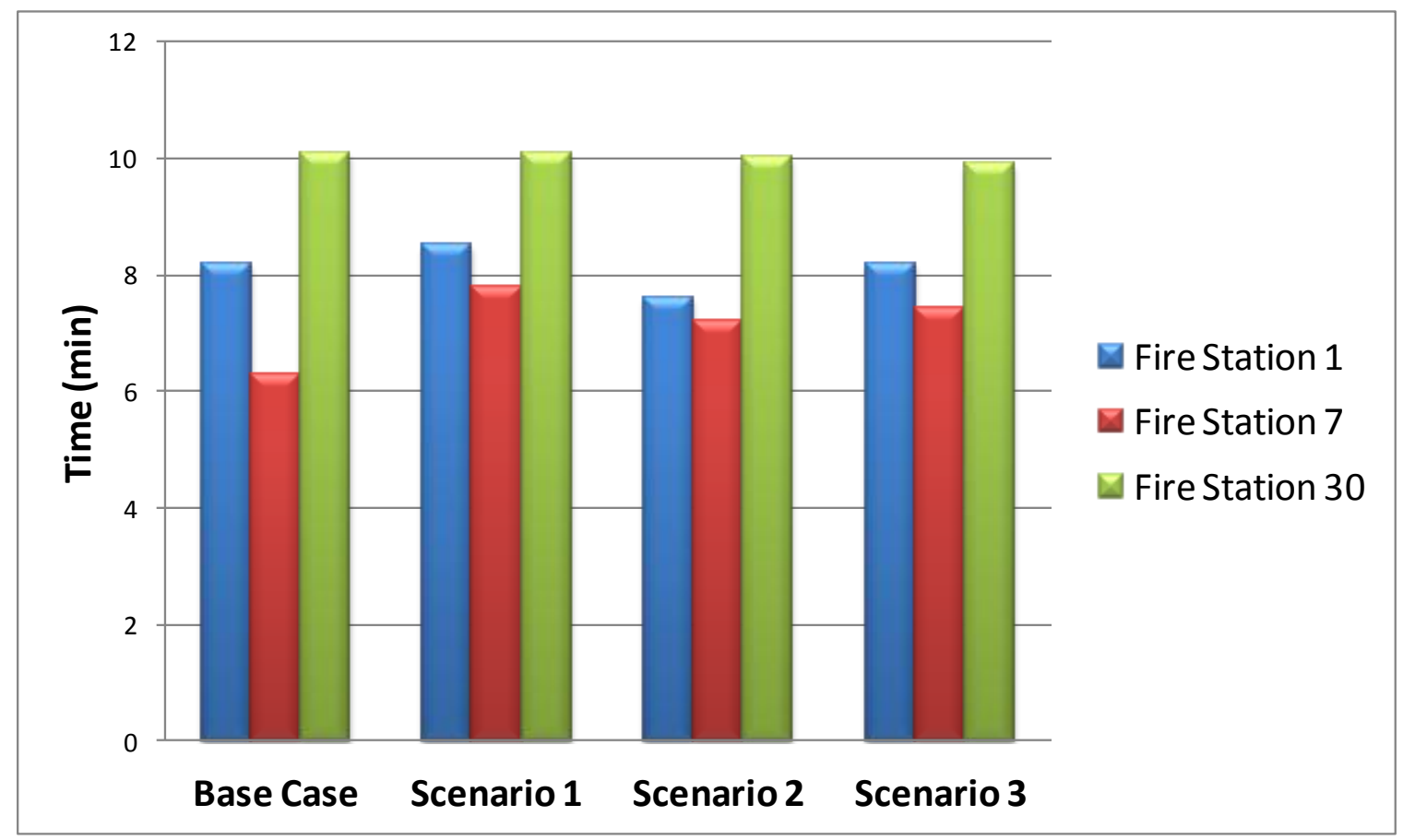

Figure 4.16 Travel Time to San Jose Convention Center from Fire Stations

When evaluating the travel times for emergency vehicles from the fire stations to San Jose Convention Center, Fire Station 7 has the clear advantage of being faster than Fire Station 1 by about one to two minutes for each scenario. From the results in Figure 4.16 above $=$, for all the simulated scenarios, Fire Station 7 should be the primary responder to the San Jose Convention Center. 


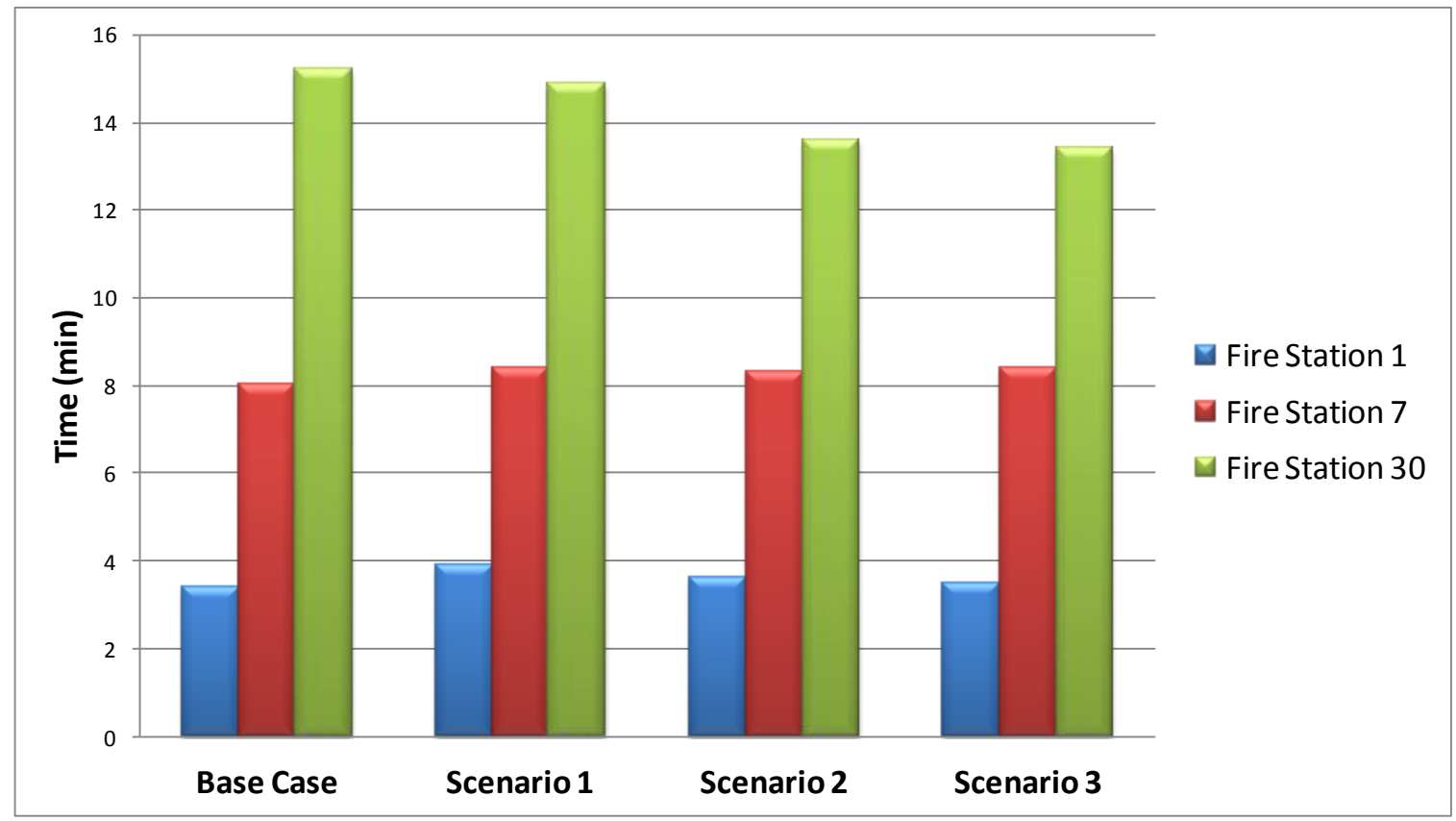

Figure 4.17Travel Time to IRS Building from Fire Stations

Due to Fire Station 1's proximity to the IRS building, (only 0.2 miles) it would make sense that regardless of the scenario Fire Station 1 was the choice, while Fire Station 7 was not a close second in terms of travel time. The time difference depicted in Figure 4.17 between Fire Station 1 and Fire Station 7 was approximately 5 minutes. 


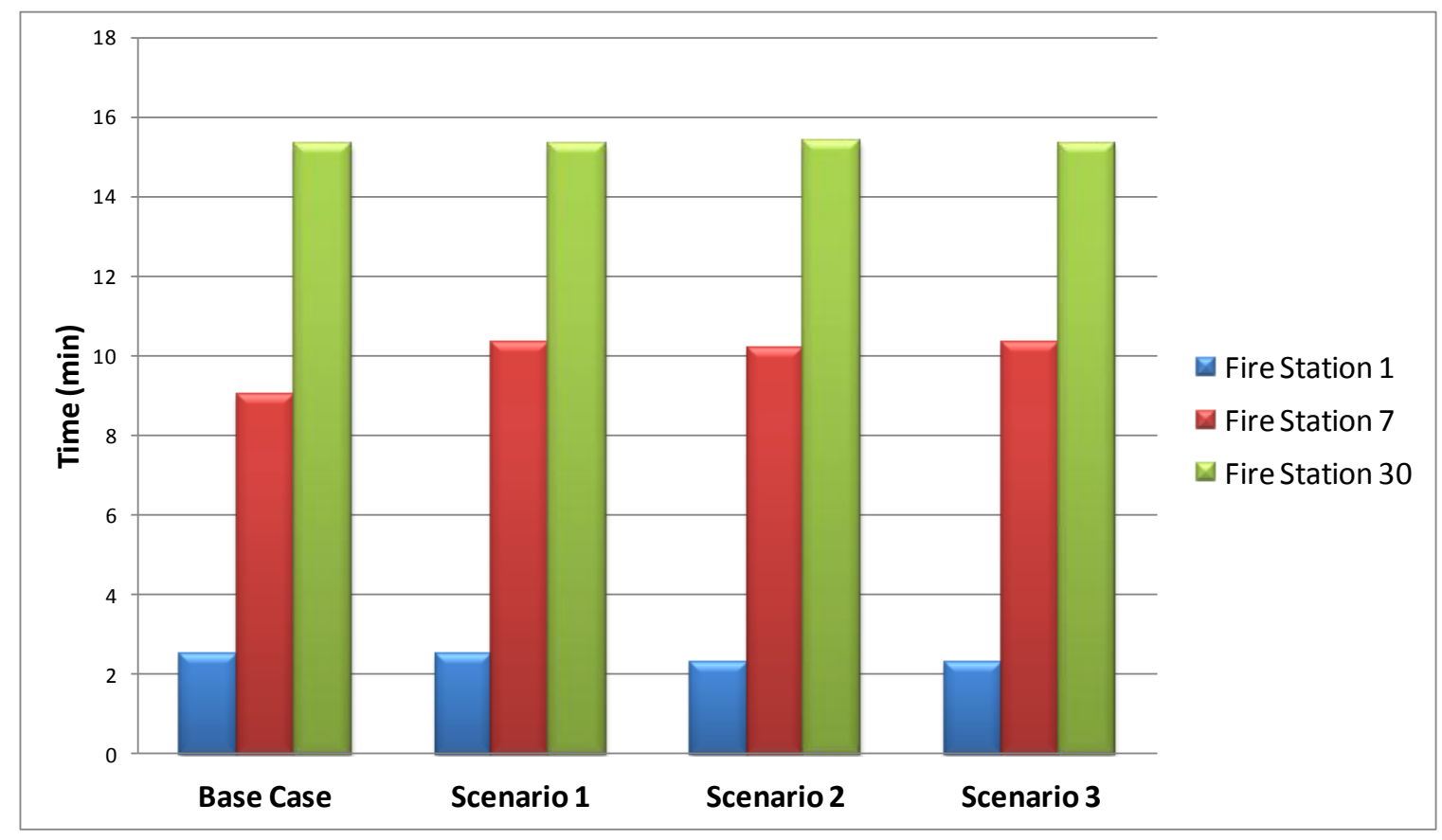

Figure 4.18 Travel Time to State of California Building from Fire Stations

For the State of California building, Fire Station 1 located on 225 North Market Street would offer the shortest travel time to the State of California building at 100 Paseo de San Antonio for all scenarios. The travel times displayed in Figure 4.18from each scenario were all around two minutes for Fire Station 1. The next closest Fire Station in terms of travel time, Fire Station 7, featured a time discrepancy of approximately 6.5 minutes for each scenario.

\subsection{Scenario Comparisons for the General Public}

After evaluating the travel times for emergency vehicles, the next step was to evaluate the travel times for the general public leaving the four disaster locations. Table 4.5 below displays the average travel times for network vehicles from each disaster area to reach their destinations. Destinations for each origin are different exit points on the network modeled in VISSIM. 
Table 4.5 Travel Time for Evacuees

\begin{tabular}{|c|c|c|c|c|}
\hline Origin & Base Case $^{\mathrm{a}}$ & ${\text { Scenario }{ }^{\mathrm{a}}}^{\mathrm{a}}$ & ${\text { Scenario } 2^{\mathrm{a}}}^{\text {Scenario } 3^{\mathrm{a}}}$ \\
\hline HP Pavilion & 11.5 & 15.6 & 5.9 & 8.5 \\
\hline San Jose Convention Center & 5.6 & 5.0 & 6.0 & 4.1 \\
\hline IRS building & 9.9 & 9.8 & 9.7 & 8.4 \\
\hline State of California Building & 7.1 & 7.1 & 5.6 & 5.3 \\
\hline $\begin{array}{l}\text { Note: } \\
\text { a Travel times are in minutes. }\end{array}$ & \\
\hline
\end{tabular}

While the specific destination is not listed in the table above it does generally show the improving or worsening travel times for each scenario from the disaster locations. The worsened travel time from HP Pavilion for Scenario 1 is caused by the simulated incident which closed a lane of traffic towards the I-280 SB and NB ramps. The incident directly influenced vehicles' travel time leaving HP Pavilion. It indicates that if the objective of the evacuation plan is to evacuate HP Pavilion, then Scenario 2 might be the best option. Also, note that Scenario 2 contained contraflow lanes designed specifically to alleviate the congestion anticipated from vehicles exiting from HP Pavilion. From the table above, Scenario 2 was able to reduce the travel time away from HP Pavilion for evacuees by half, from approximately 18 minutes to 12 minutes when comparing Scenarios 1 and 2 . However, the contraflow lanes were not able to reduce the travel time from HP Pavilion to the vehicles' intended destinations better than Scenario 3, when vehicular traffic from the disaster parking lots was reduced by $30 \%$. However, an unintended consequence of the contraflow lanes was the rerouting of vehicles onto adjacent streets, which directly affected the evacuees' travel time from the San Jose Convention Center. However, since the increase in travel time is from 6 minutes to 5 minutes, it may be an acceptable trade- 
off. To ascertain whether the differences between travel times are statistically significant, a statistical analysis is conducted in the next section. It is worth noting that Scenario 3 (with $30 \%$ fewer trips due to transit support) produced the fastest travel times from all the disaster areas save Scenario 2's HP Pavilion trips, which featured contraflow lanes to aid in the general public's departing of the area.

\subsection{Difference Among the Mean Travel times (Statistical Analysis)}

While a preliminary assessment from the numbers above and the prior analysis conducted can lead to a conclusion that a significant transit support would be needed to ideally be able to evacuate the general public while roads can mostly be used by emergency personnel to reach the disaster locations, the general inferences drawn need to be verified using statistical tests. Note that the averages of travel times were obtained using 10 simulation runs and the base case disaster scenario is essentially the do nothing scenario. The travel times were compared through a two-sample t-test (one side/one tail) was conducted for each pair of plans to test if there was indeed a significant difference between their means. Using the equation shown below, the t-value was estimated within Minitab:

$\frac{\left(\overline{X_{n}}-\overline{Y_{m}}\right)-\left(\mu_{1}-\mu_{2}\right)}{\widehat{\sigma} \sqrt{\frac{1}{n}+\frac{1}{m}}}$

T-value Equation

where

$\overline{X_{n}}=$ mean value of 10 samples in first specified scenario 
$Y_{m}=$ mean value of 10 samples in the second scenario being compared to

$\mu_{1}=$ real mean of the first specified scenario

$\mu_{2}=$ real mean of the second specified scenario

$\widehat{\sigma}=$ the Pooled estimation that is also called sample standard deviation

$n=$ number of observations for the first specified scenario

$m=$ number of observations for the second specified scenario

In this research study, the null hypothesis $\left(H_{0}\right)$ was that the populations' means are equal or smaller $\left(\mu_{1} \leq \mu_{2}\right)$ against an alternative hypothesis $\left(H_{1}\right)$. This essentially is predicting that the first scenario's times are greater than that of the second scenario.

First, the difference between the means of the Base Case and Scenario 1 was tested. The null hypothesis was that the mean value from the Base Case minus the mean value from Scenario 1 was less than or equal to zero. If it was zero, it meant that there was no significant difference between the two plans. The alternative hypothesis was that the mean value from the Base Case was larger than the mean value from Scenario 1. Both the Base Case and Scenario 1 had a range of 10 values and their mean values were 5.7 and 6.4 minutes respectively. The mean difference between the plans was estimated in Minitab to be -0.34 minutes. Therefore, using the equation in the figure above, the Tvalue was found to be -1.76 . From these estimates the P-value was calculated using MINITAB. For this particular study, the simulation constructed a $95 \%$ confidence the 
value of $\alpha$ was 0.05 . That means the interval will contain the true parameter, with $95 \%$ confidence and only $5 \%$ of all values would exceed this interval.

\section{Table 4.6 Significant Mean Difference of Base Case and Scenario 1}

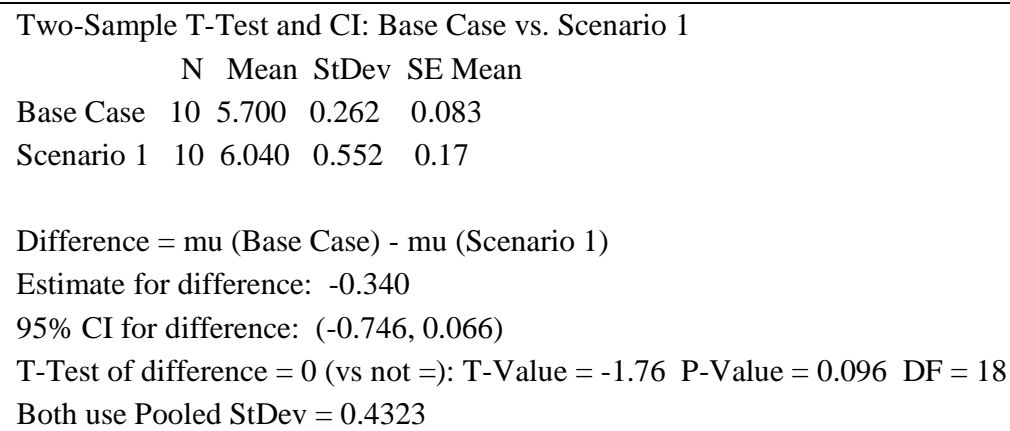

From the comparison between the Base Case and Scenario 1 in Table 4.6above, the null hypothesis was not rejected. The p-value was 0.096 which is greater than the $\alpha$ value of 0.05. Therefore, the null hypothesis was accepted that there was no strong evidence to conclude that the Base Case as a whole performed significantly better or worse than the Scenario 1 in terms of travel time.

The same procedure was also repeated to verify the difference between the Base Case and Scenario 2. The output from the statistical software program MINITAB is in Table 4.7 below.

\section{Table 4.7 Significant Mean Difference of Base Case and Scenario 2}

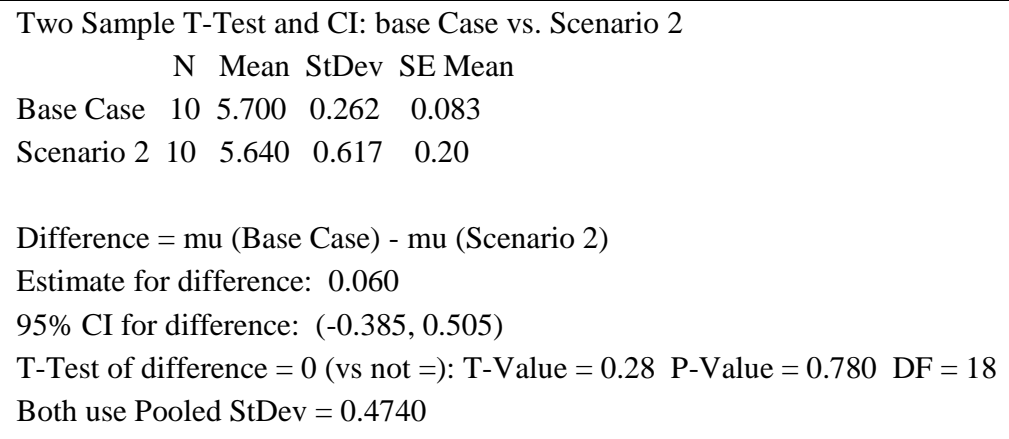


Table 4.7displays a statistical comparison between the Base Case and Scenario 2 and proves that the null hypothesis cannot be rejected. The p-value was 0.78 which is greater than the $\alpha$ value of 0.05 . This is enough evidence to conclude that with respect to travel time that the Base Case network doesn't perform significantly better or worse than the Scenario 2 network with $95 \%$ confidence.

Next, the identical procedure completed before was also performed to validate the difference between the Base Case versus Scenario 3. The output for the comparison is displayed in Table 4.8 below.

\section{Table 4.8 Significant Mean Difference of Base Case and Scenario 3}

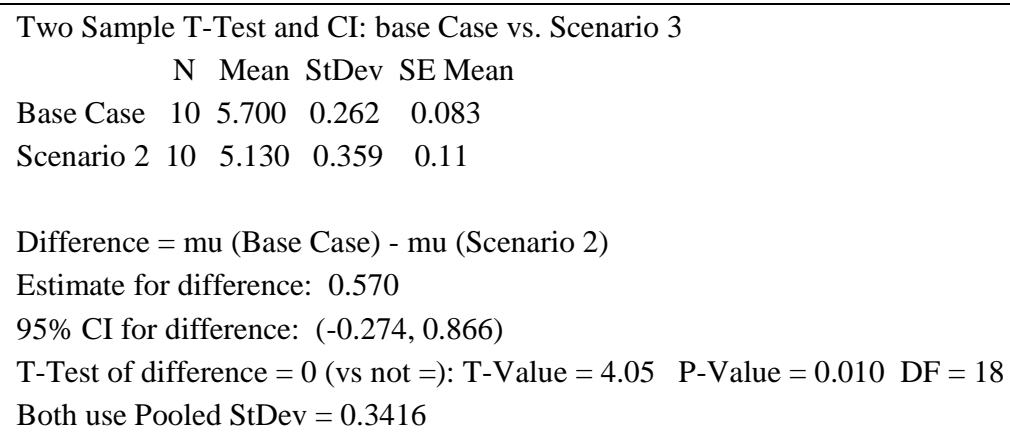

The summary table above displays the statistical summary of the differential mean test assuming equal variance. Since the p-value was 0.001 which is very nearly zero and is also less than the value of $\alpha$ value of 0.05 , the null hypothesis must be rejected. Therefore, it can be concluded that the mean travel time in the Base Case network is larger than in Scenario 3 which means that general public vehicles in the Base Case need more time to discharge and emergency vehicles need more time to reach their destinations compared to Scenario 3. 
After comparing the significance of the Base Case with the three other scenarios, statistical tests had to be conducted to verify whether or not there was a significant difference between the three scenarios themselves. First, Scenarios 1 and 2 were compared and the comparison summary is presented in Table 4.9 below.

\section{Table 4.9 Significant Mean Difference of Scenario 1 and Scenario 2}

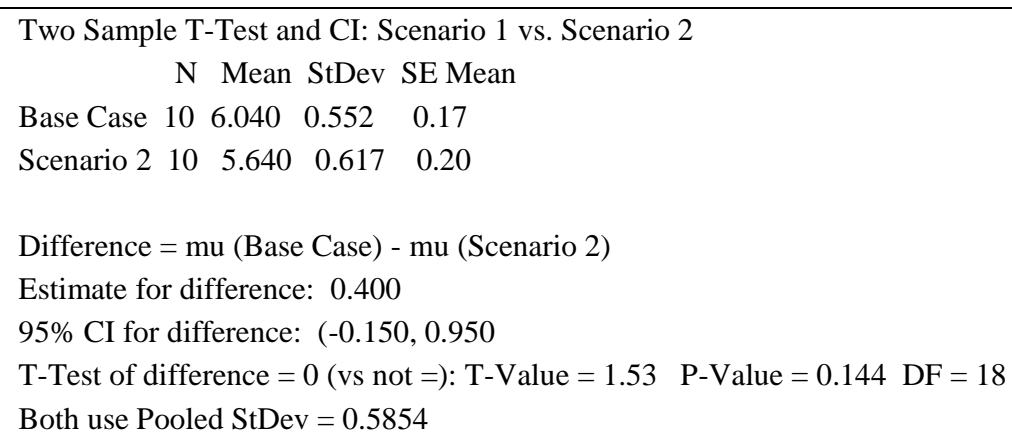

Table 4.9 displays a statistical comparison between the Scenario 1 and Scenario 2 and proves that the null hypothesis cannot be rejected. The p-value was 0.14 which is greater than the $\alpha$ value of 0.05 . This is enough evidence to conclude that with respect to travel time that the Scenario 1 network doesn't perform significantly better or worse than the Scenario 2 network with $95 \%$ confidence.

Next, the identical procedure completed before was also performed to validate the difference between Scenario 1 versus Scenario 3. The output for the comparison is displayed in Table 4.10 below. 


\section{Table 4.10 Significant Mean Difference of Scenario 1 and Scenario 3}

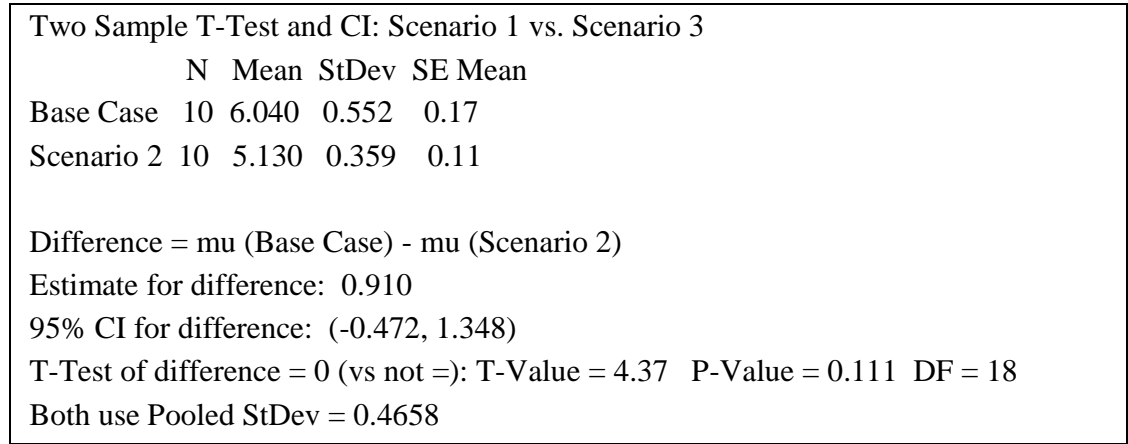

Since the p-value for the statistical comparison between Scenarios 1 and 3 was essentially zero according to the Table 4.10 above, the null hypothesis was rejected. This means that the travel time for Scenario 1 was longer for both the general public and emergency vehicles compared to Scenario 3. Therefore, it can be concluded that reducing vehicular traffic by $30 \%$ from the disaster area parking lots indeed aided the network in operating more efficiently as a whole.

\section{Table 4.11 Significant Mean Difference of Scenario 2 and Scenario 3}

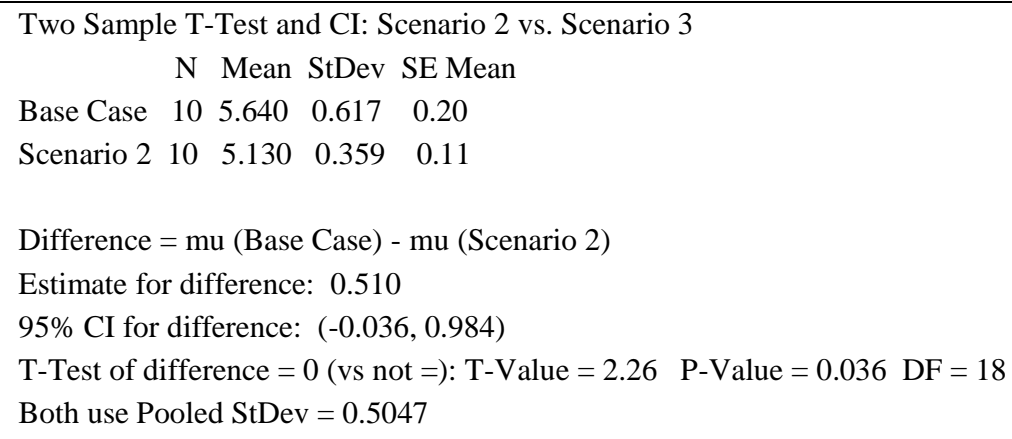

The $\mathrm{p}$-value was less than the $\alpha$ value of 0.05 . Therefore, there was sufficient evidence to conclude that Scenario 3 again operated more efficiently this time than even Scenario 2 with its contraflow lanes. 
From the six statistical tests conducted, it was found that Scenario 3 operated the most efficiently in enabling emergency vehicles and the general public to reach their intended destinations in the fastest time. For the other scenarios including the Base Case, none had a significantly worse or better travel time when compared with the others. This result is due to the fact that both Scenarios 1 and 2 made localized network changes such as incidents or contraflow lanes which weren't enough to affect the network as a whole even in the event of a disaster. 


\section{CONCLUSION}

The primary goal for this research was to apply the simulation modeling approach to investigate the various evacuation strategies and scenarios for a human-caused disaster in downtown San Jose. To accomplish this goal, first a microscopic simulation model to evaluate the pre- and post-disaster performance of the downtown street network was developed in VISSIM. Google Maps and the manual observation of the network were used to code the network correctly in terms of the lane-configuration, traffic signals, and related factors. The network was coded to have evening peak hour volumes in order to account for the worst case scenario in terms of traffic.

The application of simulation for disaster traffic modeling was demonstrated using the a scenario which included near simultaneous terrorist bombings at four downtown San Jose locations: HP Pavilion on Santa Clara Street, IRS building on Market Street, Convention Center on Almaden Boulevard and State of California Building on 100 Paseo de San Antonio. Three hospitals and fire stations were identified as locations for the emergency responders. The primary hospitals to receive patients from the disaster were (1) O' Connor Hospital, (2) Valley Medical Center, and (3) Regional Medical Center (HCA). These were destinations for ambulances from the four disaster sites. The three fire stations in the study were the origins for the emergency responders, with the four terrorist targets being the destinations. The later were also the origins for evacuees (general public), with their destinations being different exit points on the network.

The simulation model created in this study was used to identify efficient routing strategies for four different scenarios. The four scenarios were chosen based on the 
different complications or potential improvements that could be made in the event of a large scale terrorist attack on San Jose. The fastest route for each of the four scenarios was chosen after averaging the travel times from the 10 simulation runs. These fastest routes were identified not only for the evacuees to exit the downtown but also ambulances to reach the area hospitals from targeted locations, and fire dispatch vehicles to reach the targeted locations from nearby fire stations.

Under the 'do-nothing' base disaster scenario the most severe traffic bottlenecks occurred along Santa Clara Street and Montgomery Street, as many vehicles exiting from the surrounding HP Pavilion parking lots attempted to flee the area. The Santa Clara Street bottleneck began at the intersection of Santa Clara Street and Cahill Street, and continued until Santa Clara Street and Market Street As for the Montgomery Street bottleneck, the worst traffic occurred from the intersection of Montgomery Street and Santa Clara to Montgomery Street and the I-280 on and off-ramps. This information from the base case disaster scenario can be used by emergency response planners to come up with different scenario that can improve traffic. In this research the value of the simulation model was demonstrated by four different scenarios (summarized above).

Contraflow lanes on Montgomery Street/ Bird Avenue helped to reduce the bottleneck on Montgomery Street, and subsequently reduced the bottleneck on Santa Clara Street as well, with fewer cars able to turn onto Santa Clara Street from Autumn Street. Therefore, any bottleneck directly associated by implementing contraflow can be alleviated by the fact that the reversal begins at the intersection of Park Avenue and Montgomery Street In addition to providing two contraflow lanes for the general public to exit the disaster area, 
one of the lanes immediately adjacent to the contraflow lanes was used only for emergency vehicle access to HP Pavilion. This was used in Scenario 2, but did not seem to produce a more efficient travel time compared to scenarios without the emergencyvehicle-only lane on Montgomery Street.

As expected reducing the number of evacuating vehicles on the road seemed to be the best scenario in terms of reduced travel times. In the scenario where $30 \%$ of traffic was diverted to transit via the Diridon Transit Center, the least amount of congestion was encountered by the remaining evacuees, as well as emergency responders. While this is a logical conclusion, putting it into practice and implementing a plan of having drivers abandon their vehicles in a car-oriented society would be difficult. It would help to have sufficient communication from emergency responders and emergency planning to advertise their plan in a way to effectively communicate this idea. In the absence of transit (possibly due to potential attacks on station or on tracks), the contraflow lanes (Scenarios 2) will be helpful. It is worth noting that it is possible for emergency professionals to devise even more effective scenarios that can be evaluated using the simulation model developed in this research. As mentioned above, though the real value of this research is not necessarily in identifying the best possible strategy but demonstrating how any evacuation and response strategy can be evaluated using the simulation model.

A potential scenario that could be explored is the use of high capacity vehicle transit on Highway 87. Although, Highway 87 in our scenarios was closed to the general public, by 
allowing it to be a thoroughfare to transport large amount so people away from the area, it could become a valuable medium for a quicker evacuation away from San Jose.

The simulation model developed herein can be used by emergency planners to keep revising the strategies and different evacuation scenarios to test what evacuation strategy works best for any given disaster scenarios. If the evacuation planners would like to analyze more scenarios, it can be done at very little additional effort for downtown San Jose now that this model is available. The results of this research can also serve as a basis for further research into disaster planning. Time horizon of the evacuation, as well as the inclusion of more area, would be helpful. In this study many attempts were made to create a network that would be encompassed by Highway 101, I-880, and I-280 (20 sq. mile area) by creating detailed VISSIM network with all roads coded. However, the traffic assignments were never able to converge with so many details and large amount of traffic. Based on investigators' experience, increasing the modeled area might make it impossible to model the network in the detail attained here. Mesoscopic modeling (instead of very detailed microscopic approach used here) such as cell transmission model may be used in that case. From the queue clearance observation during the VISSIM simulation, even after background traffic had mostly diminished, queues would take some time to clear the network. Therefore, a potential investigation would delve deeper into the data to estimate a point in time where queues have successfully cleared the network from an emergency management standpoint.

Simulated downtown San Jose network may be used for many other applications as well. In addition to evacuation applications, one can examine the quality of traffic flow in 
downtown San Jose through an application such as the two-fluid model. Any proposed changes to the network, such as lane-widening or one-way streets, could be easily coded into the existing VISSIM model, and the resulting quality of traffic flow can be represented with new two-fluid model parameters. It could help assess the impact of the newly proposed improvement on the traffic flow. Given the accuracy of the model, it could be a valuable tool for the city of San Jose to assess the impact of operational changes on the entire network. 


\section{BIBLIOGRAPHY}

Algers, Stefan, Eric Bernauer, Marco Boero, Laurent Breheret, Carlo Di Taranto, KenFox and Jean Francois Gabard. "Smartest Simulation-Modeling Applied to Transport European Scheme Tests.” Institute for Transport Studies, University of Leeds, 1996.

Burton, L. Mark and Michael J. Hicks. "Hurricane Katrina: Preliminary Estimates of Commercial and Public Sector Damages." Center for Business and Economic Research September 2005, www.marshall.edu/cber/research/katrina/KatrinaEstimates.pdf (accessed 14 April 2010)

Chiu, Yi-Chang and Hong Zheng. "Real-time mobilization decisions for multi-priority emergency response resources and evacuation groups: Model formulation and solution." Transportation Research Part E 43 (2007) 710-736.

Cooper, Christopher and Robert Block. Disaster! Hurricane Katrina and the Failure of Homeland Security. New York: Henry Holt and Company, Inc., 2006.

Elmitiny, Noor, Shankar Ramasamy and Essam Radwan. "Emergency Evacuation Planning and Preparedness of Transit Facilities: Simulation Modeling." Transportation Research Board: Journal of the Transportation Research Board 1992 (2007): 121-126

Fellendorf, Martin and Peter Vortisch. "Validation of the Microscopic Traffic Flow Model VISSIM in Different Real World Situations." Transportation Research Board 2001 (2001)

Haghani, Ali, Huijun Hu and Qiang Tian. “An Optimization Model for Real-Time Emergency Vehicle Dispatching and Routing." Transportation Research Board January 2003 http://www.ltrc.lsu.edu/TRB_82/TRB2003-000710.pdf (accessed 3 April 2010)

Jones, L. Steven, Andrew J. Sullivan and Naveen Cheekoti. "Traffic Simulation Software Comparison Study." UTCA Report 02217 (2004)

Kilbert, Steven "A Microsimulation of Traffic, Parking, and Emissions at California Polytechnic State University - San Luis Obispo.” M.S.thesis, California Polytechnic State University: San Luis Obispo, 2010

Lieberman, Edward and Ajay K. Rathi. "Traffic simulation" in The Theory of Traffic Flow, Turner-Fairbank Highway Research Center, Federal Highway 
Administration, edited by Ajay K. Rathi, 10-1 to 10-25.

http://www.fhwa.dot.gov/publications/research/operations/tft/chap10.pdf

(accessed 2 September 2011)

Litman, Todd. "Lessons from Katrina and Rita: What Major Disasters Can Teach

Transportation Planners." Journal of Transportation Engineering 132 (2006): 1118

Mollaghasemi, Masooreh, and Mohamed Abdel-Aty. "Post Disaster Dynamic Routing of Emergency Vehicles." October 2003

http://catss.ucf.edu/projects/documents/abstracts/pdf/projects_41.pdf (accessed 16 December 2009)

Pal, Akhilesh, Andrew J. Graettinger and Michael H. Triche. "Emergency Evacuation Modeling based on Geographical Information System Data." (August 2002) http://www.ltrc.lsu.edu/TRB_82/TRB2003-001689.pdf (accessed 3 April 2010)

Rousseau, Guy, Wolfgang Scherr, Fang Yuan, and Cherry Xiong. "Linking Atlanta's Regional Transportation Model with Microscopic Traffic Simulation.” (2007) http://www.ptvamerica.com/fileadmin/files_ptvamerica.com/2007_NARSC_Rous seau_Scherr_et_al_Regional_Model_and_MicroSim.pdf (accessed 2 September 2011)

Schreckenberg, Michael, L. Neubert and Joachim Wahle. "Simulation of Traffic in Large Road Networks." (2001)

http://dl.acm.org/citation.cfm?id=J283\&picked=prox\&cfid=74491991\&cftoken=8 $\underline{6813099}$ (accessed 3 September 2011)

Sisiopiku, Virginia P., Steven L. Jones, Jr., Andrew J. Sullivan, Sameer S. Patharkar, Xiaohong Tang. "Regional traffic Simulation for Emergency Preparedness." UCTA Report 03226 (2004): 1-5

Tagliaferri, A. "Use and Comparison of Traffic Simulation Models in the Analysis of Emergency Evacuation Conditions." M.S.thesis, North Carolina State University, 2005 http://repository.lib.ncsu.edu/ir/handle/1840.16/1988 (accessed 3 April 2010)

Theodoulou, Gregoris. "Contraflow Evacuation on the Westbound I-10 Out of the City of New Orleans." M.S. thesis, Louisiana State University, August 2003 http://etd.lsu.edu/docs/available/etd-0609103112838/unrestricted/Theodoulou_thesis.pdf (accessed 3 April 2010) 
National Research Council (U.S.). Highway Capacity Manual, (2000) Chapter 31, Washington, D.C, Transportation Research Board

U.S. Department of Transportation: Federal Highway Administration. "5.6 Calibration Targets," (June 2002)

http://ops.fhwa.dot.gov/trafficanalysistools/tat_vol3/sect5.htm (accessed August 20, 2011) 


\section{APPENDIX A: GEH STATISTICS}

The following tables display the data used to determine the GEH statistics for the five iterations during the calibration and validation period.

GEH Statistic Initial Run Summary

\begin{tabular}{|c|c|c|c|c|c|c|c|c|c|c|c|c|c|c|c|}
\hline Roadway/Intersection & Movement Direction & Simulation & Actual & GEH statistic & Seed 1 & Seed 191 & Seed 42 & Seed 198 & Seed 2626 & Seed 500 & Seed 5430 & Seed 52 & Seed 681 & Seed 266 & Seed 8734 \\
\hline \multirow{12}{*}{ Almaden \& San Carlos } & $\mathrm{NbR}$ & 132 & 158 & 2.17 & 122 & 142 & 164 & 142 & 134 & 135 & 113 & 121 & 122 & 115 & 140 \\
\hline & $\mathrm{NbT}$ & 285 & 348 & 3.56 & 298 & 286 & 284 & 272 & 304 & 296 & 271 & 265 & 278 & 275 & 303 \\
\hline & $\mathrm{NbL}$ & 69 & 88 & 2.10 & 69 & 75 & 69 & 68 & 73 & 62 & 72 & 68 & 65 & 72 & 70 \\
\hline & EbR & 217 & 209 & 0.54 & 220 & 227 & 227 & 207 & 204 & 212 & 215 & 216 & 218 & 203 & 237 \\
\hline & $\mathrm{EbT}$ & 826 & 759 & 2.37 & 840 & 825 & 805 & 789 & 829 & 793 & 857 & 823 & 815 & 881 & 825 \\
\hline & EbL & 198 & 184 & 1.01 & 180 & 188 & 211 & 169 & 206 & 180 & 197 & 216 & 215 & 218 & 197 \\
\hline & $\mathrm{SbR}$ & 103 & 100 & 0.29 & 109 & 111 & 94 & 96 & 115 & 97 & 106 & 106 & 101 & 96 & 101 \\
\hline & $\mathrm{SbT}$ & 1009 & 1017 & 0.25 & 1042 & 1043 & 920 & 1015 & 986 & 1034 & 1053 & 986 & 1015 & 1005 & 1000 \\
\hline & $\mathrm{SbL}$ & 113 & 104 & 0.89 & 113 & 111 & 104 & 95 & 111 & 116 & 123 & 105 & 123 & 126 & 119 \\
\hline & WbL & 120 & 106 & 1.33 & 120 & 126 & 119 & 109 & 121 & 140 & 134 & 113 & 105 & 108 & 127 \\
\hline & WbT & 588 & 514 & 3.16 & 586 & 583 & 599 & 601 & 597 & 550 & 614 & 580 & 579 & 594 & 586 \\
\hline & WbR & 94 & 83 & 1.22 & 106 & 83 & 94 & 104 & 103 & 89 & 90 & 65 & 104 & 105 & 96 \\
\hline \multirow{12}{*}{ Almaden \& Park } & $\mathrm{NbR}$ & 34 & 36 & 0.37 & 31 & 35 & 30 & 29 & 40 & 25 & 41 & 34 & 35 & 37 & 35 \\
\hline & $\mathrm{NbT}$ & 223 & 237 & 0.93 & 232 & 226 & 241 & 193 & 229 & 213 & 201 & 220 & 237 & 242 & 218 \\
\hline & $\mathrm{NbL}$ & 35 & 37 & 0.36 & 29 & 21 & 29 & 33 & 42 & 37 & 32 & 44 & 39 & 38 & 39 \\
\hline & EbR & 116 & 117 & 0.13 & 131 & 117 & 101 & 103 & 125 & 110 & 116 & 128 & 114 & 116 & 110 \\
\hline & EbT & 83 & 86 & 0.37 & 69 & 79 & 84 & 89 & 75 & 95 & 87 & 79 & 88 & 83 & 81 \\
\hline & EbL & 97 & 105 & 0.79 & 85 & 98 & 111 & 94 & 84 & 85 & 91 & 107 & 109 & 105 & 99 \\
\hline & SbR & 87 & 86 & 0.10 & 99 & 85 & 97 & 91 & 70 & 83 & 85 & 94 & 82 & 81 & 89 \\
\hline & $\begin{array}{ll}\mathrm{SbT} \\
\end{array}$ & 955 & 965 & 0.33 & 983 & 987 & 856 & 957 & 920 & 976 & 1015 & 922 & 955 & 958 & 975 \\
\hline & SbL & 43 & 48 & 0.70 & 46 & 35 & 38 & 39 & 37 & 52 & 41 & 54 & 43 & 50 & 41 \\
\hline & WbL & 178 & 163 & 1.17 & 169 & 189 & 183 & 170 & 192 & 186 & 169 & 169 & 195 & 171 & 168 \\
\hline & WbT & 112 & 104 & 0.79 & 106 & 106 & 125 & 104 & 101 & 119 & 132 & 107 & 97 & 122 & 115 \\
\hline & WbR & 68 & 60 & 0.98 & 71 & 63 & 74 & 59 & 60 & 74 & 77 & 80 & 54 & 64 & 70 \\
\hline \multirow{12}{*}{ Market and Santa Clara } & $\mathrm{NbR}$ & 47 & 41 & 0.93 & 49 & 62 & 47 & 50 & 37 & 41 & 57 & 49 & 46 & 41 & 40 \\
\hline & $\mathrm{NbT}$ & 276 & 231 & 2.85 & 264 & 306 & 296 & 272 & 277 & 292 & 269 & 278 & 270 & 258 & 259 \\
\hline & $\mathrm{NbL}$ & 79 & 69 & 1.14 & 78 & 83 & 90 & 59 & 77 & 78 & 84 & 79 & 88 & 76 & 75 \\
\hline & $\mathrm{EbR}$ & 119 & 114 & 0.49 & 124 & 110 & 120 & 112 & 111 & 111 & 124 & 146 & 113 & 121 & 120 \\
\hline & EbT & 613 & 581 & 1.29 & 605 & 627 & 587 & 639 & 607 & 612 & 612 & 576 & 646 & 611 & 617 \\
\hline & EbL & 92 & 87 & 0.51 & 86 & 102 & 97 & 68 & 96 & 84 & 91 & 93 & 99 & 83 & 111 \\
\hline & SbR & 125 & 80 & 4.48 & 116 & 118 & 107 & 116 & 141 & 127 & 120 & 136 & 132 & 130 & 137 \\
\hline & $\mathrm{SbT}$ & 886 & 760 & 4.40 & 876 & 906 & 892 & 879 & 913 & 880 & 885 & 930 & 866 & 888 & 832 \\
\hline & SbL & 79 & 118 & 3.93 & 105 & 70 & 60 & 76 & 79 & 77 & 93 & 84 & 71 & 74 & 80 \\
\hline & $\mathrm{WbL}$ & 107 & 90 & 1.68 & 104 & 107 & 106 & 91 & 124 & 121 & 98 & 129 & 103 & 99 & 91 \\
\hline & WbT & 448 & 395 & 2.56 & 428 & 414 & 408 & 421 & 639 & 429 & 449 & 442 & 431 & 430 & 433 \\
\hline & WbR & 91 & 80 & 1.20 & 88 & 90 & 82 & 79 & 94 & 89 & 98 & 91 & 119 & 89 & 83 \\
\hline
\end{tabular}


GEH Statistic Iteration 1 Run Summary

\begin{tabular}{|c|c|c|c|c|c|c|c|c|c|c|c|c|c|c|c|}
\hline \multicolumn{16}{|c|}{ GEH Statistic Iteration 1 Run Summary } \\
\hline Roadway/Intersection & Movement Direction & Simulation & Actual & GEH statistic & Seed 1 & Seed 191 & Seed 42 & Seed 198 & Seed 2626 & Seed 500 & Seed 5430 & Seed 52 & Seed 681 & Seed 266 & Seed 8734 \\
\hline \multirow{12}{*}{ Almaden \& San Carlos } & $\mathrm{NbR}$ & 132 & 158 & 2.16 & 124 & 142 & 164 & 142 & 134 & 135 & 113 & 121 & 122 & 115 & 140 \\
\hline & $\mathrm{NbT}$ & 285 & 348 & 3.57 & 296 & 286 & 284 & 272 & 304 & 296 & 271 & 265 & 278 & 275 & 303 \\
\hline & $\mathrm{NbL}$ & 69 & 88 & 2.10 & 69 & 75 & 69 & 68 & 73 & 62 & 72 & 68 & 65 & 72 & 70 \\
\hline & $\mathrm{EbR}$ & 217 & 209 & 0.53 & 218 & 227 & 227 & 207 & 204 & 212 & 215 & 216 & 218 & 203 & 237 \\
\hline & EbT & 826 & 759 & 2.36 & 839 & 825 & 805 & 789 & 829 & 793 & 857 & 823 & 815 & 881 & 825 \\
\hline & EbL & 198 & 184 & 1.01 & 181 & 188 & 211 & 169 & 206 & 180 & 197 & 216 & 215 & 218 & 197 \\
\hline & SbR & 103 & 100 & 0.31 & 111 & 111 & 94 & 96 & 115 & 97 & 106 & 106 & 101 & 96 & 101 \\
\hline & SbT & 1009 & 1017 & 0.26 & 1040 & 1043 & 920 & 1015 & 986 & 1034 & 1053 & 986 & 1015 & 1005 & 1000 \\
\hline & SbL & 113 & 104 & 0.88 & 112 & 111 & 104 & 95 & 111 & 116 & 123 & 105 & 123 & 126 & 119 \\
\hline & WbL & 120 & 106 & 1.33 & 119 & 126 & 119 & 109 & 121 & 140 & 134 & 113 & 105 & 108 & 127 \\
\hline & WbT & 589 & 514 & 3.18 & 593 & 583 & 599 & 601 & 597 & 550 & 614 & 580 & 579 & 594 & 586 \\
\hline & WbR & 94 & 83 & 1.20 & 104 & 83 & 94 & 104 & 103 & 89 & 90 & 65 & 104 & 105 & 96 \\
\hline \multirow{12}{*}{ Almaden \& Park } & $\mathrm{NbR}$ & 34 & 36 & 0.37 & 31 & 35 & 30 & 29 & 40 & 25 & 41 & 34 & 35 & 37 & 35 \\
\hline & $\mathrm{NbT}$ & 223 & 237 & 0.95 & 228 & 226 & 241 & 193 & 229 & 213 & 201 & 220 & 237 & 242 & 218 \\
\hline & $\mathrm{NbL}$ & 35 & 37 & 0.36 & 29 & 21 & 29 & 33 & 42 & 37 & 32 & 44 & 39 & 38 & 39 \\
\hline & EbR & 115 & 117 & 0.14 & 130 & 117 & 101 & 103 & 125 & 110 & 116 & 128 & 114 & 116 & 110 \\
\hline & EbT & 83 & 86 & 0.35 & 71 & 79 & 84 & 89 & 75 & 95 & 87 & 79 & 88 & 83 & 81 \\
\hline & EbL & 97 & 105 & 0.80 & 84 & 98 & 111 & 94 & 84 & 85 & 91 & 107 & 109 & 105 & 99 \\
\hline & SbR & 87 & 86 & 0.10 & 99 & 85 & 97 & 91 & 70 & 83 & 85 & 94 & 82 & 81 & 89 \\
\hline & $\mathrm{SbT}$ & 955 & 965 & 0.33 & 982 & 987 & 856 & 957 & 920 & 976 & 1015 & 922 & 955 & 958 & 975 \\
\hline & SbL & 43 & 48 & 0.69 & 47 & 35 & 38 & 39 & 37 & 52 & 41 & 54 & 43 & 50 & 41 \\
\hline & WbL & 178 & 163 & 1.17 & 169 & 189 & 183 & 170 & 192 & 186 & 169 & 169 & 195 & 171 & 168 \\
\hline & WbT & 112 & 104 & 0.79 & 106 & 106 & 125 & 104 & 101 & 119 & 132 & 107 & 97 & 122 & 115 \\
\hline & WbR & 68 & 60 & 0.98 & 71 & 63 & 74 & 59 & 60 & 74 & 77 & 80 & 54 & 64 & 70 \\
\hline \multirow{12}{*}{ Market and Santa Clara } & $\mathrm{NbR}$ & 47 & 41 & 0.94 & 50 & 62 & 47 & 50 & 37 & 41 & 57 & 49 & 46 & 41 & 40 \\
\hline & $\mathrm{NbT}$ & 277 & 231 & 2.86 & 266 & 306 & 296 & 272 & 277 & 292 & 269 & 278 & 270 & 258 & 259 \\
\hline & $\mathrm{NbL}$ & 79 & 69 & 1.13 & 77 & 83 & 90 & 59 & 77 & 78 & 84 & 79 & 88 & 76 & 75 \\
\hline & EbR & 119 & 114 & 0.49 & 124 & 110 & 120 & 112 & 111 & 111 & 124 & 146 & 113 & 121 & 120 \\
\hline & EbT & 612 & 581 & 1.27 & 598 & 627 & 587 & 639 & 607 & 612 & 612 & 576 & 646 & 611 & 617 \\
\hline & EbL & 92 & 87 & 0.51 & 86 & 102 & 97 & 68 & 96 & 84 & 91 & 93 & 99 & 83 & 111 \\
\hline & SbR & 125 & 80 & 4.47 & 114 & 118 & 107 & 116 & 141 & 127 & 120 & 136 & 132 & 130 & 137 \\
\hline & SbT & 886 & 760 & 4.40 & 879 & 906 & 892 & 879 & 913 & 880 & 885 & 930 & 866 & 888 & 832 \\
\hline & SbL & 79 & 118 & 3.92 & 106 & 70 & 60 & 76 & 79 & 77 & 93 & 84 & 71 & 74 & 80 \\
\hline & WbL & 107 & 90 & 1.70 & 106 & 107 & 106 & 91 & 124 & 121 & 98 & 129 & 103 & 99 & 91 \\
\hline & WbT & 423 & 395 & 1.38 & 427 & 414 & 408 & 421 & 369 & 429 & 449 & 442 & 431 & 430 & 433 \\
\hline & WbR & 91 & 80 & 1.20 & 88 & 90 & 82 & 79 & 94 & 89 & $\begin{array}{l}98 \\
\end{array}$ & 91 & 119 & $\begin{array}{l}89 \\
\end{array}$ & 83 \\
\hline
\end{tabular}




\begin{tabular}{|c|c|c|c|c|c|c|c|c|c|c|c|c|c|c|c|}
\hline \multicolumn{16}{|c|}{ GEH Statistic Iteration 2 Summary } \\
\hline Roadway/Intersection & Movement Direction & Simulation & Actual & GEH statistic & Seed 1 & Seed 191 & Seed 42 & Seed 198 & Seed 2626 & Seed 500 & Seed 5430 & Seed 52 & Seed 681 & Seed 266 & Seed 8734 \\
\hline \multirow{12}{*}{ Almaden \& San Carlos } & $\mathrm{NbR}$ & 131 & 158 & 2.21 & 122 & 140 & 164 & 140 & 134 & 133 & 113 & 120 & 124 & 116 & 140 \\
\hline & $\mathrm{NbT}$ & 285 & 348 & 3.55 & 298 & 286 & 284 & 273 & 300 & 297 & 272 & 267 & 280 & 274 & 303 \\
\hline & $\mathrm{NbL}$ & 69 & 88 & 2.17 & 69 & 74 & 69 & 66 & 72 & 61 & 71 & 69 & 64 & 72 & 70 \\
\hline & $\mathrm{EbR}$ & 217 & 209 & 0.54 & 220 & 223 & 227 & 207 & 200 & 215 & 213 & 216 & 224 & 204 & 237 \\
\hline & EbT & 826 & 759 & 2.37 & 840 & 828 & 805 & 790 & 829 & 791 & 858 & 823 & 812 & 881 & 825 \\
\hline & EbL & 197 & 184 & 0.97 & 180 & 189 & 211 & 168 & 205 & 180 & 198 & 216 & 209 & 218 & 197 \\
\hline & SbR & 102 & 100 & 0.23 & 109 & 112 & 94 & 96 & 112 & 96 & 105 & 105 & 103 & 92 & 101 \\
\hline & $\mathrm{SbT}$ & 1009 & 1017 & 0.27 & 1042 & 1050 & 920 & 1016 & 979 & 1030 & 1057 & 978 & 1024 & 998 & 1000 \\
\hline & SbL & 113 & 104 & 0.84 & 113 & 112 & 104 & 93 & 109 & 117 & 124 & 105 & 118 & 126 & 119 \\
\hline & WbL & 120 & 106 & 1.33 & 120 & 126 & 119 & 109 & 121 & 140 & 134 & 113 & 107 & 106 & 127 \\
\hline & $\mathrm{WbT}$ & 588 & 514 & 3.16 & 586 & 584 & 599 & 599 & 597 & 548 & 616 & 585 & 578 & 591 & 586 \\
\hline & WbR & 95 & 83 & 1.24 & 106 & 85 & 94 & 103 & 103 & 89 & 91 & 66 & 105 & 104 & 96 \\
\hline \multirow{12}{*}{ Almaden \& Park } & $\mathrm{NbR}$ & 34 & 36 & 0.42 & 31 & 35 & 30 & 28 & 40 & 25 & 40 & 34 & 35 & 36 & 35 \\
\hline & $\mathrm{NbT}$ & 223 & 237 & 0.92 & 232 & 225 & 241 & 194 & 228 & 214 & 202 & 221 & 237 & 242 & 218 \\
\hline & NbL & 35 & 37 & 0.29 & 29 & 22 & 29 & 33 & 40 & 38 & 37 & 44 & 39 & 38 & 39 \\
\hline & EbR & 115 & 117 & 0.21 & 131 & 118 & 101 & 102 & 118 & 111 & 117 & 127 & 115 & 112 & 110 \\
\hline & EbT & 83 & 86 & 0.37 & 69 & 76 & 84 & 91 & 74 & 97 & 87 & 79 & 84 & 87 & 81 \\
\hline & EbL & 89 & 105 & 1.60 & 85 & 103 & 111 & 95 & 85 & 85 & 92 & 108 & 11 & 108 & 99 \\
\hline & SbR & 87 & 86 & 0.16 & 99 & 85 & 97 & 92 & 70 & 86 & 85 & 94 & 82 & 83 & 89 \\
\hline & $\begin{array}{l}\mathrm{SbT} \\
\end{array}$ & 955 & 965 & 0.34 & 983 & 996 & 856 & 955 & 917 & 972 & 1019 & 916 & 958 & 953 & 975 \\
\hline & SbL & 43 & 48 & 0.73 & 46 & 34 & 38 & 39 & 37 & 52 & 41 & 54 & 43 & 49 & 41 \\
\hline & WbL & 178 & 163 & 1.17 & 169 & 189 & 183 & 170 & 192 & 185 & 168 & 169 & 196 & 172 & 168 \\
\hline & $\mathrm{WbT}$ & 112 & 104 & 0.80 & 106 & 106 & 125 & 105 & 102 & 119 & 130 & 108 & 98 & 122 & 115 \\
\hline & WbR & 68 & 60 & 1.01 & 71 & 64 & 74 & 59 & 60 & 73 & 77 & 81 & 54 & 66 & 70 \\
\hline \multirow{12}{*}{ Market and Santa Clara } & $\mathrm{NbR}$ & 48 & 41 & 0.98 & 49 & 61 & 47 & 50 & 37 & 44 & 57 & 49 & 47 & 42 & 40 \\
\hline & $\mathrm{NbT}$ & 276 & 231 & 2.83 & 264 & 307 & 296 & 270 & 277 & 291 & 269 & 279 & 268 & 257 & 259 \\
\hline & NbL & 79 & 69 & 1.11 & 78 & 83 & 90 & 58 & 78 & 77 & 84 & 79 & 88 & 74 & 75 \\
\hline & EbR & 119 & 114 & 0.50 & 124 & 109 & 120 & 112 & 111 & 111 & 126 & 146 & 114 & 121 & 120 \\
\hline & EbT & 612 & 581 & 1.27 & 605 & 622 & 587 & 632 & 603 & 610 & 610 & 582 & 651 & 614 & 617 \\
\hline & EbL & 92 & 87 & 0.55 & 86 & 100 & 97 & 68 & 99 & 84 & 93 & 95 & 98 & 83 & 111 \\
\hline & $\mathrm{SbR}$ & 125 & 80 & 4.47 & 116 & 115 & 107 & 116 & 141 & 129 & 117 & 137 & 133 & 130 & 137 \\
\hline & $\mathrm{SbT}$ & 885 & 760 & 4.37 & 876 & 904 & 892 & 876 & 913 & 876 & 881 & 934 & 868 & 888 & 832 \\
\hline & $\mathrm{SbL}$ & 79 & 118 & 3.90 & 105 & 70 & 60 & 77 & 80 & 79 & 92 & 84 & 71 & 74 & 80 \\
\hline & $\mathrm{WbL}$ & 106 & 90 & 1.63 & 104 & 103 & 106 & 85 & 123 & 122 & 99 & 129 & 103 & 102 & 91 \\
\hline & $\mathrm{WbT}$ & 423 & 395 & $\begin{array}{l}1.39 \\
\end{array}$ & 428 & 417 & 408 & 426 & 366 & 429 & 447 & 440 & 431 & 429 & 433 \\
\hline & WbR & 92 & 80 & 1.26 & 88 & 90 & 82 & 82 & 95 & 90 & $\begin{array}{l}99 \\
\end{array}$ & 91 & 120 & 88 & 83 \\
\hline
\end{tabular}




\begin{tabular}{|c|c|c|c|c|c|c|c|c|c|c|c|c|c|c|c|}
\hline \multicolumn{16}{|c|}{ GEH Statistic Iiteration 3 Summary } \\
\hline Roadway/Intersection & Movement Direction & Simulation & Actual & GEH statistic & Seed 1 & Seed 191 & Seed 42 & Seed 198 & Seed 2626 & Seed 500 & Seed 5430 & Seed 52 & Seed 681 & Seed 266 & Seed 8734 \\
\hline \multirow{12}{*}{ Almaden \& San Carlos } & $\mathrm{NbR}$ & 131 & 158 & 2.21 & 122 & 140 & 164 & 140 & 134 & 133 & 113 & 120 & 124 & 116 & 140 \\
\hline & $\mathrm{NbT}$ & 285 & 348 & 3.55 & 298 & 286 & 284 & 273 & 300 & 297 & 272 & 267 & 280 & 274 & 303 \\
\hline & $\mathrm{NbL}$ & 69 & 88 & 2.17 & 69 & 74 & 69 & 66 & 72 & 61 & 71 & 69 & 64 & 72 & 70 \\
\hline & EbR & 217 & 209 & 0.54 & 220 & 223 & 227 & 207 & 200 & 215 & 213 & 216 & 224 & 204 & 237 \\
\hline & EbT & 826 & 759 & 2.37 & 840 & 828 & 805 & 790 & 829 & 791 & 858 & 823 & 812 & 881 & 825 \\
\hline & EbL & 197 & 184 & 0.97 & 180 & 189 & 211 & 168 & 205 & 180 & 198 & 216 & 209 & 218 & 197 \\
\hline & SbR & 102 & 100 & 0.23 & 109 & 112 & 94 & 96 & 112 & 96 & 105 & 105 & 103 & 92 & 101 \\
\hline & SbT & 1009 & 1017 & 0.27 & 1042 & 1050 & 920 & 1016 & 979 & 1030 & 1057 & 978 & 1024 & 998 & 1000 \\
\hline & SbL & 113 & 104 & 0.84 & 113 & 112 & 104 & 93 & 109 & 117 & 124 & 105 & 118 & 126 & 119 \\
\hline & WbL & 120 & 106 & 1.33 & 120 & 126 & 119 & 109 & 121 & 140 & 134 & 113 & 107 & 106 & 127 \\
\hline & WbT & 588 & 514 & 3.16 & 586 & 584 & 599 & 599 & 597 & 548 & 616 & 585 & 578 & 591 & 586 \\
\hline & WbR & 95 & 83 & 1.24 & 106 & 85 & 94 & 103 & 103 & 89 & 91 & 66 & 105 & 104 & 96 \\
\hline \multirow{12}{*}{ Almaden \& Park } & $\mathrm{NbR}$ & 34 & 36 & 0.42 & 31 & 35 & 30 & 28 & 40 & 25 & 40 & 34 & 35 & 36 & 35 \\
\hline & $\mathrm{NbT}$ & 223 & 237 & 0.92 & 232 & 225 & 241 & 194 & 228 & 214 & 202 & 221 & 237 & 242 & 218 \\
\hline & $\mathrm{NbL}$ & 35 & 37 & 0.29 & 29 & 22 & 29 & 33 & 40 & 38 & 37 & 44 & 39 & 38 & 39 \\
\hline & EbR & 115 & 117 & 0.21 & 131 & 118 & 101 & 102 & 118 & 111 & 117 & 127 & 115 & 112 & 110 \\
\hline & $\mathrm{EbT}$ & 83 & 86 & 0.37 & 69 & 76 & 84 & 91 & 74 & 97 & 87 & 79 & 84 & 87 & 81 \\
\hline & $\mathrm{EbL}$ & 98 & 105 & 0.66 & 85 & 103 & 111 & 95 & 85 & 85 & 92 & 108 & 111 & 108 & 99 \\
\hline & $\mathrm{SbR}$ & 87 & 86 & 0.16 & 99 & 85 & 97 & 92 & 70 & 86 & 85 & 94 & 82 & 83 & 89 \\
\hline & $\mathrm{SbT}$ & 955 & 965 & 0.34 & 983 & 996 & 856 & 955 & 917 & 972 & 1019 & 916 & 958 & 953 & 975 \\
\hline & SbL & 43 & 48 & 0.73 & 46 & 34 & 38 & 39 & 37 & 52 & 41 & 54 & 43 & 49 & 41 \\
\hline & WbL & 178 & 163 & 1.17 & 169 & 189 & 183 & 170 & 192 & 185 & 168 & 169 & 196 & 172 & 168 \\
\hline & WbT & 112 & 104 & 0.80 & 106 & 106 & 125 & 105 & 102 & 119 & 130 & 108 & 98 & 122 & 115 \\
\hline & WbR & 68 & 60 & 1.01 & 71 & 64 & 74 & 59 & 60 & 73 & 77 & 81 & 54 & 66 & 70 \\
\hline \multirow{12}{*}{ Market and Santa Clara } & $\mathrm{NbR}$ & 48 & 41 & 0.98 & 49 & 61 & 47 & 50 & 37 & 44 & 57 & 49 & 47 & 42 & 40 \\
\hline & $\mathrm{NbT}$ & 276 & 231 & 2.83 & 264 & 307 & 296 & 270 & 277 & 291 & 269 & 279 & 268 & 257 & 259 \\
\hline & $\mathrm{NbL}$ & 79 & 69 & 1.11 & 78 & 83 & 90 & 58 & 78 & 77 & 84 & 79 & 88 & 74 & 75 \\
\hline & $\mathrm{EbR}$ & 110 & 114 & 0.34 & 124 & 109 & 120 & 112 & 11 & 111 & 126 & 146 & 114 & 121 & 120 \\
\hline & $\mathrm{EbT}$ & 612 & 581 & 1.27 & 605 & 622 & 587 & 632 & 603 & 610 & 610 & 582 & 651 & 614 & 617 \\
\hline & EbL & 92 & 87 & 0.55 & 86 & 100 & 97 & 68 & 99 & 84 & 93 & 95 & 98 & 83 & 111 \\
\hline & $\mathrm{SbR}$ & 125 & 80 & 4.47 & 116 & 115 & 107 & 116 & 141 & 129 & 117 & 137 & 133 & 130 & 137 \\
\hline & $\begin{array}{l}\mathrm{SbT} \\
\end{array}$ & 885 & 760 & 4.37 & 876 & 904 & 892 & 876 & 913 & 876 & 881 & 934 & 868 & 888 & 832 \\
\hline & $\mathrm{SbL}$ & 79 & 118 & 3.90 & 105 & 70 & 60 & 77 & 80 & 79 & 92 & 84 & 71 & 74 & 80 \\
\hline & $\mathrm{WbL}$ & 106 & 90 & 1.63 & 104 & 103 & 106 & 85 & 123 & 122 & $\begin{array}{l}99 \\
\end{array}$ & 129 & 103 & 102 & 91 \\
\hline & WbT & 423 & 395 & 1.39 & 428 & 417 & 408 & 426 & 366 & 429 & 447 & 440 & 431 & 429 & 433 \\
\hline & WbR & 92 & 80 & 1.26 & 88 & 90 & 82 & 82 & 95 & 90 & $\begin{array}{l}99 \\
\end{array}$ & 91 & 120 & 88 & 83 \\
\hline
\end{tabular}


GEH Statistic Iteration 4 Summary

\begin{tabular}{|c|c|c|c|c|c|c|c|c|c|c|c|c|c|c|c|}
\hline Roadway/Intersection & Movement Direction & Simulation & Actual & GEH statistic & Seed 1 & Seed 191 & Seed 42 & Seed 198 & Seed 2626 & Seed 500 & Seed 5430 & Seed 52 & Seed 681 & Seed 266 & Seed 8734 \\
\hline \multirow{12}{*}{ Almaden \& San Carlos } & $\mathrm{NbR}$ & 132 & 158 & 2.20 & 124 & 140 & 165 & 140 & 134 & 133 & 113 & 120 & 124 & 116 & 138 \\
\hline & $\mathrm{NbT}$ & 285 & 348 & 3.55 & 296 & 286 & 286 & 273 & 300 & 297 & 272 & 267 & 280 & 274 & 302 \\
\hline & $\mathrm{NbL}$ & 69 & 88 & 2.19 & 69 & 74 & 69 & 66 & 72 & 61 & 71 & 69 & 64 & 72 & 68 \\
\hline & EbR & 217 & 209 & 0.56 & 218 & 223 & 228 & 207 & 200 & 215 & 213 & 216 & 224 & 204 & 241 \\
\hline & $\mathrm{EbT}$ & 825 & 759 & 2.36 & 839 & 828 & 803 & 790 & 829 & 791 & 858 & 823 & 812 & 881 & 825 \\
\hline & $\mathrm{EbL}$ & 197 & 184 & 0.94 & 181 & 189 & 208 & 168 & 205 & 180 & 198 & 216 & 209 & 218 & 195 \\
\hline & $\mathrm{SbR}$ & 103 & 100 & 0.25 & 111 & 112 & 96 & 96 & 112 & 96 & 105 & 105 & 103 & 92 & 100 \\
\hline & $\mathrm{SbT}$ & 1008 & 1017 & 0.28 & 1040 & 1050 & 916 & 1016 & 979 & 1030 & 1057 & 978 & 1024 & 998 & 1002 \\
\hline & $\mathrm{SbL}$ & 113 & 104 & 0.82 & 112 & 112 & 103 & 93 & 109 & 117 & 124 & 105 & 118 & 126 & 119 \\
\hline & $\mathrm{WbL}$ & 120 & 106 & 1.34 & 119 & 126 & 120 & 109 & 121 & 140 & 134 & 113 & 107 & 106 & 128 \\
\hline & WbT & 588 & 514 & 3.16 & 593 & 584 & 597 & 599 & 597 & 548 & 616 & 585 & 578 & 591 & 583 \\
\hline & WbR & 95 & 83 & 1.25 & 104 & 85 & 94 & 103 & 103 & 89 & 91 & 66 & 105 & 104 & 99 \\
\hline \multirow{12}{*}{ Almaden \& Park } & $\mathrm{NbR}$ & 33 & 36 & 0.45 & 31 & 35 & 28 & 28 & 40 & 25 & 40 & 34 & 35 & 36 & 35 \\
\hline & $\mathrm{NbT}$ & 223 & 237 & 0.93 & 228 & 225 & 243 & 194 & 228 & 214 & 202 & 221 & 237 & 242 & 218 \\
\hline & $\mathrm{NbL}$ & 35 & 37 & 0.30 & 29 & 22 & 28 & 33 & 40 & 38 & 37 & 44 & 39 & 38 & 39 \\
\hline & EbR & 114 & 117 & 0.26 & 130 & 118 & 99 & 102 & 118 & 111 & 117 & 127 & 115 & 112 & 107 \\
\hline & $\mathrm{EbT}$ & 83 & 86 & 0.37 & 71 & 76 & 80 & 91 & 74 & 97 & 87 & 79 & 84 & 87 & 83 \\
\hline & $\mathrm{EbL}$ & 98 & 105 & 0.70 & 84 & 103 & 108 & 95 & 85 & 85 & 92 & 108 & 111 & 108 & 98 \\
\hline & SbR & 87 & 86 & 0.13 & 99 & 85 & 95 & 92 & 70 & 86 & 85 & 94 & 82 & 83 & 88 \\
\hline & $\mathrm{SbT}$ & 955 & 965 & 0.34 & 982 & 996 & 854 & 955 & 917 & 972 & 1019 & 916 & 958 & 953 & 978 \\
\hline & $\mathrm{SbL}$ & 43 & 48 & 0.70 & 47 & 34 & 39 & 39 & 37 & 52 & 41 & 54 & 43 & 49 & 41 \\
\hline & $\mathrm{WbL}$ & 178 & 163 & 1.17 & 169 & 189 & 183 & 170 & 192 & 185 & 168 & 169 & 196 & 172 & 168 \\
\hline & $\mathrm{WbT}$ & 112 & 104 & 0.80 & 106 & 106 & 125 & 105 & 102 & 119 & 130 & 108 & 98 & 122 & 115 \\
\hline & WbR & 68 & 60 & 1.01 & 71 & 64 & 74 & 59 & 60 & 73 & 77 & 81 & 54 & 66 & 70 \\
\hline \multirow{12}{*}{ Market and Santa Clara } & $\mathrm{NbR}$ & 48 & 41 & 1.00 & 50 & 61 & 47 & 50 & 37 & 44 & 57 & 49 & 47 & 42 & 40 \\
\hline & $\mathrm{NbT}$ & 276 & 231 & 2.85 & 266 & 307 & 298 & 270 & 277 & 291 & 269 & 279 & 268 & 257 & 259 \\
\hline & $\mathrm{NbL}$ & 78 & 69 & 1.08 & 77 & 83 & 88 & 58 & 78 & 77 & 84 & 79 & 88 & 74 & 75 \\
\hline & $\mathrm{EbR}$ & 120 & 114 & 0.51 & 124 & 109 & 120 & 112 & 111 & 111 & 126 & 146 & 114 & 121 & 121 \\
\hline & $\mathrm{EbT}$ & 611 & 581 & 1.23 & 598 & 622 & 587 & 632 & 603 & 610 & 610 & 582 & 651 & 614 & 613 \\
\hline & $\mathrm{EbL}$ & 92 & 87 & 0.53 & 86 & 100 & 97 & 68 & 99 & 84 & 93 & 95 & 98 & 83 & 109 \\
\hline & $\mathrm{SbR}$ & 125 & 80 & 4.45 & 114 & 115 & 109 & 116 & 141 & 129 & 117 & 137 & 133 & 130 & 135 \\
\hline & $\mathrm{SbT}$ & 885 & 760 & 4.37 & 879 & 904 & 889 & 876 & 913 & 876 & 881 & 934 & 868 & 888 & 831 \\
\hline & $\mathrm{SbL}$ & 79 & 118 & 3.89 & 106 & 70 & 59 & 77 & 80 & 79 & 92 & 84 & 71 & 74 & 81 \\
\hline & $\mathrm{WbL}$ & 106 & 90 & 1.65 & 106 & 103 & 107 & 85 & 123 & 122 & 99 & 129 & 103 & 102 & 91 \\
\hline & $\mathrm{WbT}$ & 423 & 395 & 1.37 & 427 & 417 & 407 & 426 & 366 & 429 & 447 & 440 & 431 & 429 & 431 \\
\hline & $\mathrm{WbR}$ & 92 & 80 & 1.27 & 88 & 90 & 83 & 82 & 95 & 90 & 99 & 91 & 120 & 88 & 83 \\
\hline
\end{tabular}


GEH Statistic Iiteration 5 Summary

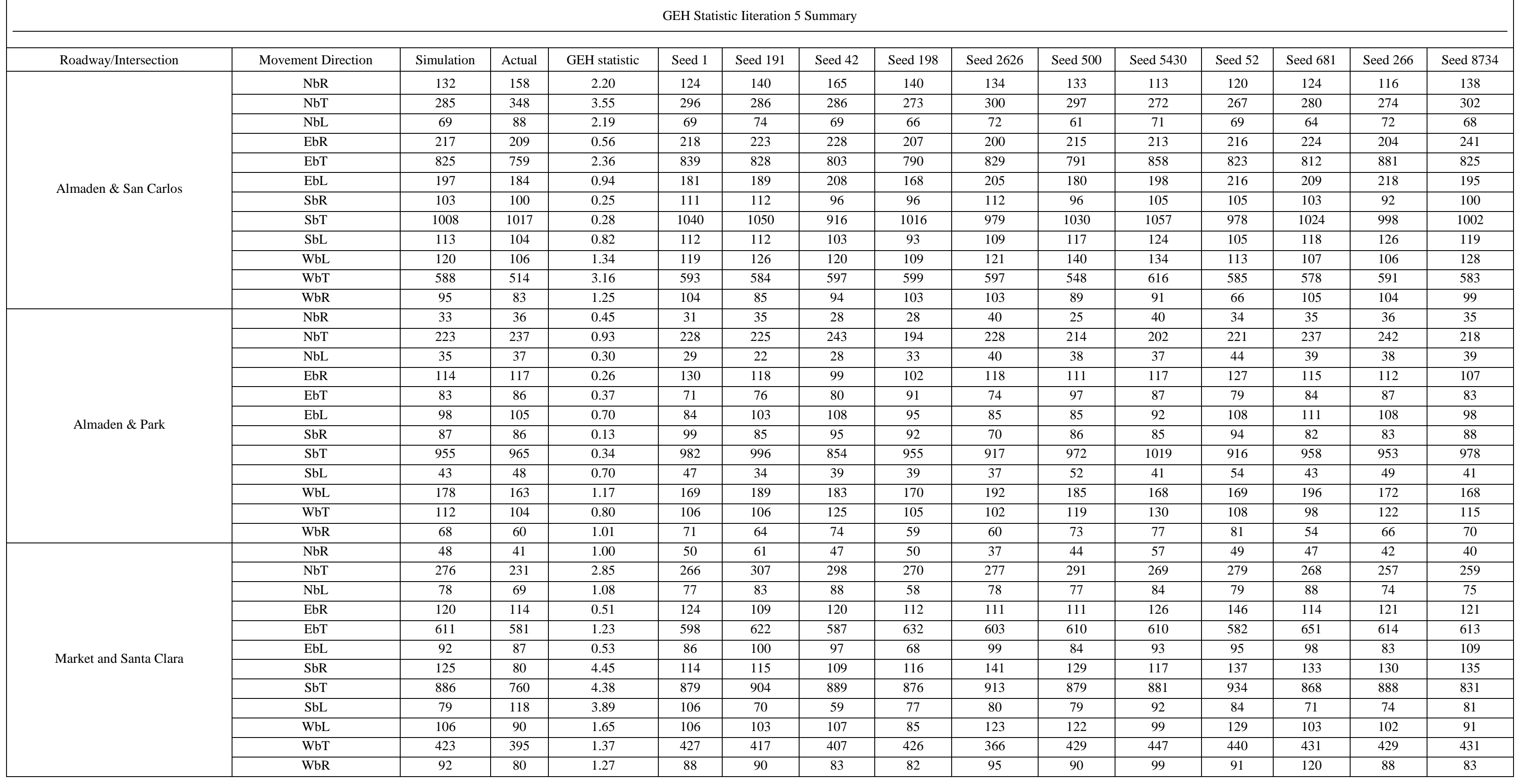


APPENDIX B: TRAVEL TIME SUMMARY FOR CALIBRATION AND VALIDATION

\begin{tabular}{|c|c|c|c|c|c|c|c|c|c|c|c|c|c|c|}
\hline \multicolumn{15}{|c|}{ Travel Time Summary (min) } \\
\hline Roadway & Actual & Percent error & Simulation Average & Seed 1 & Seed 191 & Seed 42 & Seed 198 & Seed 2626 & Seed 500 & Seed 5430 & Seed 52 & Seed 681 & Seed 266 & Seed 8734 \\
\hline $\mathrm{I}-280 \mathrm{NB}$ & 3.43 & $-3.3 \%$ & 3.3 & 3.4 & 3.2 & 3.4 & 3.3 & 3.3 & 3.2 & 3.2 & 3.3 & 3.4 & 3.5 & 3.3 \\
\hline $\mathrm{I}-280 \mathrm{SB}$ & 4.15 & $-3.2 \%$ & 4.0 & 4 & 3.9 & 4.1 & 4 & 4 & 4 & 4.1 & 4.1 & 4 & 4 & 4 \\
\hline Hwy 87 NB & 3.15 & $-2.5 \%$ & 3.1 & 3 & 3.1 & 3.1 & 3 & 3.1 & 3.1 & 3.1 & 3 & 3.1 & 3.1 & 3.1 \\
\hline Hwy $87 \mathrm{SB}$ & 3.15 & $7.1 \%$ & 3.4 & 3.4 & 3.4 & 3.4 & 3.4 & 3.4 & 3.4 & 3.4 & 3.3 & 3.3 & 3.4 & 3.3 \\
\hline \multicolumn{15}{|c|}{ Travel Time Summary for Iteration 1 (min) } \\
\hline Roadway & Actual & Percent error & Simulation Average & Seed 1 & Seed 191 & Seed 42 & Seed 198 & Seed 2626 & Seed 500 & Seed 5430 & Seed 52 & Seed 681 & Seed 266 & Seed 8734 \\
\hline $\mathrm{I}-280 \mathrm{NB}$ & 3.43 & $-3.79 \%$ & 3.3 & 3.4 & 3.2 & 3.4 & 3.3 & 3.3 & 3.2 & 3.2 & 3.3 & 3.4 & 3.3 & 3.3 \\
\hline $\mathrm{I}-280 \mathrm{SB}$ & 4.15 & $-3.18 \%$ & 4.0 & 4 & 3.9 & 4.1 & 4 & 4 & 4 & 4.1 & 4.1 & 4 & 4 & 4 \\
\hline Hwy 87 NB & 3.15 & $-1.88 \%$ & 3.1 & 3.2 & 3.1 & 3.1 & 3 & 3.1 & 3.1 & 3.1 & 3 & 3.1 & 3.1 & 3.1 \\
\hline Hwy 87 SB & 3.15 & $7.07 \%$ & 3.4 & 3.4 & 3.4 & 3.4 & 3.4 & 3.4 & 3.4 & 3.4 & 3.3 & 3.3 & 3.4 & 3.3 \\
\hline \multicolumn{15}{|c|}{ Travel Time Summary for Iteration 2 (min) } \\
\hline Roadway & Actual & Percent error & Simulation Average & Seed 1 & Seed 191 & Seed 42 & Seed 198 & Seed 2626 & Seed 500 & Seed 5430 & Seed 52 & Seed 681 & Seed 266 & Seed 8734 \\
\hline $\mathrm{I}-280 \mathrm{NB}$ & 3.43 & $-3.79 \%$ & 3.3 & 3.4 & 3.2 & 3.4 & 3.2 & 3.4 & 3.2 & 3.1 & 3.1 & 3.5 & 3.5 & 3.3 \\
\hline $\mathrm{I}-280 \mathrm{SB}$ & 4.15 & $-1.86 \%$ & 4.1 & 3.9 & 4.2 & 4.1 & 4.1 & 4 & 4.3 & 4.2 & 4.1 & 4 & 3.9 & 4 \\
\hline Hwy 87 NB & 3.15 & $-1.88 \%$ & 3.1 & 3.2 & 3 & 3.1 & 3.1 & 3.2 & 3.1 & 3 & 3 & 3.1 & 3.1 & 3.1 \\
\hline Hwy 87 SB & 3.15 & $7.07 \%$ & 3.4 & 3.4 & 3.3 & 3.4 & 3.4 & 3.4 & 3.4 & 3.4 & 3.3 & 3.4 & 3.4 & 3.3 \\
\hline \multicolumn{15}{|c|}{ Travel Time Summary for Iteration 3 (min) } \\
\hline Roadway & Actual & Percent error & Simulation Average & Seed 1 & Seed 191 & Seed 42 & Seed 198 & Seed 2626 & Seed 500 & Seed 5430 & Seed 52 & Seed 681 & Seed 266 & Seed 8734 \\
\hline $\mathrm{I}-280 \mathrm{NB}$ & 3.43 & $-3.79 \%$ & 3.3 & 3.4 & 3.2 & 3.4 & 3.2 & 3.4 & 3.2 & 3.1 & 3.1 & 3.5 & 3.5 & 3.3 \\
\hline $\mathrm{I}-280 \mathrm{SB}$ & 4.15 & $-1.42 \%$ & 4.090909091 & 4.1 & 4.2 & 4.1 & 4.1 & 4 & 4.3 & 4.2 & 4.1 & 4 & 3.9 & 4 \\
\hline Hwy $87 \mathrm{NB}$ & 3.15 & $-2.45 \%$ & 3.072727273 & 3 & 3 & 3.1 & 3.1 & 3.2 & 3.1 & 3 & 3 & 3.1 & 3.1 & 3.1 \\
\hline Hwy 87 SB & 3.15 & $7.07 \%$ & 3.372727273 & 3.4 & 3.3 & 3.4 & 3.4 & 3.4 & 3.4 & 3.4 & 3.3 & 3.4 & 3.4 & 3.3 \\
\hline \multicolumn{15}{|c|}{ Travel Time Summary for Iteration 4 (min) } \\
\hline Roadway & Actual & Percent error & Simulation Average & Seed 1 & Seed 191 & Seed 42 & Seed 198 & Seed 2626 & Seed 500 & Seed 5430 & Seed 52 & Seed 681 & Seed 266 & Seed 8734 \\
\hline $\mathrm{I}-280 \mathrm{NB}$ & 3.43 & $-4.59 \%$ & 3.3 & 3.4 & 3.2 & 3.2 & 3.2 & 3.4 & 3.2 & 3.1 & 3.1 & 3.5 & 3.5 & 3.2 \\
\hline $\mathrm{I}-280 \mathrm{SB}$ & 4.15 & $-2.08 \%$ & 4.1 & 3.9 & 4.1 & 4.1 & 4.1 & 4 & 4.3 & 4.2 & 4.1 & 4 & 3.9 & 4 \\
\hline Hwy 87 NB & 3.15 & $-1.59 \%$ & 3.1 & 3.2 & 3.1 & 3.1 & 3.1 & 3.2 & 3.1 & 3 & 3 & 3.1 & 3.1 & 3.1 \\
\hline Hwy 87 SB & 3.15 & $7.36 \%$ & 3.4 & 3.4 & 3.4 & 3.4 & 3.4 & 3.4 & 3.4 & 3.4 & 3.3 & 3.4 & 3.4 & 3.3 \\
\hline \multicolumn{15}{|c|}{ Travel Time Summary for Iteration 5 (min) } \\
\hline Roadway & Actual & Percent error & Simulation Average & Seed 1 & Seed 191 & Seed 42 & Seed 198 & Seed 2626 & Seed 500 & Seed 5430 & Seed 52 & Seed 681 & Seed 266 & Seed 8734 \\
\hline $\mathrm{I}-280 \mathrm{NB}$ & 3.43 & $-4.32 \%$ & 3.3 & 3.4 & 3.2 & 3.3 & 3.2 & 3.4 & 3.2 & 3.1 & 3.1 & 3.5 & 3.5 & 3.2 \\
\hline $\mathrm{I}-280 \mathrm{SB}$ & 4.15 & $-2.52 \%$ & 4.0 & 4 & 3.9 & 4 & 4.1 & 4 & 4.3 & 4.2 & 4.1 & 4 & 3.9 & 4 \\
\hline Hwy 87 NB & 3.15 & $-1.59 \%$ & 3.1 & 3.2 & 3.1 & 3.1 & 3.1 & 3.2 & 3.1 & 3 & 3 & 3.1 & 3.1 & 3.1 \\
\hline Hwy 87 SB & 3.15 & $7.07 \%$ & 3.4 & 3.4 & 3.4 & 3.3 & 3.4 & 3.4 & 3.4 & 3.4 & 3.3 & 3.4 & 3.4 & 3.3 \\
\hline
\end{tabular}


APPENDIX C: PEAK HOUR TRAFFIC COUNTS IN DOWNTOWN SAN JOSE

\begin{tabular}{|c|c|c|c|c|c|c|c|c|c|c|c|c|c|c|c|c|}
\hline \multirow{2}{*}{ Node } & \multirow{2}{*}{ Intersection } & \multirow{2}{*}{ Peak } & \multirow{2}{*}{$\begin{array}{l}\text { Peak } \\
\text { Hour }\end{array}$} & \multicolumn{3}{|c|}{ NB } & \multicolumn{3}{|c|}{ EB } & \multicolumn{3}{|c|}{ SB } & \multicolumn{3}{|c|}{ WB } & \multirow{2}{*}{$\begin{array}{c}\text { Count } \\
\text { Date }\end{array}$} \\
\hline & & & & $\mathrm{L}$ & $\mathrm{T}$ & $\mathrm{R}$ & $\mathrm{L}$ & $\mathrm{T}$ & $\mathrm{R}$ & $\mathrm{L}$ & $\mathrm{T}$ & $\mathrm{R}$ & $\mathrm{L}$ & $\mathrm{T}$ & $\mathrm{R}$ & \\
\hline 3013 & 87/JULIAN (E) * & $\mathrm{AM}$ & 8:00-9:00 & 76 & 414 & 56 & 100 & 511 & 0 & 391 & 603 & 0 & 0 & 473 & 137 & $9 / 17 / 2008$ \\
\hline 3013 & 87/JULIAN (E) * & PM & $4: 45-5: 45$ & 407 & 352 & 41 & 117 & 328 & 0 & 162 & 317 & 0 & 0 & 1156 & 126 & $9 / 17 / 2008$ \\
\hline 3014 & 87/JULIAN (W) & $\mathrm{AM}$ & $7: 45-8: 45$ & 0 & 0 & 0 & 0 & 398 & 21 & 338 & 158 & 129 & 74 & 655 & 327 & $9 / 17 / 2008$ \\
\hline 3014 & 87/JULIAN (W) & PM & $5: 00-6: 00$ & 0 & 0 & 0 & 0 & 837 & 25 & 172 & 87 & 75 & 165 & 376 & 1084 & $9 / 17 / 2008$ \\
\hline 3015 & 87/SANTA CLARA & $\mathrm{AM}$ & $7: 45-8: 45$ & 397 & 0 & 1266 & 0 & 522 & 0 & 0 & 0 & 0 & 0 & 560 & 0 & $9 / 17 / 2008$ \\
\hline 3015 & 87/SANTA CLARA & PM & $4: 45-5: 45$ & 243 & 0 & 495 & 0 & 635 & 0 & 0 & 0 & 0 & 0 & 589 & 0 & $9 / 17 / 2008$ \\
\hline 3032 & 280/BIRD (N) & $\mathrm{AM}$ & $7: 30-8: 30$ & 331 & 1077 & 0 & 0 & 0 & 0 & 0 & 546 & 176 & 254 & 5 & 517 & $9 / 16 / 2008$ \\
\hline 3032 & 280/BIRD (N) & PM & 5:00-6:00 & 170 & 401 & 0 & 0 & 0 & 0 & 0 & 1297 & 572 & 690 & 12 & 248 & $9 / 16 / 2008$ \\
\hline 3033 & 280/BIRD (S) & $\mathrm{AM}$ & $7: 15-8: 15$ & 0 & 1013 & 391 & 309 & 2 & 93 & 390 & 465 & 0 & 0 & 0 & 0 & $9 / 16 / 2008$ \\
\hline 3033 & 280/BIRD (S) & PM & $5: 00-6: 00$ & 0 & 373 & 233 & 210 & 14 & 409 & 586 & 1044 & 0 & 0 & 0 & 0 & $9 / 16 / 2008$ \\
\hline 3059 & ALAMEDA/RACE & $\mathrm{AM}$ & $7: 45-8: 45$ & 1 & 579 & 66 & 6 & 369 & 215 & 25 & 11 & 1 & 135 & 715 & 10 & $9 / 24 / 2008$ \\
\hline 3059 & ALAMEDA/RACE & PM & 5:00-6:00 & 11 & 304 & 107 & 0 & 730 & 508 & 10 & 7 & 0 & 183 & 488 & 0 & $9 / 24 / 2008$ \\
\hline 3061 & ALMADEN/SAN CARLOS & AM & 8:00-9:00 & 162 & 1506 & 179 & 77 & 440 & 39 & 97 & 233 & 46 & 80 & 549 & 128 & $9 / 30 / 2008$ \\
\hline 3061 & ALMADEN/SAN CARLOS & PM & $4: 45-5: 45$ & 88 & 348 & 158 & 184 & 759 & 209 & 104 & 1017 & 100 & 106 & 514 & 83 & $9 / 30 / 2008$ \\
\hline 3066 & AUTUMN/SANTA CLARA & $\mathrm{AM}$ & $7: 45-8: 45$ & 232 & 151 & 113 & 29 & 391 & 0 & 18 & 0 & 40 & 0 & 836 & 46 & $9 / 24 / 2008$ \\
\hline 3066 & AUTUMN/SANTA CLARA & PM & $5: 00-6: 00$ & 85 & 58 & 68 & 25 & 564 & 0 & 23 & 0 & 88 & 0 & 621 & 51 & $9 / 24 / 2008$ \\
\hline
\end{tabular}




\begin{tabular}{|c|c|c|c|c|c|c|c|c|c|c|c|c|c|c|c|c|}
\hline 3077 & BIRD/SAN CARLOS & $\mathrm{AM}$ & $7: 30-8: 30$ & 212 & 886 & 132 & 95 & 280 & 112 & 35 & 370 & 38 & 35 & 233 & 29 & $9 / 16 / 2008$ \\
\hline 3077 & BIRD/SAN CARLOS & PM & $4: 45-5: 45$ & 124 & 304 & 127 & 70 & 505 & 293 & 75 & 1030 & 81 & 209 & 370 & 25 & $9 / 16 / 2008$ \\
\hline 3107 & MARKET/SAN CARLOS & AM & $7: 30-8: 30$ & 353 & 1186 & 18 & 70 & 292 & 84 & 54 & 208 & 59 & 0 & 285 & 38 & $10 / 9 / 2008$ \\
\hline 3107 & MARKET/SAN CARLOS & PM & $5: 00-6: 00$ & 115 & 184 & 2 & 78 & 374 & 145 & 96 & 860 & 86 & 0 & 357 & 21 & $10 / 9 / 2008$ \\
\hline 3112 & MONTGOMERY/SANTA CLARA & AM & $7: 30-8: 30$ & 0 & 0 & 0 & 0 & 432 & 88 & 0 & 0 & 0 & 133 & 1010 & 0 & $9 / 24 / 2008$ \\
\hline 3112 & MONTGOMERY/SANTA CLARA & PM & $5: 00-6: 00$ & 0 & 0 & 0 & 0 & 612 & 249 & 0 & 0 & 0 & 188 & 716 & 0 & $9 / 24 / 2008$ \\
\hline 3209 & $87 / \mathrm{WOZ}$ & AM & $7: 30-8: 30$ & 0 & 143 & 0 & 134 & 0 & 21 & 0 & 66 & 0 & 0 & 0 & 0 & $3 / 11 / 2008$ \\
\hline 3209 & $87 / \mathrm{WOZ}$ & PM & 5:00-6:00 & 0 & 146 & 0 & 166 & 0 & 42 & 0 & 197 & 0 & 0 & 0 & 0 & $3 / 11 / 2008$ \\
\hline 3227 & ALAMEDA/JULIAN & AM & $7: 45-8: 45$ & 0 & 1157 & 77 & 0 & 0 & 0 & 122 & 478 & 0 & 48 & 0 & 158 & $5 / 17 / 2006$ \\
\hline 3227 & ALAMEDA/JULIAN & PM & $4: 45-5: 45$ & 0 & 638 & 69 & 0 & 0 & 0 & 127 & 1098 & 0 & 119 & 0 & 166 & $5 / 17 / 2006$ \\
\hline 3230 & ALAMEDA/STOCKTON & AM & $7: 45-8: 45$ & 0 & 0 & 1 & 132 & 428 & 4 & 75 & 0 & 42 & 1 & 608 & 259 & $5 / 17 / 2006$ \\
\hline 3230 & ALAMEDA/STOCKTON & PM & $4: 45-5: 45$ & 1 & 1 & 1 & 74 & 628 & 1 & 205 & 1 & 191 & 0 & 542 & 79 & $5 / 17 / 2006$ \\
\hline 3231 & ALAMEDA/SUNOL & $\mathrm{AM}$ & $7: 45-8: 45$ & 46 & 3 & 60 & 6 & 445 & 21 & 5 & 5 & 6 & 26 & 660 & 9 & $2 / 24 / 2009$ \\
\hline 3231 & ALAMEDA/SUNOL & PM & $4: 45-5: 45$ & 30 & 5 & 39 & 13 & 536 & 53 & 11 & 7 & 12 & 76 & 600 & 20 & $2 / 24 / 2009$ \\
\hline 3244 & ALMADEN/WOZ & AM & $7: 45-8: 45$ & 87 & 1642 & 80 & 14 & 30 & 30 & 43 & 129 & 22 & 18 & 53 & 95 & $3 / 11 / 2008$ \\
\hline 3244 & ALMADEN/WOZ & PM & $5: 00-6: 00$ & 50 & 264 & 73 & 26 & 90 & 227 & 137 & 1461 & 29 & 61 & 51 & 42 & $3 / 11 / 2008$ \\
\hline 3249 & ALMADEN/PARK & AM & $8: 00-9: 00$ & 215 & 974 & 45 & 340 & 72 & 60 & 27 & 122 & 85 & 12 & 46 & 28 & $2 / 12 / 2009$ \\
\hline 3249 & ALMADEN/PARK & PM & $5: 00-6: 00$ & 37 & 237 & 36 & 105 & 86 & 117 & 48 & 965 & 86 & 163 & 104 & 60 & $3 / 12 / 2009$ \\
\hline 3252 & ALMADEN/SANTA CLARA(E) & AM & $8: 00-9: 00$ & 154 & 578 & 122 & 199 & 1246 & 0 & 0 & 0 & 0 & 56 & 334 & 83 & $3 / 12 / 2008$ \\
\hline 3252 & ALMADEN/SANTA CLARA(E) & PM & $5: 00-6: 00$ & 111 & 226 & 118 & 182 & 971 & 1 & 0 & 0 & 0 & 161 & 425 & 126 & $3 / 12 / 2008$ \\
\hline
\end{tabular}




\begin{tabular}{|c|c|c|c|c|c|c|c|c|c|c|c|c|c|c|c|c|}
\hline 3263 & AUTUMN/JULIAN & $\mathrm{AM}$ & $7: 45-8: 45$ & 23 & 35 & 215 & 10 & 347 & 9 & 28 & 4 & 12 & 46 & 318 & 102 & $5 / 18 / 2006$ \\
\hline 3263 & AUTUMN/JULIAN & PM & $4: 45-5: 45$ & 20 & 12 & 85 & 10 & 447 & 13 & 82 & 14 & 19 & 96 & 395 & 49 & $5 / 18 / 2006$ \\
\hline 3266 & AUZERAIS/BIRD & $\mathrm{AM}$ & $7: 30-8: 30$ & 196 & 1155 & 117 & 20 & 40 & 155 & 47 & 430 & 29 & 63 & 38 & 12 & $2 / 19 / 2009$ \\
\hline 3266 & AUZERAIS/BIRD & PM & 5:00-6:00 & 129 & 577 & 77 & 23 & 57 & 230 & 72 & 1261 & 32 & 152 & 44 & 26 & $2 / 19 / 2009$ \\
\hline 3267 & AUZERAIS/DELMAS & $\mathrm{AM}$ & $7: 45-8: 45$ & 0 & 0 & 0 & 0 & 64 & 86 & 9 & 92 & 20 & 24 & 37 & 0 & $1 / 10 / 2007$ \\
\hline 3267 & AUZERAIS/DELMAS & PM & $5: 00-6: 00$ & 0 & 0 & 0 & 0 & 57 & 59 & 92 & 395 & 70 & 34 & 73 & 0 & $1 / 10 / 2007$ \\
\hline 3268 & AUZERAIS/LINCOLN & AM & $7: 30-8: 30$ & 90 & 604 & 27 & 13 & 31 & 49 & 15 & 153 & 21 & 25 & 59 & 24 & $2 / 25 / 2009$ \\
\hline 3268 & AUZERAIS/LINCOLN & PM & $4: 45-5: 45$ & 33 & 262 & 30 & 14 & 70 & 81 & 28 & 495 & 28 & 46 & 64 & 39 & $2 / 25 / 2009$ \\
\hline 3269 & AUZERAIS/MERIDIAN & $\mathrm{AM}$ & $7: 30-8: 30$ & 0 & 1058 & 5 & 0 & 0 & 0 & 1 & 574 & 0 & 8 & 0 & 17 & $5 / 3 / 2006$ \\
\hline 3269 & AUZERAIS/MERIDIAN & PM & $4: 30-5: 30$ & 0 & 643 & 15 & 0 & 0 & 0 & 7 & 1124 & 0 & 4 & 0 & 7 & $5 / 3 / 2006$ \\
\hline 3270 & AUZERAIS/RACE & AM & $7: 45-8: 45$ & 5 & 199 & 45 & 19 & 1 & 4 & 64 & 100 & 2 & 45 & 1 & 86 & $2 / 25 / 2009$ \\
\hline 3270 & AUZERAIS/RACE & PM & $4: 45-5: 45$ & 7 & 250 & 87 & 3 & 2 & 1 & 110 & 261 & 17 & 62 & 3 & 68 & $2 / 25 / 2009$ \\
\hline 3271 & AUZERAIS/WOZ & $\mathrm{AM}$ & $7: 45-8: 45$ & 53 & 167 & 0 & 50 & 0 & 48 & 0 & 19 & 11 & 0 & 0 & 9 & $2 / 18 / 2009$ \\
\hline 3271 & AUZERAIS/WOZ & PM & 5:00-6:00 & 102 & 202 & 0 & 23 & 0 & 130 & 0 & 79 & 30 & 8 & 1 & 7 & $2 / 18 / 2009$ \\
\hline 3304 & BIRD/VIRGINIA & $\mathrm{AM}$ & $7: 30-8: 30$ & 17 & 1071 & 40 & 39 & 16 & 5 & 231 & 261 & 18 & 42 & 7 & 289 & $2 / 24 / 2009$ \\
\hline 3304 & BIRD/VIRGINIA & PM & $5: 00-6: 00$ & 29 & 394 & 53 & 31 & 9 & 4 & 316 & 1283 & 36 & 46 & 11 & 133 & $2 / 24 / 2009$ \\
\hline 3417 & COLEMAN/TAYLOR & $\mathrm{AM}$ & $7: 30-8: 30$ & 180 & 843 & 48 & 224 & 554 & 102 & 175 & 395 & 52 & 78 & 482 & 159 & $3 / 29 / 2007$ \\
\hline 3417 & COLEMAN/TAYLOR & PM & $4: 45-5: 45$ & 167 & 516 & 63 & 113 & 274 & 70 & 245 & 801 & 114 & 162 & 519 & 145 & $2 / 21 / 2007$ \\
\hline 3445 & DELMAS/PARK & $\mathrm{AM}$ & & 43 & 235 & 341 & 0 & 323 & 27 & 80 & 129 & 41 & 18 & 50 & 0 & $4 / 29 / 2008$ \\
\hline 3445 & DELMAS/PARK & PM & & 77 & 365 & 249 & 0 & 121 & 46 & 49 & 306 & 70 & 121 & 323 & 0 & $4 / 29 / 2008$ \\
\hline
\end{tabular}




\begin{tabular}{|c|c|c|c|c|c|c|c|c|c|c|c|c|c|c|c|c|}
\hline 3446 & DELMAS/SAN CARLOS & $\mathrm{AM}$ & 8:00-9:00 & 0 & 0 & 0 & 0 & 374 & 41 & 23 & 72 & 62 & 18 & 261 & 0 & $1 / 10 / 2007$ \\
\hline 3446 & DELMAS/SAN CARLOS & PM & $4: 45-5: 45$ & 0 & 0 & 0 & 0 & 428 & 106 & 35 & 468 & 203 & 40 & 338 & 0 & $1 / 10 / 2007$ \\
\hline 3489 & FIFTH/SANTA CLARA & AM & $7: 45-8: 45$ & 0 & 0 & 0 & 55 & 396 & 0 & 15 & 0 & 17 & 0 & 589 & 114 & $4 / 8 / 2009$ \\
\hline 3489 & FIFTH/SANTA CLARA & PM & $5: 00-6: 00$ & 0 & 0 & 0 & 21 & 745 & 0 & 41 & 0 & 28 & 0 & 493 & 33 & $4 / 8 / 2009$ \\
\hline 3491 & FIRST/ST. JAMES & AM & $7: 45-8: 45$ & 0 & 485 & 20 & 44 & 456 & 0 & 0 & 0 & 0 & 0 & 0 & 0 & $3 / 8 / 2007$ \\
\hline 3491 & FIRST/ST. JAMES & PM & $4: 30-5: 30$ & 0 & 232 & 30 & 53 & 710 & 0 & 0 & 0 & 0 & 0 & 0 & 0 & $3 / 8 / 2007$ \\
\hline 3494 & FIRST/HAWTHORNE & $\mathrm{AM}$ & $8: 00-9: 00$ & 0 & 336 & 0 & 9 & 0 & 0 & 0 & 191 & 2 & 0 & 0 & 0 & $2 / 14 / 2007$ \\
\hline 3494 & FIRST/HAWTHORNE & PM & $4: 45-5: 45$ & 0 & 297 & 0 & 15 & 0 & 4 & 0 & 374 & 9 & 0 & 0 & 0 & $2 / 14 / 2007$ \\
\hline 3505 & FIRST/RANKIN & AM & $7: 45-8: 45$ & 1 & 335 & 0 & 5 & 0 & 4 & 0 & 225 & 13 & 0 & 0 & 0 & $2 / 14 / 2007$ \\
\hline 3505 & FIRST/RANKIN & PM & $5: 00-6: 00$ & 1 & 291 & 0 & 13 & 0 & 7 & 0 & 449 & 14 & 0 & 0 & 0 & $2 / 14 / 2007$ \\
\hline 3511 & FIRST/SAN FERNANDO & AM & $8: 00-9: 00$ & 21 & 167 & 34 & 23 & 211 & 0 & 0 & 0 & 0 & 0 & 179 & 57 & $2 / 15 / 2007$ \\
\hline 3511 & FIRST/SAN FERNANDO & PM & $5: 00-6: 00$ & 2 & 153 & 28 & 31 & 390 & 0 & 0 & 0 & 0 & 0 & 198 & 71 & $2 / 15 / 2007$ \\
\hline 3512 & FIRST/SAN SALVADOR & AM & $8: 00-9: 00$ & 4 & 256 & 37 & 28 & 60 & 0 & 0 & 0 & 6 & 3 & 54 & 36 & $2 / 15 / 2007$ \\
\hline 3512 & FIRST/SAN SALVADOR & PM & $4: 45-5: 45$ & 2 & 138 & 43 & 14 & 75 & 7 & 3 & 22 & 24 & 7 & 132 & 61 & $2 / 15 / 2007$ \\
\hline 3539 & FOURTH/SAN FERNANDO & AM & 8:00-9:00 & 0 & 0 & 0 & 0 & 374 & 109 & 68 & 412 & 62 & 132 & 125 & 0 & $3 / 8 / 2007$ \\
\hline 3539 & FOURTH/SAN FERNANDO & PM & $5: 00-6: 00$ & 0 & 0 & 0 & 0 & 311 & 144 & 70 & 1064 & 96 & 258 & 244 & 0 & $3 / 8 / 2007$ \\
\hline 3541 & FOURTH/SANTA CLARA & AM & $8: 00-9: 00$ & 0 & 0 & 0 & 0 & 407 & 142 & 56 & 303 & 79 & 116 & 461 & 0 & $4 / 8 / 2009$ \\
\hline 3541 & FOURTH/SANTA CLARA & PM & 5:00-6:00 & 0 & 0 & 0 & 0 & 625 & 252 & 125 & 800 & 56 & 130 & 378 & 0 & $4 / 8 / 2009$ \\
\hline 3543 & FOURTH/ST. JOHN & AM & $7: 45-8: 45$ & 0 & 0 & 0 & 0 & 69 & 159 & 13 & 361 & 59 & 44 & 155 & 0 & $3 / 7 / 2007$ \\
\hline 3543 & FOURTH/ST. JOHN & PM & $5: 00-6: 00$ & 0 & 0 & 0 & 0 & 135 & 133 & 24 & 1013 & 82 & 57 & 147 & 0 & $3 / 7 / 2007$ \\
\hline
\end{tabular}




\begin{tabular}{|c|c|c|c|c|c|c|c|c|c|c|c|c|c|c|c|c|}
\hline 3571 & HANCHETT/PARK & AM & $7: 30-8: 30$ & 43 & 869 & 3 & 91 & 18 & 36 & 9 & 434 & 25 & 13 & 15 & 7 & $9 / 20 / 2005$ \\
\hline 3571 & HANCHETT/PARK & PM & $5: 00-6: 00$ & 49 & 374 & 5 & 36 & 18 & 58 & 13 & 826 & 75 & 10 & 23 & 10 & $9 / 20 / 2005$ \\
\hline 3605 & JULIAN/MARKET & AM & $7: 30-8: 30$ & 45 & 843 & 0 & 0 & 0 & 0 & 0 & 393 & 88 & 124 & 455 & 258 & $3 / 11 / 2008$ \\
\hline 3605 & JULIAN/MARKET & PM & $5: 00-6: 00$ & 110 & 473 & 0 & 0 & 0 & 0 & 0 & 882 & 386 & 323 & 462 & 139 & $3 / 11 / 2008$ \\
\hline 3606 & JULIAN/MONTGOMERY & AM & $7: 45-8: 45$ & 9 & 4 & 7 & 14 & 296 & 8 & 19 & 5 & 8 & 12 & 308 & 44 & $3 / 6 / 2008$ \\
\hline 3606 & JULIAN/MONTGOMERY & PM & $4: 45-5: 45$ & 10 & 6 & 25 & 13 & 395 & 5 & 48 & 3 & 25 & 16 & 302 & 22 & $3 / 6 / 2008$ \\
\hline 3608 & JULIAN/STOCKTON & AM & $7: 45-8: 45$ & 11 & 310 & 60 & 24 & 193 & 23 & 140 & 121 & 13 & 32 & 146 & 175 & $5 / 18 / 2006$ \\
\hline 3608 & JULIAN/STOCKTON & PM & $4: 45-5: 45$ & 26 & 147 & 63 & 16 & 169 & 19 & 204 & 315 & 48 & 111 & 185 & 101 & $5 / 18 / 2006$ \\
\hline 3653 & LINCOLN/SAN CARLOS & $\mathrm{AM}$ & $7: 30-8: 30$ & 389 & 214 & 107 & 14 & 352 & 99 & 19 & 64 & 20 & 31 & 332 & 17 & $2 / 24 / 2009$ \\
\hline 3653 & LINCOLN/SAN CARLOS & PM & $4: 45-5: 45$ & 89 & 68 & 76 & 24 & 590 & 230 & 11 & 213 & 36 & 82 & 490 & 20 & $2 / 24 / 2009$ \\
\hline 3667 & MARKET/SAN FERNANDO & AM & $7: 45-8: 45$ & 86 & 953 & 56 & 29 & 159 & 33 & 59 & 184 & 29 & 37 & 149 & 36 & $4 / 19 / 2007$ \\
\hline 3667 & MARKET/SAN FERNANDO & PM & $5: 00-6: 00$ & 43 & 230 & 76 & 18 & 239 & 140 & 127 & 940 & 44 & 71 & 164 & 57 & $3 / 28 / 2007$ \\
\hline 3668 & MARKET/PARK & AM & $7: 30-8: 30$ & 0 & 1083 & 0 & 0 & 0 & 88 & 0 & 265 & 117 & 0 & 0 & 0 & $2 / 21 / 2007$ \\
\hline 3668 & MARKET/PARK & PM & $5: 00-6: 00$ & 0 & 471 & 0 & 0 & 0 & 161 & 0 & 1220 & 133 & 0 & 0 & 0 & $4 / 19 / 2007$ \\
\hline 3669 & MARKET/SAN SALVADOR & AM & $7: 15-8: 15$ & 39 & 1222 & 37 & 50 & 0 & 8 & 66 & 326 & 82 & 19 & 17 & 54 & $3 / 7 / 2007$ \\
\hline 3669 & MARKET/SAN SALVADOR & PM & $4: 45-5: 45$ & 1 & 234 & 34 & 20 & 8 & 20 & 47 & 1172 & 37 & 73 & 10 & 68 & $4 / 17 / 2007$ \\
\hline 3670 & MARKET/SANTA CLARA & AM & $7: 45-8: 45$ & 87 & 517 & 30 & 75 & 550 & 189 & 54 & 266 & 58 & 67 & 326 & 100 & $4 / 2 / 2009$ \\
\hline 3670 & MARKET/SANTA CLARA & PM & $5: 00-6: 00$ & 69 & 231 & 41 & 87 & 581 & 114 & 118 & 760 & 80 & 80 & 395 & 90 & $4 / 2 / 2009$ \\
\hline 3689 & MERIDIAN/PARK & $\mathrm{AM}$ & $7: 15-8: 15$ & 789 & 0 & 89 & 0 & 249 & 293 & 0 & 0 & 0 & 142 & 360 & 0 & $3 / 7 / 2007$ \\
\hline 3689 & MERIDIAN/PARK & PM & 5:00-6:00 & 378 & 0 & 138 & 0 & 414 & 480 & 0 & 0 & 0 & 169 & 239 & 0 & $3 / 7 / 2007$ \\
\hline
\end{tabular}




\begin{tabular}{|c|c|c|c|c|c|c|c|c|c|c|c|c|c|c|c|c|}
\hline 3693 & MERIDIAN/SAN CARLOS & $\mathrm{AM}$ & $7: 45-8: 45$ & 336 & 668 & 194 & 94 & 464 & 116 & 86 & 227 & 34 & 169 & 549 & 123 & $3 / 7 / 2007$ \\
\hline 3693 & MERIDIAN/SAN CARLOS & PM & $5: 00-6: 00$ & 99 & 375 & 255 & 125 & 1085 & 284 & 229 & 470 & 59 & 307 & 724 & 54 & $3 / 7 / 2007$ \\
\hline 3709 & MONTGOMERY/PARK & AM & & 251 & 707 & 160 & 29 & 107 & 207 & 17 & 227 & 36 & 32 & 85 & 10 & $4 / 29 / 2008$ \\
\hline 3709 & MONTGOMERY/PARK & PM & & 121 & 208 & 52 & 14 & 107 & 192 & 15 & 736 & 43 & 208 & 138 & 18 & $4 / 29 / 2008$ \\
\hline 3730 & PARK/SUNOL & $\mathrm{AM}$ & & 14 & 44 & 9 & 30 & 283 & 8 & 48 & 42 & 19 & 9 & 286 & 43 & $4 / 29 / 2008$ \\
\hline 3730 & PARK/SUNOL & PM & & 18 & 50 & 18 & 22 & 239 & 25 & 59 & 124 & 34 & 11 & 251 & 31 & $4 / 29 / 2008$ \\
\hline 3731 & PARK/WOZ & AM & & 14 & 111 & 55 & 97 & 567 & 78 & 0 & 0 & 0 & 23 & 47 & 68 & $4 / 29 / 2008$ \\
\hline 3731 & PARK/WOZ & PM & & 20 & 145 & 53 & 91 & 289 & 19 & 0 & 0 & 0 & 109 & 402 & 167 & $4 / 29 / 2008$ \\
\hline 3732 & PARK/RACE & AM & $7: 30-8: 30$ & 35 & 479 & 13 & 105 & 248 & 18 & 32 & 209 & 25 & 24 & 309 & 126 & $2 / 25 / 2009$ \\
\hline 3732 & PARK/RACE & PM & 5:00-6:00 & 28 & 271 & 44 & 97 & 343 & 33 & 102 & 503 & 67 & 44 & 233 & 51 & $2 / 25 / 2009$ \\
\hline 3748 & RACE/SAN CARLOS & AM & $7: 30-8: 30$ & 77 & 218 & 29 & 168 & 423 & 62 & 54 & 119 & 135 & 20 & 589 & 195 & $2 / 24 / 2009$ \\
\hline 3748 & RACE/SAN CARLOS & PM & $5: 00-6: 00$ & 100 & 126 & 44 & 191 & 826 & 84 & 113 & 206 & 253 & 77 & 554 & 64 & $2 / 24 / 2009$ \\
\hline 3763 & SAN CARLOS/WOZ & AM & 8:00-9:00 & 29 & 104 & 94 & 132 & 289 & 6 & 36 & 19 & 14 & 14 & 207 & 79 & $2 / 12 / 2009$ \\
\hline 3763 & SAN CARLOS/WOZ & PM & $5: 00-6: 00$ & 48 & 57 & 90 & 60 & 399 & 6 & 25 & 51 & 83 & 38 & 353 & 56 & $3 / 12 / 2009$ \\
\hline 3775 & SAN PEDRO/SANTA CLARA & AM & $7: 30-8: 30$ & 6 & 42 & 11 & 58 & 697 & 85 & 6 & 36 & 13 & 21 & 560 & 39 & $3 / 6 / 2007$ \\
\hline 3775 & SAN PEDRO/SANTA CLARA & PM & 5:00-6:00 & 35 & 51 & 31 & 66 & 748 & 42 & 19 & 70 & 57 & 16 & 553 & 30 & $4 / 17 / 2007$ \\
\hline 3782 & SANTA CLARA/SECOND & AM & $7: 45-8: 45$ & 0 & 0 & 0 & 0 & 433 & 86 & 15 & 110 & 29 & 64 & 573 & 0 & $3 / 7 / 2007$ \\
\hline 3782 & SANTA CLARA/SECOND & PM & $5: 00-6: 00$ & 0 & 0 & 0 & 0 & 700 & 174 & 45 & 298 & 49 & 103 & 514 & 0 & $3 / 7 / 2007$ \\
\hline 3794 & SECOND/ST. JAMES & AM & $7: 45-8: 45$ & 0 & 0 & 0 & 10 & 267 & 20 & 36 & 121 & 0 & 0 & 0 & 0 & $3 / 6 / 2007$ \\
\hline 3794 & SECOND/ST. JAMES & PM & 5:00-6:00 & 0 & 0 & 0 & 6 & 486 & 25 & 111 & 282 & 0 & 0 & 0 & 0 & $3 / 6 / 2007$ \\
\hline
\end{tabular}




\begin{tabular}{|c|c|c|c|c|c|c|c|c|c|c|c|c|c|c|c|c|}
\hline 3817 & STOCKTON/TAYLOR & $\mathrm{AM}$ & $7: 30-8: 30$ & 54 & 41 & 272 & 7 & 469 & 24 & 71 & 13 & 14 & 145 & 415 & 140 & $3 / 10 / 2009$ \\
\hline 3817 & STOCKTON/TAYLOR & PM & $4: 45-5: 45$ & 76 & 15 & 248 & 9 & 582 & 68 & 71 & 27 & 8 & 333 & 640 & 54 & $3 / 10 / 2009$ \\
\hline 3906 & SAN CARLOS/SUNOL & $\mathrm{AM}$ & & 34 & 24 & 24 & 62 & 248 & 48 & 5 & 21 & 6 & 49 & 251 & 66 & $4 / 30 / 2008$ \\
\hline 3906 & SAN CARLOS/SUNOL & PM & & 68 & 31 & 80 & 90 & 375 & 79 & 9 & 16 & 9 & 82 & 381 & 112 & $4 / 30 / 2008$ \\
\hline 3960 & RACE/SADDLE RACK & AM & $7: 30-8: 30$ & 22 & 268 & 0 & 122 & 0 & 13 & 0 & 78 & 86 & 0 & 0 & 0 & $5 / 4 / 2006$ \\
\hline 3960 & RACE/SADDLE RACK & PM & $4: 45-5: 45$ & 48 & 216 & 0 & 137 & 0 & 13 & 0 & 247 & 139 & 0 & 0 & 0 & $5 / 4 / 2006$ \\
\hline 3969 & AUZERAIS/SUNOL & AM & $7: 30-8: 30$ & 9 & 9 & 21 & 5 & 69 & 6 & 13 & 22 & 7 & 33 & 98 & 21 & $2 / 19 / 2009$ \\
\hline 3969 & AUZERAIS/SUNOL & PM & $4: 00-5: 00$ & 3 & 7 & 46 & 2 & 166 & 5 & 14 & 19 & 21 & 15 & 101 & 16 & $2 / 19 / 2009$ \\
\hline 4038 & GUADALUPE/TAYLOR & $\mathrm{AM}$ & $7: 30-8: 30$ & 500 & 0 & 1281 & 94 & 344 & 290 & 140 & 0 & 49 & 621 & 337 & 90 & $3 / 16 / 2005$ \\
\hline 4038 & GUADALUPE/TAYLOR & PM & 4:00-5:00 & 371 & 0 & 994 & 27 & 393 & 410 & 138 & 0 & 93 & 1098 & 357 & 121 & $3 / 16 / 2005$ \\
\hline 4042 & COLEMAN/GUADALUPE PARKWAY & AM & $7: 30-8: 30$ & 0 & 0 & 0 & 26 & 440 & 0 & 28 & 0 & 9 & 0 & 942 & 163 & $3 / 29 / 2007$ \\
\hline 4042 & COLEMAN/GUADALUPE PARKWAY & PM & $5: 00-6: 00$ & 0 & 0 & 0 & 22 & 1052 & 0 & 111 & 0 & 21 & 0 & 457 & 54 & $3 / 29 / 2007$ \\
\hline 4070 & COLEMAN/SANTA TERESA & AM & $7: 45-8: 45$ & 64 & 0 & 24 & 0 & 459 & 16 & 0 & 0 & 0 & 19 & 922 & 0 & $3 / 29 / 2007$ \\
\hline 4070 & COLEMAN/SANTA TERESA & PM & $5: 00-6: 00$ & 44 & 0 & 50 & 0 & 1007 & 108 & 0 & 0 & 0 & 31 & 446 & 0 & $3 / 29 / 2007$ \\
\hline 4071 & AUTUMN/COLEMAN & AM & $7: 45-8: 45$ & 12 & 0 & 24 & 0 & 458 & 17 & 0 & 0 & 1 & 32 & 957 & 1 & $3 / 29 / 2007$ \\
\hline 4071 & AUTUMN/COLEMAN & PM & $5: 00-6: 00$ & 18 & 0 & 49 & 0 & 1055 & 32 & 0 & 0 & 0 & 75 & 418 & 1 & $3 / 29 / 2007$ \\
\hline 4072 & COLEMAN/SAN JOES MARKET & AM & $7: 45-8: 45$ & 85 & 0 & 4 & 125 & 482 & 48 & 0 & 0 & 1 & 26 & 952 & 1 & $3 / 29 / 2007$ \\
\hline 4072 & COLEMAN/SAN JOES MARKET & PM & $5: 00-6: 00$ & 279 & 0 & 58 & 54 & 1017 & 227 & 0 & 0 & 1 & 78 & 355 & 0 & $3 / 29 / 2007$ \\
\hline
\end{tabular}




\section{APPENDIX D: TURNING MOVEMENTS FOR THE BASE}

\section{CASE SCENARIO}

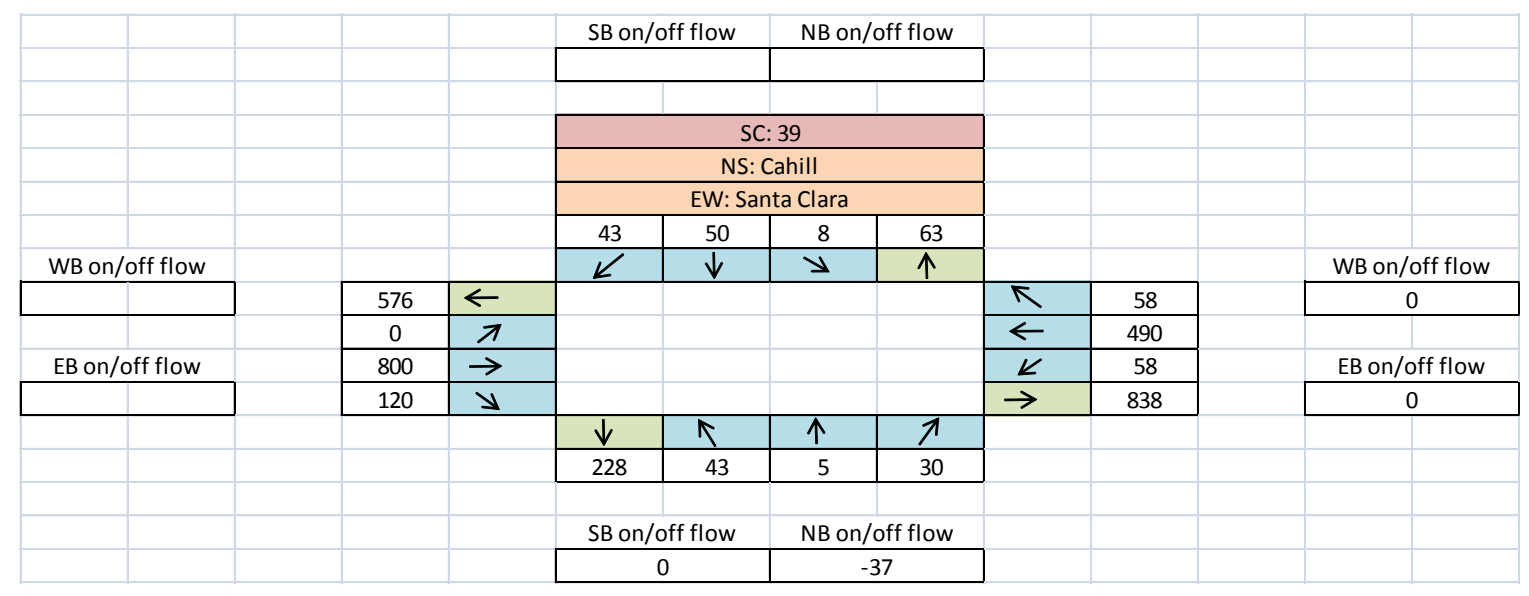

Intersection: Cahill and Santa Clara

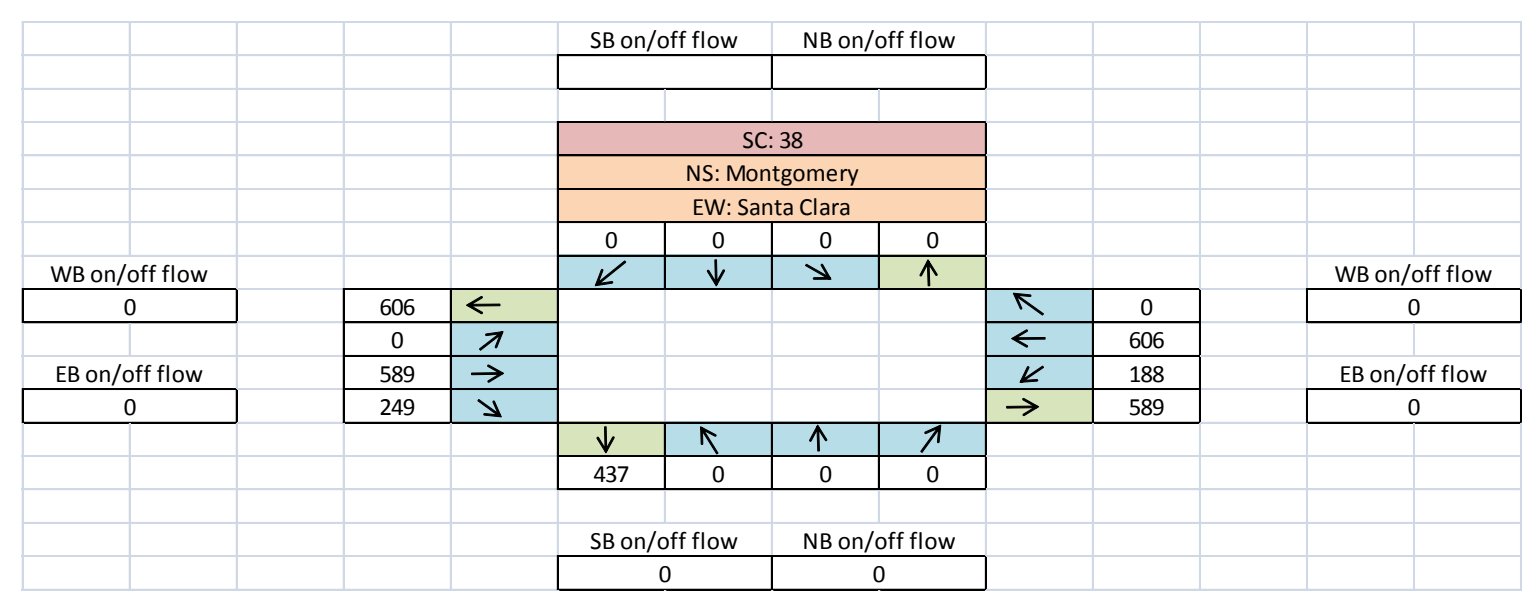

Intersection: Montgomery and Santa Clara 


\begin{tabular}{|c|c|c|c|c|c|c|c|}
\hline & & & SB on/off flow & NB on/off flow & & & \\
\hline & & & 0 & 0 & & & \\
\hline & & & \multicolumn{2}{|c|}{ SC: 14} & & & \\
\hline & & & \multicolumn{2}{|c|}{ NS: Montgomery } & & & \\
\hline & & & \multicolumn{2}{|c|}{ EW: San Fernando } & & & \\
\hline & & & 650 & 72 & & & \\
\hline WB on/off flow & & 0 & $K$ & $y$ & & & WB on/off flow \\
\hline 0 & 115 & $\leftarrow$ & & & $\mathbb{K}$ & 0 & 0 \\
\hline & 0 & $\pi$ & & & $\leftarrow$ & 100 & \\
\hline EB on/off flow & 300 & $\rightarrow$ & & & $K$ & 50 & EB on/off flow \\
\hline 0 & 150 & $y$ & & & $\rightarrow$ & 372 & 0 \\
\hline & & & $\uparrow$ & $\pi$ & & & \\
\hline & & & 850 & 0 & & & \\
\hline & & & & & & & \\
\hline & & & SB on/off flow & NB on/off flow & & & \\
\hline & & & 0 & 0 & & & \\
\hline
\end{tabular}

Intersection: Montgomery and San Fernando

\begin{tabular}{|c|c|c|c|c|c|c|c|c|}
\hline & & \multicolumn{2}{|c|}{ SB on/off flow } & \multicolumn{2}{|c|}{ NB on/off flow } & & & \\
\hline & & \multicolumn{2}{|c|}{0} & \multicolumn{2}{|c|}{0} & & & \\
\hline & & \multicolumn{4}{|c|}{ SC: 9} & & & \\
\hline & & \multicolumn{4}{|c|}{ NS: Montgomery } & & & \\
\hline & & \multicolumn{4}{|c|}{ EW: Park } & & & \\
\hline & & 43 & 736 & 15 & 240 & & & \\
\hline & & $K$ & $\downarrow$ & 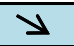 & $\uparrow$ & & & WB on/off flow \\
\hline 302 & $\leftarrow$ & & & & & $\sqrt{1}$ & 18 & 0 \\
\hline 14 & $\pi$ & & & & & $\leftarrow$ & 138 & \\
\hline 107 & $\rightarrow$ & & & & & $K$ & 208 & EB on/off flow \\
\hline \multirow[t]{6}{*}{192} & $y$ & & & & & $\rightarrow$ & 174 & 0 \\
\hline & & $\downarrow$ & $\uparrow$ & $\uparrow$ & $\pi$ & & & \\
\hline & & 1136 & 121 & 208 & 52 & & & \\
\hline & & & & & & & & \\
\hline & & \multicolumn{2}{|c|}{ SB on/off flow } & \multicolumn{2}{|c|}{ NB on/off flow } & & & \\
\hline & & 0 & & 0 & & & & \\
\hline
\end{tabular}

Intersection: Montgomery and Park 


\begin{tabular}{|c|c|c|c|c|c|c|c|c|c|}
\hline & & & & & & & & & \\
\hline & & & \multicolumn{2}{|c|}{ SB on/off flow } & \multicolumn{2}{|c|}{ NB on/off flow } & & & \\
\hline & & & \multicolumn{2}{|c|}{0} & \multicolumn{2}{|c|}{0} & & & \\
\hline & & & & & & & & & \\
\hline & & & \multicolumn{4}{|c|}{ SC: 1} & & & \\
\hline & & & \multicolumn{4}{|c|}{ NS: Bird } & & & \\
\hline & & & \multicolumn{4}{|c|}{ EW: San Carlos } & & & \\
\hline & & & 81 & 1030 & 75 & 399 & & & \\
\hline \multirow[t]{3}{*}{ WB on/off flow } & & & $K$ & $\downarrow$ & $Y$ & $\uparrow$ & & & WB on/off flow \\
\hline & 575 & $\leftarrow$ & & & & & $\pi$ & 25 & 0 \\
\hline & 70 & $\pi$ & & & & & $\leftarrow$ & 370 & \\
\hline \multirow[t]{7}{*}{ EB on/off flow } & 505 & $\rightarrow$ & & & & & $K$ & 209 & EB on/off flow \\
\hline & 261 & 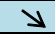 & & & & & $\rightarrow$ & 707 & 0 \\
\hline & & & $\downarrow$ & $\uparrow$ & $\uparrow$ & $\pi$ & & & \\
\hline & & & 1500 & 124 & 304 & 127 & & & \\
\hline & & & & & & & & & \\
\hline & & & \multicolumn{2}{|c|}{ SB on/off flow } & \multicolumn{2}{|c|}{ NB on/off flow } & & & \\
\hline & & & \multicolumn{2}{|c|}{0} & \multicolumn{2}{|c|}{0} & & & \\
\hline
\end{tabular}

Intersection: Bird and San Carlos

\begin{tabular}{|c|c|c|c|c|c|c|c|c|c|}
\hline & & & \multicolumn{2}{|c|}{ SB on/off flow } & \multicolumn{2}{|c|}{ NB on/off flow } & & & \\
\hline & & & \multicolumn{2}{|c|}{0} & \multicolumn{2}{|c|}{0} & & & \\
\hline & & & \multicolumn{4}{|c|}{ SC: 66} & & & \\
\hline & & & \multicolumn{4}{|c|}{ NS: Bird } & & & \\
\hline & & & \multicolumn{4}{|c|}{ EW: 280 WB } & & & \\
\hline & & & 572 & 928 & 0 & 649 & & & \\
\hline \multirow[t]{3}{*}{ WB on/off flow } & & & $\swarrow$ & $\downarrow$ & $y$ & $\uparrow$ & & & WB on/off flow \\
\hline & 768 & $\leftarrow$ & & & & & $\pi$ & 248 & \\
\hline & 0 & $\pi$ & & & & & $\leftarrow$ & 0 & \\
\hline \multirow[t]{2}{*}{ EB on/off flow } & 0 & $\rightarrow$ & & & & & $K$ & 702 & EB on/off flow \\
\hline & 0 & $y$ & & & & & $\rightarrow$ & 0 & \\
\hline & & & $\downarrow$ & $\uparrow$ & $\uparrow$ & $\pi$ & & & \\
\hline & & & 1630 & 196 & 401 & 0 & & & \\
\hline & & & & & & & & & \\
\hline & & & \multicolumn{2}{|c|}{ SB on/off flow } & \multicolumn{2}{|c|}{ NB on/off flow } & & & \\
\hline & & & \multicolumn{2}{|c|}{0} & \multicolumn{2}{|c|}{0} & & & \\
\hline
\end{tabular}

Intersection: Bird and I-280 WB

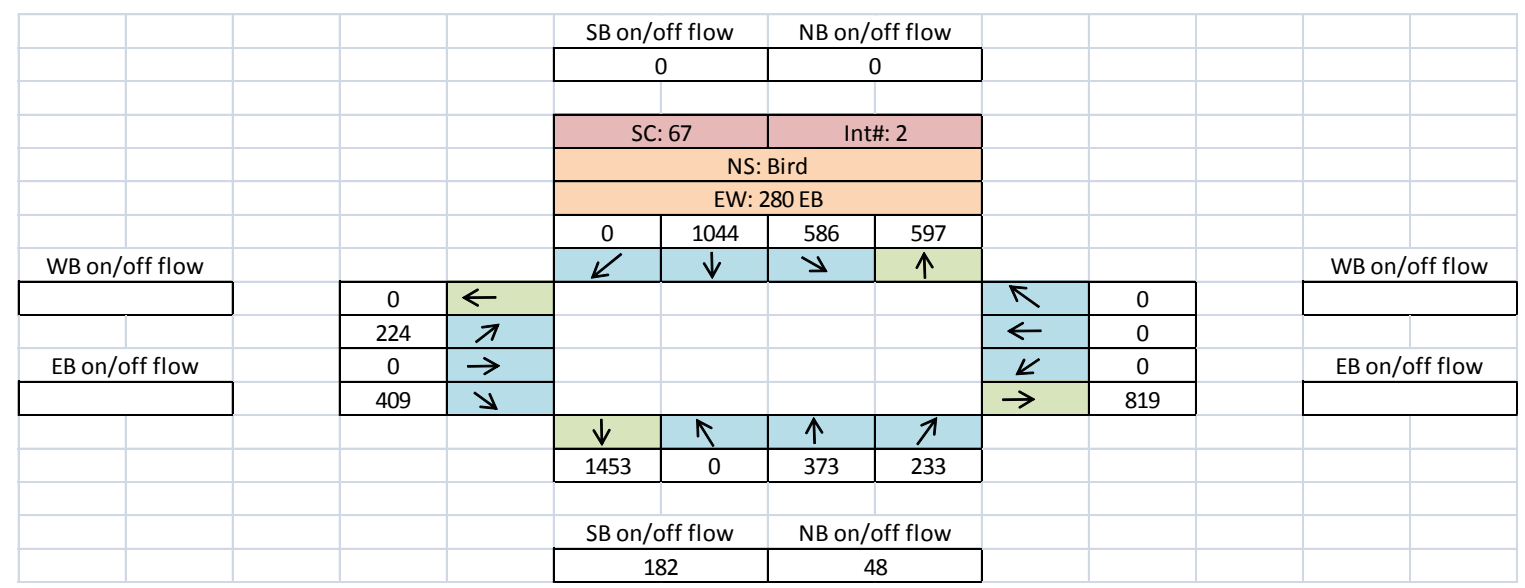

Intersection: Bird and I-280 EB 


\begin{tabular}{|c|c|c|c|c|c|c|c|c|c|}
\hline & & & \multicolumn{2}{|c|}{ SB on/off flow } & \multicolumn{2}{|c|}{ NB on/off flow } & & & \\
\hline & & & \multicolumn{2}{|c|}{0} & \multicolumn{2}{|c|}{0} & & & \\
\hline & & & & & & & & & \\
\hline & & & \multicolumn{2}{|c|}{ SC: N/A } & \multicolumn{2}{|c|}{ Int\#: 1} & & & \\
\hline & & & \multicolumn{4}{|c|}{ NS: Bird } & & & \\
\hline & & & \multicolumn{4}{|c|}{ EW: Virginia } & & & \\
\hline & & & 36 & 1283 & 316 & 558 & & & \\
\hline \multirow[t]{3}{*}{ WB on/off flow } & & & $K$ & $\downarrow$ & $y$ & $\uparrow$ & & & WB on/off flow \\
\hline & 76 & $\leftarrow$ & & & & & $\pi$ & 133 & \\
\hline & 31 & $\pi$ & & & & & $\leftarrow$ & 11 & \\
\hline \multirow[t]{4}{*}{ EB on/off flow } & 9 & $\rightarrow$ & & & & & $K$ & 46 & EB on/off flow \\
\hline & 4 & 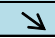 & & & & & $\rightarrow$ & 378 & \\
\hline & & & $\downarrow$ & $\uparrow$ & $\uparrow$ & $\pi$ & & & \\
\hline & & & 1333 & 29 & 394 & 53 & & & \\
\hline
\end{tabular}

\section{Intersection: Bird and Virginia}

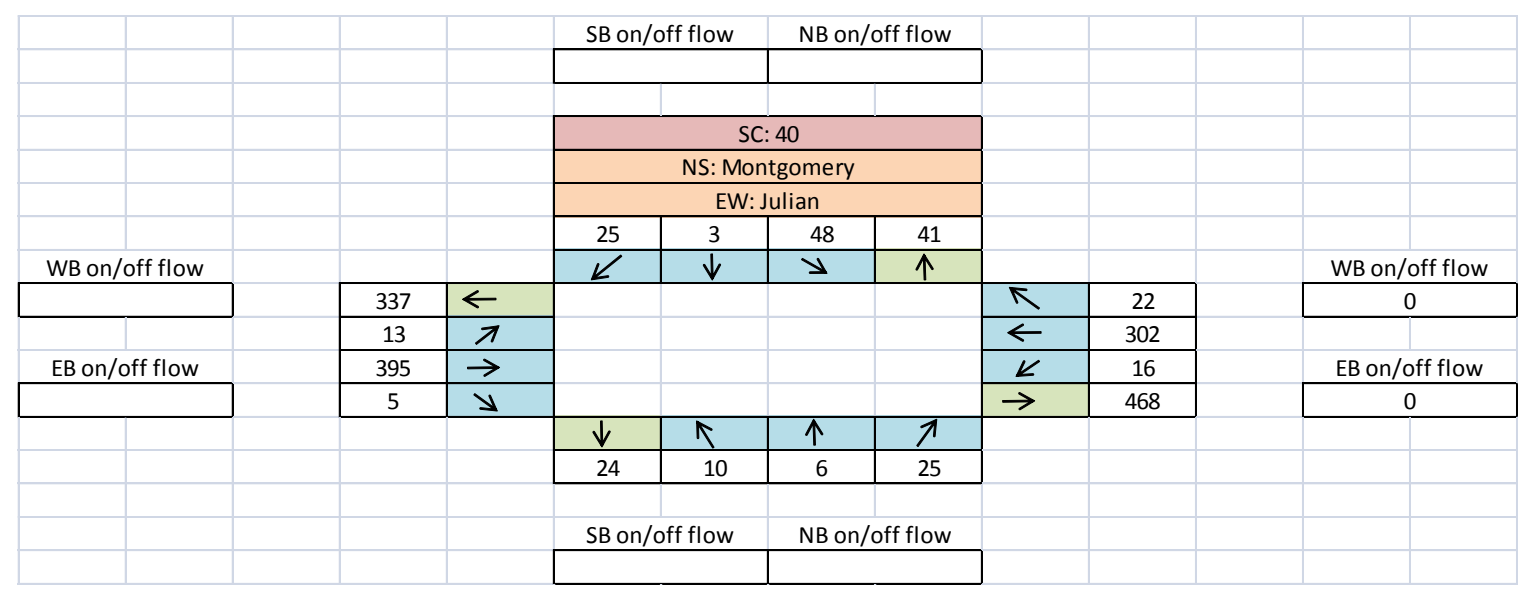

\section{Intersection: Montgomery and Julian}

\begin{tabular}{|c|c|c|c|c|c|c|c|c|c|}
\hline & & & \multicolumn{2}{|c|}{ SB on/off flow } & \multicolumn{2}{|c|}{ NB on/off flow } & & & \\
\hline & & & & & & & & & \\
\hline & & & & & & & & & \\
\hline & & & \multicolumn{4}{|c|}{ SC: 7} & & & \\
\hline & & & \multicolumn{4}{|c|}{ NS: Pleasant } & & & \\
\hline & & & \multicolumn{4}{|c|}{ EW: Julian } & & & \\
\hline & & & 0 & 0 & 394 & 111 & & & \\
\hline WB on/off flow & & & $\swarrow$ & $\downarrow$ & $y$ & $\uparrow$ & & & WB on/off flow \\
\hline 0 & 340 & $\leftarrow$ & & & & & $\pi$ & 111 & 0 \\
\hline & 0 & $\pi$ & & & & & $\leftarrow$ & 340 & \\
\hline EB on/off flow & 468 & $\rightarrow$ & & & & & $K$ & 0 & EB on/off flow \\
\hline 0 & 0 & 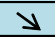 & & & & & $\rightarrow$ & 862 & 0 \\
\hline & & & $\downarrow$ & $\uparrow$ & $\uparrow$ & $\pi$ & & & \\
\hline & & & 0 & 0 & 0 & 0 & & & \\
\hline & & & & & & & & & \\
\hline & & & \multicolumn{2}{|c|}{ SB on/off flow } & \multicolumn{2}{|c|}{ NB on/off flow } & & & \\
\hline & & & & & & & & & \\
\hline
\end{tabular}

\section{Intersection: Pleasant and Julian}




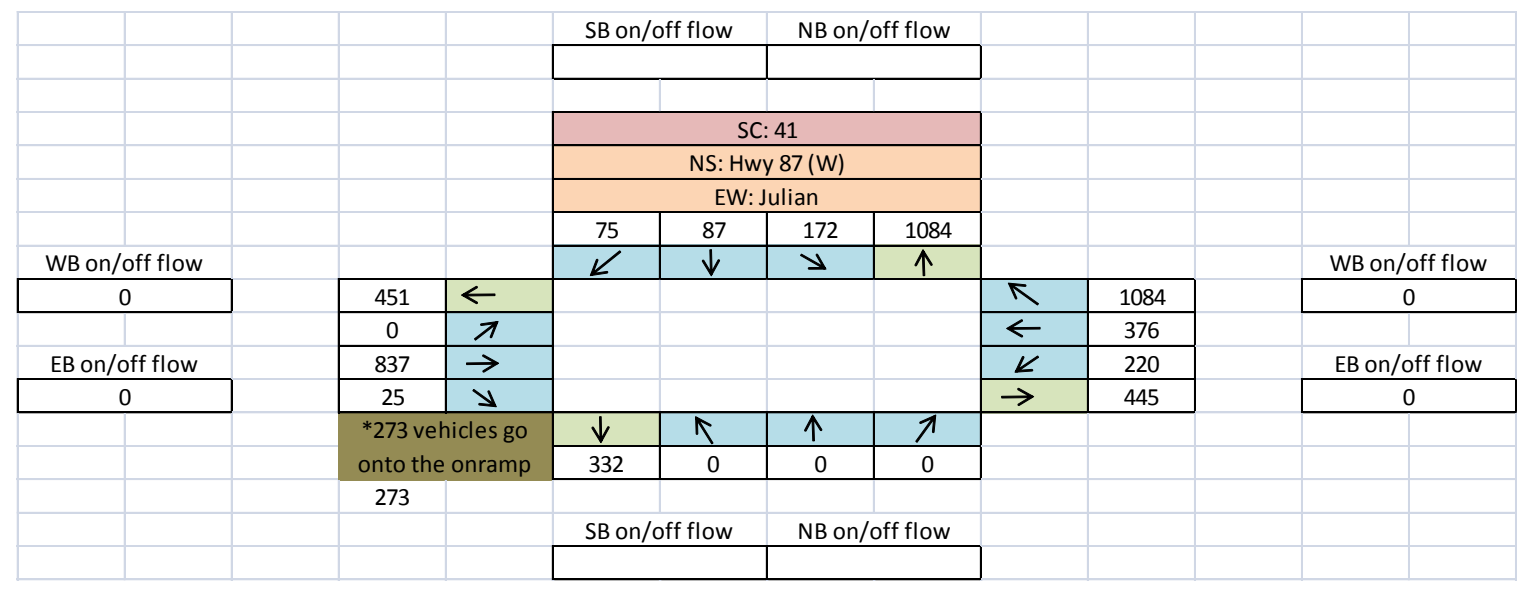

Intersection: Hwy 87 (W) and Julian

\begin{tabular}{|c|c|c|c|c|c|c|c|c|c|}
\hline & & & \multicolumn{2}{|c|}{ SB on/off flow } & \multicolumn{2}{|c|}{ NB on/off flow } & & & \\
\hline & & & \multicolumn{4}{|c|}{ SC: 42} & & & \\
\hline & & & \multicolumn{4}{|c|}{ NS: Hwy 87 (E) } & & & \\
\hline & \multirow{3}{*}{\multicolumn{2}{|c|}{$\begin{array}{c}{ }^{*} \text { Below is the } \\
\text { freeway volume }\end{array}$}} & \multicolumn{4}{|c|}{ EW: James/Julian } & & & \\
\hline & & & 0 & 317 & 162 & 757 & & & \\
\hline WB on/off flow & & & $\swarrow$ & $\downarrow$ & 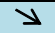 & $\uparrow$ & & & \\
\hline 0 & 1680 & $\leftarrow$ & & & & & $\pi$ & 126 & WB on/off flow \\
\hline & 117 & $\pi$ & & & & & $\leftarrow$ & 1156 & 0 \\
\hline EB on/off flow & 328 & $\rightarrow$ & & & & & $K$ & 0 & \\
\hline 0 & 0 & $\searrow$ & & & & & $\rightarrow$ & 686 & EB on/off flow \\
\hline & & & $\downarrow$ & $\uparrow$ & $\uparrow$ & $\pi$ & & & 0 \\
\hline & & & 0 & 407 & 352 & 41 & & & \\
\hline & & & \multicolumn{4}{|c|}{ *The above volume is Notre Dame Ave. } & & & \\
\hline & & & & & & & & & \\
\hline & & & \multicolumn{2}{|c|}{ SB on/off flow } & \multicolumn{2}{|c|}{ NB on/off flow } & & & \\
\hline & & & & & & & & & \\
\hline
\end{tabular}

Intersection: Hwy 87 (E) and Julian

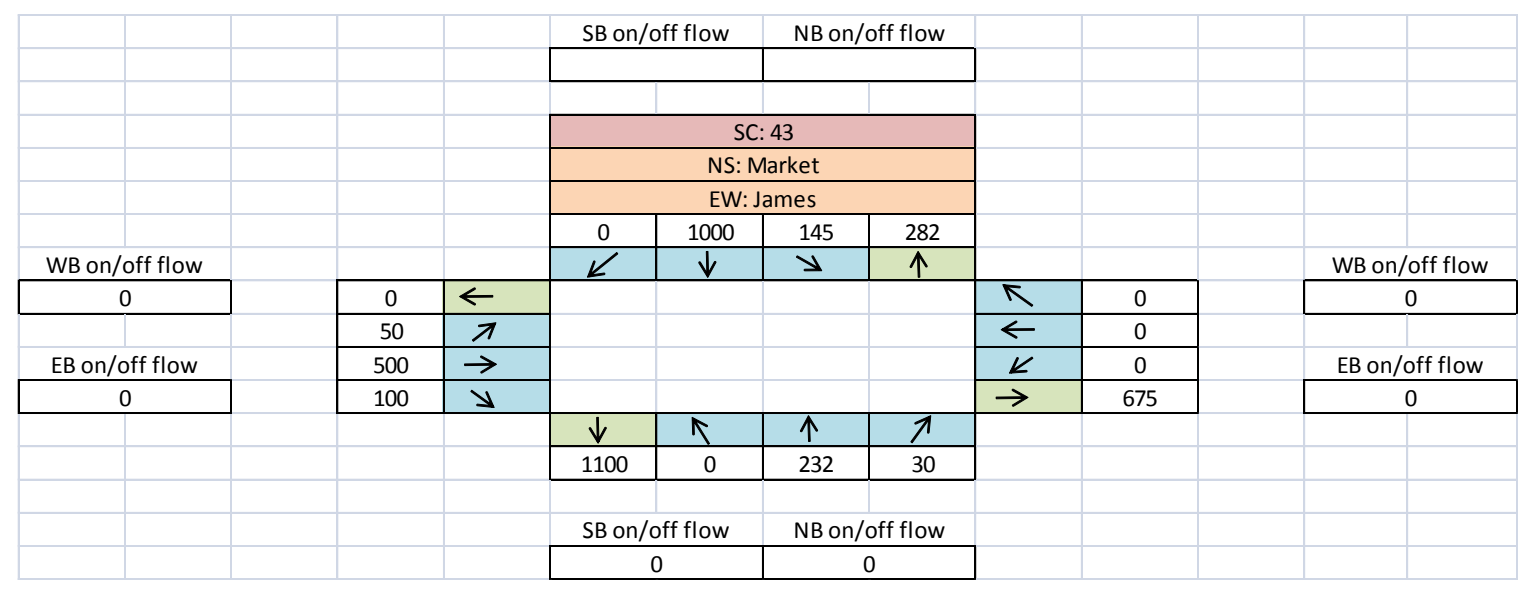

\section{Intersection: Market and James}




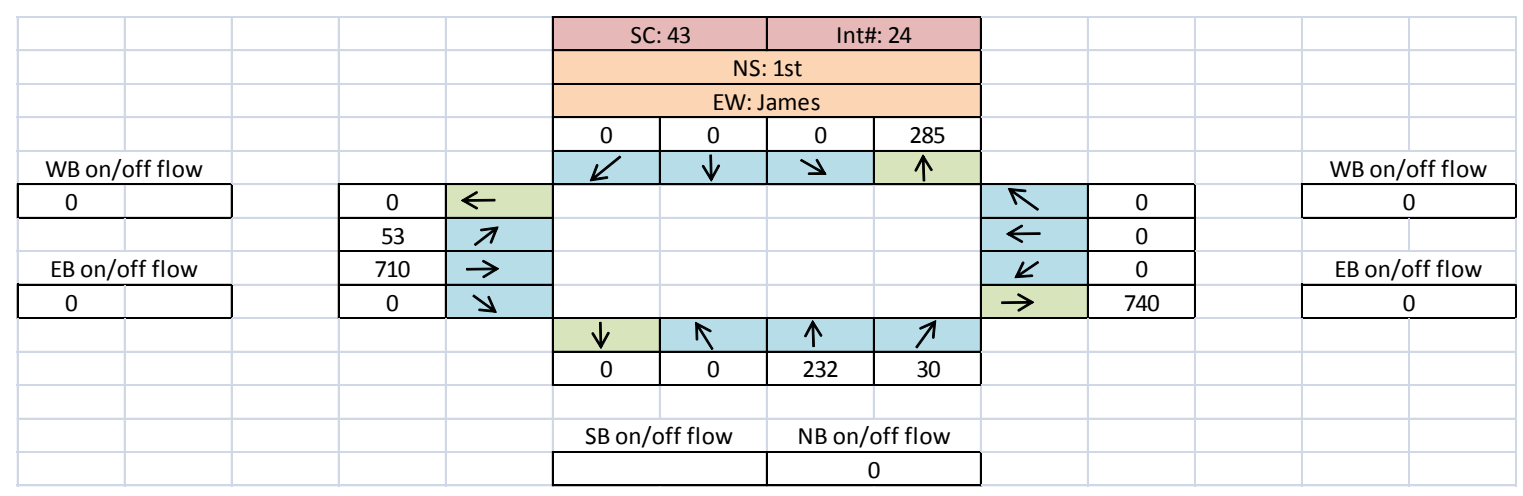

Intersection: $1^{\text {st }}$ and James

\begin{tabular}{|c|c|c|c|c|c|c|c|c|c|}
\hline & & & \multicolumn{2}{|c|}{ SC: 43} & \multicolumn{2}{|c|}{ Int\#: 24} & & & \\
\hline & & & \multicolumn{4}{|c|}{ NS: 4th } & & & \\
\hline & & & \multicolumn{4}{|c|}{ EW: James } & & & \\
\hline & & & 0 & 900 & 121 & 0 & & & \\
\hline WB on/off flow & & & $K$ & $\downarrow$ & $y$ & $\uparrow$ & & & WB on/off flow \\
\hline 0 & 0 & $\leftarrow$ & & & & & $\pi$ & 0 & 0 \\
\hline & 0 & $\pi$ & & & & & $\leftarrow$ & 0 & \\
\hline EB on/off flow & 750 & $\rightarrow$ & & & & & $K$ & 0 & EB on/off flow \\
\hline 0 & 81 & $\searrow$ & & & & & $\rightarrow$ & 871 & -871 \\
\hline & 831 & & $\downarrow$ & $\uparrow$ & $\uparrow$ & $\pi$ & & & \\
\hline & & & 981 & 0 & 0 & 0 & & & \\
\hline & & & & & & & & & \\
\hline & & & \multicolumn{2}{|c|}{ SB on/off flow } & \multicolumn{2}{|c|}{ NB on/off flow } & & & \\
\hline & & & \multicolumn{2}{|c|}{0} & \multicolumn{2}{|c|}{0} & & & \\
\hline
\end{tabular}

Intersection: $4^{\text {th }}$ and James

\begin{tabular}{|c|c|c|c|c|c|c|c|c|c|}
\hline & & & \multicolumn{2}{|c|}{ SB on/off flow } & \multicolumn{2}{|c|}{ NB on/off flow } & & & \\
\hline & & & & & & & & & \\
\hline & & & & & & & & & \\
\hline & & & \multicolumn{4}{|c|}{ SC: 37} & & & \\
\hline & & & \multicolumn{4}{|c|}{ NS: Autumn } & & & \\
\hline & & & \multicolumn{4}{|c|}{ EW: Santa Clara } & & & \\
\hline & & & 88 & 0 & 23 & 189 & & & \\
\hline WB on/off flow & & & $K$ & $\downarrow$ & 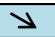 & $\uparrow$ & & & WB on/off flow \\
\hline 0 & 794 & $\leftarrow$ & & & & & $\pi$ & 106 & 0 \\
\hline & 25 & $\pi$ & & & & & $\leftarrow$ & 621 & \\
\hline EB on/off flow & 564 & $\rightarrow$ & & & & & $K$ & 0 & EB on/off flow \\
\hline 0 & 0 & $y$ & & & & & $\rightarrow$ & 655 & 0 \\
\hline & & & $\downarrow$ & $\uparrow$ & $\uparrow$ & $\pi$ & & & \\
\hline & & & 0 & 85 & 58 & 68 & & & \\
\hline & & & & & & & & & \\
\hline & & & \multicolumn{2}{|c|}{ SB on/off flow } & \multicolumn{2}{|c|}{ NB on/off flow } & & & \\
\hline & & & \multicolumn{2}{|c|}{0} & \multicolumn{2}{|c|}{0} & & & \\
\hline
\end{tabular}

Intersection: Autumn and Santa Clara 


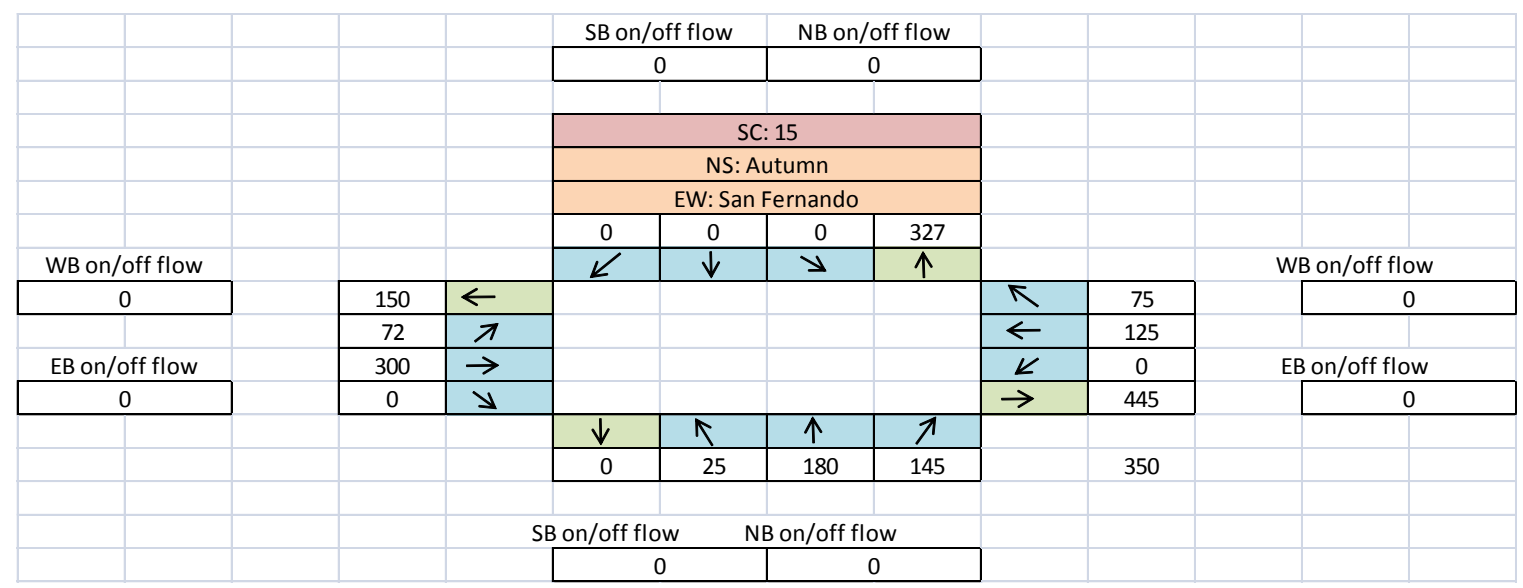

\section{Intersection: Autumn and San Fernando}

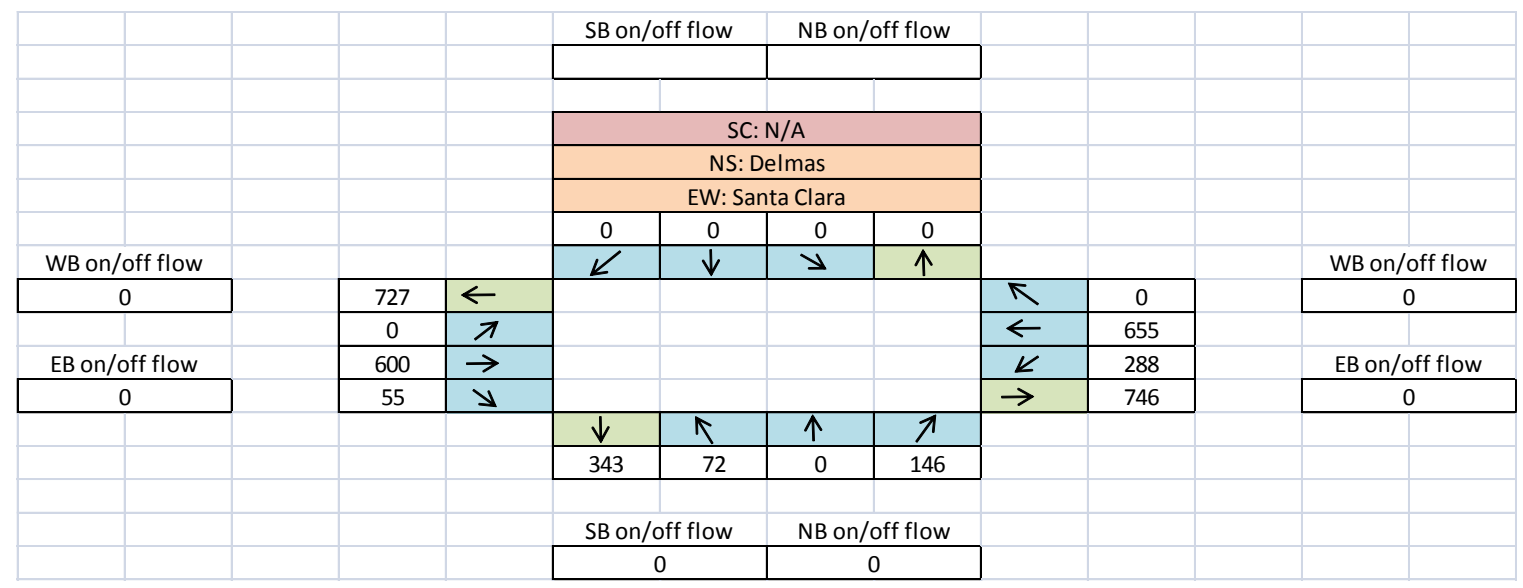

\section{Intersection: Delmas and Santa Clara}

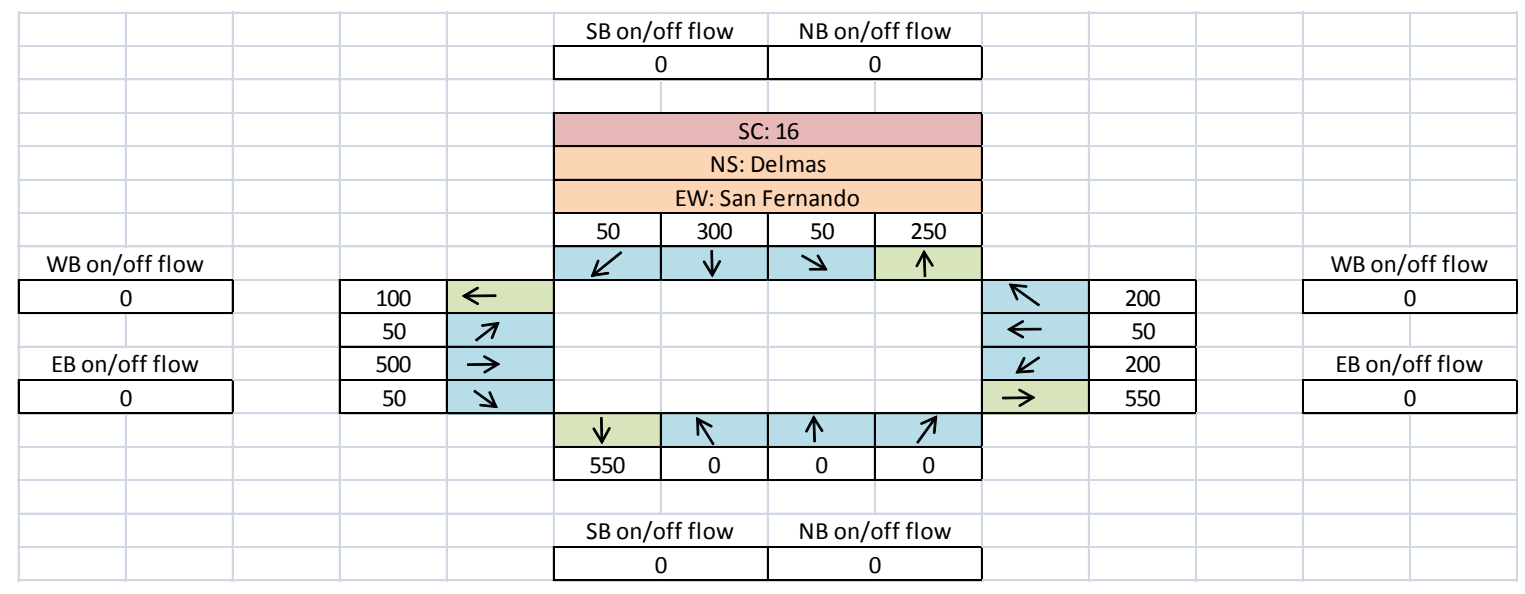

\section{Intersection: Delmas and San Fernando}




\begin{tabular}{|c|c|c|c|c|c|c|c|c|c|}
\hline & & & \multicolumn{2}{|c|}{ SB on/off flow } & \multicolumn{2}{|c|}{ NB on/off flow } & & & \\
\hline & & & \multicolumn{2}{|c|}{0} & \multicolumn{2}{|c|}{0} & & & \\
\hline & & & \multicolumn{4}{|c|}{ SC: 2} & & & \\
\hline & & & \multicolumn{4}{|c|}{ NS: Delmas } & & & \\
\hline & & & \multicolumn{4}{|c|}{ EW: Park } & & & \\
\hline & & & 77 & 365 & 249 & 306 & & & \\
\hline WB on/off flow & & & $K$ & $\downarrow$ & 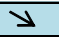 & $\uparrow$ & & & WB on/off flow \\
\hline & 470 & $\leftarrow$ & \multirow{2}{*}{\multicolumn{4}{|c|}{$\begin{array}{l}\text { The above volume is the freeway } \\
\text { offramp }\end{array}$}} & $\pi$ & 0 & 0 \\
\hline 0 & 0 & $\pi$ & & & & & $\leftarrow$ & 323 & \\
\hline EB on/off flow & 121 & $\rightarrow$ & & & & & $K$ & 121 & EB on/off flow \\
\hline 0 & 46 & 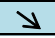 & & & & & $\rightarrow$ & 419 & 0 \\
\hline & & & $\downarrow$ & $k$ & $\downarrow$ & $\searrow$ & & & \\
\hline & & & 838 & 70 & 306 & 49 & \multicolumn{3}{|c|}{${ }^{*}$ The volumes to the right are Delmas St. SB } \\
\hline & & & & & & & & & \\
\hline & & & \multicolumn{2}{|c|}{ SB on/off flow } & \multicolumn{2}{|c|}{ NB on/off flow } & & 174 & \\
\hline & & & \multicolumn{2}{|c|}{0} & \multicolumn{2}{|c|}{-425} & & & \\
\hline
\end{tabular}

\section{Intersection: Delmas and Park}

\begin{tabular}{|c|c|c|c|c|c|c|c|c|c|}
\hline & & & \multicolumn{2}{|c|}{ SB on/off flow } & \multicolumn{2}{|c|}{ NB on/off flow } & & & \\
\hline & & & \multicolumn{2}{|c|}{0} & \multicolumn{2}{|c|}{0} & & & \\
\hline & & & \multicolumn{4}{|c|}{ SC: 2} & & & \\
\hline & & & \multicolumn{4}{|c|}{ NS: Delmas } & & & \\
\hline & & & \multicolumn{4}{|c|}{ EW: San Carlos } & & & \\
\hline & & & 203 & 468 & 35 & 0 & & & \\
\hline WB on/off flow & & & \multirow[t]{3}{*}{$\swarrow$} & \multirow[t]{3}{*}{$\downarrow$} & 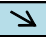 & \multirow[t]{3}{*}{$\uparrow$} & & & WB on/off flow \\
\hline 0 & 541 & $\leftarrow$ & & & & & $\pi$ & 0 & 0 \\
\hline & 0 & $\pi$ & & & & & $\leftarrow$ & 338 & \\
\hline EB on/off flow & 428 & $\rightarrow$ & & & & & $K$ & 40 & EB on/off flow \\
\hline 0 & 106 & $\searrow$ & & & & & $\rightarrow$ & 463 & 0 \\
\hline & & & $\downarrow$ & $\uparrow$ & $\uparrow$ & $\pi$ & & & \\
\hline & & & 614 & 0 & 0 & 0 & & & \\
\hline & & & & & & & & & \\
\hline & & & \multicolumn{2}{|c|}{ SB on/off flow } & \multicolumn{2}{|c|}{ NB on/off flow } & & & \\
\hline & & & & & & & & & \\
\hline
\end{tabular}

\section{Intersection: Delmas and San Carlos}

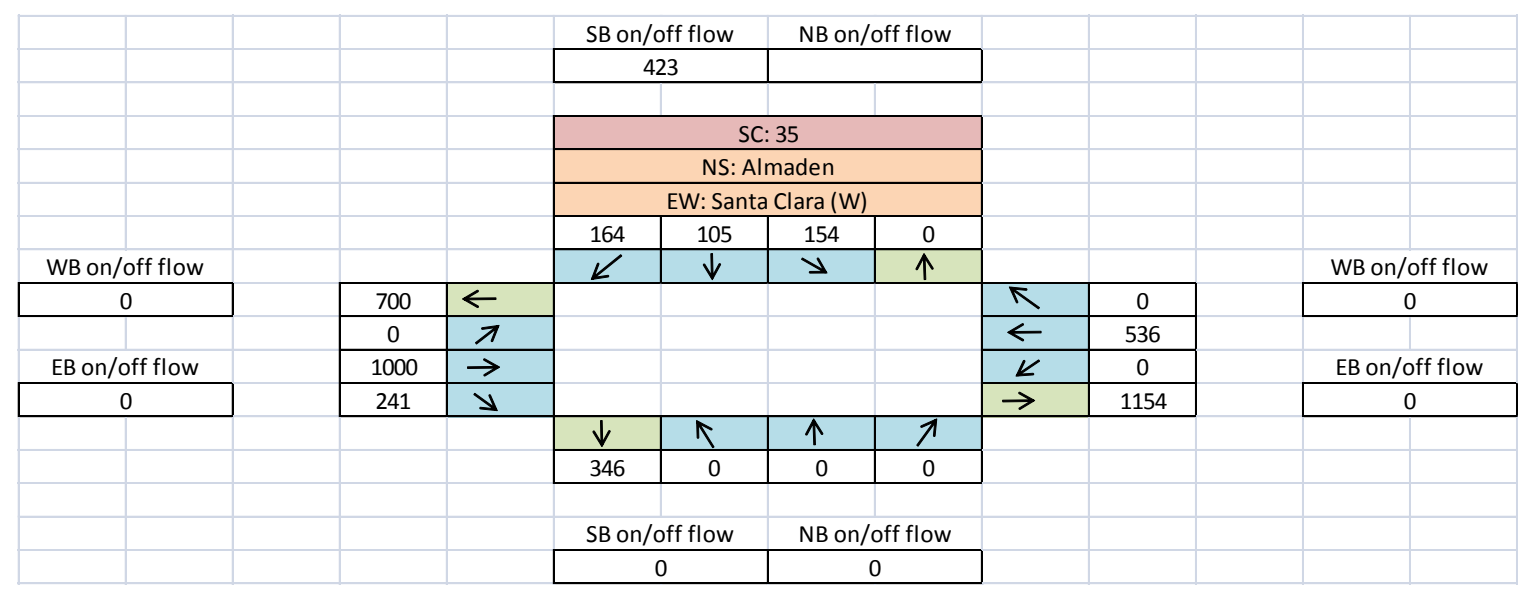

\section{Intersection: Almaden and Santa Clara (W)}




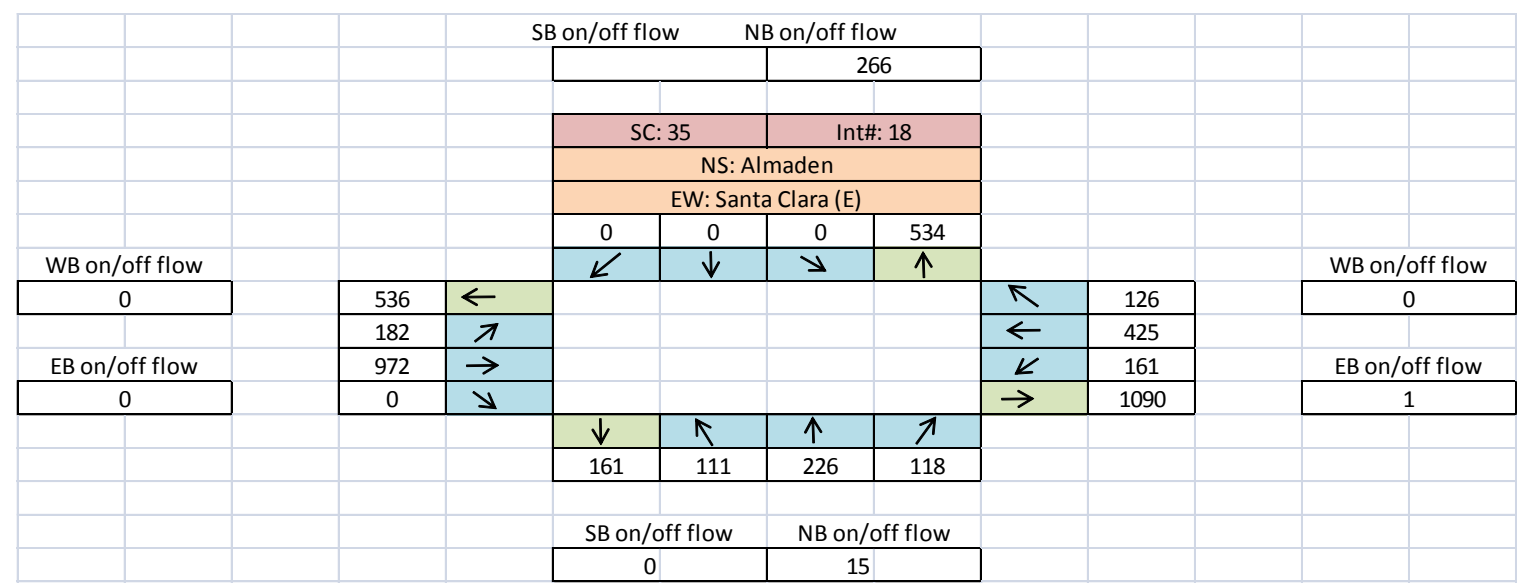

\section{Intersection: Almaden and Santa Clara (E)}

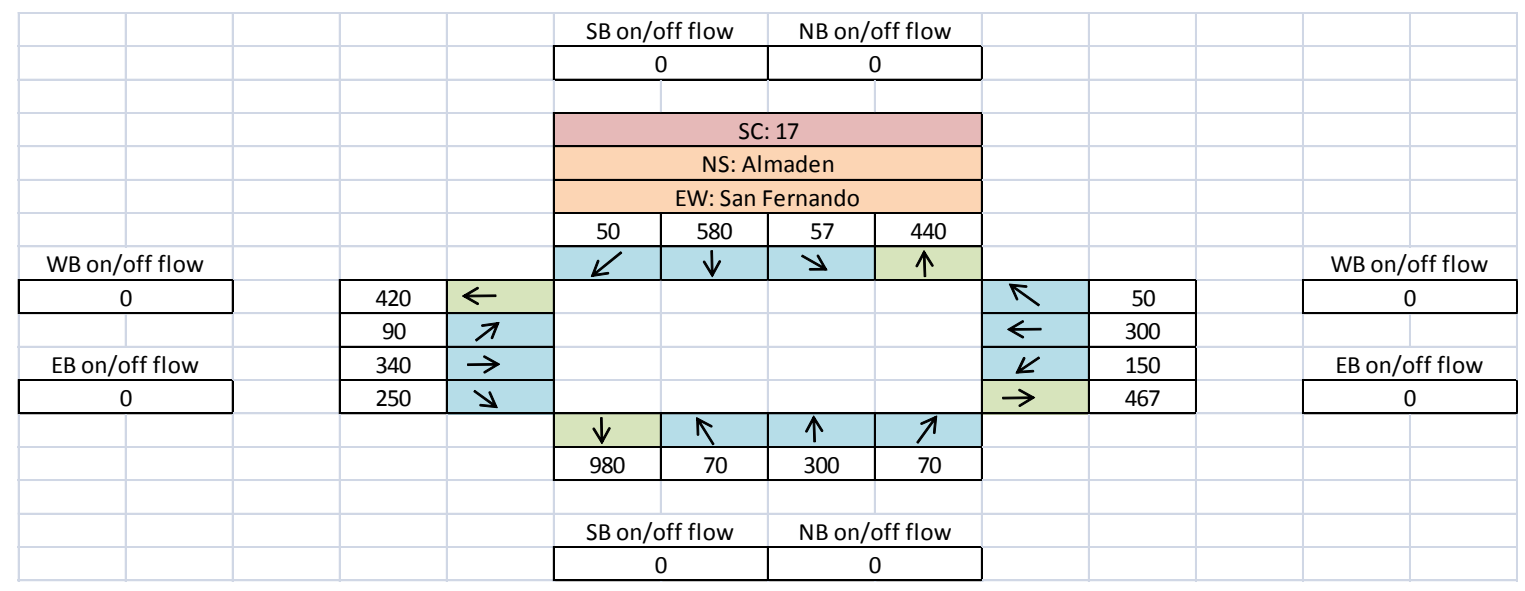

\section{Intersection: Almaden and San Fernando}

\begin{tabular}{|c|c|c|c|c|c|c|c|c|c|}
\hline & & & \multicolumn{2}{|c|}{ SB on/off flow } & \multicolumn{2}{|c|}{ NB on/off flow } & & & \\
\hline & & & \multicolumn{2}{|c|}{0} & \multicolumn{2}{|c|}{0} & & & \\
\hline & & & & & & & & & \\
\hline & & & & & & & & & \\
\hline & & & \multicolumn{4}{|c|}{ SC: 12} & & & \\
\hline & & & \multicolumn{4}{|c|}{ NS: Almaden } & & & \\
\hline WB on/off flow & & & \multicolumn{4}{|c|}{ EW: Park } & & & \\
\hline 0 & & 1099 & 86 & 965 & 48 & 402 & & & \\
\hline & & & $K$ & $\downarrow$ & 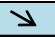 & $\uparrow$ & & & WB on/off flow \\
\hline EB on/off flow & 227 & $\leftarrow$ & & & & & $\pi$ & 60 & 0 \\
\hline 0 & 105 & $\pi$ & & & & & $\leftarrow$ & 104 & \\
\hline & 86 & $\rightarrow$ & & & & & $K$ & 163 & EB on/off flow \\
\hline & 117 & 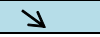 & & & & & $\rightarrow$ & 170 & 0 \\
\hline & & & $\downarrow$ & $\uparrow$ & $\uparrow$ & $\pi$ & & & \\
\hline & & & 1245 & 37 & 237 & 36 & 310 & & \\
\hline & & & & & & & & & \\
\hline & & & \multicolumn{2}{|c|}{ SB on/off flow } & \multicolumn{2}{|c|}{ NB on/off flow } & & & \\
\hline & & & \multicolumn{2}{|c|}{0} & \multicolumn{2}{|c|}{0} & & & \\
\hline
\end{tabular}

Intersection: Almaden and Park 


\begin{tabular}{|c|c|c|c|c|c|c|c|c|c|}
\hline & & & \multicolumn{2}{|c|}{ SB on/off flow } & \multicolumn{2}{|c|}{ NB on/off flow } & & & \\
\hline & & & \multicolumn{2}{|c|}{0} & \multicolumn{2}{|c|}{0} & & & \\
\hline & & & \multicolumn{4}{|c|}{ SC: 3} & & & \\
\hline & & & \multicolumn{4}{|c|}{ NS: Almaden } & & & \\
\hline WB on/off flow & & & \multicolumn{4}{|c|}{ EW: San Carlos } & & & \\
\hline 0 & & & 100 & 1017 & 104 & 615 & & & \\
\hline & & & $\swarrow$ & $\downarrow$ & $y$ & $\uparrow$ & & & WB on/off flow \\
\hline EB on/off flow & 702 & $\leftarrow$ & & & & & $\pi$ & 83 & -27 \\
\hline 0 & 184 & $\pi$ & & & & & $\leftarrow$ & 514 & \\
\hline & 759 & $\rightarrow$ & & & & & $K$ & 106 & EB on/off flow \\
\hline & 209 & $y$ & & & & & $\rightarrow$ & 1021 & 0 \\
\hline & & & $\downarrow$ & $\uparrow$ & $\uparrow$ & $\pi$ & & & \\
\hline & & & 1332 & 88 & 348 & 158 & & & \\
\hline & & & & & & & & & \\
\hline & & & \multicolumn{2}{|c|}{ SB on/off flow } & \multicolumn{2}{|c|}{ NB on/off flow } & & & \\
\hline & & & \multicolumn{2}{|c|}{0} & \multicolumn{2}{|c|}{0} & & & \\
\hline
\end{tabular}

\section{Intersection: Almaden and San Carlos}

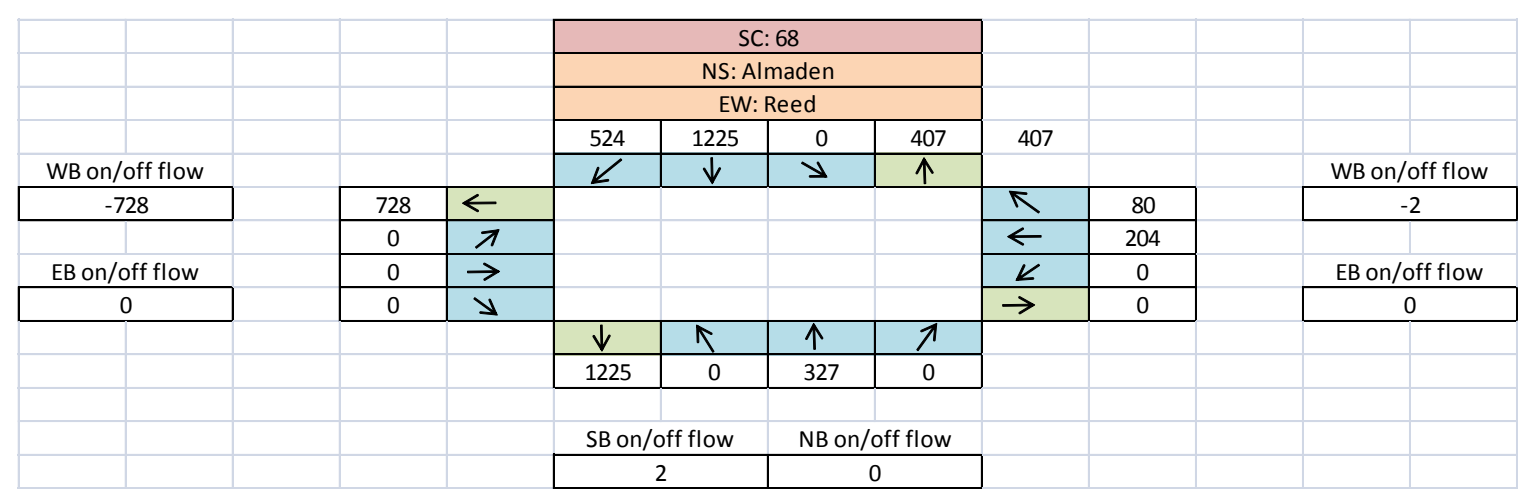

Intersection: Almaden and Reed

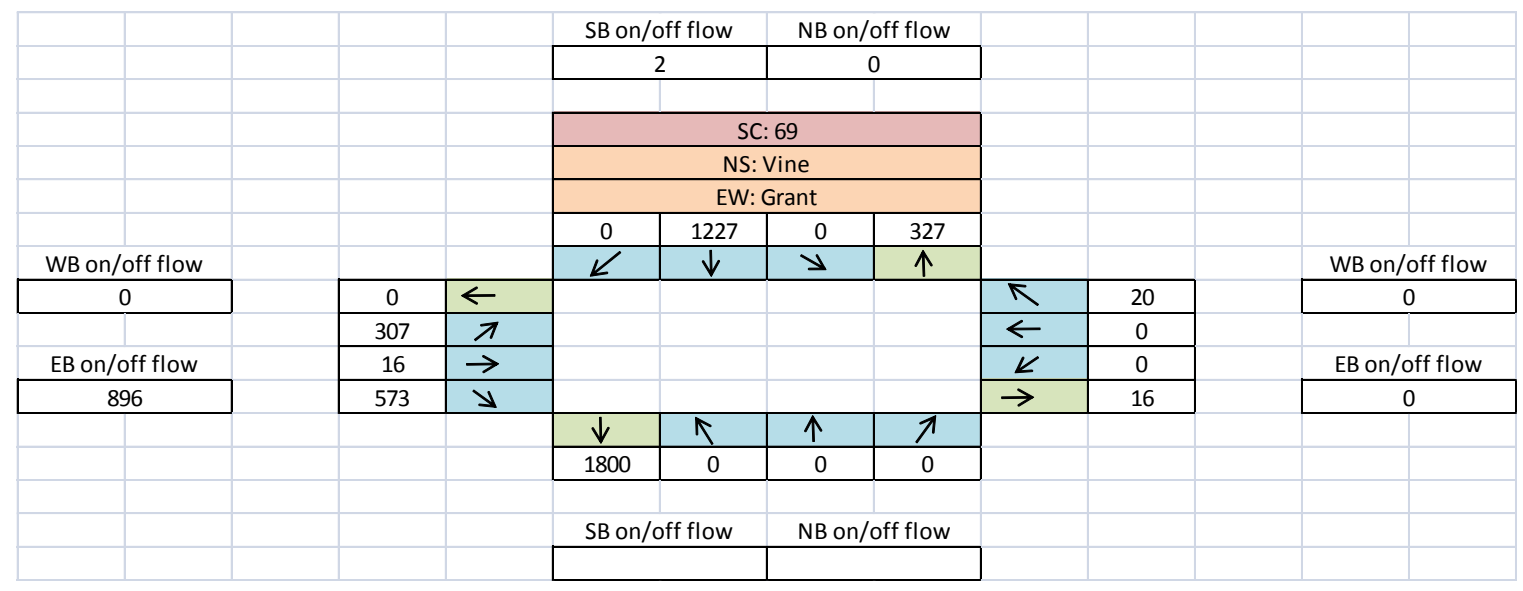

Intersection: Vine and Grant 


\begin{tabular}{|c|c|c|c|c|c|c|c|c|c|}
\hline & & & \multicolumn{2}{|c|}{ SB on/off flow } & \multicolumn{2}{|c|}{ NB on/off flow } & & & \\
\hline & & & \multicolumn{4}{|c|}{ SC: 43} & & & \\
\hline & & & \multicolumn{4}{|c|}{ NS: Market } & & & \\
\hline & & & \multicolumn{4}{|c|}{ EW: James } & & & \\
\hline & & & 0 & 1000 & 145 & 282 & & & \\
\hline WB on/off flow & & & $\swarrow$ & $\downarrow$ & $y$ & $\uparrow$ & & & WB on/off flow \\
\hline 0 & 0 & $\leftarrow$ & & & & & $\pi$ & 0 & 0 \\
\hline & 50 & $\pi$ & & & & & $\leftarrow$ & 0 & \\
\hline EB on/off flow & 500 & $\rightarrow$ & & & & & $K$ & 0 & EB on/off flow \\
\hline 0 & 100 & $y$ & & & & & $\rightarrow$ & 675 & 0 \\
\hline & & & $\downarrow$ & $\uparrow$ & $\uparrow$ & $\pi$ & & & \\
\hline & & & 1100 & 0 & 232 & 30 & & & \\
\hline & & & & & & & & & \\
\hline & & & \multicolumn{2}{|c|}{ SB on/off flow } & \multicolumn{2}{|c|}{ NB on/off flow } & & & \\
\hline & & & \multicolumn{2}{|c|}{0} & \multicolumn{2}{|c|}{0} & & & \\
\hline
\end{tabular}

\section{Intersection: Market and James}

\begin{tabular}{|c|c|c|c|c|c|c|c|}
\hline & & & SB on/off flow & NB on/off flow & & & \\
\hline & & & 0 & 0 & & & \\
\hline & & & \multicolumn{2}{|c|}{ SC: 32} & & & \\
\hline & & & \multicolumn{2}{|c|}{ NS: Market } & & & \\
\hline & & & \multicolumn{2}{|c|}{ EW: Santa Clara (E) } & & & \\
\hline & & 958 & 760 & 118 & & & \\
\hline WB on/off flow & & & $\swarrow$ & $y$ & & & WB on/off flow \\
\hline \multirow[t]{2}{*}{0} & 544 & $\leftarrow$ & & & $\pi$ & 90 & 0 \\
\hline & 87 & $\pi$ & & & $\leftarrow$ & 395 & \\
\hline EB on/off flow & 581 & $\rightarrow$ & & & $K$ & 80 & EB on/off flow \\
\hline 0 & 114 & $\searrow$ & & & $\rightarrow$ & 740 & 0 \\
\hline & & & $\uparrow$ & $\pi$ & & & \\
\hline & & & 954 & 231 & & & \\
\hline & & & & & & & \\
\hline & & & SB on/off flow & NB on/off flow & & & \\
\hline & & & 0 & 0 & & & \\
\hline
\end{tabular}

Intersection: Market and Santa Clara (E)

\begin{tabular}{|c|c|c|c|c|c|c|c|c|c|}
\hline & & & \multicolumn{2}{|c|}{ SB on/off flow } & \multicolumn{2}{|c|}{ NB on/off flow } & & & \\
\hline & & & \multicolumn{2}{|c|}{0} & \multicolumn{2}{|c|}{0} & & & \\
\hline & & & \multicolumn{4}{|c|}{ SC: 18} & & & \\
\hline & & & \multicolumn{4}{|c|}{ NS: Market } & & & \\
\hline & & & \multicolumn{4}{|c|}{ EW: San Fernando } & & & \\
\hline & & & 44 & 940 & 127 & 305 & & & \\
\hline WB on/off flow & & & $\swarrow$ & $\downarrow$ & 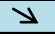 & $\uparrow$ & & & WB on/off flow \\
\hline 0 & 251 & $\leftarrow$ & & & & & $\pi$ & 57 & 0 \\
\hline & 18 & $\pi$ & & & & & $\leftarrow$ & 164 & \\
\hline EB on/off flow & 239 & $\rightarrow$ & & & & & $K$ & 71 & EB on/off flow \\
\hline 0 & 140 & 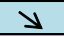 & & & & & $\rightarrow$ & 442 & 0 \\
\hline & & & $\downarrow$ & $\uparrow$ & $\uparrow$ & $\nearrow$ & & & \\
\hline & 397 & & 1151 & 43 & 230 & 76 & & & \\
\hline & & & & & & & & & \\
\hline & & & \multicolumn{2}{|c|}{ SB on/off flow } & \multicolumn{2}{|c|}{ NB on/off flow } & & & \\
\hline & & & \multicolumn{2}{|c|}{0} & \multicolumn{2}{|c|}{0} & & & \\
\hline
\end{tabular}

Intersection: Market and San Fernando 


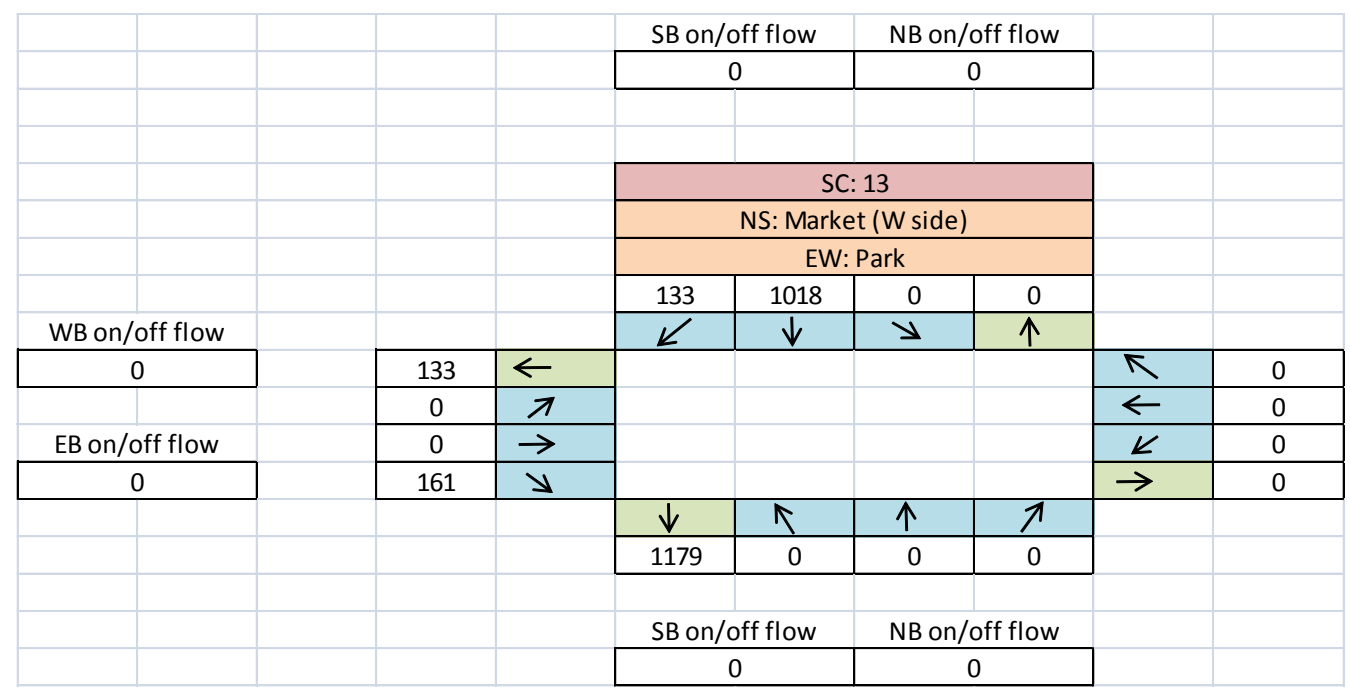

Intersection: Market (W side) and Park

\begin{tabular}{|c|c|c|c|c|c|c|c|c|}
\hline & & & \multicolumn{2}{|c|}{ SB on/off flow } & \multicolumn{2}{|c|}{ NB on/off flow } & & \\
\hline & & & \multicolumn{2}{|c|}{0} & \multicolumn{2}{|c|}{0} & & \\
\hline & & & \multicolumn{4}{|c|}{ SC: 4} & & \\
\hline & & & \multicolumn{4}{|c|}{ NS: Market } & & \\
\hline & & & \multicolumn{4}{|c|}{ EW: San Carlos } & & \\
\hline & & & 86 & 860 & 96 & 283 & & \\
\hline WB on/off flow & & & $K$ & $\downarrow$ & $y$ & $\uparrow$ & & \\
\hline 0 & 558 & $\leftarrow$ & & & & & $\pi$ & 21 \\
\hline & 78 & $\pi$ & & & & & $\leftarrow$ & 357 \\
\hline EB on/off flow & 374 & $\rightarrow$ & & & & & $K$ & 0 \\
\hline 0 & 145 & $У$ & & & & & $\rightarrow$ & 472 \\
\hline & & & $\downarrow$ & $\uparrow$ & $\uparrow$ & $\pi$ & & \\
\hline & & & 1005 & 115 & 184 & 2 & & \\
\hline & & & & & & & & \\
\hline & & & \multicolumn{2}{|c|}{ SB on/off flow } & \multicolumn{2}{|c|}{ NB on/off flow } & & \\
\hline & & & \multicolumn{2}{|c|}{0} & \multicolumn{2}{|c|}{0} & & \\
\hline
\end{tabular}

Intersection: Market and San Carlos 


\begin{tabular}{|c|c|c|c|c|c|c|c|c|c|c|}
\hline & & & \multicolumn{2}{|c|}{ SB on/off flow } & \multicolumn{2}{|c|}{ NB on/off flow } & & & & \\
\hline & & & \multicolumn{2}{|c|}{0} & \multicolumn{2}{|c|}{0} & & & & \\
\hline & & & \multicolumn{4}{|c|}{ SC: 50} & & & & \\
\hline & & & \multicolumn{4}{|c|}{ NS: Market } & & & & \\
\hline & & & \multicolumn{4}{|c|}{ EW: San Salvador } & & & & \\
\hline & & & 37 & 1172 & 47 & 322 & & & & \\
\hline WB on/off flow & & & $K$ & $\downarrow$ & 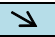 & $\uparrow$ & & & \multicolumn{2}{|l|}{ WB on/off flow } \\
\hline-48 & 48 & $\leftarrow$ & & & & & $\pi$ & 68 & \multicolumn{2}{|l|}{$\begin{array}{r}0 \\
\end{array}$} \\
\hline & 20 & $\pi$ & & & & & $\leftarrow$ & 10 & & \\
\hline EB on/off flow & 8 & $\rightarrow$ & & & & & $K$ & 73 & \multicolumn{2}{|l|}{ EB on/off flow } \\
\hline 48 & 20 & $y$ & & & & & $\rightarrow$ & 89 & \multicolumn{2}{|l|}{$\begin{array}{r}0 \\
\end{array}$} \\
\hline & & & $\downarrow$ & $\uparrow$ & $\uparrow$ & $\pi$ & & & & \\
\hline & & & 1265 & 1 & 234 & 34 & & & & \\
\hline & & & & & & & & & & \\
\hline & & & \multicolumn{2}{|c|}{ SB on/off flow } & \multicolumn{2}{|c|}{ NB on/off flow } & & & & \\
\hline & & & \multicolumn{2}{|c|}{0} & \multicolumn{2}{|c|}{0} & & & & \\
\hline
\end{tabular}

\section{Intersection: Market and San Salvador}

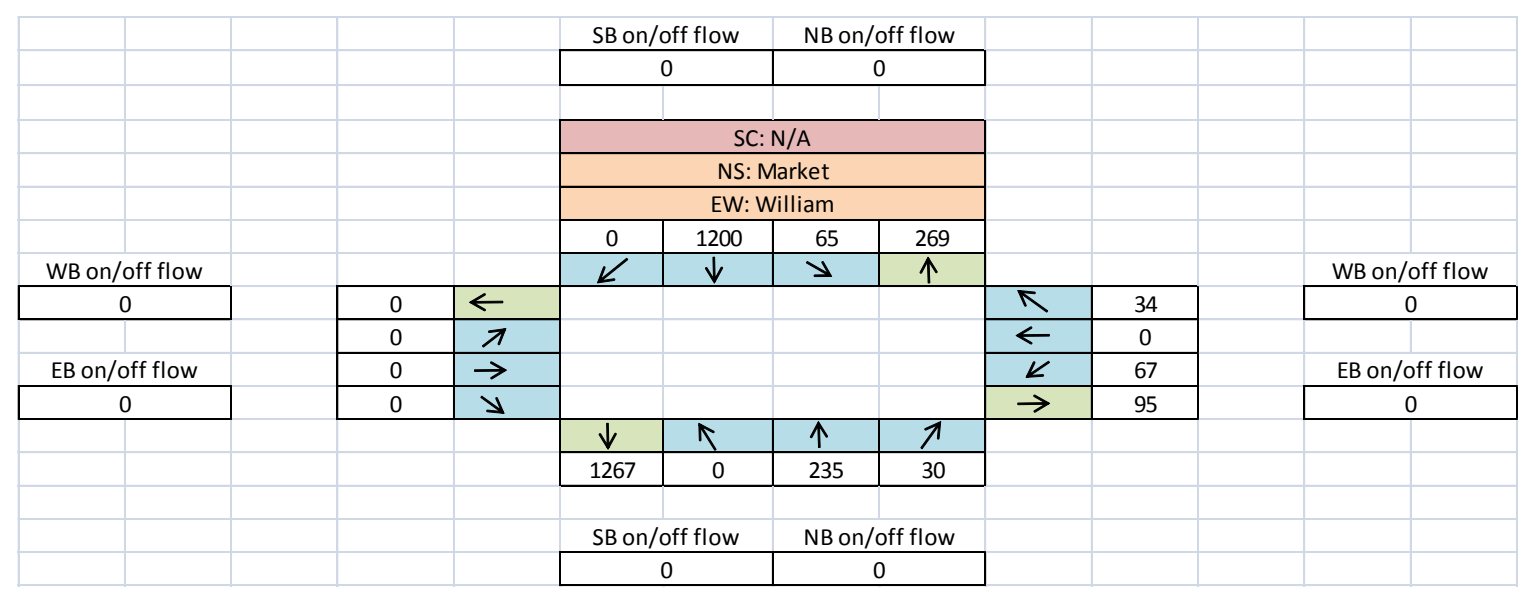

\section{Intersection: Market and William}

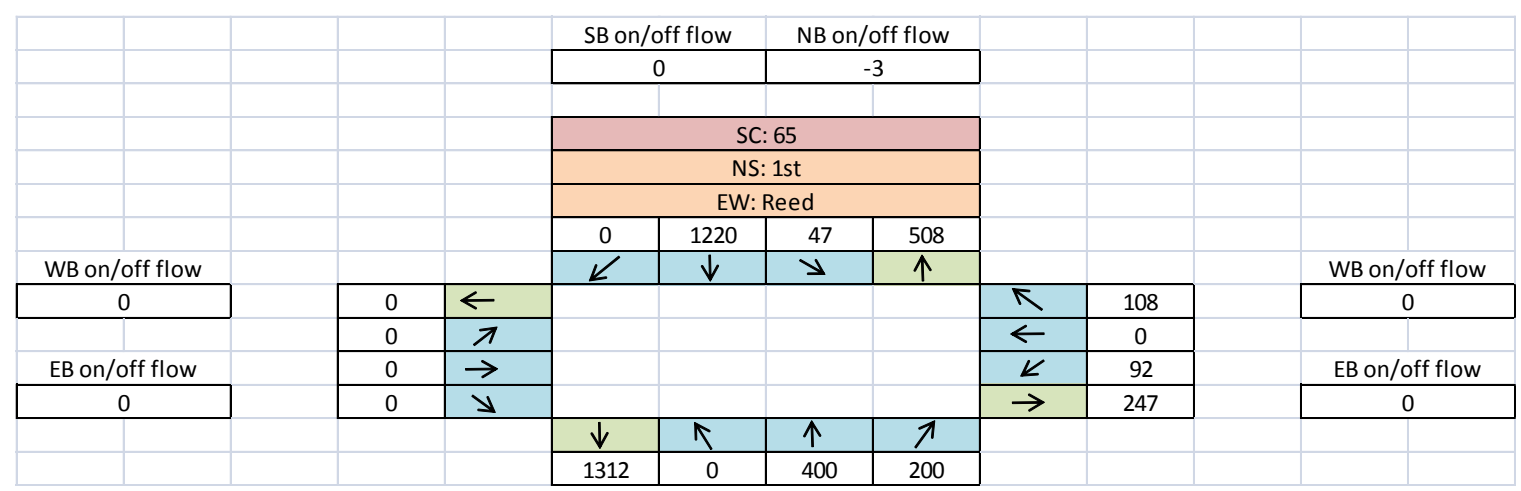

Intersection: $1^{\text {st }}$ and Reed 


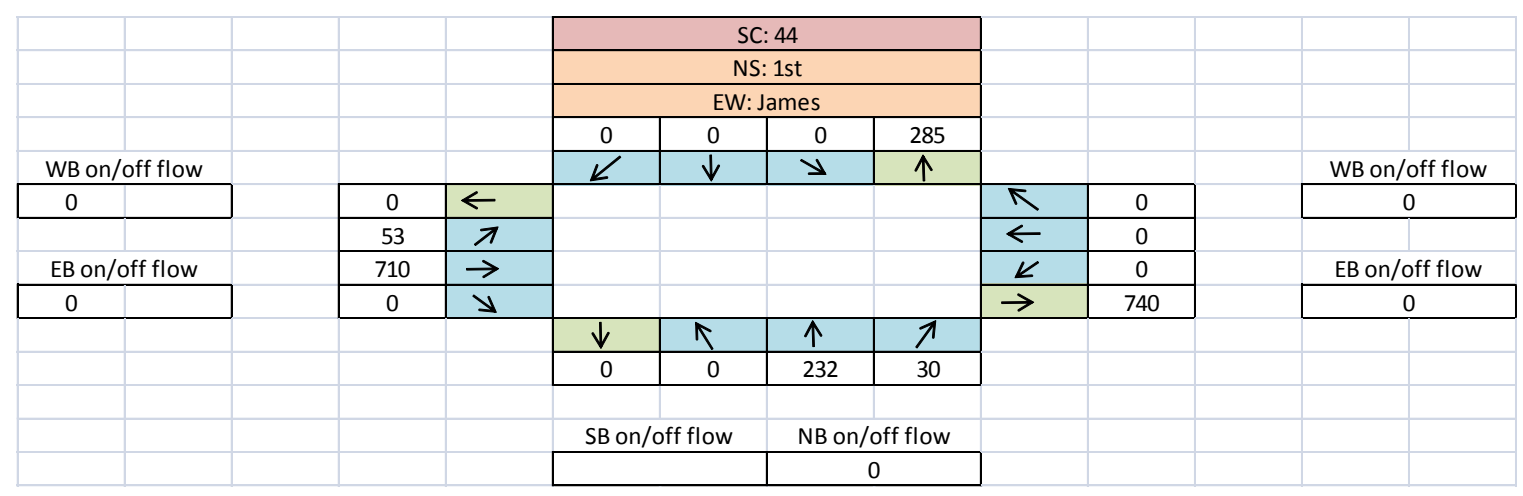

Intersection: $1^{\text {st }}$ and James

\begin{tabular}{|c|c|c|c|c|c|c|c|c|c|}
\hline & & & \multicolumn{2}{|c|}{ SB on/off flow } & \multicolumn{2}{|c|}{ NB on/off flow } & & & \\
\hline & & & & & \multicolumn{2}{|c|}{0} & & & \\
\hline & & & \multicolumn{4}{|c|}{ SC: 31} & & & \\
\hline & & & \multicolumn{4}{|c|}{ NS: 1st } & & & \\
\hline & & & \multicolumn{4}{|c|}{ EW: Santa Clara (E) } & & & \\
\hline & & & 0 & 0 & 0 & 448 & & & \\
\hline WB on/off flow & & & $K$ & $\downarrow$ & 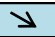 & $\uparrow$ & & & WB on/off flow \\
\hline 0 & 565 & $\leftarrow$ & & & & & $\pi$ & 90 & 0 \\
\hline & 87 & $\pi$ & & & & & $\leftarrow$ & 445 & \\
\hline EB on/off flow & 653 & $\rightarrow$ & & & & & $K$ & 0 & EB on/off flow \\
\hline 0 & 0 & $y$ & & & & & $\rightarrow$ & 880 & 0 \\
\hline & & & $\downarrow$ & $\uparrow$ & $\uparrow$ & $\pi$ & & & \\
\hline & & & 0 & 120 & 271 & 227 & & & \\
\hline & & & & & & & & & \\
\hline & & & \multicolumn{2}{|c|}{ SB on/off flow } & \multicolumn{2}{|c|}{ NB on/off flow } & & & \\
\hline & & & \multicolumn{2}{|c|}{0} & \multicolumn{2}{|c|}{1} & & & \\
\hline
\end{tabular}

Intersection: $1^{\text {st }}$ and Santa Clara (E)

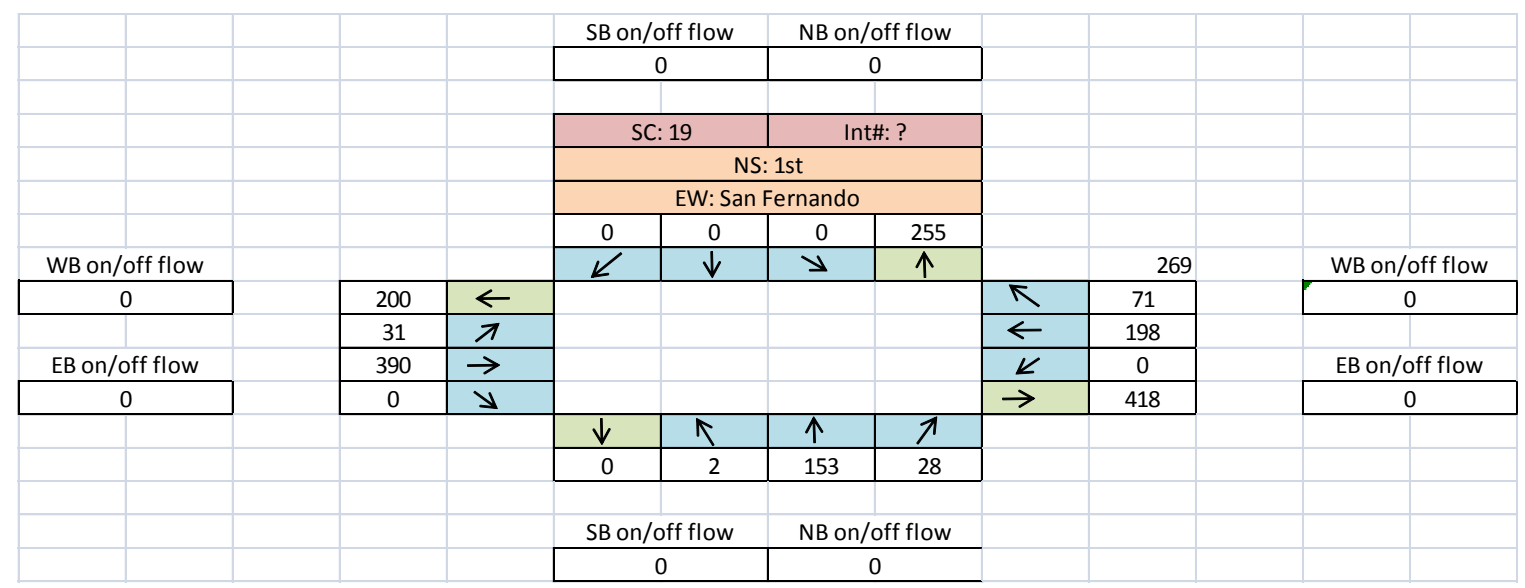

Intersection: $1^{\text {st }}$ and San Fernando 


\begin{tabular}{|c|c|c|c|c|c|c|c|c|c|}
\hline & & & \multicolumn{2}{|c|}{ SB on/off flow } & \multicolumn{2}{|c|}{ NB on/off flow } & & & \\
\hline & & & \multicolumn{2}{|c|}{0} & \multicolumn{2}{|c|}{0} & & & \\
\hline & & & \multicolumn{4}{|c|}{ SC: 5} & & & \\
\hline & & & \multicolumn{4}{|c|}{ NS: 1st } & & & \\
\hline & & & \multicolumn{4}{|c|}{ EW: San Carlos } & & & \\
\hline & & & 0 & 0 & 0 & 268 & & & \\
\hline WB on/off flow & & & $K$ & $\downarrow$ & 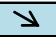 & $\uparrow$ & & & WB on/off flow \\
\hline 0 & 378 & $\leftarrow$ & & & & & $\mathbb{K}$ & 20 & 0 \\
\hline & 48 & $\pi$ & & & & & $\leftarrow$ & 378 & \\
\hline EB on/off flow & 375 & $\rightarrow$ & & & & & $K$ & 0 & EB on/off flow \\
\hline 0 & 49 & $y$ & & & & & $\rightarrow$ & 431 & 0 \\
\hline & & & $\downarrow$ & $\uparrow$ & $\uparrow$ & $\pi$ & & & \\
\hline & & & 49 & 0 & 200 & 56 & & & \\
\hline & & & & & & & & & \\
\hline & & & \multicolumn{2}{|c|}{ SB on/off flow } & \multicolumn{2}{|c|}{ NB on/off flow } & & & \\
\hline & & & \multicolumn{2}{|c|}{0} & \multicolumn{2}{|c|}{0} & & & \\
\hline
\end{tabular}

Intersection: $1^{\text {st }}$ and San Carlos

\begin{tabular}{|c|c|c|c|c|c|c|c|c|c|}
\hline & & & \multicolumn{2}{|c|}{ SB on/off flow } & \multicolumn{2}{|c|}{ NB on/off flow } & & & \\
\hline & & & \multicolumn{2}{|c|}{0} & \multicolumn{2}{|c|}{0} & & & \\
\hline & & & & & & & & & \\
\hline & & & \multicolumn{4}{|c|}{ SC: 51} & & & \\
\hline & & & \multicolumn{4}{|c|}{ NS: 1st } & & & \\
\hline & & & \multicolumn{4}{|c|}{ EW: San Salvador } & & & \\
\hline & & & 24 & 22 & 3 & 213 & & & \\
\hline WB on/off flow & & & $K$ & $\downarrow$ & 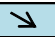 & $\uparrow$ & & & WB on/off flow \\
\hline 0 & 158 & $\leftarrow$ & & & & & $\pi$ & 61 & 0 \\
\hline & 14 & $\pi$ & & & & & $\leftarrow$ & 132 & \\
\hline EB on/off flow & 75 & $\rightarrow$ & & & & & $K$ & 7 & EB on/off flow \\
\hline 0 & 7 & $\searrow$ & & & & & $\rightarrow$ & 121 & 0 \\
\hline & & & $\downarrow$ & $\uparrow$ & $\uparrow$ & $\pi$ & & & \\
\hline & & & 36 & 2 & 138 & 43 & & & \\
\hline & & & & & & & & & \\
\hline & & & \multicolumn{2}{|c|}{ SB on/off flow } & \multicolumn{2}{|c|}{ NB on/off flow } & & & \\
\hline & & & \multicolumn{2}{|c|}{0} & \multicolumn{2}{|c|}{0} & & & \\
\hline
\end{tabular}

Intersection: $1^{\text {st }}$ and San Salvador

\begin{tabular}{|c|c|c|c|c|c|c|c|c|c|}
\hline & & & \multicolumn{4}{|c|}{ SC: 6} & & & \\
\hline & & & \multicolumn{4}{|c|}{ NS: 4th } & & & \\
\hline & & & \multicolumn{4}{|c|}{ EW: James } & & & \\
\hline & & & 0 & 900 & 121 & 0 & & & \\
\hline WB on/off flow & & & $K$ & $\downarrow$ & $\searrow$ & $\uparrow$ & & & WB on/off flow \\
\hline \multirow[t]{2}{*}{0} & 0 & $\leftarrow$ & & & & & $\pi$ & 0 & 0 \\
\hline & 0 & $\pi$ & & & & & $\leftarrow$ & 0 & \\
\hline EB on/off flow & 750 & $\rightarrow$ & & & & & $K$ & 0 & EB on/off flow \\
\hline 0 & 81 & $y$ & & & & & $\rightarrow$ & 871 & -871 \\
\hline & & & $\downarrow$ & $\uparrow$ & $\uparrow$ & $\pi$ & & & \\
\hline & & & 981 & 0 & 0 & 0 & & & \\
\hline & & & & & & & & & \\
\hline & & & \multicolumn{2}{|c|}{ SB on/off flow } & \multicolumn{2}{|c|}{ NB on/off flow } & & & \\
\hline & & & \multicolumn{2}{|c|}{0} & \multicolumn{2}{|c|}{0} & & & \\
\hline
\end{tabular}

Intersection: $4^{\text {th }}$ and San James 


\begin{tabular}{|c|c|c|c|c|c|c|c|c|c|}
\hline & & & \multirow{2}{*}{\multicolumn{2}{|c|}{$\frac{\text { SB on/off flow }}{0}$}} & \multicolumn{2}{|c|}{ NB on/off flow } & & & \\
\hline & & & & & & & & & \\
\hline & & & & & & & & & \\
\hline & & & \multicolumn{4}{|c|}{ SC: 28} & & & \\
\hline & & & \multicolumn{4}{|c|}{ NS: 4th } & & & \\
\hline & & & \multicolumn{4}{|c|}{ EW: Santa Clara (E) } & & & \\
\hline & & & 56 & 800 & 125 & 0 & & & \\
\hline WB on/off flow & & & $K$ & $\downarrow$ & $y$ & $\uparrow$ & & & WB on/off flow \\
\hline 0 & 434 & $\leftarrow$ & & & & & $\mathbb{K}$ & 0 & \\
\hline & 0 & $\pi$ & & & & & $\leftarrow$ & 378 & \\
\hline \multirow{2}{*}{$\frac{\text { EB on/off flow }}{0}$} & 625 & $\rightarrow$ & & & & & $K$ & 130 & EB on/off flow \\
\hline & 252 & 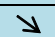 & & & & & $\rightarrow$ & 750 & \\
\hline & & & $\downarrow$ & $\uparrow$ & $\uparrow$ & $\pi$ & & & \\
\hline & & & 1182 & 0 & 0 & 0 & & & \\
\hline & & & & & & & & & \\
\hline & & & \multicolumn{2}{|c|}{ SB on/off flow } & \multicolumn{2}{|c|}{ NB on/off flow } & & & \\
\hline & & & \multicolumn{2}{|c|}{0} & & & & & \\
\hline
\end{tabular}

Intersection: $4^{\text {th }}$ and Santa Clara

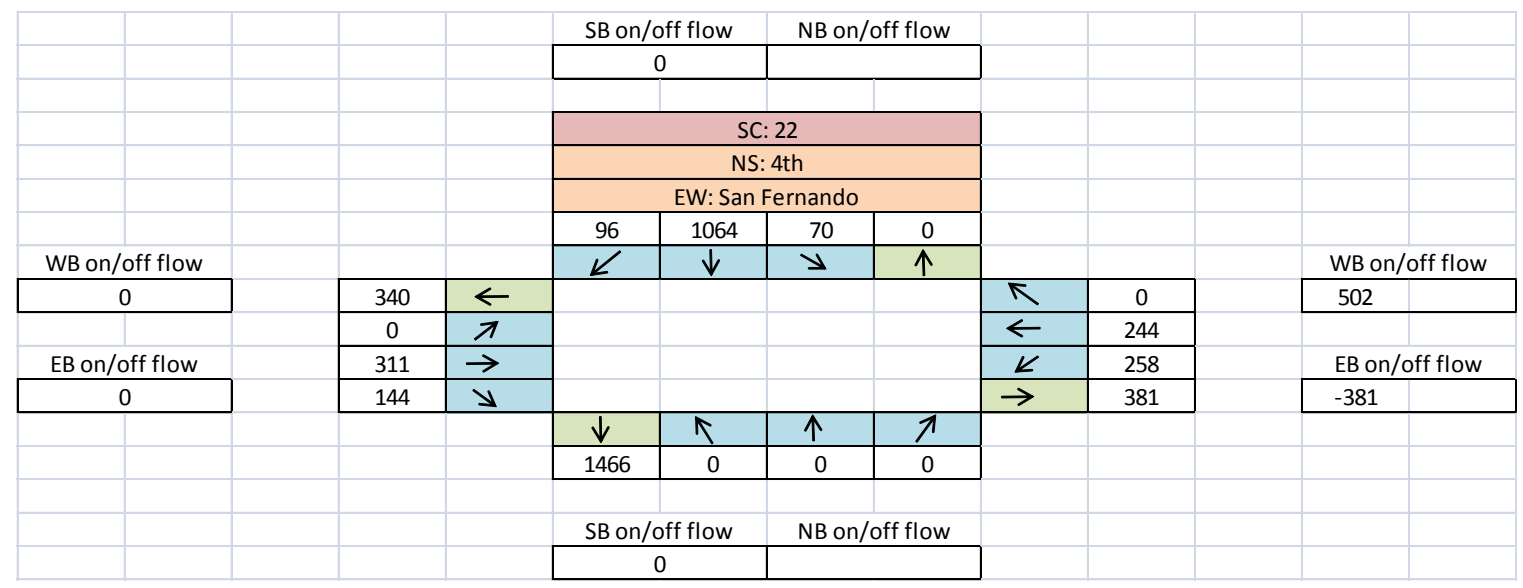

Intersection: $4^{\text {th }}$ and San Fernando

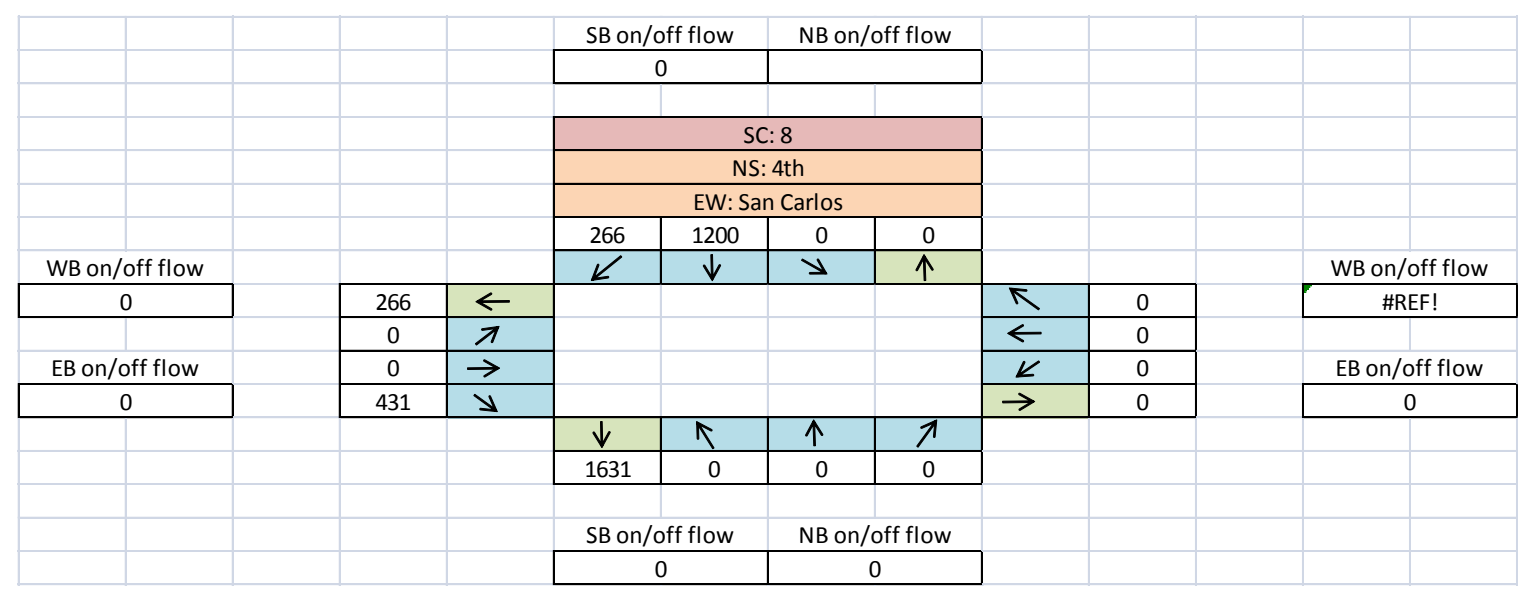

Intersection: $4^{\text {th }}$ and San Carlos 


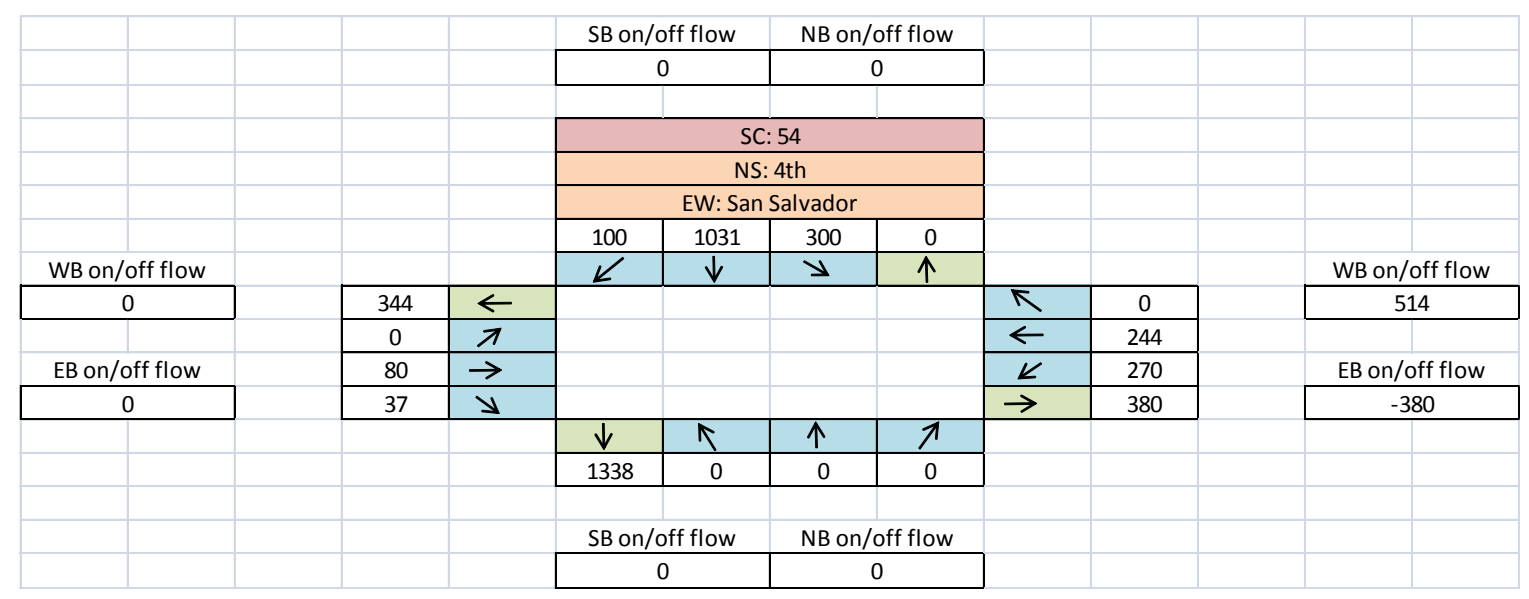

Intersection: $4^{\text {th }}$ and San Salvador

\begin{tabular}{|c|c|c|c|c|c|c|c|c|}
\hline & & & \multicolumn{2}{|c|}{ SB on/off flow } & \multicolumn{2}{|c|}{ NB on/off flow } & & \\
\hline & & & \multicolumn{2}{|c|}{0} & \multicolumn{2}{|c|}{0} & & \\
\hline & & & & & & & & \\
\hline & & & \multicolumn{4}{|c|}{ SC: 62} & & \\
\hline & & & \multicolumn{4}{|c|}{ NS: 4th } & & \\
\hline & & & \multicolumn{4}{|c|}{ EW: Reed } & & \\
\hline & & & 100 & 593 & 300 & 0 & & \\
\hline WB on/off flow & & & $\underline{k}$ & $\downarrow$ & $y$ & $\uparrow$ & & \\
\hline 0 & 200 & $\leftarrow$ & & & & & $\bar{K}$ & 0 \\
\hline & 0 & $\pi$ & & & & & $\leftarrow$ & 100 \\
\hline EB on/off flow & 100 & $\rightarrow$ & & & & & $K$ & 50 \\
\hline 0 & 20 & 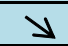 & & & & & $\rightarrow$ & 400 \\
\hline & & & $\downarrow$ & $\uparrow$ & $\uparrow$ & $\pi$ & & \\
\hline & & & 663 & 0 & 0 & 0 & & \\
\hline & & & & & & & & \\
\hline & & & \multirow{3}{*}{\multicolumn{4}{|c|}{$\begin{array}{l}\text { The above volume is the freeway } \\
\text { onramp this is different from CUBE } \\
\text { model }\end{array}$}} & & \\
\hline & & & & & & & & \\
\hline & & & & & & & & \\
\hline
\end{tabular}

Intersection: $4^{\text {th }}$ and Reed 


\section{APPENDIX E: DYNAMIC ASSIGNMENT RESULTS}

These were the results of the attempts to run a 48 x 48 OD matrix that was created for the purpose of dynamic assignment in VISSIM The "From to" row indicates the real time of which is simulated, which in this case is 4:00 to 5:00 pm. The Factor row is the scale factor for the network. The number of network objects is the number of zones within the network while the network object numbers is the reference for which the later summaries should be looked upon.

$\$ \mathrm{~V} ; \mathrm{D} 3$

* From to

16.0017 .00

* Factor

1.00

$*$

* Cal Poly

$* 01 / 31 / 11$

* Number of network objects

48

* Network object numbers

$\begin{array}{llllllllllll}1 & 2 & 3 & 4 & 5 & 6 & 7 & 8 & 9 & 10 & \\ 11 & 12 & 13 & 14 & 15 & 16 & 17 & 18 & 19 & 20 \\ 21 & 22 & 23 & 24 & 25 & 26 & 27 & 28 & 29 & 30 \\ 31 & 32 & 33 & 34 & 35 & 36 & 37 & 38 & 39 & 40 \\ 41 & 42 & 43 & 44 & 45 & 46 & 47 & 48 & & \end{array}$


* Obj 1 Sum $=68.000$

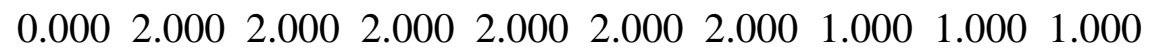

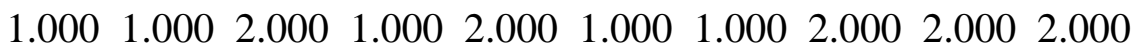

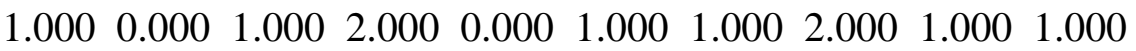

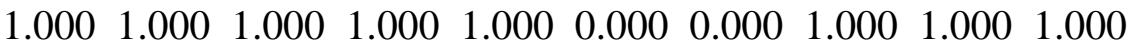

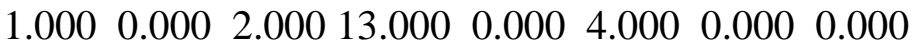

* Obj 2 Sum $=867.000$

$1.000 \quad 0.00021 .00011 .00021 .00021 .0001 .000 \quad 1.0005 .0002 .000$

$\begin{array}{lllllll}1.000 & 1.000 & 3.000 & 2.00021 .000 & 1.000 & 5.00021 .000 & 1.00021 .000\end{array}$

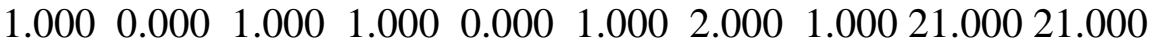

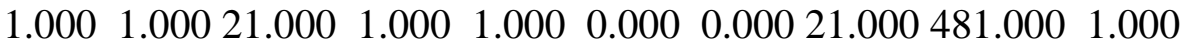

$1.000 \quad 0.00021 .00066 .000 \quad 0.00041 .000 \quad 0.000 \quad 0.000$

* Obj 3 Sum $=929.000$

1.00011 .0000 .00011 .00022 .00022 .00022 .0001 .0004 .0004 .000

$\begin{array}{llllllll}1.000 & 1.000 & 4.000 & 1.00022 .000 & 1.000 & 1.00022 .000 & 2.00022 .000\end{array}$

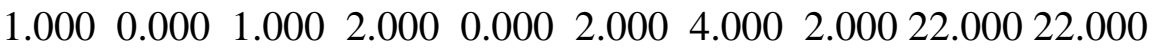

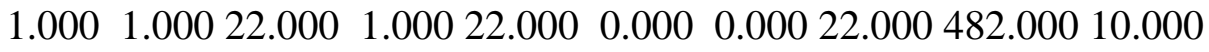

$22.00022 .00022 .00022 .000 \quad 0.00049 .000 \quad 0.000 \quad 0.000$

$*$ Obj 4 Sum $=583.000$

$0.00014 .00014 .000 \quad 0.00014 .0001 .00014 .000 \quad 1.0005 .0004 .000$

1.0001 .0005 .0002 .00014 .0001 .0005 .00014 .0004 .00014 .000

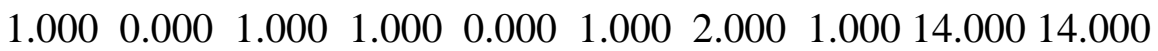

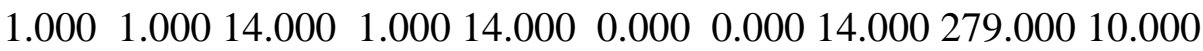

$14.00014 .00014 .00014 .000 \quad 0.00030 .000 \quad 0.000 \quad 0.000$

* Obj 5 Sum $=2352.000$ 
$1.00028 .00056 .00042 .000 \quad 0.00056 .000 \quad 1.000 \quad 1.0006 .0001 .000$

$1.000 \quad 1.0005 .0003 .00056 .000 \quad 1.0001 .00056 .0002 .00056 .000$

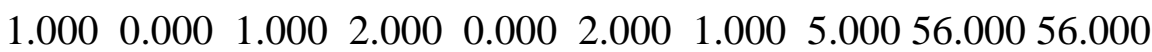

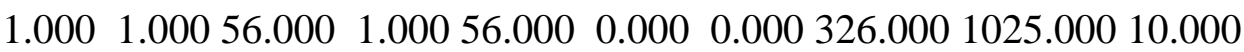

$56.00056 .00056 .00056 .000 \quad 0.000154 .000 \quad 0.000 \quad 0.000$

$*$ Obj 6 Sum $=1222.000$

$1.00015 .00029 .00029 .00029 .000 \quad 0.00029 .000 \quad 1.000 \quad 8.0005 .000$

$29.000 \quad 1.000 \quad 1.000 \quad 4.00029 .0001 .0002 .00029 .0003 .00029 .000$

$\begin{array}{llllllll}1.000 & 0.000 & 1.000 & 1.000 & 0.000 & 2.000 & 29.000 & 4.00029 .00029 .000\end{array}$

$1.000 \quad 1.00029 .0001 .00029 .000 \quad 0.0000 .00031 .000557 .00010 .000$

$29.00029 .00029 .00029 .000 \quad 0.00077 .000 \quad 0.000 \quad 0.000$

* Obj 7 Sum $=291.000$

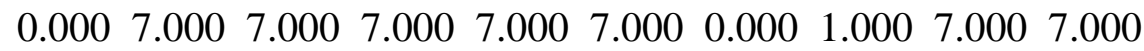

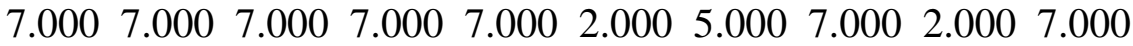

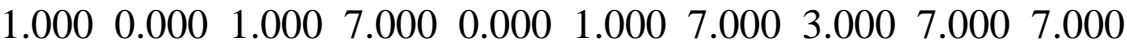

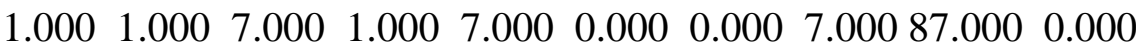

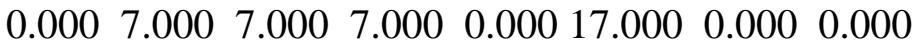

* Obj 8 Sum $=160.000$

$1.000 \quad 4.0004 .0004 .0004 .0004 .0004 .000 \quad 1.0004 .0004 .000$

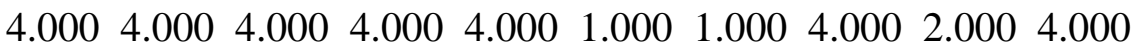

$\begin{array}{llllllllll}1.000 & 0.000 & 1.000 & 4.000 & 0.000 & 2.000 & 4.000 & 2.000 & 4.000 & 4.000\end{array}$

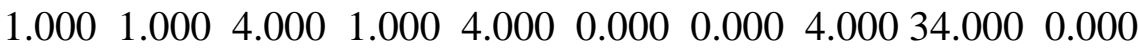

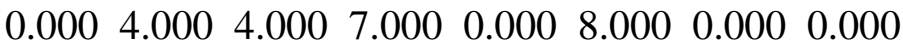

* Obj 9 Sum $=1297.000$

$1.00016 .00032 .0001 .00032 .00032 .0001 .0001 .000 \quad 0.00010 .000$

$32.00032 .00032 .00032 .00032 .000 \quad 1.000 \quad 1.00032 .000 \quad 1.00032 .000$ 


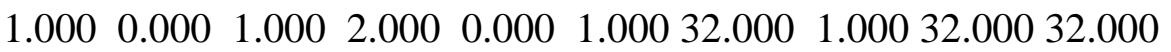

1.0001 .00032 .0001 .00032 .0000 .0000 .00032 .000582 .0001 .000

32.00032 .00032 .00032 .0000 .00032 .0000 .0000 .000

* Obj 10 Sum $=6552.000$

$182.00020 .00035 .00017 .000365 .00065 .00012 .0001 .000165 .000 \quad 0.000$

98.000165 .00065 .0009 .000285 .000182 .000183 .000346 .000196 .000165 .000

13.0000 .000195 .000182 .0000 .000191 .000211 .000186 .000165 .000229 .000

216.000244 .000346 .000182 .000196 .0000 .0000 .000165 .000597 .0001 .000

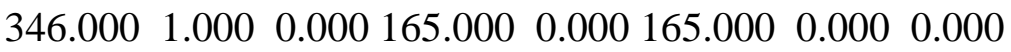

* Obj 11 Sum $=799.000$

$1.00019 .00019 .00019 .000265 .00019 .0001 .0001 .0007 .000 \quad 0.000$

0.00019 .00019 .00019 .00019 .00019 .0001 .00019 .00019 .00019 .000

$19.000 \quad 0.00019 .0005 .000 \quad 0.0000 .00019 .0004 .00071 .00019 .000$

1.00019 .00019 .0001 .00019 .0000 .0000 .0001 .00019 .0001 .000

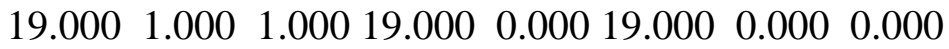

* Obj 12 Sum $=1550.000$

0.00037 .00037 .00037 .00037 .00037 .00037 .0001 .00037 .00010 .000

37.0000 .00037 .00037 .00037 .00037 .0002 .00037 .00037 .00037 .000

$37.000 \quad 0.00037 .000 \quad 4.0000 .0003 .00037 .0002 .00037 .00037 .000$

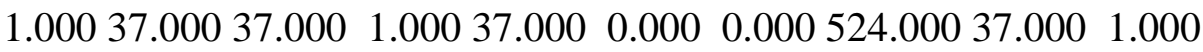

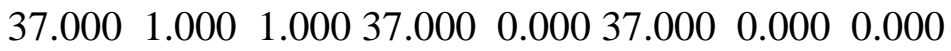

* Obj 13 Sum $=677.000$

1.00016 .00016 .00016 .00016 .00016 .00016 .0001 .00016 .0001 .000

$16.00016 .000 \quad 0.00016 .00016 .00016 .00030 .00016 .00016 .00016 .000$

16.0000 .00016 .0003 .0000 .0004 .00016 .0003 .00016 .00016 .000

1.00016 .00016 .0001 .00016 .0000 .0000 .00016 .00016 .0001 .000

122 
$16.0001 .0001 .00016 .000 \quad 0.000197 .000 \quad 0.000 \quad 0.000$

$*$ Obj 14 Sum $=793.000$

1.00019 .00019 .0001 .00019 .00019 .00019 .0000 .00019 .0002 .000

19.00019 .00019 .0000 .00019 .00019 .00030 .00019 .00019 .00019 .000

$19.000 \quad 0.00019 .0002 .000 \quad 0.0005 .00019 .0002 .00019 .0001 .000$

1.00019 .00019 .0001 .00019 .0000 .0000 .00019 .00019 .0001 .000

$19.0001 .0001 .00019 .000 \quad 0.000269 .000 \quad 0.000 \quad 0.000$

* Obj 15 Sum $=1303.000$

$1.00031 .00031 .0001 .00031 .00031 .0000 .000 \quad 0.000 \quad 0.0001 .000$

31.00031 .00031 .00031 .0000 .00031 .0004 .00031 .00031 .00031 .000

$31.000 \quad 0.00031 .0004 .0000 .0006 .00031 .0001 .00031 .0001 .000$

$1.00031 .00031 .0001 .00031 .000 \quad 0.0000 .000566 .00031 .0001 .000$

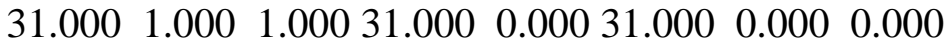

$*$ Obj 16 Sum $=793.000$

$1.00019 .00019 .00019 .00019 .00019 .0000 .0000 .000 \quad 0.0005 .000$

19.00019 .00019 .00019 .00019 .0000 .00025 .00019 .00019 .00019 .000

$19.000 \quad 0.00019 .000 \quad 1.000 \quad 0.0008 .00019 .0004 .00019 .0001 .000$

$1.00019 .00019 .0001 .00019 .000 \quad 0.0000 .00019 .000287 .0001 .000$

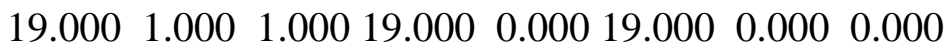

* Obj 17 Sum $=467.000$

$1.00011 .00011 .00011 .00011 .00011 .0000 .0000 .000 \quad 0.0004 .000$

11.00011 .00011 .00011 .00011 .00011 .0000 .00011 .00011 .00011 .000

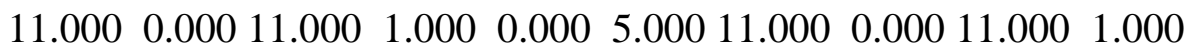

1.00011 .00011 .0001 .00011 .0000 .0000 .00011 .00011 .0001 .000

$11.0001 .0001 .00011 .0000 .000175 .0000 .000 \quad 0.000$

* Obj 18 Sum $=2141.000$ 
$1.00051 .00051 .0001 .00051 .00051 .0000 .000 \quad 0.000 \quad 0.0003 .000$

51.00051 .00051 .00051 .00051 .00051 .00051 .0000 .00051 .000352 .000

$51.000 \quad 0.00051 .00020 .0000 .0005 .00051 .0000 .00051 .0001 .000$

$1.00051 .00051 .0001 .00051 .000 \quad 0.0000 .000580 .00051 .0001 .000$

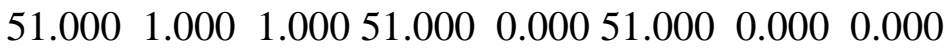

* Obj 19 Sum $=1472.000$

$1.00010 .00035 .0001 .00035 .00035 .000 \quad 0.000 \quad 0.000 \quad 0.0004 .000$

35.00035 .00035 .00035 .00035 .00035 .00040 .00035 .0000 .000596 .000

$35.000 \quad 0.00035 .000 \quad 1.000 \quad 0.0004 .00035 .0005 .00035 .0001 .000$

$1.00035 .00035 .00035 .00035 .000 \quad 0.0000 .00035 .00035 .0001 .000$

$\begin{array}{lllllll}35.000 & 1.000 & 1.000 & 35.000 & 0.00035 .000 & 0.000 & 0.000\end{array}$

* Obj 20 Sum $=8964.000$

150.0005 .00021 .00017 .000221 .000145 .00017 .0000 .00017 .00010 .000

$17.000133 .00021 .00011 .000270 .000193 .000154 .000370 .000370 .000 \quad 0.000$

71.0000 .000270 .000161 .0000 .000153 .000170 .000170 .000136 .000169 .000

$170.000270 .000370 .000170 .000370 .0000 .000 \quad 0.000577 .0002821 .000 \quad 1.000$

229.0001 .0001 .000321 .0000 .000221 .0000 .0000 .000

* Obj 21 Sum $=1214.000$

$\begin{array}{llllll}1.000 & 1.00029 .000 & 0.00029 .00029 .000 & 0.000 & 0.00029 .000 & 2.000\end{array}$

29.00029 .0001 .0001 .00029 .00029 .0003 .00029 .00029 .000279 .000

$\begin{array}{llllll}0.000 & 0.00029 .00029 .000 & 0.000 & 4.00029 .000 & 1.00029 .000 & 2.000\end{array}$

$29.00029 .00029 .00029 .00029 .000 \quad 0.0000 .00029 .000249 .0001 .000$

$29.000 \quad 1.000 \quad 1.00029 .000 \quad 0.00029 .000 \quad 0.000 \quad 0.000$

* Obj 22 Sum $=1126.000$

$1.000 \quad 1.00027 .000 \quad 0.00027 .00027 .000 \quad 0.000 \quad 0.00027 .0001 .000$

1.00027 .0001 .0001 .00027 .00027 .0002 .00027 .00027 .000258 .000

124 
$27.000 \quad 0.00027 .00027 .000 \quad 0.0003 .00027 .000 \quad 1.00027 .00027 .000$

$27.00027 .00027 .00027 .00027 .000 \quad 0.000 \quad 0.00027 .00027 .000 \quad 1.000$

$27.00010 .0001 .00027 .0000 .000196 .000 \quad 0.000 \quad 0.000$

$*$ Obj 23 Sum $=0.000$

$\begin{array}{llllllllll}0.000 & 0.000 & 0.000 & 0.000 & 0.000 & 0.000 & 0.000 & 0.000 & 0.000 & 0.000\end{array}$

$\begin{array}{llllllllll}0.000 & 0.000 & 0.000 & 0.000 & 0.000 & 0.000 & 0.000 & 0.000 & 0.000 & 0.000\end{array}$

$\begin{array}{llllllllll}0.000 & 0.000 & 0.000 & 0.000 & 0.000 & 0.000 & 0.000 & 0.000 & 0.000 & 0.000\end{array}$

$\begin{array}{llllllllll}0.000 & 0.000 & 0.000 & 0.000 & 0.000 & 0.000 & 0.000 & 0.000 & 0.000 & 0.000\end{array}$

$\begin{array}{llllllll}0.000 & 0.000 & 0.000 & 0.000 & 0.000 & 0.000 & 0.000 & 0.000\end{array}$

* Obj 24 Sum $=284.000$

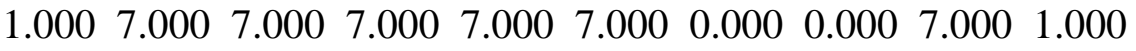

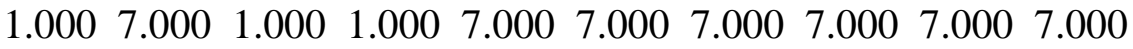

$\begin{array}{llllllllll}7.000 & 0.000 & 7.000 & 0.000 & 0.000 & 1.000 & 7.000 & 2.000 & 7.000 & 7.000\end{array}$

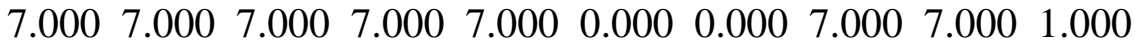

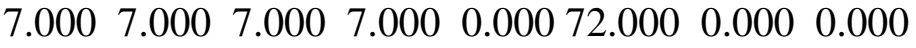

$*$ Obj 25 Sum $=322.000$

$\begin{array}{llllllllll}1.000 & 8.000 & 8.000 & 1.000 & 8.000 & 8.000 & 0.000 & 0.000 & 8.000 & 2.000\end{array}$

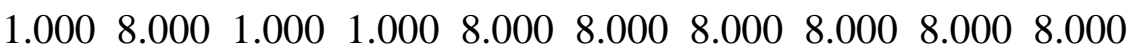

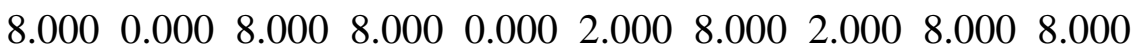

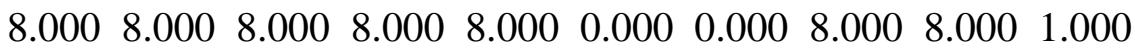

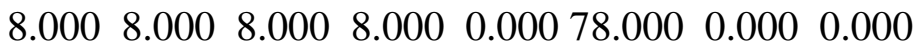

* Obj 26 Sum $=0.000$

$\begin{array}{llllllllll}0.000 & 0.000 & 0.000 & 0.000 & 0.000 & 0.000 & 0.000 & 0.000 & 0.000 & 0.000\end{array}$

$\begin{array}{llllllllll}0.000 & 0.000 & 0.000 & 0.000 & 0.000 & 0.000 & 0.000 & 0.000 & 0.000 & 0.000\end{array}$

$\begin{array}{llllllllll}0.000 & 0.000 & 0.000 & 0.000 & 0.000 & 0.000 & 0.000 & 0.000 & 0.000 & 0.000\end{array}$

$\begin{array}{llllllllll}0.000 & 0.000 & 0.000 & 0.000 & 0.000 & 0.000 & 0.000 & 0.000 & 0.000 & 0.000\end{array}$ 
$\begin{array}{llllllll}0.000 & 0.000 & 0.000 & 0.000 & 0.000 & 0.000 & 0.000 & 0.000\end{array}$

* Obj 27 Sum $=1504.000$

$1.00036 .00036 .000 \quad 1.00036 .00036 .000 \quad 1.000 \quad 0.00036 .000 \quad 5.000$

1.00036 .0002 .00036 .00036 .00036 .00036 .00036 .00036 .00036 .000

$36.000 \quad 0.00036 .00036 .000 \quad 0.000 \quad 0.00036 .00036 .00036 .00036 .000$

$36.00036 .00036 .00036 .00036 .000 \quad 0.000 \quad 0.000376 .00036 .000 \quad 1.000$

$36.00036 .00036 .00036 .000 \quad 0.00036 .000 \quad 0.000 \quad 0.000$

$*$ Obj 28 Sum $=211.000$

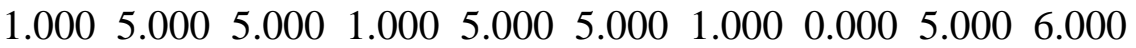

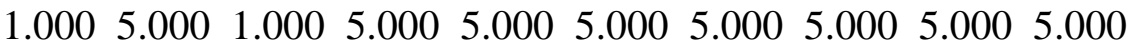

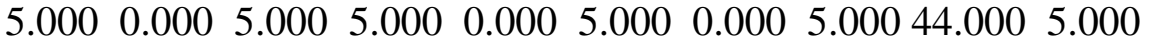

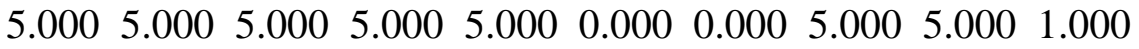

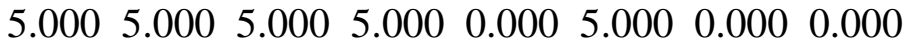

$*$ Obj 29 Sum $=5500.000$

$1.0001 .0001 .00010 .000431 .00031 .00010 .000 \quad 0.000131 .00010 .000$

10.000131 .00020 .000131 .000131 .000131 .00031 .000131 .000131 .0001146 .000

$69.000 \quad 0.000131 .00012 .000 \quad 0.00011 .000131 .000 \quad 0.0001564 .000131 .000$

$131.00031 .000131 .00011 .000131 .000 \quad 0.000 \quad 0.000131 .000131 .0001 .000$

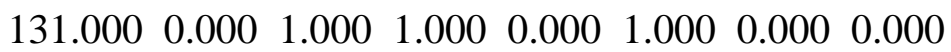

* Obj 30 Sum $=879.000$

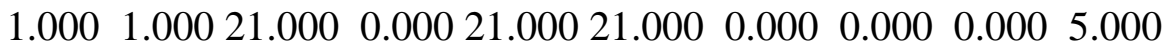

1.00021 .00010 .0001 .0001 .0001 .0001 .00021 .0002 .00021 .000

$21.000 \quad 0.00021 .0002 .000 \quad 0.0001 .00021 .00021 .000408 .00021 .000$

$21.00021 .00021 .00021 .00021 .000 \quad 0.000 \quad 0.00021 .00021 .0001 .000$

$21.0001 .0001 .00021 .000 \quad 0.00021 .000 \quad 0.000 \quad 0.000$

* Obj 31 Sum $=804.000$ 


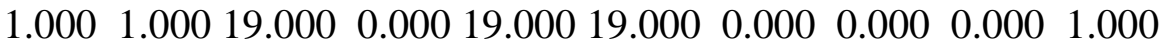
$2.00019 .000 \quad 2.0001 .0001 .0001 .0001 .00019 .0001 .00019 .000$ $19.000 \quad 0.00019 .00019 .000 \quad 0.0002 .00019 .00019 .00019 .000 \quad 0.000$ $19.00019 .00019 .00019 .00019 .000 \quad 0.0000 .000389 .00019 .000 \quad 0.000$

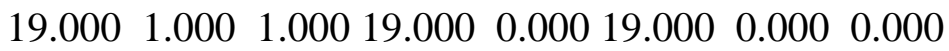
$*$ Obj 32 Sum $=1492.000$

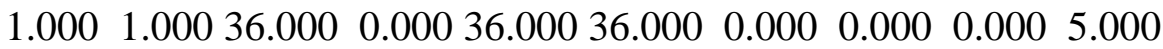
1.00036 .0001 .0001 .0001 .0001 .0001 .00036 .0005 .00036 .000

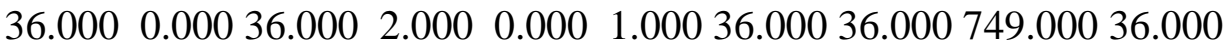
$0.00036 .00036 .00036 .00036 .000 \quad 0.000 \quad 0.00036 .00036 .000 \quad 0.000$

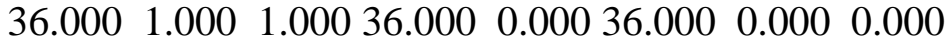

* Obj 33 Sum $=1340.000$

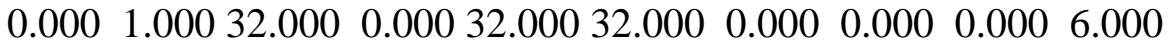

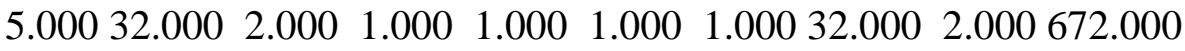
$32.000 \quad 0.00032 .000 \quad 4.0000 .0002 .00032 .00032 .00032 .00032 .000$ $32.0000 .00032 .00032 .00032 .000 \quad 0.0000 .00032 .00032 .000 \quad 0.000$

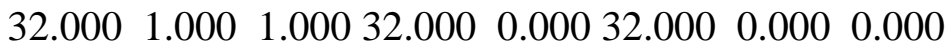

$*$ Obj 34 Sum $=423.000$

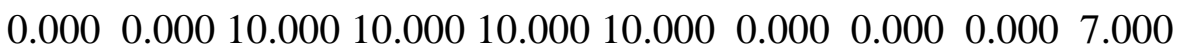

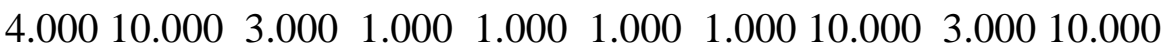
$10.000 \quad 0.00010 .0002 .000 \quad 0.0004 .00010 .00010 .00010 .00010 .000$ $10.00010 .000 \quad 0.00010 .00010 .000 \quad 0.000 \quad 0.00010 .000175 .000 \quad 0.000$ $10.00010 .0001 .00010 .000 \quad 0.00010 .0000 .000 \quad 0.000$

* Obj 35 Sum $=1759.000$

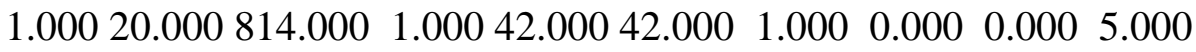
$5.00042 .0004 .0002 .0002 .000 \quad 1.000 \quad 1.00042 .0004 .00042 .000$ 
$42.000 \quad 0.00042 .000 \quad 3.000 \quad 0.000 \quad 1.00042 .00042 .00042 .00042 .000$ $42.00042 .00042 .000 \quad 0.00042 .000 \quad 0.000 \quad 0.00042 .00042 .000 \quad 0.000$ $42.00042 .00012 .00042 .0000 .00042 .0000 .000 \quad 0.000$

$*$ Obj 36 Sum $=129.000$

$\begin{array}{llllllllll}1.000 & 0.000 & 3.000 & 3.000 & 3.000 & 3.000 & 3.000 & 0.000 & 0.000 & 6.000\end{array}$

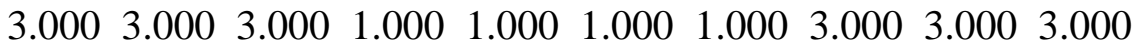

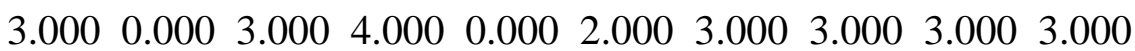

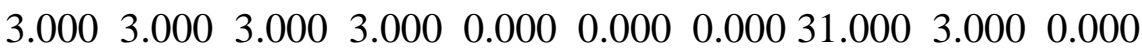

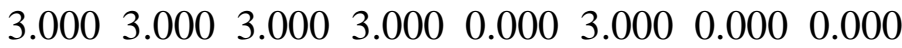

* Obj 37 Sum $=1173.000$

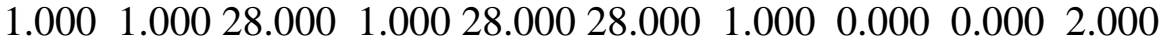

$28.00028 .000 \quad 5.0002 .0001 .0001 .0001 .00028 .00028 .00028 .000$

$28.000 \quad 0.00028 .000 \quad 5.000 \quad 0.0003 .00028 .00028 .000448 .00028 .000$

$28.00028 .00028 .00028 .00028 .000 \quad 0.000 \quad 0.00028 .00028 .000 \quad 1.000$

$28.00028 .00028 .00028 .0000 .00028 .000 \quad 0.000 \quad 0.000$

* Obj 38 Sum $=5334.000$

$123.0006 .0001 .00010 .000384 .00033 .0009 .000 \quad 0.000133 .00071 .000$

13.000133 .00033 .00033 .000206 .000156 .000156 .000156 .000156 .000133 .000

$33.000 \quad 0.000156 .000144 .0000 .000126 .000256 .000156 .000 \quad 0.000156 .000$

156.000256 .000256 .000146 .000256 .0000 .0000 .000323 .000133 .000105 .000

$124.000133 .000133 .000208 .0000 .000133 .000 \quad 0.000 \quad 0.000$

$*$ Obj 39 Sum $=7847.000$

184.00020 .0001 .00015 .000196 .0000 .00014 .0000 .000196 .00098 .000 20.000196 .00048 .00046 .000279 .000229 .000229 .000579 .000296 .00070 .000 96.0000 .000229 .000195 .0000 .000203 .000237 .000302 .000566 .000233 .000 $279.000379 .000489 .000379 .000379 .000 \quad 0.000 \quad 0.000 \quad 0.000196 .0001 .000$ 128 
$184.000196 .000196 .000196 .0000 .000196 .000 \quad 0.000 \quad 0.000$

$*$ Obj 40 Sum $=164.000$

$\begin{array}{llllllllll}1.000 & 4.000 & 0.000 & 0.000 & 4.000 & 0.000 & 0.000 & 0.000 & 0.000 & 1.000\end{array}$

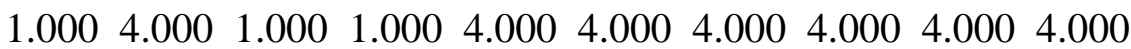

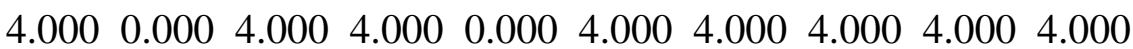

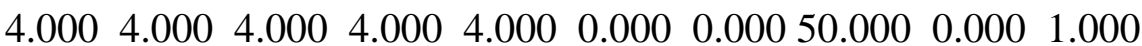

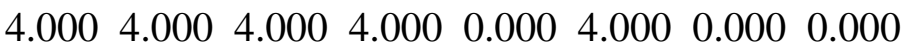

$*$ Obj 41 Sum $=1547.000$

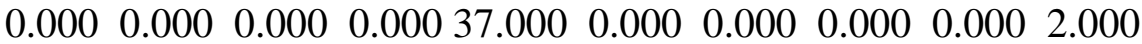

$2.00037 .000 \quad 1.0001 .00037 .0001 .0001 .000187 .00037 .000392 .000$

$37.000 \quad 0.00037 .00037 .000 \quad 0.0005 .00037 .0005 .000208 .00037 .000$

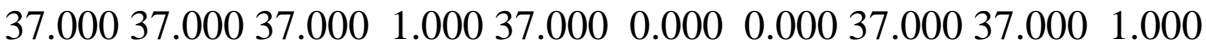

$37.00037 .00037 .00037 .000 \quad 0.00037 .000 \quad 0.000 \quad 0.000$

* Obj 42 Sum $=1000.000$

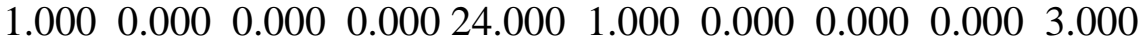

$1.00024 .000 \quad 1.0002 .00024 .0002 .0002 .00024 .00024 .00024 .000$

$24.000 \quad 0.00024 .000 \quad 1.000 \quad 0.0004 .00024 .0004 .000496 .00024 .000$

$24.00024 .00024 .0001 .00024 .000 \quad 0.0000 .00024 .00024 .0001 .000$

$0.00024 .00024 .00024 .000 \quad 0.00024 .000 \quad 0.000 \quad 0.000$

* Obj 43 Sum $=999.000$

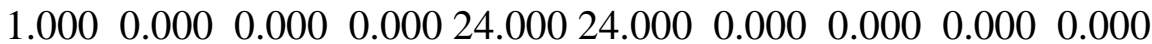

1.00024 .0001 .0004 .00024 .0001 .0004 .00024 .00024 .000474 .000

$24.000 \quad 0.00024 .000 \quad 1.000 \quad 0.0003 .00024 .0003 .00024 .00024 .000$

$24.00024 .00024 .000 \quad 1.00024 .000 \quad 0.0000 .00024 .00024 .0001 .000$

$24.000 \quad 0.00024 .00024 .000 \quad 0.00024 .000 \quad 0.000 \quad 0.000$

$*$ Obj 44 Sum $=254.000$ 
$\begin{array}{llllllllll}1.000 & 6.000 & 0.000 & 0.000 & 6.000 & 6.000 & 0.000 & 0.000 & 0.000 & 1.000\end{array}$

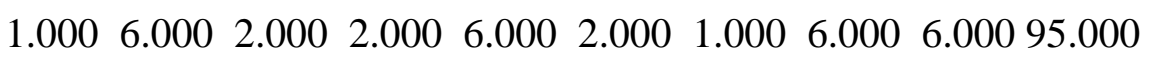
$\begin{array}{llllllllll}6.000 & 0.000 & 6.000 & 6.000 & 0.000 & 2.000 & 6.000 & 2.000 & 6.000 & 6.000\end{array}$ $\begin{array}{llllllllll}6.000 & 6.000 & 6.000 & 6.000 & 6.000 & 0.000 & 0.000 & 6.000 & 6.000 & 1.000\end{array}$ $\begin{array}{llllllll}6.000 & 6.000 & 0.000 & 6.000 & 0.000 & 6.000 & 0.000 & 0.000\end{array}$ * Obj 45 Sum $=2945.000$

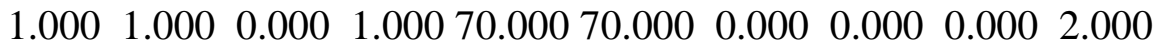
$\begin{array}{lllll}1.00070 .000 & 3.000 & 1.00070 .000 & 1.000 & 1.00070 .00070 .000902 .000\end{array}$

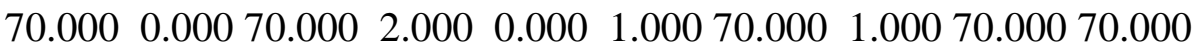
$28.00070 .00070 .000 \quad 1.00070 .000 \quad 0.000 \quad 0.000450 .00070 .000 \quad 1.000$ $70.00070 .00070 .00070 .000 \quad 0.000217 .000 \quad 0.000 \quad 0.000$

* Obj 46 Sum $=0.000$

$\begin{array}{llllllllll}0.000 & 0.000 & 0.000 & 0.000 & 0.000 & 0.000 & 0.000 & 0.000 & 0.000 & 0.000\end{array}$ $\begin{array}{llllllllll}0.000 & 0.000 & 0.000 & 0.000 & 0.000 & 0.000 & 0.000 & 0.000 & 0.000 & 0.000\end{array}$ $\begin{array}{llllllllll}0.000 & 0.000 & 0.000 & 0.000 & 0.000 & 0.000 & 0.000 & 0.000 & 0.000 & 0.000\end{array}$ $\begin{array}{llllllllll}0.000 & 0.000 & 0.000 & 0.000 & 0.000 & 0.000 & 0.000 & 0.000 & 0.000 & 0.000\end{array}$ $\begin{array}{llllllll}0.000 & 0.000 & 0.000 & 0.000 & 0.000 & 0.000 & 0.000 & 0.000\end{array}$

$*$ Obj 47 Sum $=622.000$

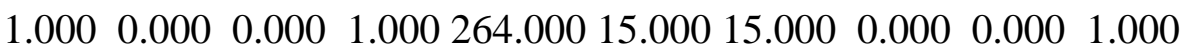
1.00015 .0002 .0001 .00015 .0001 .0001 .00015 .00015 .00015 .000 $15.000 \quad 0.00015 .00015 .000 \quad 0.0001 .00015 .000 \quad 0.00015 .00015 .000$ $15.00015 .00015 .000 \quad 1.00015 .000 \quad 0.0000 .00015 .00015 .0001 .000$ $15.0001 .00015 .00015 .000 \quad 0.00015 .0000 .000 \quad 0.000$

* Obj 48 Sum $=156.000$

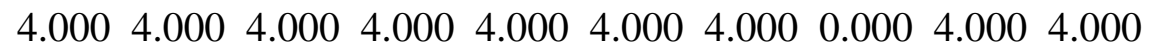
$4.000 \quad 4.0004 .0004 .0004 .0004 .0004 .0004 .0004 .0004 .000$ 


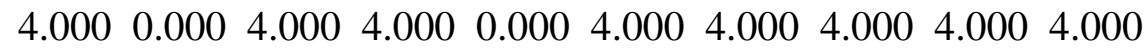

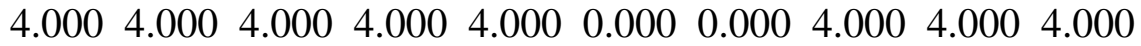

$\begin{array}{llllllll}4.000 & 0.000 & 4.000 & 4.000 & 0.000 & 4.000 & 0.000 & 0.000\end{array}$ 